\title{
Moored Observations of Shelfbreak Processes at the Inflow to and Outflow from the Arctic Ocean
}

\author{
by \\ Wilken-Jon von Appen \\ B.S., Jacobs University, Bremen, Germany, 2007
}

Submitted in partial fulfillment of the requirements for the degree of

Doctor of Philosophy in Physical Oceanography

at the
MASSACHUSETTS INSTITUTE OF TECHNOLOGY
and the
WOODS HOLE OCEANOGRAPHIC INSTITUTION

February 2013

(C) 2013 Wilken-Jon von Appen

All rights reserved.

The author hereby grants to MIT and to WHOI permission to reproduce and to distribute publicly paper and electronic copies of this thesis document in whole or in part.

Author

Joint Program in Physical Oceanography

December 20, 2012

Certified by . .

Robert S. Pickart

Senior Scientist

Thesis Supervisor

Accepted by

Glenn Flierl

Chair, Joint Committee for Physical Oceanography 


\title{
Moored Observations of Shelfbreak Processes at the Inflow to and Outflow from the Arctic Ocean
}

\author{
by \\ Wilken-Jon von Appen

\begin{abstract}
Submitted to the Joint Program in Physical Oceanography
Massachusetts Institute of Technology and Woods Hole Oceanographic Institution

on December 20, 2012, in partial fulfillment of the

requirements for the degree of

Doctor of Philosophy in Physical Oceanography
\end{abstract}

\begin{abstract}
Two high-resolution mooring arrays extending from the outer shelf to the mid continental slope are used to elucidate shelf-basin exchange at the inflow to and the outflow from the Arctic Ocean. Pacific Water entering the Arctic Ocean forms the Western Arctic shelfbreak current along the Beaufort Sea slope. Data from the mooring array at $152^{\circ} \mathrm{W}$ - approximately $150 \mathrm{~km}$ east of Pt. Barrow, AK - reveals that this current has two distinct states in summer depending on the water mass it transports. When advecting Alaskan Coastal Water it is surface-intensified and both baroclinically and barotropically unstable. This configuration lasts about a month with an average transport of $0.7 \mathrm{~Sv}$. When advecting Chukchi Summer Water the current is bottom-intensified and is only baroclinically unstable. This state also exists for approximately a month with an average transport of $0.6 \mathrm{~Sv}$. The strong mean-toeddy energy conversion causes both configurations of the current to spin down over a distance of a few hundred kilometers, suggesting that warm Pacific Water does not enter the Canadian Arctic Archipelago via this route.

Dense water formed in the Nordic Seas overflows the Denmark Strait and undergoes vortex stretching, forming intense cyclones that propagate along the East Greenland slope. Data from the mooring array at $65^{\circ} \mathrm{N}$-roughly $300 \mathrm{~km}$ downstream of Denmark Strait - was used to determine the full water column structure of the cyclones. On average a cyclone passes the array every other day in the vicinity of the $900 \mathrm{~m}$ isobath, although the depth range of individual cyclones ranges between the $500 \mathrm{~m}$ and $1600 \mathrm{~m}$ isobaths. The cyclones self-propagate at $0.45 \mathrm{~m} / \mathrm{s}$ and are also advected by the mean flow of $0.27 \mathrm{~m} / \mathrm{s}$, resulting in a total propagation speed of $0.72 \mathrm{~m} / \mathrm{s}$. They have a peak azimuthal speed of $0.22 \mathrm{~m} / \mathrm{s}$ at a radius of $7.8 \mathrm{~km}$ and contain overflow water in their core. In the absence of the cyclones, the background
\end{abstract}


flow is dominated by the East Greenland Spill Jet. This is shown to be a year-round feature transporting 2-4 Sv of dense water equatorward along the upper continental slope.

Thesis Supervisor: Robert S. Pickart

Title: Senior Scientist 


\section{Acknowledgments}

There are many individuals who were instrumental in the making of this thesis either by helping me with its content or by supporting me in my life. Unfortunately, this list has to be finite, so I unfortunately cannot mention you all.

First and foremost I would like to thank my advisor Bob Pickart. He has taught me a lot of science as well as how to think, do, and write science. He has always been a great role model for what it means to be a scientist. I have gone to sea with him multiple times which has always been a fun and instructional experience.

The members of my thesis committee Ken Brink, Tom Haine, and Paola Rizzoli always had great ideas and comments and made sure that I would stay on track when I was once again ready to go off in a different direction. They spent many hours reviewing my work in great detail and finding the big and little things that improved the argumentation.

This work would not have been possible without the diligent efforts of many people in collecting and processing the data. We thank the crews of the $R / V$ Árni Friðriksson and $R / V$ Knorr and the WHOI Mooring Operations, Engineering and Field Support Group, in particular John Kemp and Jim Ryder. Héðinn Valdimarsson assisted in various aspects of the fieldwork. I am grateful to the following people for processing various parts of the data: Paula Fratantoni, Frank Bahr, Dan Torres, Terry McKee, Jeremy Kasper, Carolina Nobre, Leah Trafford, and Ben Harden. I have also asked them many questions which were always happily answered. Fruitful science (and nonscience) discussions with Kjetil Våge, Donglai Gong, Lena Schulze, and Eric Brugler gave me insights about this thesis and other more important things.

My fellow SSFs in 2006 Nate, Jeff, Carly, Sophie, and Maya as well as my SSF advisor Amy Bower gave me a great introduction to Woods Hole that made me want 
to come back for much more. I would also like to thank Amy for supporting me again after so many years as the chair of my thesis defense.

The WHOI Academic Programs Office always kept any sort of administrative issues off my back and special thanks go to Marsha Gomes, Julia Westwater, and Tricia Gebbie.

My fellow students in physical oceanography Julian, Nick, Ru, Sophie, Malte, Daniela, Rachel, Elise, Ping, and Marilena helped me learn a huge amount of oceanography, kept me sane to go through the General Exam and have been a great resource ever since. Thanks for the many lunch time (and other) conversations.

Woods Hole would not be the same without my friends (many have already been mentioned above). Julian was the best housemate and friend to have and I happily look back at our countless adventures. I would also like to thank Dan O, Nate, Kate, Elise, Leah, and Marilena for a great time.

Susan and Bill are my Massachusetts family while Christin, Laura, and Lennart helped me keep in touch with "back home".

Didi and Christa deserve a special thanks for never giving up the hope that something good would come of that little boy and for always quietly working toward that end.

My mom and my dad have always supported me and I can't thank them enough for raising me to be who I am. Without them I would not have been the confident running maniac that is so obsessed with the natural wonders of the ocean to spend five years to write 250 pages about the physics of the water.

Finally I would like to thank Liz for being the luckiest thing that has happened to me in Woods Hole.

Financial support for this work was provided by National Science Foundation grants OCE-0726640 and OCE-0612143, by the Arctic Research Initiative at WHOI, 
by the Y-S Anonymous Fellowship from the Office of the Dean of Graduate Education at MIT, and by WHOI Academic Programs Office funds. 


\section{Contents}

1 Introduction 13

1.1 The Importance of Shelfbreak Processes at High Latitudes . . . . . . 14

1.2 Pacific Water Circulation in the Arctic Ocean . . . . . . . . . 17

1.3 Atlantic Water Circulation in the Arctic Ocean and the Nordic Seas . 18

1.4 Export of Arctic and Nordic Seas Waters to the North Atlantic ... 20

1.5 Motivation and Outline of the Thesis . . . . . . . . . . . 22

2 Two Configurations of the Western Arctic Shelfbreak Current in $\begin{array}{ll}\text { Summer } & 25\end{array}$

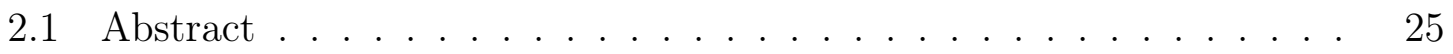

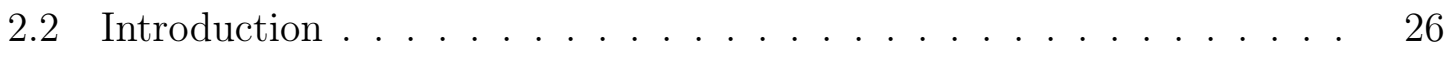

2.3 Data and Methods ... . . . . . . . . . . . . 33

2.3.1 Mooring Array at $152^{\circ} \mathrm{W} \ldots \ldots \ldots \ldots 33$

2.3 .2 Shipboard Sections . . . . . . . . . . . . . . . 35

2.3 .3 Two Year Mean State . . . . . . . . . . . . . . . . . 36

2.4 Characteristics and Timing of Summer Water Masses . . . . . . . 38

2.4.1 Definition of Summer Water Types . . . . . . . . . . . 38

2.4.2 Temporal Patterns of Summer Water . . . . . . . . . . . 42

2.4 .3 Seasonal Variability . . . . . . . . . . . . . . . . . . . 44 
2.4.4 Interannual Variability . . . . . . . . . . . . . . . 44

2.5 Summer Water Current Configurations and their Transports . . . . 45

2.5.1 Alaskan Coastal Water Configuration . . . . . . . . . . . 45

2.5.2 Chukchi Summer Water Configuration . . . . . . . . . . 49

2.5 .3 Transports. . . . . . . . . . . . . . . . . 51

2.6 Energetics and Downstream Fate of the Shelfbreak Current . . . . . 56

2.6 .1 Energetics . . . . . . . . . . . . . . . 56

2.6.2 Decay Distances and Downstream Fate . . . . . . . . . 65

2.6.3 Limitations of Distance Estimates . . . . . . . . . . . . . . 69

2.7 Discussion . . . . . . . . . . . . . . . . . . . . . . . . 71

2.8 Acknowledgments . . . . . . . . . . . . . . . . . . 75

\section{A Case Study of Denmark Strait Overflow Water Cyclones from a} $\begin{array}{ll}\text { Cross-stream Mooring Array } & 77\end{array}$

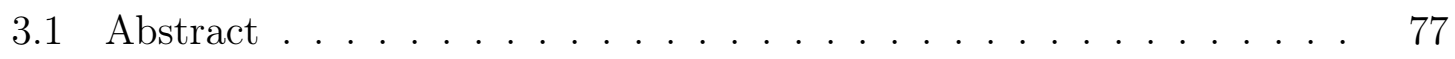

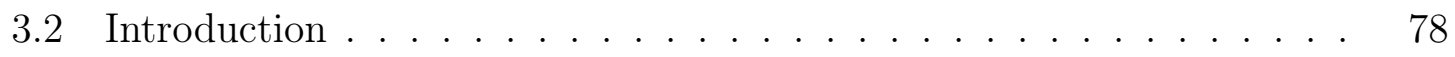

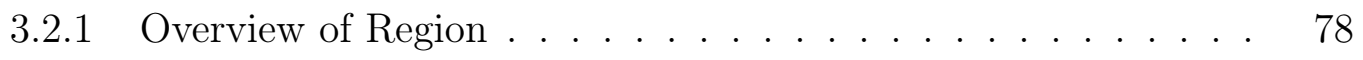

3.2 .2 Denmark Strait . . . . . . . . . . . . . . . . . . . 79

3.2.3 Steady Models of the Overflow South of the Strait . . . . . . 83

3.2.4 DSOW Eddies and Cyclogenesis Mechanisms . . . . . . . . 84

3.2.5 The Region Between Denmark Strait and Cape Farewell _ . . 89

3.2 .6 Cape Farewell Region . . . . . . . . . . . . . . . . . . . . . . . 93

3.2.7 Motivation and Outline of the Chapter . . . . . . . . . 95

3.3 Data . . . . . . . . . . . . . . . . . . 96

3.3 .1 Mooring Array . . . . . . . . . . . . . . . 96

3.3 .2 Synoptic CTD Data . . . . . . . . . . . . . . . 100 
3.3.3 Satellite SST data . . . . . . . . . . . . . . . . . 100

3.4 Mean Velocity on the Slope and its Dominant Variability . . . . . . . 101

3.5 Range of Observed Temperatures and Salinities . . . . . . . . . 108

3.6 Characteristics of the EGC/IC Front . . . . . . . . . . . 110

3.7 Theoretical Considerations Regarding Eddies on a Slope . . . . . . 113

3.7.1 Gradient Wind Balance . . . . . . . . . . . . . . . . 113

3.7.2 Eddy Structure Predicted by Spall and Price (1998) . . . . . 116

3.8 Shipboard Section through a DSOW Cyclone . . . . . . . . . . . . 119

3.9 Case Study of Three DSOW Cyclones in September 2007 . . . . . . . 123

3.9 .1 Detection from SST . . . . . . . . . . . . . . . . . 123

3.9.2 Detection from the Mooring Array _ . . . . . . . . . 126

3.9.3 Center of Eddy . . . . . . . . . . . . . . . . . . . 132

3.9.4 Offshore Side of Eddy . . . . . . . . . . . . . . . 137

3.10 Evidence for Spilling . . . . . . . . . . . . . . . . . . . . . 142

3.10 .1 A Type II spilling event . . . . . . . . . . . . . . . 143

3.10 .2 A Type I spilling event . . . . . . . . . . . . . . . . . . 144

3.11 Discussion . . . . . . . . . . . . . . . . . 150

3.12 Acknowledgments . . . . . . . . . . . . . . . . 153

4 Mean Structure and Statistics of Denmark Strait Overflow Water $\begin{array}{ll}\text { Cyclones } & 155\end{array}$

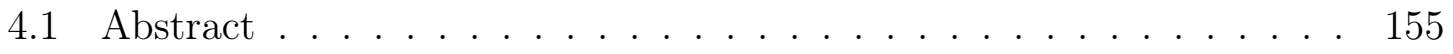

4.2 Introduction $\ldots \ldots \ldots \ldots \ldots \ldots \ldots \ldots \ldots$

4.3 Methods . . . . . . . . . . . . . . . . . . 160

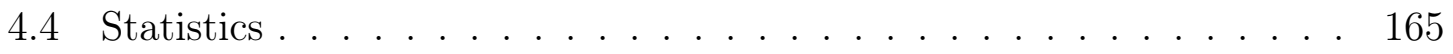

4.5 Composite Cyclone . . . . . . . . . . . . . . . . . 167 
4.5.1 Depth Mean Structure of the Composite Cyclone . . . . . . . 170

4.5.2 Vertical Structure of the Composite Cyclone . . . . . . . . . . 185

4.5.3 Cross-stream Variation of Cyclones . . . . . . . . . . . . . . 192

4.5.4 Pressure Field of the Composite Cyclone . . . . . . . . . . . . 197

4.6 Sea-surface Temperature Signature of DSOW Cyclones . . . . . . . . 204

4.7 Structure of the Background East Greenland Boundary Current System 209

4.8 Discussion . . . . . . . . . . . . . . . . . . 216

4.9 Acknowledgments . . . . . . . . . . . . . . . . 221

5 Summary and Discussion $\quad 223$

5.1 Summary of Major Findings of the Thesis . . . . . . . . . . . . 223

5.2 Questions Raised by the Work in the Thesis . . . . . . . . . . . . . 224

A Data Processing of the East Greenland Mooring Array 229

A.1 Description of Planned Array . . . . . . . . . . . . . . 229

A.2 Mooring Blowdown . . . . . . . . . . . . . . . 231

A.3 ADCP Compass Correction . . . . . . . . . . . . . . 233

A.3.1 Theory of Magnetic Compass Deviation . . . . . . . . . . . . . 234

A.3.2 Implementation of Method . . . . . . . . . . . . 239

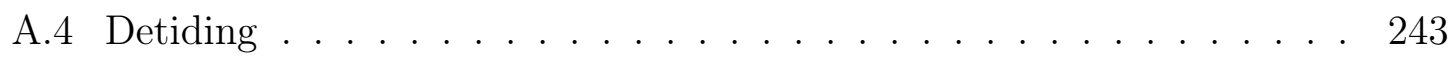

A.5 Determination of Alongstream Direction . . . . . . . . . . . 247

A.6 Description of Structure Array Containing Mooring Array Data . . . 250

A.7 Discussion of Sources of Errors . . . . . . . . . . . . . . . . . . 254

$\begin{array}{ll}\text { Bibliography } & 259\end{array}$ 


\section{Chapter 1}

\section{Introduction}

It is commonly accepted that anthropogenic forcing will lead to a change in the energy budget of the planet (e.g. Solomon et al., 2007), with a particularly large impact on the cryosphere of the Arctic. The reduction of the albedo at high latitudes - and the well-known positive feedback - will lead to a decrease in the volume of Arctic sea-ice and the Greenland ice-sheet, with enhanced fluxes of freshwater into the northern North Atlantic. With the subsequent increase of upper ocean stability in this region, there could be an inhibition of dense deep water formation. This is predicted to lead to a decrease and possible collapse of the ocean's Atlantic meridional overturning circulation (AMOC). Since the AMOC is a major contributor to the heat transport toward Europe (e.g. Pohlmann et al., 2006), a decrease in the AMOC may lead to a regional cooling in western and central Europe.

This simple scenario is how the change in global climate was envisioned based on the earliest numerical general circulation models (GCMs) (e.g. Bryan and Cox, 1967). Current generation IPCC models have a much higher resolution and are more complex, but are still not able to resolve adequately many of the small-scale and regional processes present in the oceanic and atmospheric system. Instead, these 
models rely on parameterizations of many phenomena. Both sea-ice and deep water formation are strongly affected by such small-scale processes that are currently only partially understood. This may in cases lead to significant differences between the predictions and the actual evolution of the physical system. An example of this is the inability of any of the current generation IPCC models to reproduce the recent drastic decrease of summer Arctic sea-ice extent (e.g. Kattsov et al., 2010).

\subsection{The Importance of Shelfbreak Processes at High Latitudes}

Shelf-basin exchanges make up a particular category of these small-scale and regional processes. They are the dynamical processes by which water properties and transports on the shelf and in boundary currents get communicated to and exchanged with the interior basin circulation. This has been a long-standing area of interest in physical oceanography and has received a lot of attention, in particular at mid latitudes. Broadly speaking, there are three types of forcing that lead to shelf-basin exchange: internal dynamics of a boundary current, oceanic forcing external to the boundary current, and atmospheric wind forcing.

Baroclinic instability (e.g. Pedlosky, 1987) is the most prominent example of internal dynamics that leads to shelf-basin exchange. It leads to the formation of eddies that can leave a boundary current and propagate into the interior basin thereby communicating the boundary current properties with the basin. Among many other

places, this has for example been shown to be important in the Middle Atlantic Bight (Lozier et al., 2002; Fratantoni and Pickart, 2003), and off western Australia (Brink et al., 2007). Boundary currents can also be barotropically unstable, shedding eddies 
(e.g. Griffiths and Linden, 1981).

Offshore oceanic forcing can be due to Rossby waves bringing energy from the basin westward to the boundary current, the horizontal shear due to an offshore gyre at a different velocity than the boundary current (e.g. the Beaufort Gyre, Spall et al., 2008), and oceanic eddies and rings impinging on the boundary current such as slope eddies and Gulf Stream rings interacting with the Mid-Atlantic shelfbreak current (e.g. Gawarkiewicz et al., 2001).

Coast parallel winds result in upwelling or downwelling depending on their direction (e.g. Gill and Clarke, 1974). If the duration and strength of the storms is long enough, this can move water from the shelf and the boundary current into the basin and vice versa. This, for example, is important in the California Current system (Checkley and Barth, 2009) and along the Oregon shelf (Allen and Newberger, 1996; Federiuk and Allen, 1995).

There are no reasons to believe that these processes do not occur at the high latitudes of the Arctic Ocean and the Nordic Seas. However, the internal Rossby radius will be smaller than at low and mid latitudes. This fact combined with the general data sparsity in the ice-covered oceans led to the fact that they were historically under appreciated in their impact on the circulation in the Arctic Ocean and the northern North Atlantic.

To help explain the importance of these shelf-basin exchange mechanisms in the high northern latitudes and to motivate the research undertaken in this thesis, we now summarize the oceanic flow patterns in the Arctic Ocean and the northern North Atlantic, including the Nordic Seas where sea-ice resides and deep water formation occurs. The geographical place names mentioned in this chapter are shown in Figure 1-1. 


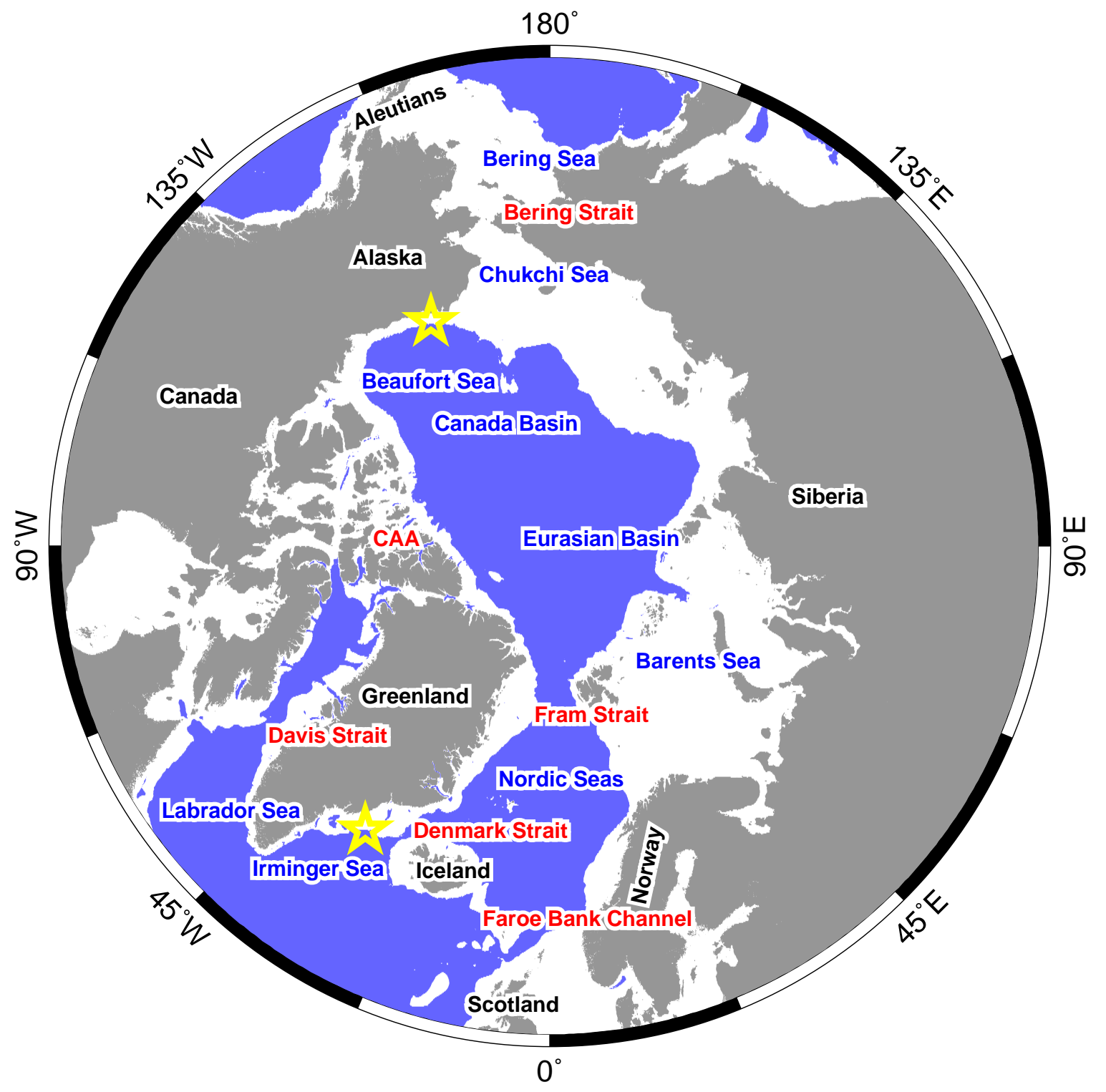

Figure 1-1: Map of the Arctic Ocean showing land (gray), shelves delineated by the $0 \mathrm{~m}$ and $500 \mathrm{~m}$ isobaths (white) and the deep ocean (blue). Places mentioned in the text are named. The two study regions addressed in this thesis are highlighted by yellow stars. 


\subsection{Pacific Water Circulation in the Arctic Ocean}

Sea-ice in the Arctic forms in the Polar Surface Water which overlies Pacific Water $(\mathrm{PW})$. The $\mathrm{PW}$ in turn resides above warmer Atlantic Water (AW) that is on average 1 salinity unit saltier than the PW. This contrast between the PW and the AW forms the Arctic halocline (e.g. Shimada et al., 2005). In this way PW insulates sea-ice from the warmer water below, but also has the ability to melt sea-ice directly. As this initial melting is occurring, the albedo gets reduced, leading to subsequently stronger melting from solar irradiation, making both of those effects important (e.g. Steele et al., 2010). In addition to impacting the distribution and evolution of sea-ice and the ventilation of the halocline, PW is also the major source of nutrients for the Arctic Ocean ecosystem.

Due to the large scale atmospheric circulation, the Pacific Ocean is on average fresher than the Atlantic (Huang and Schmitt, 1993). This leads to a pressure head at Bering Strait and a northward flow of PW into the Arctic Ocean. The long-term mean influx is $0.8 \mathrm{~Sv}$ (Woodgate and Aagaard, 2005) and is actually opposed by the mean winds in the region. The PW exits the Arctic Ocean through the Fram Strait and the Canadian Arctic Archipelago (CAA), which is comprised of many small channels (Melling et al., 2008). Upon leaving the shallow ( $\approx 50 \mathrm{~m})$ Chukchi Sea, there are two alternative pathways for the PW to get to the CAA and Fram Strait, which are associated with differing residence times of the PW in the Arctic Ocean.

The first pathway is via the anti-cyclonic Beaufort Gyre (Proshutinsky and Johnson, 1997) and the Transpolar Drift, transporting PW to the region northwest of Greenland. The Beaufort Gyre is a wind-driven upper ocean gyre that results from the wind-stress curl of the Beaufort High. During a strong anti-cyclonic atmospheric 
circulation regime, the gyre spins up and stores freshwater (here defined as water fresher than the mean Atlantic Water salinity in the Arctic Ocean) from both PW as well as meteoric sources. Conversely, if the Beaufort High decreases in intensity, the gyre can release freshwater which may lead to far field freshwater anomalies in the North Atlantic (e.g. the "Great Salinity Anomaly", Dickson et al., 1988) with possible impacts on deep convection there (Lazier, 1988).

The second pathway by which PW exits the Chukchi Sea is via the Western Arctic shelfbreak current. The extent to which this current is able to transport PW all the way to the CAA is not clear; for example, upwelling and downwelling storms can lead to cross-stream fluxes in the surface and bottom boundary layers (Pickart et al., 2009, 2011; Schulze and Pickart, 2012). The interannual strengths of the Beaufort High and the Aleutian Low also impact the frequency and intensity of upwelling storms along the Beaufort slope (Schulze et al., 2012). In the absence of winds, the current has been shown to be baroclinically unstable when it transports cold winter PW in a bottom intensified jet (Spall et al., 2008). This leads to the shedding of eddies providing a mechanism for the shelf-basin exchange of PW properties.

Regardless of the pathway that PW takes, it is known to exit the Arctic Ocean through Fram Strait and the CAA (Jones et al., 2003). In Fram Strait and Davis Strait (south of the CAA), the PW joins the Atlantic Water pathways.

\subsection{Atlantic Water Circulation in the Arctic Ocean and the Nordic Seas}

Warm Atlantic Water (AW) is transported northward in the Gulf Stream-North Atlantic Current system, which is the northern boundary of the subtropical gyre and the 
southern boundary of the subpolar gyre. Along this pathway, the AW loses significant amounts of heat to the atmosphere which is responsible for the warm temperatures in Europe (Pohlmann et al., 2006). Some of the warm water enters the Nordic Seas west of Norway as the Norwegian Atlantic Current. It then flows cyclonically around the perimeter of the Nordic Seas, continually losing heat to the atmosphere. It is also subject to baroclinic instability along the pathway, shedding eddies into the interior basin of the Nordic Seas (Orvik et al., 2001). North of Norway, a part of the AW gets diverted into the Barents Sea, while another part flows through Fram Strait into the Arctic Ocean. The AW flowing through the Barents Sea is subject to intense heat loss and subsequently becomes saltier due to brine rejection. This makes it denser than the AW emanating from Fram Strait, which is why the Barents Sea branch subducts below the Fram Strait branch northeast of the Barents Sea. This composite AW boundary current begins as a near-surface flow along the Svalbard and Siberian shelfbreaks, but eventually descends below the winter Pacific Water forming the lower halocline (Aagaard, 1989) of the Arctic Ocean. Portions of the AW boundary current are believed to be diverted by the different deep ocean ridges in the Arctic, leading to deep cyclonic gyres in the different sub-basins of the Arctic Ocean (Rudels et al., 1994). These different pathways ultimately join again to exit through Fram Strait (Woodgate et al., 2001). The longest pathway of AW through the Arctic is estimated to take $O(30$ years) (Karcher et al., 2007). It should be noted that the large stratification of the halocline isolates the AW flow from any direct atmospheric impact. Measurements in the Eurasian Basin suggest that the AW boundary current is unstable (Schauer et al., 1997) and changes in the topographic slope around the Chukchi Border Land also seem to impact the stability of the flow (Woodgate et al., 2007) leading to the formation of AW eddies (Carpenter and Timmermans, 2012).

The return flows of the different AW branches come together in the vicinity of 
Fram Strait to form the East Greenland Current (EGC). In its upper part, the EGC transports remnant PW as well as Polar Surface Water. The transformed AW exiting the Arctic, as well as the return AW that gets retroflected south of Fram Strait, together form one of the components of the dense overflow across the GreenlandScotland Ridge (Rudels et al., 2002). The fresh PW and Polar Surface Water shield the underlying AW from atmospheric influence thereby inhibiting further heat loss and densification of this AW.

In addition to the broad overturning loop associated with the AW entering the Nordic Seas west of Norway, there is also transformation of AW that takes place locally in the Iceland Sea. AW from the Irminger Sea flows on the eastern side of Denmark Strait into the Iceland Sea. This water gets cooled and densifies during open ocean convection within the Iceland Sea gyre (Våge et al., 2011). It then flows southward again joining with the dense component of the EGC to form the overflow water across the Denmark Strait, known as Denmark Strait Overflow Water (DSOW). The remainder of the dense water in the Nordic Seas exits through the Faroe Bank Channel (Hansen and Østerhus, 2000). Together these overflow waters are the source of the dense component of the North Atlantic Deep Water (NADW).

\subsection{Export of Arctic and Nordic Seas Waters to the North Atlantic}

Since the overflow waters are significantly denser than the ambient water in the North Atlantic at sill depth, they descend along the topography. During this descent the water mixes, and ambient water is entrained into the overflow plume increasing its

transport and decreasing its density (Price and O'Neil Baringer, 1994). This means 
that the properties of the product water which subsequently gets exported in the Deep Western Boundary Current (DWBC) depends both on the densification setting the source water mass and on the entrainment upon overflowing the sill. There have only been a small number of observations of this entrainment process and its temporal variability has not been well quantified (e.g. Fer et al., 2010).

The DSOW displays a unique type of variability (Spall and Price, 1998): as the dense water descends, the water column height increases and this vortex stretching leads to the formation of intense cyclones. These DSOW cyclones dominate the variability along the East Greenland slope (Bruce, 1995), and, as such, likely impact the entrainment which depends upon the turbulence levels.

Above the descending overflow water, the surface-intensified EGC joins with the Irminger Current (IC) which is the subtropical-origin water that did not enter the Nordic Seas. In addition to the dense water that passes southward through Denmark Strait in the vicinity of the $650 \mathrm{~m}$ deep sill, there is also dense water that remains on the East Greenland shelf on its way through the strait (Brearley et al., 2012). It is now known that some of this dense water cascades off the shelf. It adjusts to form a current along the upper continental slope south of Denmark Strait. This feature has been termed the East Greenland Spill Jet (Pickart et al., 2005a), and it is believed to be formed by a combination of the atmospheric and oceanic offshore forcing mechanisms outlined below

Barrier Winds result from the interaction of the Icelandic Low with the tall topography of Greenland. These strong northerly winds along the East Greenland slope occur throughout the year, but are strongest and arise more frequently in the winter months (Harden et al., 2011). They result in downwelling and cross-shelfbreak flow near the bottom that brings the dense water from the shelf onto the continental slope (Harden et al., 2012). The water that spills is denser than the ambient water 
on the upper slope. This leads to an adjustment process, which includes symmetric instability, forming the bottom-intensified East Greenland Spill Jet. To date, the observational evidence for the Spill Jet is limited to a handful of shipboard hydrographic and velocity sections (Brearley et al., 2012).

A numerical model study of the region found that DSOW cyclones also lead to spilling of dense water off the shelf (Magaldi et al., 2011). The cyclones are associated with strong offshore velocities on their leading edge that pull the water off the shelf. It then adjusts and mixes such that the onshore velocities of the cyclones on their trailing edge can only move less dense water back onto the shelf leading to a net offshore flux of dense water. Meanders of the EGC/IC were also found to induce spilling. The mean structure of the Spill Jet in the model qualitatively agreed with the observations of Brearley et al. (2012), but the peak velocities were weaker at around $0.6 \mathrm{~m} / \mathrm{s}$ (the velocities of Brearley et al. (2012) are calculated assuming geostrophy holds and likely overestimate the true fluid velocities).

Intriguingly, there is no indication of the presence of the Spill Jet or the DSOW cyclones at Cape Farewell, the southern tip of Greenland (Bacon and Saunders, 2010; Daniault et al., 2011a). This indicates that they spin down or get significantly transformed along the East Greenland slope. The EGC, which possibly contains the Spill Jet water in its deep extension, and the DWBC are present at Cape Farewell and turn the corner to flow along the West Greenland slope.

\subsection{Motivation and Outline of the Thesis}

Our emerging understanding of the complex oceanic circulation at high northern latitudes, including the inflow to and outflow of water from the Arctic Ocean, shows the importance of several complex small-scale and regional processes. These internal 
and externally forced mesoscale dynamics account for much of the water mass transformation, and in turn affect the large scale circulation by facilitating the exchange between the boundary current and the interior flow pathways. For example, the evolution of the Arctic sea-ice undoubtedly depends on the geographical distribution of the heat transported northward with PW through Bering Strait (Woodgate et al., 2010). By ventilating the upper Arctic halocline, the reach of PW also defines the extent of the region where strong stratification insulates AW from atmospheric fluxes. Another example is that the global deep ocean is filled with NADW, so changes in its formation rate and properties would impact a large portion of the global deep ocean (Danabasoglu et al., 2010).

More research is clearly needed to further our understanding of the mesoscale dynamics that impact both the inflow to and outflow from the Arctic Ocean. Recently, two mooring arrays were maintained in the Western Arctic shelfbreak current on the Beaufort slope at $152^{\circ} \mathrm{W}$ and in the East Greenland boundary current system at $65^{\circ} \mathrm{N}$ (for the locations, see Figure 1-1). As such, these arrays measured important components of the Arctic inflow and outflow at high resolution for the first time away from oceanic straits. Both arrays used moorings extending from the outer shelf to the mid continental slope to measure temperature, salinity, and velocity for at least a year. A unique aspect different from previous mooring arrays was that the horizontal spacing was on the order of the internal Rossby radius, making it possible to use these arrays for studies of mesoscale dynamics.

The aim of this thesis is to use these data sets to answer fundamental questions about high latitude mesoscale dynamics in general, and about those at work at these two crucial locations in particular. Knowledge of these shelf-basin exchange and water mass transformation processes will help to constrain better the circulation through the Arctic Ocean. We purposefully focus on periods that are not strongly wind forced 
to elucidate the internal oceanic dynamics, noting that there are more aspects to the whole boundary current systems than can be addressed at one time.

Chapter 2 of this thesis investigates the dynamical state of the Western Arctic shelfbreak current when it transports warm summer Pacific Water. The contribution of mesoscale instabilities to the spin-down of the current and the flux of summer Pacific Water from the shelf to the basin is determined. In Chapters 3 and 4, we address the detailed three-dimensional structure of Denmark Strait Overflow Water cyclones and establish their frequency and depth distribution. Their effect on the entrainment into the dense overflow water is discussed as is the relation of the cyclones to the East Greenland Spill Jet. The Spill Jet is also shown to be a year-round component of the East Greenland boundary current system. A summary and discussion in Chapter 5 concludes the thesis. 


\section{Chapter 2}

\section{Two Configurations of the Western}

\section{Arctic Shelfbreak Current in Summer}

This chapter has been published as an article in the Journal of Physical Oceanography. The authors are Wilken-Jon von Appen and Robert S. Pickart.

von Appen, W. and R. Pickart, 2012: Two Configurations of the Western Arctic Shelfbreak Current in Summer. Journal of Physical Oceanography, 42 (3), 329-351. (C) American Meteorological Society. Used with permission.

\subsection{Abstract}

Data from a closely-spaced array of moorings situated across the Beaufort Sea shelfbreak at $152^{\circ} \mathrm{W}$ are used to study the Western Arctic shelfbreak current, with emphasis on its configuration during the summer season. Two dynamically distinct states of the current are revealed in the absence of wind, each lasting approximately one month. The first is a surface-intensified shelfbreak jet transporting warm and buoyant Alaskan Coastal Water in late summer. This is the eastward continuation of 
the Alaskan Coastal Current. It is both baroclinically and barotropically unstable and hence capable of forming the surface-intensified warm-core eddies observed in the southern Beaufort Sea. The second configuration, present during early summer, is a bottom-intensified shelfbreak current advecting weakly stratified Chukchi Summer Water. It is baroclinically unstable and likely forms the mid-depth warm-core eddies present in the interior basin. The mesoscale instabilities extract energy from the mean flow such that the surface-intensified jet should spin down over an e-folding distance of $300 \mathrm{~km}$ beyond the array site, while the bottom-intensified configuration should decay within $150 \mathrm{~km}$. This implies that Pacific Summer Water does not extend far into the Canadian Beaufort Sea as a well-defined shelfbreak current. In contrast, the configuration of the shelfbreak jet when advecting Pacific Winter Water is estimated to decay over a much greater distance of approximately $1400 \mathrm{~km}$, implying that it should reach the first entrance to the Canadian Arctic Archipelago.

\subsection{Introduction}

The Western Arctic shelfbreak current advects Pacific origin waters eastward along the edge of the narrow $(\approx 50 \mathrm{~km})$ and shallow $(<50 \mathrm{~m})$ Beaufort Sea shelf. While the current influences local conditions on the Beaufort Shelf such as ice cover and nutrient supply available for biological production, it also influences the interior Canada Basin. For example, the lateral transport of properties away from the current, via processes such as baroclinic instability (e.g. Spall et al., 2008), helps ventilate the cold halocline

of the interior Canada Basin (Pickart et al., 2005b). Such mesoscale variability of the current also impacts the pathways of Pacific Water through the Arctic Ocean and ultimately into the North Atlantic.

Pacific Water first enters the Arctic Ocean through Bering Strait, where, in the 
multi-year mean, $0.8 \mathrm{~Sv}$ of water flows from the Bering Sea to the Chukchi Sea, though this number varies seasonally from $0.4 \mathrm{~Sv}$ to $1.3 \mathrm{~Sv}$ (Woodgate et al., 2005b). Both of these shelf seas are shallow $(<50 \mathrm{~m})$ and are strongly influenced by wind forcing and the seasonal sea-ice melt/thaw cycle. The northward flow of Pacific Water is driven by a pressure head that arises because the Pacific is significantly fresher than the Atlantic (Woodgate and Aagaard, 2005; Huang and Schmitt, 1993). This flow persists despite the fact that the predominant winds in Bering Strait are northerly and therefore oppose the current (Overland and Roach, 1987). Three types of Pacific Water have been identified in the strait based on their distinct sources (Woodgate and Aagaard, 2005): Nutrient rich Anadyr Water flows through the western (Russian) passage of Bering Strait, while the generally saltier and colder Bering Shelf Waters occupy the eastern (US) passage. The third water mass is Alaskan Coastal Water, which is transported seasonally by the Alaskan Coastal Current in the eastern-most part of the strait. This current originates from river run-off into the Gulf of Alaska and Bering Sea (Weingartner et al., 2005). While there is general agreement in the literature on the nomenclature of the Alaskan Coastal Current and the warm, fresh water it advects, the remaining water masses, which change seasonally, are less precisely defined. Furthermore, significant water mass transformation takes place north of the strait in the Chukchi Sea (e.g. Weingartner et al., 1998).

The topography of the Chukchi Sea helps channel the Pacific Water into three distinct northward-flowing branches as shown in Figure 2-1 (Paquette and Bourke (1981), see also Woodgate et al. (2005a) for a more recent treatment). The eastern branch generally follows the Alaskan coast into Barrow Canyon; in summertime this is the pathway of the Alaskan Coastal Current. The middle branch extends through the depression between Hanna and Herald shoals, known as the Central Channel (Weingartner et al., 1998), and the western branch flows through Herald Canyon 

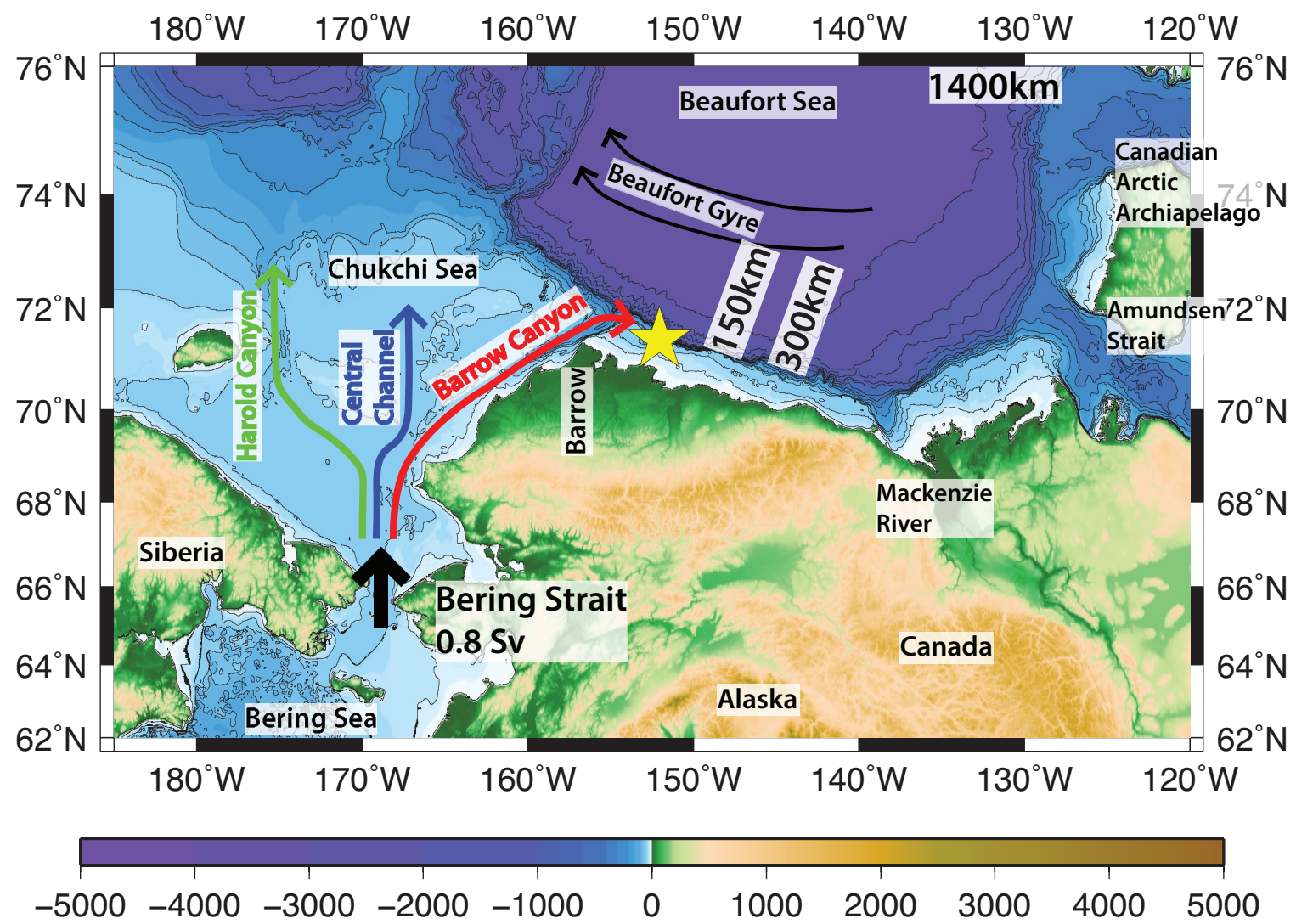

Figure 2-1: Map of the study region in the Western Arctic, including geographical names. Elevation is shown in color (data from Jakobsson et al. (2008)). The circulation is represented schematically by arrows (see text). The mooring array at $152^{\circ} \mathrm{W}$ is indicated by the yellow star, and downstream distances of $150 \mathrm{~km}, 300 \mathrm{~km}$ and $1400 \mathrm{~km}$ from the array are marked. 
east of Wrangel Island (Pickart et al., 2010). Both summer and winter water masses are advected in each of these branches. However, uncertainties remain regarding the relative timing of the seasonal transition and the potential interaction of the summer and winter waters within the individual branches. Synoptically, as well as seasonally, the partitioning of transport varies between the three branches as shown by numerical models (e.g. Winsor and Chapman, 2004; Panteleev et al., 2010).

Pacific Water is found throughout the Arctic Ocean and has important impacts there. The halocline is in part maintained by an influx of freshwater from Bering Strait, which together with precipitation and river run-off balances the upward mixing of salt from the Atlantic Water layer (Aagaard et al., 1981). As warm Pacific Water enters the Arctic in the beginning of summer, it is able to facilitate ice-melt. For the extreme ice minimum year of 2007, Woodgate et al. (2010) argued that the heat flux through Bering Strait was sufficient to account for a third of the sea-ice retreat. Pacific Water also carries nutrients required for primary productivity into the Arctic Ocean. As a result of upwelling in the Bering Sea shelf, the Anadyr Water is particularly high in nutrient concentration (Sambrotto et al., 1984), while the Alaskan Coastal Water is nutrient poor as it is composed of river run-off mixed with ambient oceanic water (Weingartner et al., 2005).

Within the halocline layer of the interior western Arctic Ocean there exist both a local temperature minimum near 150-200 m, attributed to Pacific Winter Water, and an overlying temperature maximum attributed to Pacific Summer Water (Steele et al., 2004). The Winter Water is formed during freeze-up in the Bering and Chukchi Seas (Muench et al., 1988; Weingartner et al., 1998). Throughout the winter season, it further densifies due to brine rejection during freezing within leads and polynyas in the Chukchi Sea (Cavalieri and Martin, 1994). The densest variety of Winter Water is referred to as hypersaline water (Weingartner et al., 1998). Pacific Summer Water 
comes in two varieties that have a multitude of naming conventions found in the literature. The first, characterized by temperatures near $-1^{\circ} \mathrm{C}$ and salinities greater than 32, has been referred to as Summer Bering Sea Water by Steele et al. (2004) and Western Chukchi Summer Water by Shimada et al. (2001). In the present study we simply call it Chukchi Summer Water. The second is the Alaskan Coastal Water with salinities between 31 and 32 . In some other places, this has also been called Eastern Chukchi Summer Water after it spreads into the interior basin (e.g. Shimada et al., 2001). Here we adopt the former terminology.

While climatologies (e.g. Environmental Working Group, 1998) indicate that the cold and warm temperature extrema within the halocline layer exist over a broad region of the Canada basin, local measurements from drifting platforms often reveal small-scale features with anomalously cold and warm signatures relative to the ambient water (e.g. Manley and Hunkins, 1985; Muench et al., 2000; Timmermans et al., 2008, Plueddemann and Krishfield, pers. comm. 2007). It is now known that such features are usually associated with subsurface eddies of Pacific Water. The majority of the eddies are mid-depth intensified cold-core anti-cyclones with diameters of 10$20 \mathrm{~km}$. Plueddemann and Krishfield (pers. comm., 2007) found that, on average, an eddy was encountered every $100 \mathrm{~km}$ of drift of their instrument platform. Azimuthal velocities of up to $0.4 \mathrm{~m} \mathrm{~s}^{-1}$ at depths between $50 \mathrm{~m}$ and $200 \mathrm{~m}$ were observed in the eddies compared to the mean flow of $<0.05 \mathrm{~m} \mathrm{~s}^{-1}$ at these depths. In general, the centers of the cold-core eddies have temperature anomalies $\geq 0.1^{\circ} \mathrm{C}$ and are not warmer than $-1^{\circ} \mathrm{C}$. In addition to these cold features, shipboard measurements north of the Chukchi Sea have revealed a shallower $(<100 \mathrm{~m})$ warm-core subsurface eddy $\left(\approx 0^{\circ} \mathrm{C}\right)$, as well as a surface-intensified warm core $\left(>2^{\circ} \mathrm{C}\right)$ anti-cyclone containing Alaskan Coastal Water (Pickart and Stossmeister, 2008). Thus, eddies of the three different seasonal Pacific Water masses noted above (Winter Water, Summer Water, 
Alaskan Coastal Water) have been observed.

There have been a number of explanations for the formation of the eddies. A series of studies suggested that the cold-core eddies can originate in the interior basin due to brine rejection during the opening of leads (Chao and Shaw, 1996, 1998, 1999). Synoptic winds over the interior Arctic Ocean have also been suggested as an eddy generation mechanism (see the discussion in Hunkins, 1974). However, Hunkins (1974) argued that such processes in the interior Arctic occur on scales inconsistent with the dimensions of the eddies. In particular, the wind forcing occurs on scales that are too large, while the brine rejection occurs on scales that are too small. This led Hunkins (1974) to speculate that the eddies might be formed at the boundary of the basin as part of a shelfbreak circulation. Consistent with this idea, Spall et al. (2008) demonstrated that mid-depth, cold-core eddies are readily formed from baroclinic instability of a simulated shelfbreak jet when it advects Winter Water. These numerical results compared well with observations. The model current formed dipole pairs, but the shallow cyclones spun-down rapidly due to contact with the (parameterized) ice. This is consistent with Ou and Gordon (1986) who investigated eddy spin down due to pack-ice, and also with the fact that cyclones are mainly observed close to the Beaufort Shelf (i.e. before they have a chance to spin down, Plueddemann and Krishfield, pers. comm. 2007). The formation mechanism of warmcore eddies is less well understood. The observations of D'Asaro (1988a) suggested that eddy generation occurs in both Barrow Canyon and Harold Canyon (D'Asaro, 1988b). The model study of Watanabe and Hasumi (2009) implies that the source is the shelfbreak current during its seasonal warm phase, but the eddies so produced are significantly larger than indicated by the observations. The results to date suggest that horizontal processes such as eddy formation seem necessary to maintain the Pacific Summer Water temperature extremum in the interior basin, but uncertainty 
remains about the detailed mechanisms at work.

Recent observations have elucidated the structure and transport of the flow of Pacific Water along the shelf-edge and slope of the Beaufort Sea, referred to here as the Western Arctic shelfbreak current. A mooring array maintained across the current revealed that the mean flow is eastward with a volume flux of $0.13 \pm 0.08 \mathrm{~Sv}$ (Nikolopoulos et al., 2009). The fact that this value is less than a quarter of the estimated mean inflow through Bering Strait suggested that much of the Pacific Water transport is quickly lost to the basin. Nikolopoulos et al. (2009) constructed seasonal composites of the shelfbreak current and found that in late-winter and spring it is bottom-intensified and transports Pacific Winter Water, while in late-summer and early-fall it is surface-intensified and advects Alaskan Coastal Water. The Winter Water configuration of the current is baroclinically unstable in the absence of wind (Spall et al., 2008), while autumn and winter storms reverse the flow to the west and cause upwelling (Nikolopoulos et al., 2009; Pickart et al., 2011).

To date, the detailed structure, variability, and dynamics of the summer configuration of the Western Arctic shelfbreak current have not been quantified, including the implications for eddy formation. This is the aim of the present study. Using the same mooring data set considered by Nikolopoulos et al. (2009), we demonstrate that there are in fact two structurally and dynamically distinct configurations of the shelfbreak current advecting the two types of Summer Water noted above: Alaskan Coastal Water and Chukchi Summer Water. We investigate the timing, structure, stability, and energetics of the two current states, which provides insights regarding the fate of the warm waters advected by the current and their potential impact on the interior basin. 


\subsection{Data and Methods}

\subsubsection{Mooring Array at $152^{\circ} \mathrm{W}$}

The Western Arctic Shelf-Basin Interactions (SBI) program was designed to investigate the various physical, chemical, and biological mechanisms influencing the ecosystem at the interface between the shelf and slope in the Chukchi and Beaufort Seas (Grebmeier and Harvey, 2005). As part of SBI, a mooring array was deployed at $152^{\circ} \mathrm{W}$ (yellow star on Figure 2-1) across the shelfbreak downstream of Barrow Canyon primarily to investigate the Pacific Water flow along the Beaufort Slope. Eight moorings were aligned roughly perpendicular to the local bathymetry.

Figure 2-2 shows a view of the mooring array in the vertical plane. (The shorewardmost mooring failed in year 1 and is not considered in this study.) Each site contained a moored conductivity/temperature/depth (CTD) profiler to measure the hydrographic properties (the inner five sites employed coastal moored profilers sampling four times a day, and the outer two sites contained McLane moored profilers sampling twice a day). For velocity, upward-facing acoustic Doppler current profilers (ADCPs) were situated at the base of the inner five moorings, while acoustic current meters (ACMs) were used in conjunction with the moored profilers at the outer two sites. In the present study we use only data from the five inner moorings, which measured temperature and salinity every six hours and velocity hourly. The mooring array was deployed from 3 August, 2002 to 9 September, 2004, with an approximate three week gap (10 September to 1 October, 2003) when the mooring array was serviced. The moored profilers sampled only to $50 \mathrm{~m}$ water depth in order to remain a safe distance from ridging sea-ice, while the ADCPs sampled in the lower $85 \%$ of the water column. This means that the near-surface temperature, salinity, and velocity were not recorded. Details of the instrumentation as well as estimates of the errors associated 


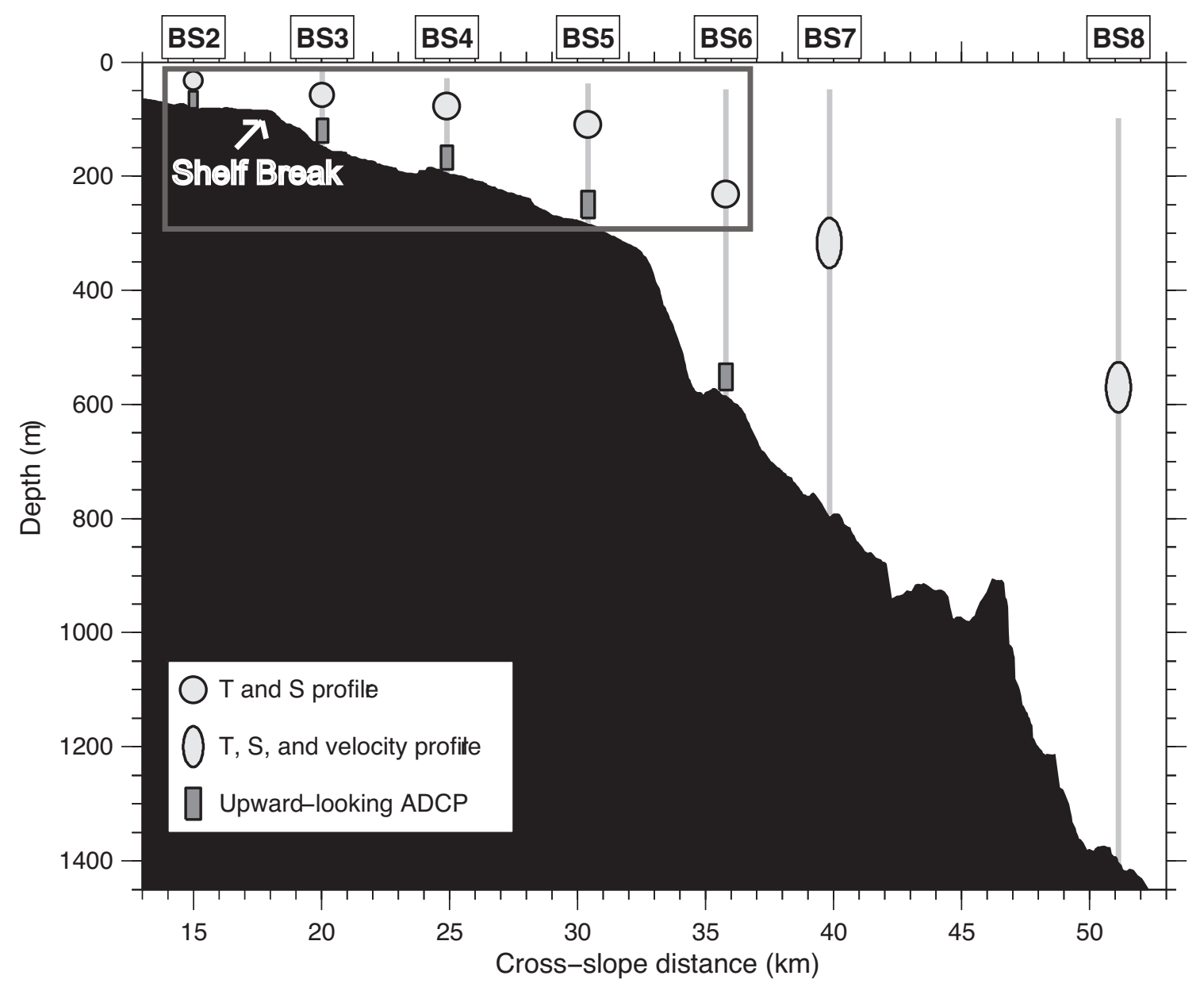

Figure 2-2: The SBI mooring array at $152^{\circ} \mathrm{W}$ (after Spall et al., 2008). The different instruments are shown in the key (see text for details). The gray box shows the area of the array addressed in this study. The location of the shelfbreak is indicated (the coastline is $70 \mathrm{~km}$ inshore of the shelfbreak). 
with the measurements are given in Nikolopoulos et al. (2009) for the velocity and in Spall et al. (2008) for the hydrography.

A local coordinate system was defined using the depth-averaged flow in conjunction with the principal axis variance ellipses (see Nikolopoulos et al., 2009). The positive $x$-direction is essentially aligned along the bathymetry upstream of the array, i.e. east-southeast $\left(125^{\circ} \mathrm{T}\right)$, and the positive $y$-direction is north-northeast $\left(35^{\circ} \mathrm{T}\right)$. The $z$-direction is vertical (positive upward). In the following, $x$ will be referred to as the alongstream direction and $y$ as the cross-stream direction. The tidal signal on the Beaufort Slope is $O\left(0.01 \mathrm{~m} \mathrm{~s}^{-1}\right)$ which is weak compared to the mean velocities $O\left(0.1 \mathrm{~m} \mathrm{~s}^{-1}\right)$. In order to focus on mesoscale and longer time-scale variability, the velocities were low-pass filtered using a second order lowpass Butterworth filter with a cutoff period of $1 /(36$ hours $)$.

Both the measured and derived variables from the array were gridded in the vertical plane using Laplacian-spline interpolation. This resulted in vertical sections of potential temperature, salinity, potential density, alongstream and cross-stream velocity, and the components of the potential vorticity at 6 hour intervals. The standard grid has a horizontal spacing of $2 \mathrm{~km}$ and a vertical spacing of $10 \mathrm{~m}$. In order to focus on the Pacific Water shelfbreak current, the grid is limited to $300 \mathrm{~m}$ in the vertical and $24 \mathrm{~km}$ in cross-stream distance as shown by the gray box in Figure 2-2.

\subsubsection{Shipboard Sections}

As noted above, the hydrographic measurements from the mooring array did not extend shallower than $50 \mathrm{~m}$ in the water column. To assess the impact of this gap in part of the analysis below, we made use of shipboard hydrographic and velocity data. In particular, three transects coincident with the mooring line at $152^{\circ} \mathrm{W}$ during the 
summer season provided synoptic full water column measurements of the shelfbreak current. The $R / V$ Palmer completed CTD and vessel mounted ADCP sections on 19 July and 14 August, 2003 (Swift, 2003) when the shelfbreak current was advecting Alaskan Coastal Water. The USCGC Healy occupied a CTD and vessel mounted ADCP section on 3 August, 2009 during which time the shelfbreak current transported Chukchi Summer Water. These temperature, salinity, and velocity data were interpolated onto the same standard grid as the mooring data.

\subsubsection{Two Year Mean State}

The mean hydrographic and velocity structure of the Western Arctic shelfbreak current over the two year period of the mooring array is shown in Figure 2-3. This is an extension of the presentation by Nikolopoulos et al. (2009) who used data from the first year only. The general features remain the same with the additional year of data. Water as cold as $-1.4^{\circ} \mathrm{C}$ corresponding to Pacific Winter Water is situated offshore between $100 \mathrm{~m}$ and $200 \mathrm{~m}$ depth. Pacific Summer Water is more prevalent inshore and above $100 \mathrm{~m}$ where it results in mean temperatures as warm as $-0.4^{\circ} \mathrm{C}$ even though it is only present for a comparatively short time of the year. The warm and salty Atlantic Water resides below the Pacific Winter Water (i.e. deeper than $200 \mathrm{~m}$ ); the temperature maximum of the Atlantic layer is situated at roughly $400 \mathrm{~m}$. In the region of the upper continental slope the mean temperatures are moderate even though the coldest Winter Water is found here during spring and early summer (Spall et al., 2008). This is because upwelling during autumn and winter often brings warm Atlantic Water up the slope, impacting the annual mean (Pickart et al., 2009).

In the mean density section the isopycnals are sloping upward near the outer shelf and upper slope (the shelfbreak is situated near $85 \mathrm{~m}$ ). This is consistent with the 

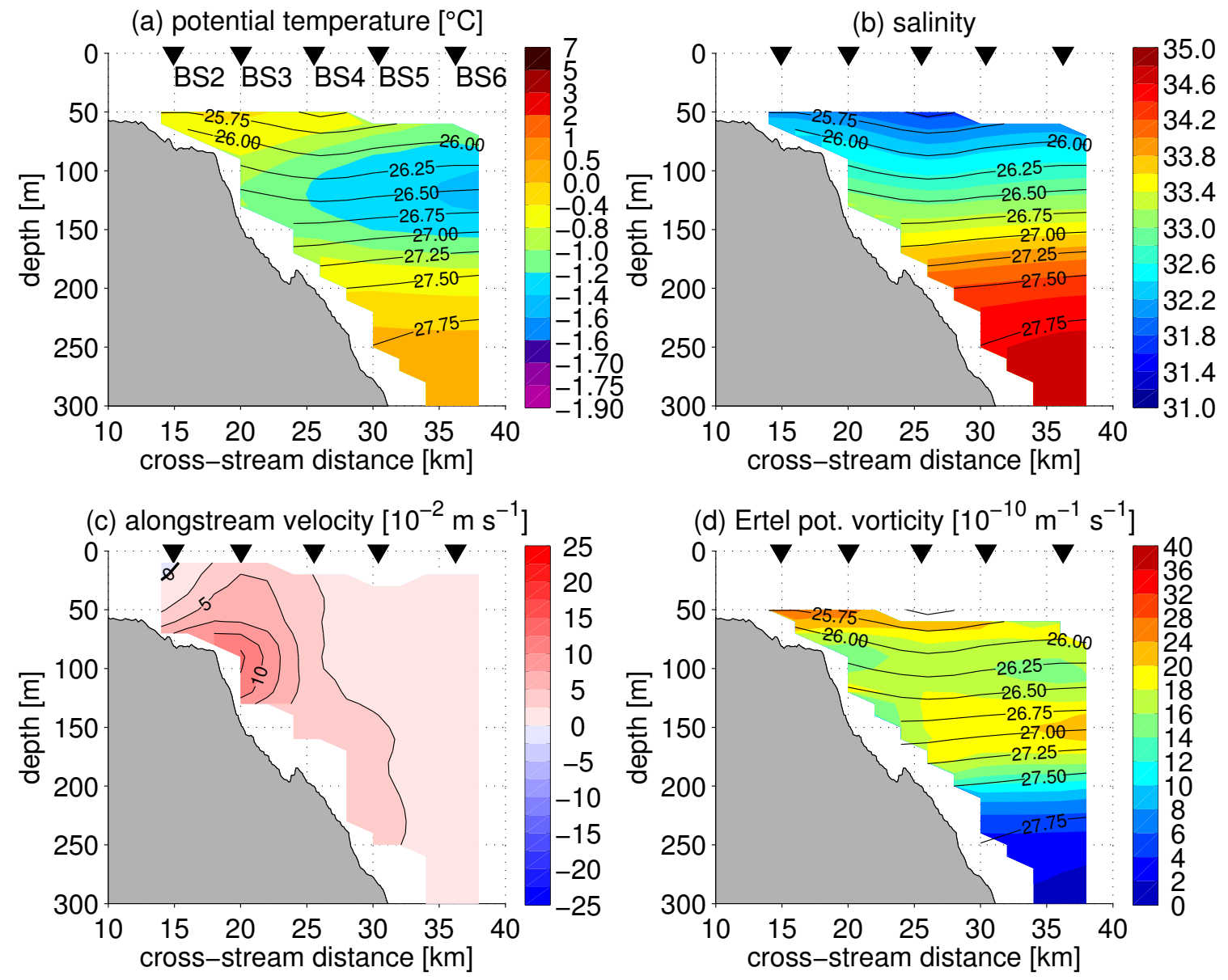

Figure 2-3: Mean state of the Western Arctic shelfbreak current from 1 August 2002 to 1 August 2004. The colors show (a) potential temperature, (b) salinity, (c) alongstream velocity, and (d) Ertel potential vorticity and the overlain contours show $(\mathrm{a}, \mathrm{b}, \mathrm{d})$ potential density and (c) alongstream velocity. The five moorings BS2 through BS6 used in the analysis are indicated by inverted black triangles and labeled in panel (a). The bathymetry is shaded gray. 
bottom intensification of the shelfbreak current as seen in the mean velocity section

(velocity maximum of $0.125 \mathrm{~m} \mathrm{~s}^{-1}$ ). The full Ertel potential vorticity (see eq. (2.1) below) is dominated by the stratification term. One sees that the Atlantic Water is characterized by very low stratification, above which lies a layer of stronger stratification within the halocline separating this water mass from the weakly stratified Pacific Winter Water above. The mean signature of Pacific Summer Water is characterized by enhanced stratification near $50 \mathrm{~m}$ depth.

\subsection{Characteristics and Timing of Summer Water Masses}

\subsubsection{Definition of Summer Water Types}

The Western Arctic shelfbreak current has a well-defined signature in the two year mean as shown above. However, the mean represents the superposition of different configurations of the current occurring on mesoscale to seasonal time scales. To understand the mean and variability of the full boundary current system, the various dynamical processes at work need to be considered, sometimes individually. As such, the present study attempts to elucidate the summertime state of the Western Arctic shelfbreak current when it advects Pacific-origin waters that have been warmed in the Bering Sea and/or Chukchi Sea in early to mid-summer before arriving at the array site. The first step, therefore, is to objectively define the two types of Summer Water noted above - the Alaskan Coastal Water (ACW) and Chukchi Summer Water (CSW) - and identify when they are present at the array site.

Figure 2-4 shows the percentages of time during which different water masses are observed at the array. Atlantic Water (AW) is defined here as $\theta>-1^{\circ} \mathrm{C}, \mathrm{S}>33$ and 


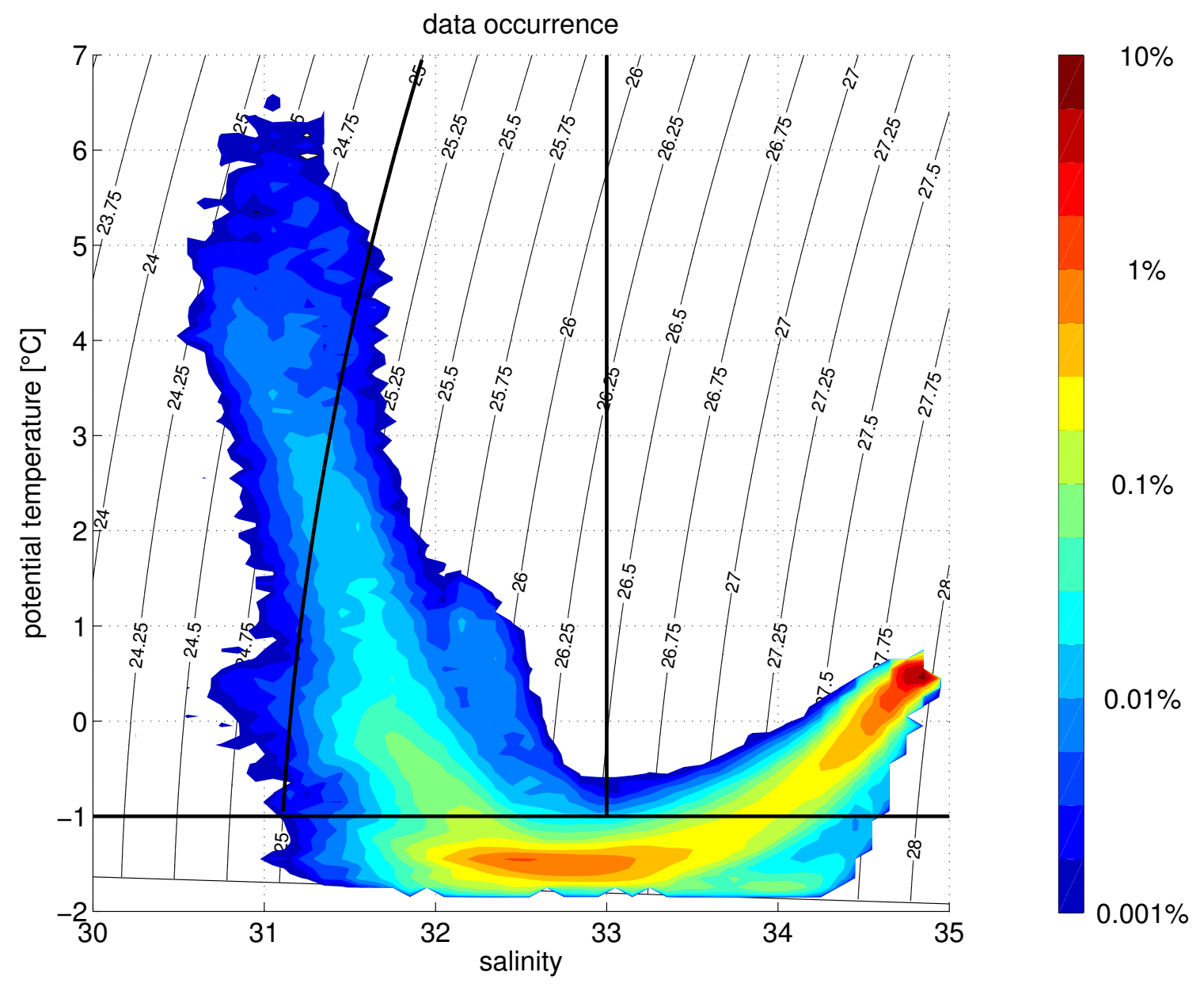

Figure 2-4: Occurrence of water types as a function of temperature and salinity over the two-year deployment. Units are percentage of all measurements per $0.1^{\circ} \mathrm{C}$ and 0.1 salinity (note the logarithmic scale). The 33 line separating the Pacific from the Atlantic Water and the $-1^{\circ} \mathrm{C}$ line separating the Winter Water are indicated along with the $25 \mathrm{~kg} \mathrm{~m}^{-3}$ line separating the two Summer Water types. 
Pacific Winter Water (PWW) is defined as $\theta<-1^{\circ} \mathrm{C}$; we do not attempt to distinguish different types of Winter Water, such as those discussed in Weingartner et al. (1998). AW and PWW were both present throughout the year with the PWW overlying the AW typically at and below $200 \mathrm{~m}$ (except during periods of upwelling when it can reach the upper slope and outer shelf). The PWW layer thickness varies both seasonally and synoptically, thinning considerably in summer.

Our study focuses on Pacific Summer Water (PSW) broadly classified here as $\theta>-$ $1^{\circ} \mathrm{C}, \mathrm{S}<33$. It is present at the array intermittently from June through November each year. In order to distinguish between the two summer water types, the alongstream transport was calculated as a function of temperature and salinity. Within the Summer Water domain there are two distinct mixing lines with the Pacific Winter Water: one containing an endmember $<25 \mathrm{~kg} \mathrm{~m}^{-3}$ and the other an endmember $>25 \mathrm{~kg} \mathrm{~m}^{-3}$ (Figure 2-5). We interpret this to mean that the shelfbreak current at times advects predominantly very light water (ACW) mixing with PWW below, and at other times advects less light water (CSW) mixing with PWW below. This distinction was used as an objective criterion for defining the two types of Summer Waters. For the shelfbreak current to be in the $\mathrm{ACW}$ configuration it is required to contain water lighter than $25 \mathrm{~kg} \mathrm{~m}^{-3}$ somewhere within the domain, while the CSW configuration consists only of water denser than $25 \mathrm{~kg} \mathrm{~m}^{-3}$. This criterion may seem somewhat ad hoc, but it was motivated and supported by further evidence. For example, the sense of the thermal wind shear within the current varies in correspondence to summer water states defined as such.

In the mean, the shelfbreak current flows eastward, but as discussed in Pickart et al. (2009) the flow is often reversed to the west during autumn and winter upwelling storms. Inspection of the summer record also revealed westward flow reversals of the current (though less frequent). Comparing the summertime velocity record to wind 


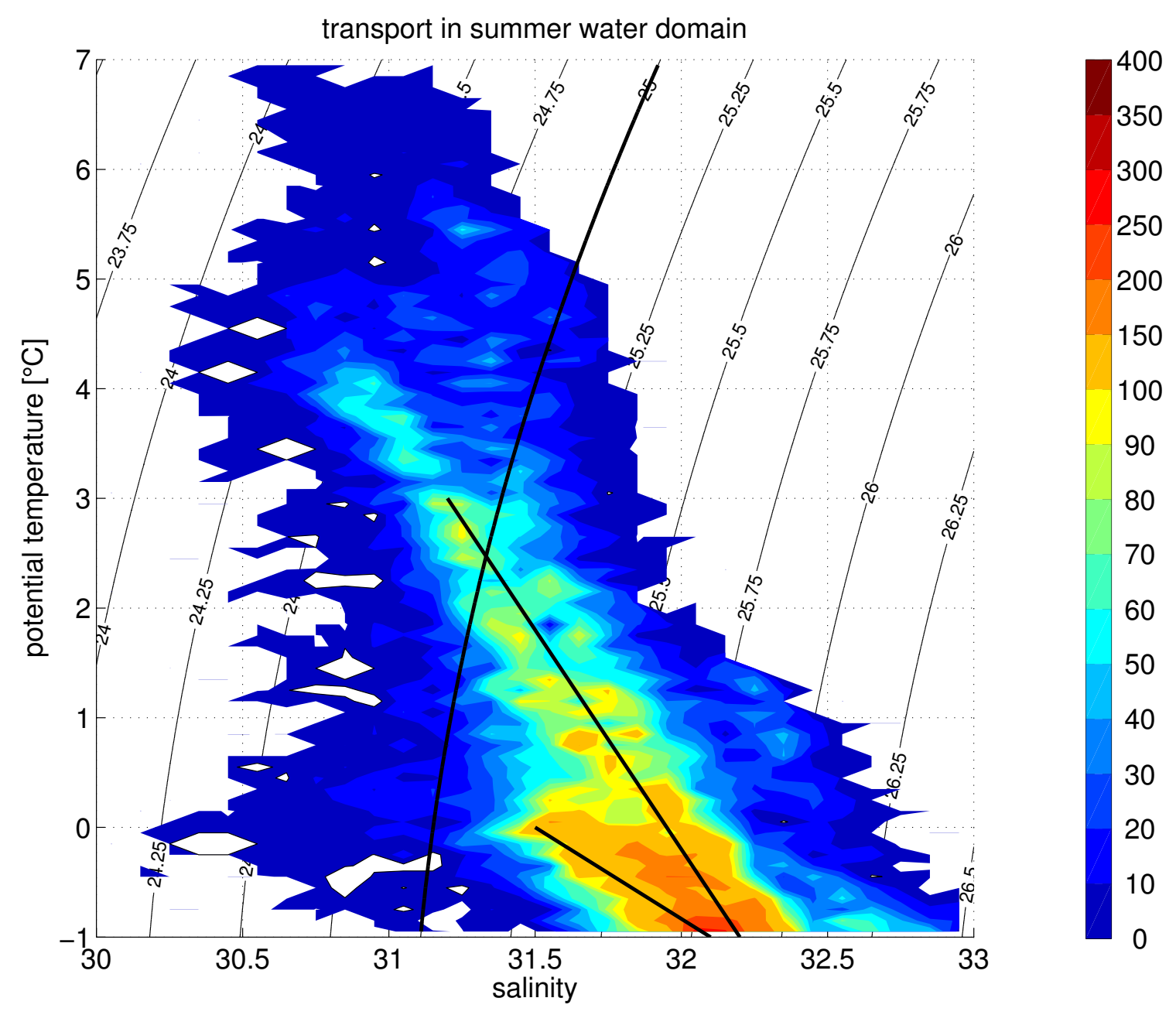

Figure 2-5: Transport within the Summer Water domain $\left(S<33, \theta>-1^{\circ} \mathrm{C}\right)$ over the two-year deployment as a function of temperature and salinity. Units are $\mathrm{m}^{3} \mathrm{~s}^{-1}$ per $0.1^{\circ} \mathrm{C}$ and 0.1 salinity (note the nonlinear scale). The $25 \mathrm{~kg} \mathrm{~m}^{-3}$ line separating the two Summer Water types is highlighted along with the major mixing lines between PWW and ACW and between PWW and CSW. 
data at Barrow airport (Climate-Radar Data Inventories, 2010), it was found that these current reversals were also due to upwelling favorable winds. Since the aim of the present study is to focus on the internal dynamics of the unforced eastward-flowing shelfbreak current, these wind-forced flow periods were excluded from our analysis.

\subsubsection{Temporal Patterns of Summer Water}

Both ACW and CSW were present in the shelfbreak jet for prolonged periods (Figure 2-6). Note that by definition only one of the water types can be present at any one time, which is why occasionally the record alternates rapidly between ACW and CSW (when in fact there may have been a bit of both present in the current). The abrupt end of the record in early September 2003 is due to the mooring turn-around. The mooring array was operational again at the beginning of October 2003, and while there were small quantities of water fulfilling CSW criteria present into mid January 2004, comparison to the velocity fields showed that this water was situated shallower than the bottom-intensified shelfbreak jet. Therefore this time period was excluded from consideration. Also, the data from early August 2004 onward is heavily biased by the fact that mooring BS5 stopped functioning, making it impossible to construct meaningful vertical sections. This time period was excluded as well. In the analysis below we ignore the short "intrusion events" of one of the water masses during periods of sustained presence of the other. As mentioned above we also removed periods of current reversals. The resulting time periods of the unforced shelfbreak current accounted for more than $60 \%$ of the summer record in 2002 and 2004 and more than 90\% in 2003. The division between the ACW and CSW states of the shelfbreak jet is denoted by the red and green symbols, respectively, along the top of the panels in Figure 2-6. 

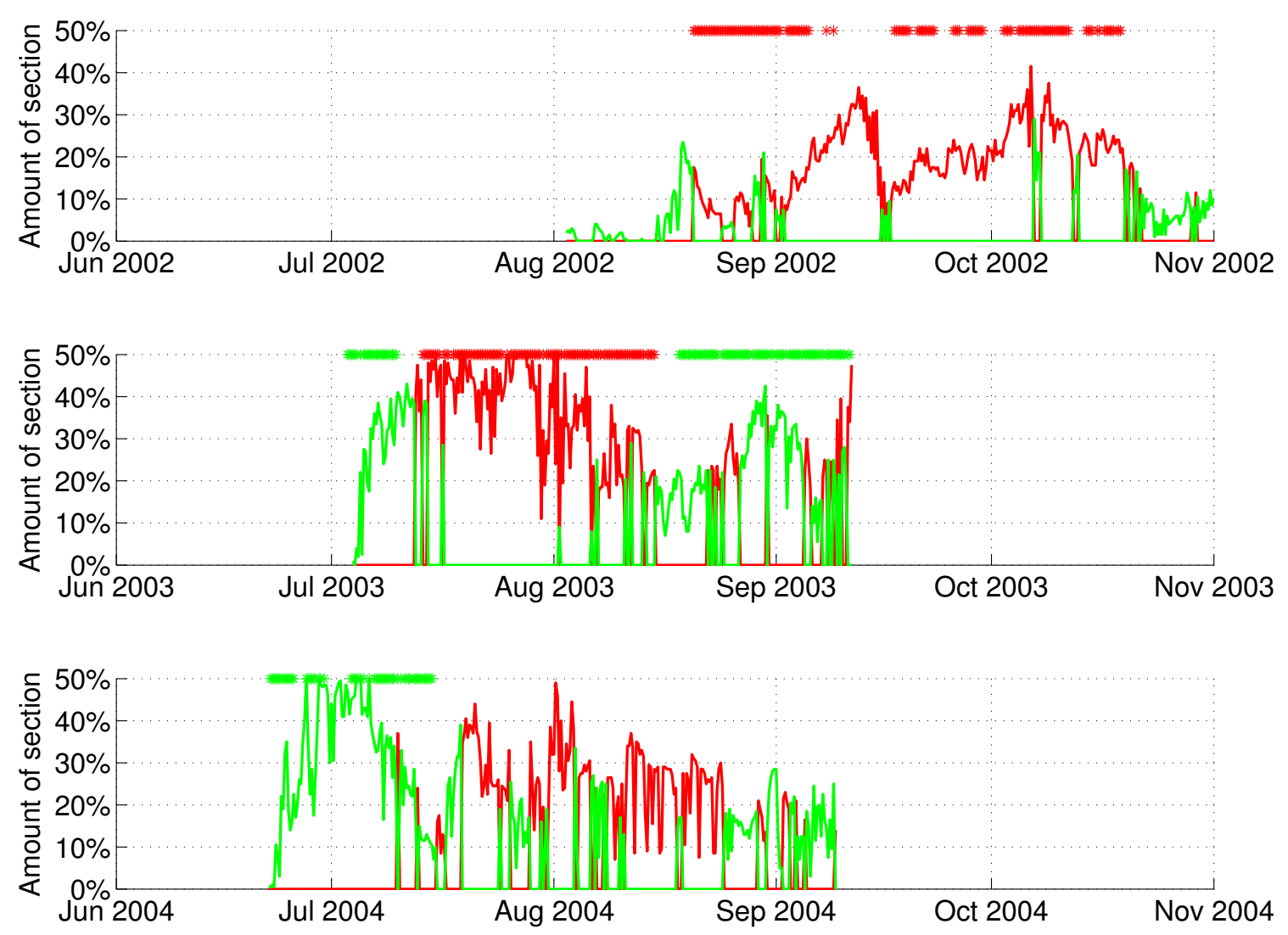

Figure 2-6: Amount of area within the gray box of Figure 2-2 occupied by Alaskan Coastal Water (red curve) and Chukchi Summer Water (green curve) as a function of time. The time periods that have been considered for the composite averages of the boundary current are indicated by the symbols at the top of each panel: ACW (red) and CSW (green). The record termination on 10 September, 2003 is due to the mooring turnaround that lasted until 1 October, 2003. 


\subsubsection{Seasonal Variability}

Although there is significant interannual variability of the shelfbreak current (see below), and our record is too short to exactly determine the seasonal cycle, a typical seasonal progression of the two summer states of the jet emerges based on the 26 months of mooring data. In particular, the summer season (i.e. when warm water is present at the array site) begins with the arrival of CSW, followed 2-4 weeks later by warmer, lighter ACW. Then in late-summer/early-fall CSW appears again. While one may wonder if this sequence is due to our water mass definition equating very light water with $\mathrm{ACW}$, below we demonstrate that these two states of the summertime shelfbreak jet are dynamically distinct as well.

\subsubsection{Interannual Variability}

As seen in Figure 2-6, the arrival of Summer Water in 2002 (17 August) was significantly later than in 2003 (5 July) and 2004 (23 June). Note that this discrepancy was not due to the timing of the mooring array deployment in 2002, as the instruments did not detect the presence of Summer Water during the first two weeks of the deployment. One possible explanation for this significant delay is that warm water did not enter Bering Strait until later in the year in 2002. To investigate this we considered data from mooring A4 in Bering Strait (e.g. Woodgate and Aagaard, 2005). The time when the near-bottom potential temperature at $\mathrm{A} 4$ first exceeded $-1^{\circ} \mathrm{C}$ was used as an indication for the arrival of Summer Water at the strait. For all three summers in question (2002-04), the arrival times fell between 10-17 May, i.e. within a one week period. Hence this cannot explain the delay at the Beaufort Slope array site.

A second possibility is that the flow speed in Bering Strait was weaker in summer 2002 and hence the water took longer to progress to the Beaufort Sea. As a proxy for 
this we integrated the near-bottom velocity in time (using data from a point current meter at $40 \mathrm{~m}$ depth until 26 June, 2002 and the lowest ADCP bin at $34 \mathrm{~m}$ depth thereafter). For the month-long period after the arrival of Summer Water in the strait, the cumulative displacement of water parcels was $1400 \mathrm{~km}$ and $1600 \mathrm{~km}$ in 2003 and 2004 respectively, while it was $1000 \mathrm{~km}$ in 2002. Although the distance is shorter in 2002, it is nonetheless the same order of magnitude as the distance from Bering Strait to the mooring array $(1150 \mathrm{~km})$. Therefore, we conclude that conditions in Bering Strait alone cannot account for the late arrival of the Summer Water in 2002 at the array site. A preliminary analysis of the large scale winds over the Chukchi Sea from NCEP (Kalnay et al., 1996) revealed no obvious interannual change explaining the delay (for a discussion about the quality of wind velocities from atmospheric reanalyses in the region see Pickart et al. (2011)). Instead, oceanic processes in the Chukchi Sea and/or in Barrow Canyon were likely responsible for the delay.

\subsection{Summer Water Current Configurations and their Transports}

\subsubsection{Alaskan Coastal Water Configuration}

The configuration of the Western Arctic shelfbreak current when it advects Alaskan Coastal Water (ACW) was investigated by constructing composite average vertical sections of the flow for both 2002 and 2003, corresponding to the ACW realizations identified in Figure 2-6. For all properties we computed the mean and standard error at each grid point of the standard section. The mean structure of the current in 2002 is shown in Figure 2-7. There are three water masses present in the section: ACW, PWW (or more precisely remnant Winter Water), and Atlantic Water (AW, 

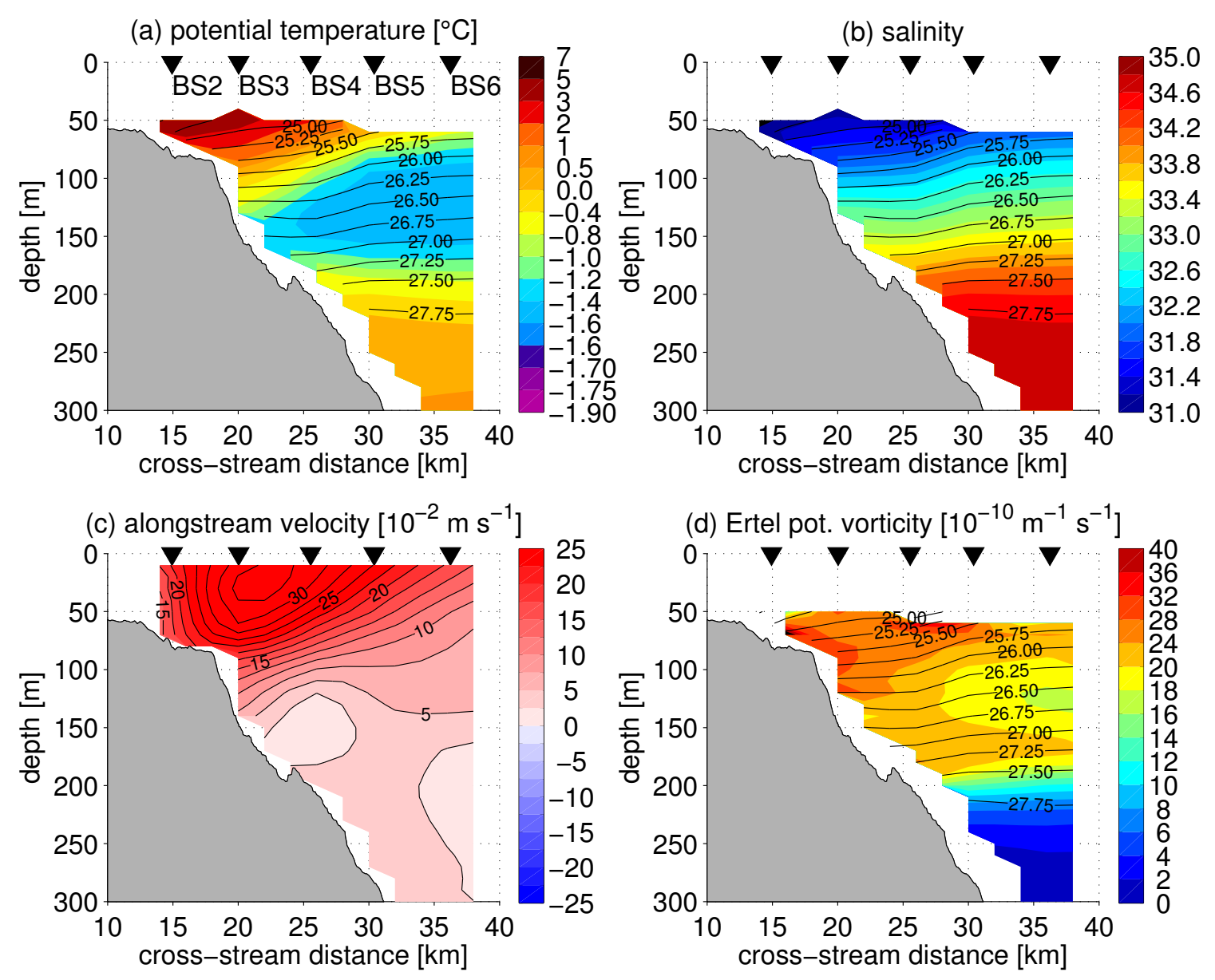

Figure 2-7: Mean state of the Western Arctic shelfbreak current advecting Alaskan Coastal Water in 2002. Quantities plotted are the same as in Figure 2-3.

at depths greater than $200 \mathrm{~m}$ ). The PWW is located between $80 \mathrm{~m}$ and $200 \mathrm{~m}$ with temperatures as low as $-1.6^{\circ} \mathrm{C}$ (i.e. less than $0.2^{\circ} \mathrm{C}$ above the freezing point). As noted above, PWW was present somewhere in the water column during the entire record.

In the composite mean section the ACW occupies the region inshore of $30 \mathrm{~km}$ and above $100 \mathrm{~m}$ with water as fresh as 31 and as warm as $5^{\circ} \mathrm{C}$. The hydrographic data coverage does not extend inshore of $18 \mathrm{~km}$ and above $50 \mathrm{~m}$, but the fact that the measured temperature maximum and salinity minimum are found on the edge of the 
data coverage suggests that there is warmer and fresher water inshore and at shallower depths. This is usually the case in shipboard CTD sections. For example, the $R / V$ Palmer occupied a transect across the array line in summer 2003, which provides an opportunity to compare such a shipboard section with a synoptic snapshot from the array. As seen in Figure 2-8, both the qualitative and quantitative agreement is very good in the region of overlap. However, the minimum salinity in the shipboard section in the near-surface water is lower by a value of 2 than that measured near $50 \mathrm{~m}$ by the moorings (interestingly the maximum temperatures are comparable in the two sections).

In the vicinity of the shelfbreak at $18 \mathrm{~km}$, the mean isopycnals in Figure 2-7 slope upward in the offshore direction. By thermal wind, this implies an increase in the alongstream velocity toward the surface. This is consistent with the alongstream velocity measured directly from the ADCPs. The mean current is surface-intensified and clearly trapped to the shelfbreak. However, there is strong eastward flow as far as $20 \mathrm{~km}$ offshore of the shelfbreak. The standard error in velocity (not shown) is smaller than the mean everywhere above $200 \mathrm{~m}$.

The Ertel potential vorticity $\Pi$ is defined as

$$
\Pi=\frac{-f}{\rho_{0}} \frac{\partial \sigma_{\theta}}{\partial z}+\frac{1}{\rho_{0}} \frac{\partial u}{\partial y} \frac{\partial \sigma_{\theta}}{\partial z}-\frac{1}{\rho_{0}} \frac{\partial u}{\partial z} \frac{\partial \sigma_{\theta}}{\partial y},
$$

where the three terms correspond to the stretching vorticity, relative vorticity, and tilting vorticity (see e.g. Hall, 1994). Instantaneously, the relative vorticity can be as large as the stretching vorticity, indicating that the flow is highly energetic and variable. However, in the composite time-mean of Figure 2-7, the potential vorticity is dominated by the stretching term. The core of the shelfbreak current is strongly stratified, which is due to the fact that ACW originates from river run-off in the Gulf 
(a) Palmer potential temperature $\left[{ }^{\circ} \mathrm{C}\right]$

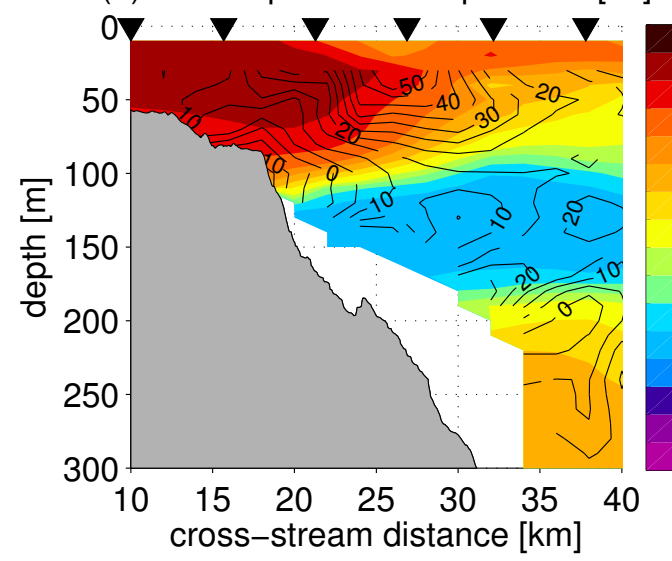

(c) mooring potential temperature $\left[{ }^{\circ} \mathrm{C}\right]$

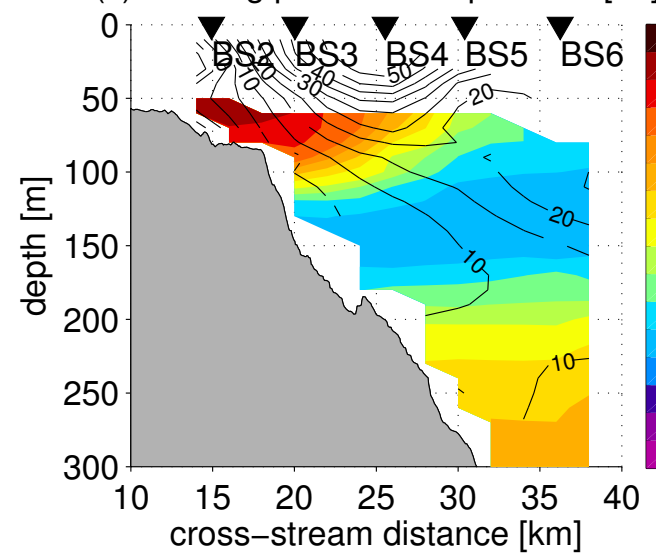

(b) Palmer salinity
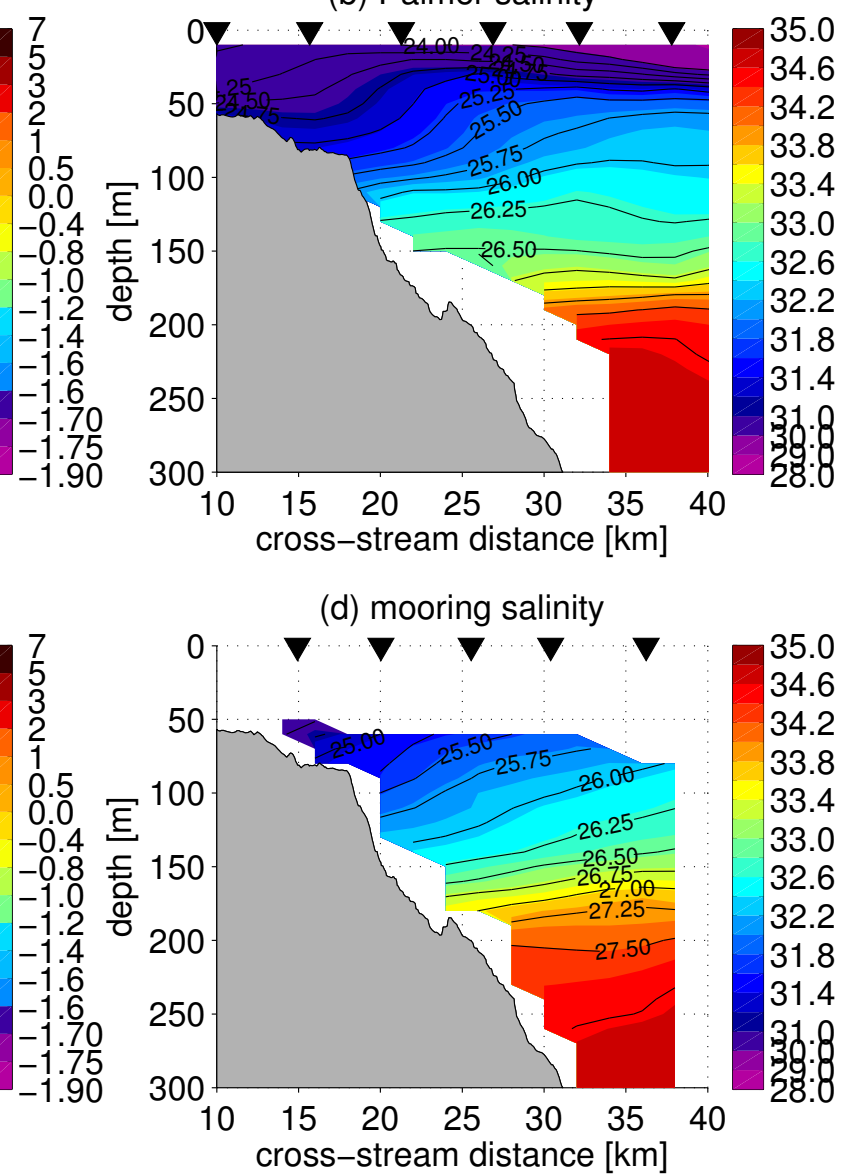

(d) mooring salinity

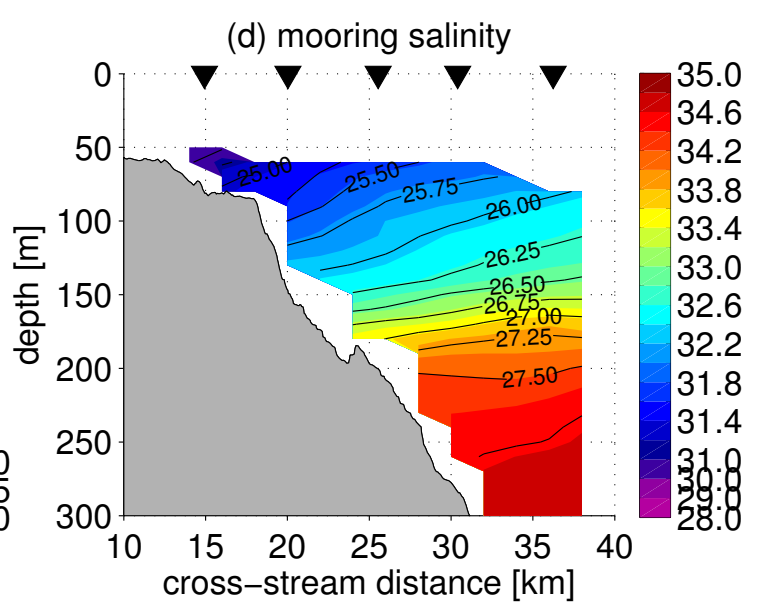

Figure 2-8: Synoptic snapshot of the Western Arctic shelfbreak current advecting Alaskan Coastal Water in 2003. Data from the mooring array is presented at 0600 UTC 14 August, 2003. The $R / V$ Palmer performed an offshore to inshore CTD and VMADCP section on the same day and was at cross-stream distance $27 \mathrm{~km}$ at 0600 UTC. (a,b) show data from $R / V$ Palmer and (c,d) show data from the mooring array. (a,c) show potential temperature in color overlain by alongstream velocity and $(\mathrm{b}, \mathrm{d})$ show salinity in color overlain by potential density. Note the added contour intervals for salinity between 28 and 31. Flux estimates of volume, freshwater, and heat for an extrapolation as described in the text agree to within $25 \%$ of each other: $0.73 \mathrm{~Sv}, 61 \mathrm{mSv}$, and $7.8^{*} 10^{12} \mathrm{~J} \mathrm{~s}^{-1}$ from $R / V$ Palmer and $0.84 \mathrm{~Sv}, 49 \mathrm{mSv}$, and $6.2^{*} 10^{12} \mathrm{~J} \mathrm{~s}^{-1}$ from the mooring array. 
of Alaska (Weingartner et al., 2005). The second region of enhanced stratification corresponds to the interface between PWW and the AW near a depth of $180 \mathrm{~m}$ (see also Nikolopoulos et al., 2009). Note that near $70 \mathrm{~m}$ depth, $\Pi$ increases in the offshore direction, while the opposite is true near $130 \mathrm{~m}$. This reversal of the horizontal mean potential vorticity gradient is a necessary condition for baroclinic instability of the shelfbreak current. Overall, the ACW configuration can be described as a surfaceintensified shelfbreak current of strongly stratified warm water.

While not presented here, the ACW composite for 2003 agrees well with the above findings. However, in 2003 the jet transported more buoyant water than in 2002 , resulting in somewhat more pronounced lateral property gradients across the shelfbreak current.

\subsubsection{Chukchi Summer Water Configuration}

The Chukchi Summer Water (CSW) configuration of the Western Arctic shelfbreak current was well sampled in the summer of 2003 for about a month, while the record in 2004 was shorter and more intermittent due to instrument failures. Hence we present the 2003 composite sections in Figure 2-9, although the 2004 means are qualitatively similar. Again, there are three distinct water masses present in the section with the CSW overlying remanent PWW and AW. In this case, the temperature of the Summer Water exceeds $1^{\circ} \mathrm{C}$ and the salinity is as low as 31.6.

In contrast to the ACW configuration, the current here is bottom-intensified with eastward flow $>0.2 \mathrm{~m} \mathrm{~s}^{-1}$ in the mean. The isopycnals slope downward in the offshore direction just offshore of the shelfbreak and just above the core of the bottomintensified flow (between $20 \mathrm{~km}$ and $25 \mathrm{~km}$ ). By thermal wind, the isopycnal slope implies increasing flow with depth consistent with the observed flow field. Again the 

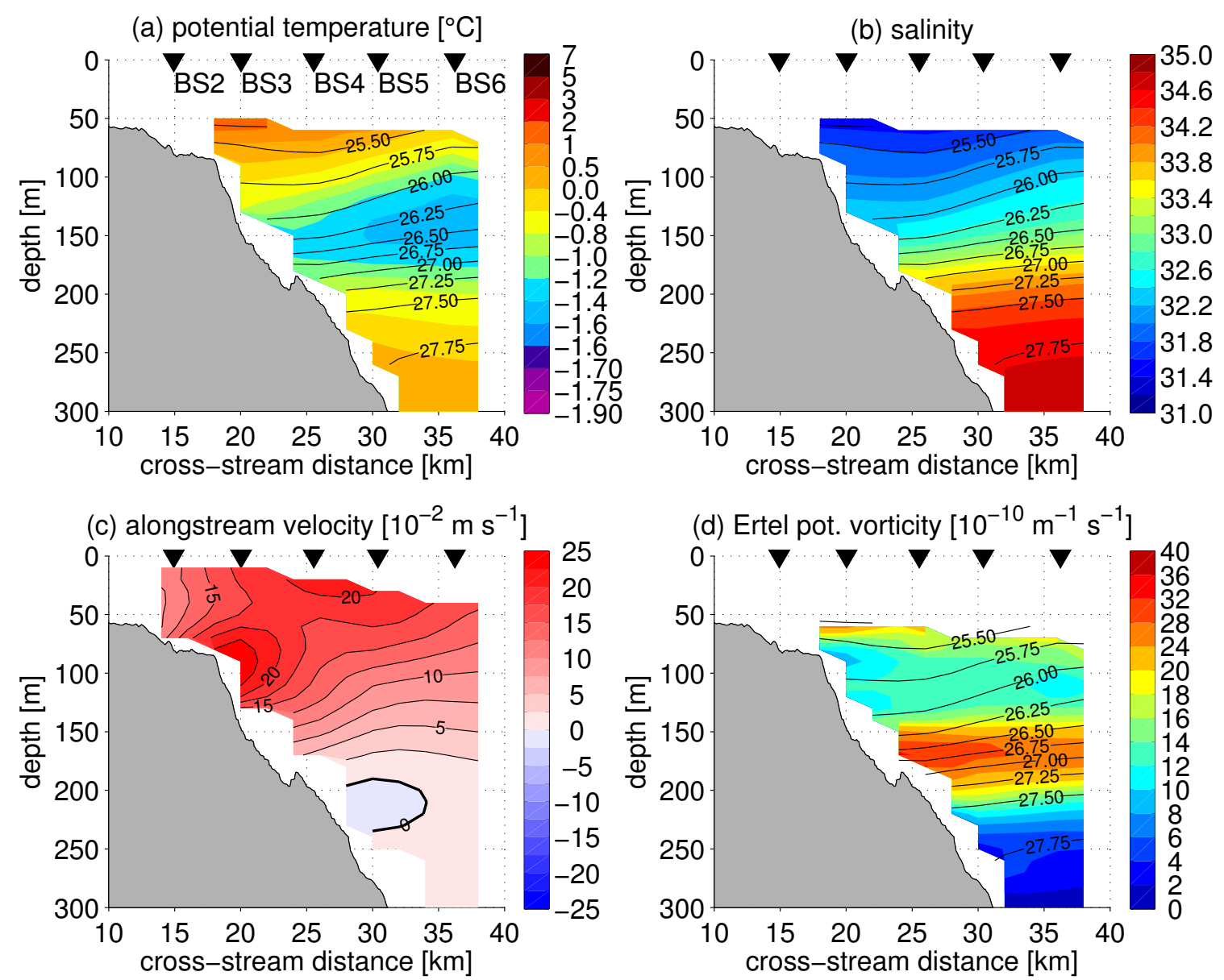

Figure 2-9: Mean state of the Western Arctic shelfbreak current advecting Chukchi Summer Water in 2003. Quantities plotted are the same as in Figure 2-3. 
current is trapped to the shelfbreak (although there is a hint of surface-intensified flow in the middle of the section). Also in contrast to the ACW state, the CSW is weakly stratified. The potential vorticity structure of the CSW composite mean is such that there is a minimum in the core of the current near $100 \mathrm{~m}$ with increasing values in the offshore direction. Deeper than this the sense of the lateral gradient of $\Pi$ is reversed (near $180 \mathrm{~m}$ at the interface between the PWW and AW). Hence, the potential vorticity structure also fulfills the necessary condition for baroclinic instability. Overall, the CSW configuration can be described as a bottom-intensified shelfbreak current of weakly stratified warm water.

\subsubsection{Transports}

We now present the fluxes of mass, heat, and salt for the different states of the shelfbreak current. For completeness, in addition to the ACW and CSW configurations described above, we also consider the Pacific Winter Water (PWW) case investigated by Spall et al. (2008). This corresponds to the time period April-June 2003 when the coldest (most recently ventilated) Winter Water passed by the array. The composite vertical sections for this configuration are shown in Figure 2-10. As in the CSW case, the current is weakly stratified, bottom-intensified, and trapped to the shelfbreak. However, the water it advects has temperatures near the freezing point. As discussed in Spall et al. (2008), this configuration of the current is baroclinically unstable and forms cold-core, anti-cyclonic eddies.

In terms of data coverage, the $\mathrm{ADCP}$ measurements in the mooring array were able to span the shelfbreak current adequately, enabling accurate estimates of volume flux for all three configurations (ACW, CSW, and PWW). However, the CTD profilers did not measure the upper $50 \mathrm{~m}$ of the water column. As noted above, Figure 2-8 

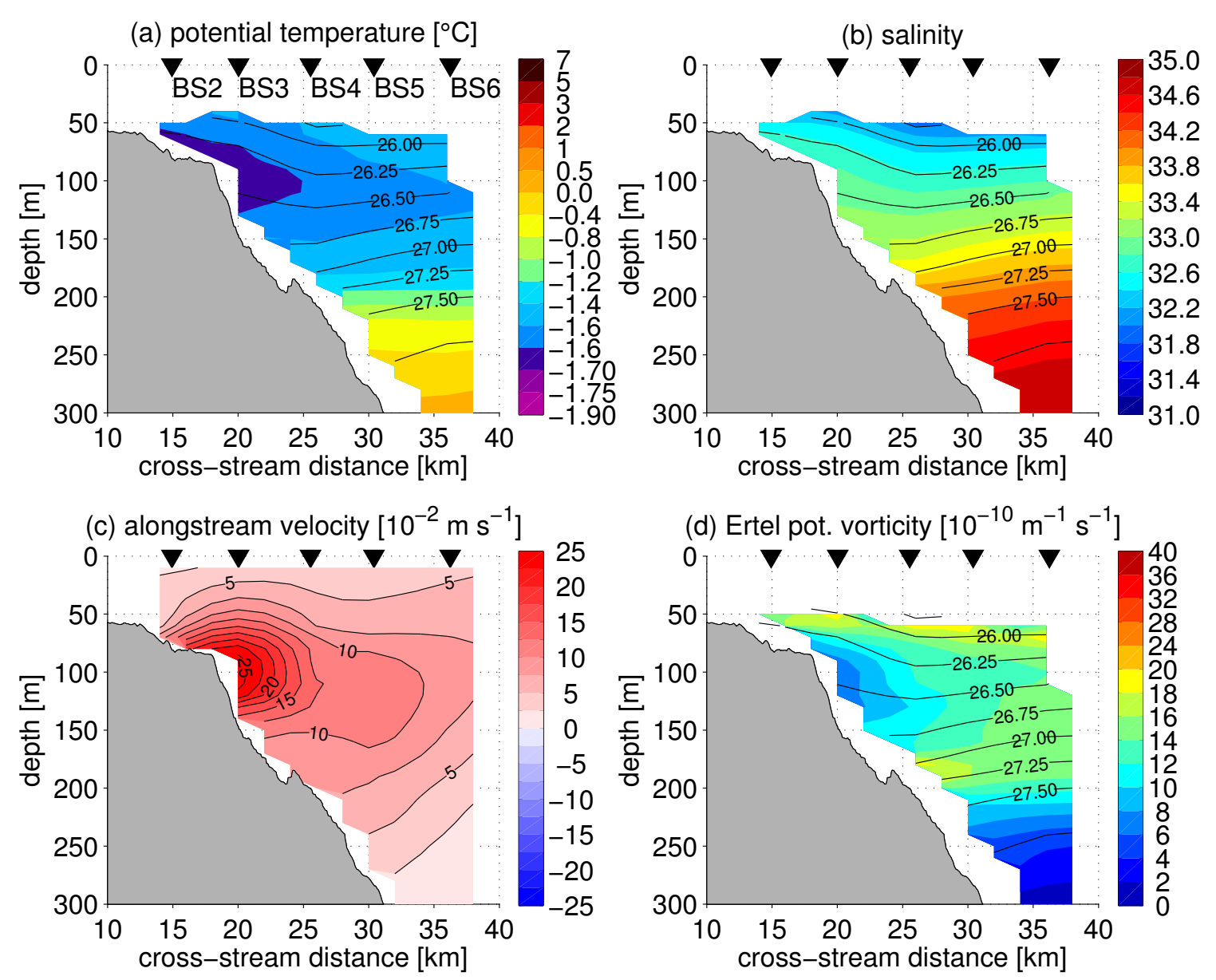

Figure 2-10: Mean state of the Western Arctic shelfbreak current advecting Pacific Winter Water in 2003 (after Spall et al., 2008). Quantities plotted are the same as in Figure 2-3. 
illustrates the impact of this data gap for the ACW case. As seen, the water column continues to become fresher and (slightly) warmer upward of where it was sampled by the moorings. As a simple attempt to fill this gap, we performed a constant extrapolation of the temperature and salinity fields to the surface, realizing that this will lead to an underestimate of the heat and freshwater fluxes. In order to assess the magnitude of this bias, we compare transports computed from the mooring array (using the constant extrapolation) and from the ship section (see Figure 2-8). This shows that in the ACW case the mooring-based estimates of heat and freshwater transport account for at least $70 \%$ of the ship based estimates. For the CSW and the PWW case, the velocity maximum is within the hydrographic coverage and therefore the heat and freshwater flux estimates are less biased.

Since there is a non-zero net volume flux across the array, we cannot compute formal estimates of freshwater and heat flux divergence (for a discussion see Schauer and Beszczynska-Möller, 2009). Following earlier studies, we chose a reference salinity of 34.8. This is the mean salinity of Atlantic Water in the Arctic Ocean and therefore provides a freshwater flux that is relevant for the maintenance of the halocline. For temperature we chose a reference value of $-1.91^{\circ} \mathrm{C}$ which is the freezing point at the reference salinity and thus reflects the heat available for melting sea-ice.

The fluxes of mass, heat, and freshwater in the upper $300 \mathrm{~m}$ of the water column, including random (but not systematic) errors, are given in Table 2.1 which also presents data from other studies for comparison. The reader should keep in mind that these values are for periods when the jet was not forced by easterly (upwelling favorable) winds. Since the shelfbreak current reverses during those events (Nikolopoulos et al., 2009), the transports become negative and the sum of unforced and reversed transports will be smaller than for the unforced states by themselves. The volume flux during all three (unforced) configurations is $O(0.5 \mathrm{~Sv})$, with slightly larger values 
Table 2.1: Fluxes during different configurations of the shelfbreak current compared to Bering Strait. The duration is the length of time over which the estimate was made for each case. The freshwater flux is relative to 34.8 , and the heat flux is relative to $-1.91^{\circ} \mathrm{C}$. Standard errors take into account the cross-correlation between the time series at the individual grid points. The four Summer Water time periods are identified in Section 2.4. PWW2003 is the Pacific Winter Water period in spring 2003 discussed by Spall et al. (2008). The fluxes for these cases, plus the first-year, secondyear, and two-year mean, are based on the gray box in Figure 2-2. For comparison, the first-year fluxes at $152^{\circ} \mathrm{W}$ from (Nikolopoulos et al., 2009) are included. These are based on the entire array down to $800 \mathrm{~m}$, where the Pacific Water (PW) and Atlantic Water (AW) contributions have been distinguished. The Bering Strait fluxes are primarily based on the single mooring A3 in the strait (Woodgate, pers. comm. 2010 and Woodgate et al., 2010). The freshwater fluxes include the additional contribution of the Alaskan Coastal Current (ACC) and stratification. The heat fluxes include a $10 \mathrm{~m}$ thick layer of water at the same temperature as the satellite-derived sea surface temperature. The fluxes resulting from the ACC (present for 3-5 months per year) alone are also presented.

\begin{tabular}{|c|c|c|c|c|}
\hline & duration & volume flux & freshwater flux & heat flux \\
\hline & {$[$ days $]$} & {$\left[\mathrm{Sv}=10^{6} \mathrm{~m}^{3} \mathrm{~s}^{-1}\right]$} & {$\left[\mathrm{mSv}=10^{3} \mathrm{~m}^{3} \mathrm{~s}^{-1}\right]$} & {$\left[10^{12} \mathrm{~J} \mathrm{~s}^{-1}\right]$} \\
\hline ACW2002 & 35 & $0.60 \pm 0.12$ & $44 \pm 9$ & $6.4 \pm 1.4$ \\
\hline ACW2003 & 29 & $0.87 \pm 0.17$ & $61 \pm 10$ & $10.1 \pm 1.7$ \\
\hline CSW2003 & 29 & $0.57 \pm 0.11$ & $39 \pm 7$ & $3.7 \pm 0.8$ \\
\hline CSW2004 & 15 & $0.62 \pm 0.13$ & $42 \pm 7$ & $4.2 \pm 1.2$ \\
\hline \hline PWW2003 & 57 & $0.44 \pm 0.07$ & $21 \pm 4$ & $0.8 \pm 0.2$ \\
\hline 1st Year (Aug02-Jul03) & 365 & $0.16 \pm 0.05$ & $9 \pm 3$ & $1.3 \pm 0.4$ \\
\hline 2nd Year (Aug03-Jul04) & 366 & $0.20 \pm 0.05$ & $13 \pm 3$ & $1.6 \pm 0.3$ \\
\hline 2 Years (Aug02-Jul04) & 731 & $0.18 \pm 0.03$ & $11 \pm 2$ & $1.5 \pm 0.3$ \\
\hline 1st Year PW (Aug02-Jul03) & 365 & $0.13 \pm 0.08$ & - & - \\
\hline \hline Bering St 2002 (Jan02-Dec02) & 365 & $0.82 \pm 0.10$ & $(51+29) \pm 10$ & $11 \pm 3$ \\
\hline Bering St 2003 (Jan03-Dec03) & 365 & $0.89 \pm 0.10$ & $(64+29) \pm 13$ & $12 \pm 3$ \\
\hline Bering St ACC (2000-2003) & $90-150$ & $0.24 \pm 0.07$ & $32 \pm 13$ & $10 \pm 3$ \\
\hline
\end{tabular}


for the ACW state. Nikolopoulos et al. (2009) distinguished between the transport of Pacific Water and Atlantic Water using stratification to determine the interface between the two water masses. We made no such attempt here. However, since the transport of Atlantic Water within the array shallower than $300 \mathrm{~m}$ is quite small, we conclude that the transports presented in Table 2.1 are reasonable proxies for $\mathrm{Pa}$ cific Water transport. The fluxes for the ACW state during 2003 were roughly $30 \%$ stronger than for 2002.

The year-long (including all different wind regimes) volume, freshwater, and heat fluxes are on the order of $0.2 \mathrm{~Sv}, 10 \mathrm{mSv}$, and $1.5^{*} 10^{12} \mathrm{~J} \mathrm{~s}^{-1}$ respectively, with the second year being somewhat stronger than the first. These fluxes are between $10 \%$ and $20 \%$ of the corresponding fluxes of Pacific Water through Bering Strait (Table 2.1). The heat fluxed eastward past $152^{\circ} \mathrm{W}$ would be able to melt roughly $160,000 \mathrm{~km}^{2}$ of $1 \mathrm{~m}$ thick sea-ice. Both the heat and freshwater fluxes during the ACW periods are stronger than during the CSW periods, mainly due to the fact that the current is stronger and the salinity and temperature anomalies are larger. Keep in mind that, due to the constant extrapolation above $50 \mathrm{~m}$ for the hydrographic variables, the $\mathrm{ACW}$ case underestimates the freshwater and heat transports more so than in the CSW case.

Despite the relatively large error bars in Table 2.1, it is clear that a significant portion of the Pacific Water entering the Chukchi Sea through Bering Strait does not end up in the shelfbreak current east of Pt. Barrow (consistent with the results of Nikolopoulos et al., 2009). The year-long Bering Strait flux estimates in Table 2.1 (Woodgate, pers. comm. 2010) includes the contribution due to the Alaskan Coastal Current, which is 2-5 times larger than the (year-long) transport associated with $\mathrm{ACW}$ at $152^{\circ} \mathrm{W}$ determined here. This is mainly due to the fact that the Alaskan Coastal Current is present in Bering Strait for a longer duration than ACW is observed 
at the mooring array. This suggests that there are times when the the Alaskan Coastal Current reaches the Beaufort Shelf with little change in transport (note the large transport of the ACW composite vertical section), but that there are also significant periods when the current is diverted from the Beaufort Shelf.

\subsection{Energetics and Downstream Fate of the Shelf- break Current}

\subsubsection{Energetics}

As noted earlier, eddies with ACW and CSW signatures have been observed in the interior Beaufort Sea. It is natural to hypothesize that instability of the summertime shelfbreak jet may lead to the formation of these eddies. We now investigate this hypothesis by analyzing the energetics of the observed states of the jet using a similar approach as Brink et al. (2007).

Following a fluid parcel, the change of the total energy of the mean current is

$$
D(P+K) / D t=-C-T-S \pm \text { pressure work } \pm \text { wind work }- \text { bottom friction, }
$$

where $D / D t$ is the advective derivative acting on the sum of the mean available potential energy:

$$
P=-\frac{1}{2} g \bar{\rho}^{2}\left(\rho_{0 z}\right)^{-1}
$$

and mean kinetic energy:

$$
K=\frac{1}{2} \rho_{0}\left(\bar{u}^{2}+\bar{v}^{2}\right)
$$

Here $\rho_{0}(z)$ is the mean density profile outside of the shelfbreak current and $\rho(x, y, z, t)$ 
is the deviation from that mean density profile. The total energy of the system changes over time due to baroclinic mean-to-eddy conversion:

$$
C=g \overline{\rho^{\prime} v^{\prime}} \frac{\bar{\rho}_{y}}{\bar{\rho}_{z}}=-g \overline{\rho^{\prime} v^{\prime}} \frac{\partial z}{\partial y},
$$

where $\partial z / \partial y$ is the slope of the isopycnals, and barotropic mean-to-eddy conversion:

$$
T=-\rho_{0} \overline{u^{\prime} v^{\prime}} \bar{u}_{y},
$$

as well as shear mean-to-eddy conversion $S$. In addition, there is pressure work, wind forcing, and bottom friction. All quantities have been decomposed into their time-mean (e.g. $\bar{u}$ ) and the time-dependent deviation from the mean (e.g. $\left.u^{\prime}\right)$. No observations of the typical scale of alongstream variations $L^{x}$ are available, but the topographic control suggests that $L^{x}$ is much larger than the typical scale of crossstream variations $L^{y}$. Assuming that variations in the alongstream direction are advected past the array by the alongstream velocity, temporal variability at the array can be transformed into alongstream variability, which confirms the assumption that $L^{x} \gg L^{y}$. This assumption has been used to arrive at the simplified expressions for $C$ and $T$ above. Additionally, assuming that the continuity equation is balanced in the horizontal to lowest order (as in quasi-geostrophic theory), the vertical velocities are much smaller than the horizontal velocities times the aspect ratio. This means that the shear mean-to-eddy conversion term $S$ is much smaller than $T$, hence we neglect it here. The effects of large-scale pressure gradients, wind forcing and friction are not included explicitly here, but their effects are discussed qualitatively below.

With the exception of $\rho_{0}(z)$ (the background profile of density offshore of where the shelfbreak current deforms the isopycnals), all of the necessary information is 
available from the mooring data to compute the simplified expressions for $P, K, C$, and $T$ given above. Since Figures 2-7, 2-9, and 2-10 show that the shelfbreak current is situated inshore of mooring BS6, we have computed a mean density profile $\rho_{0}$ from the outer two moorings BS7 and BS8. The terms in the energy equation plotted in the vertical plane are shown in Figures 2-11, 2-12, and 2-13 for the three states of the current (ACW, CSW, and PWW). These quantities have also been summed over the full cross-section and-taking into account the cross-correlation of the time-series at each grid point - the standard errors of the sums have been calculated. These sums are given in Table 2.2 for each of the time-periods considered.

For the ACW in 2002 (Figure 2-11), the baroclinic conversion from mean to eddy available potential energy is greatest in the region where the isopycnals slope upward most strongly. The barotropic conversion from mean-to-eddy kinetic energy shows two distinct maxima at the inshore and offshore edge of the mean current. The sums of these two conversion terms are statistically different from zero. The baroclinic conversion is $180 \pm 78 \mathrm{~W} \mathrm{~m}^{-1}$, while the barotropic conversion is $102 \pm 34 \mathrm{~W} \mathrm{~m}^{-1}$ (roughly a factor of two smaller). As noted above, the potential vorticity structure of the ACW state in 2002 satisfies the necessary condition for baroclinic instability. Together with the strong baroclinic conversion, this implies that the jet is baroclinically unstable. Although the current in this state also satisfies the two necessary conditions (Rayleigh's and Fjørtoft's criteria) for barotropic instability, these are relevant for a beta plane. As discussed in Spall and Pedlosky (2008), when topographic effects are taken into account these conditions are no longer adequate. Hence, we are unable to unequivocally rely on theory to make the case that barotropic instability is active. However, the two regions of strong barotropic conversion computed from the data are located where the horizontal shear in the mean velocity is largest (Figure 2-11), which is as expected for classical barotropic instability. Thus, these results suggest 

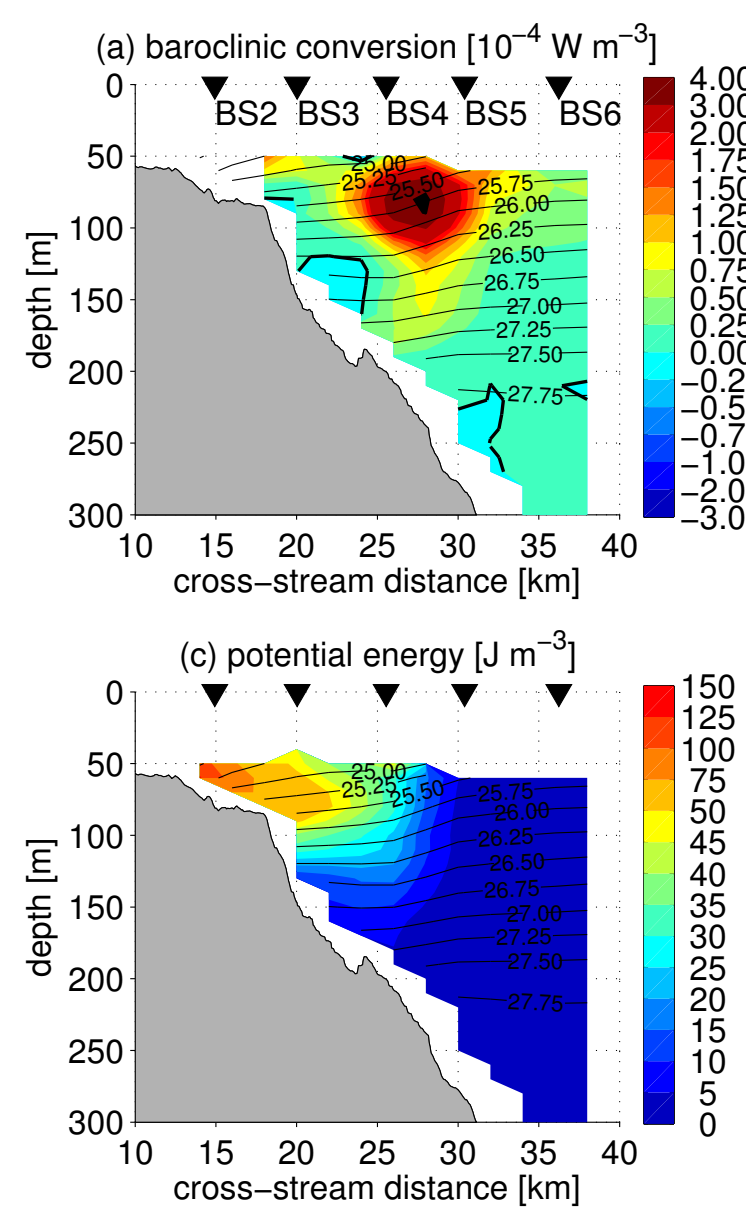
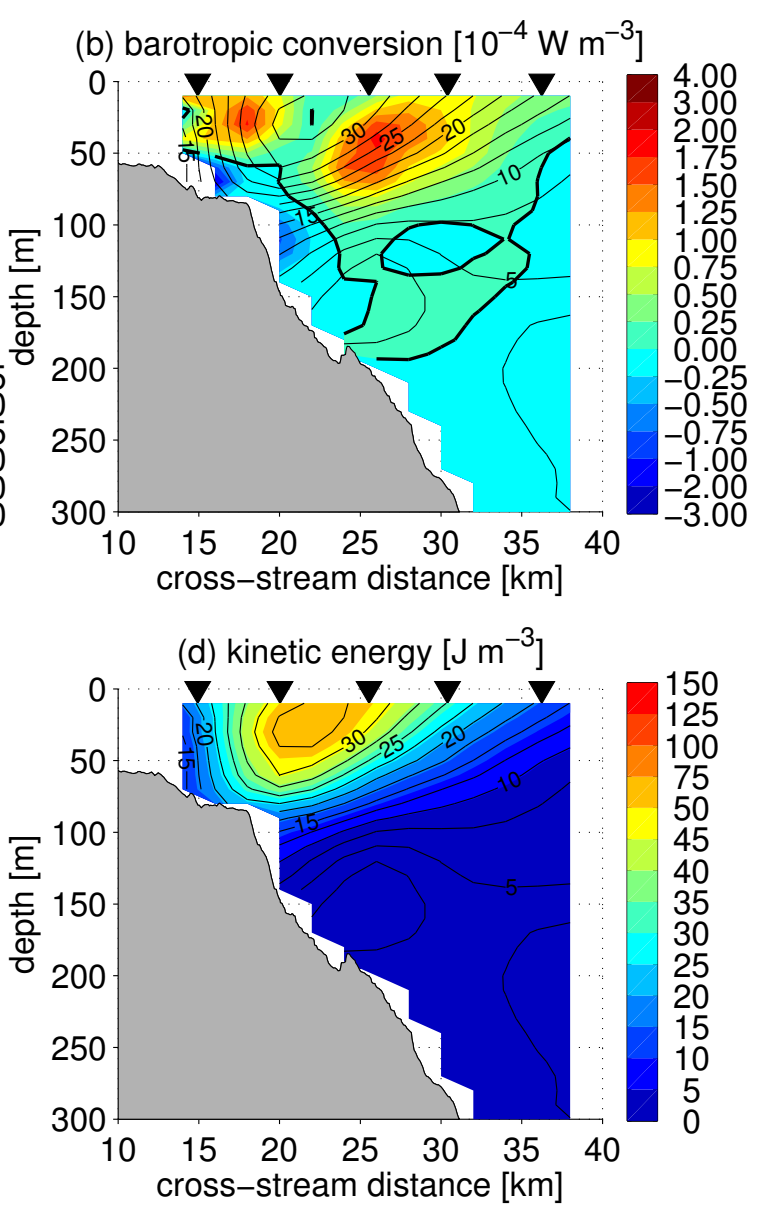

Figure 2-11: Energetics of the Western Arctic shelfbreak current advecting Alaskan Coastal Water in 2002. The colors show (a) baroclinic mean-to-eddy conversion, (b) barotropic mean-to-eddy conversion, (c) available potential energy, and (d) kinetic energy. The overlain contours show $(\mathrm{a}, \mathrm{c})$ potential density and $(\mathrm{b}, \mathrm{d})$ alongstream velocity. 

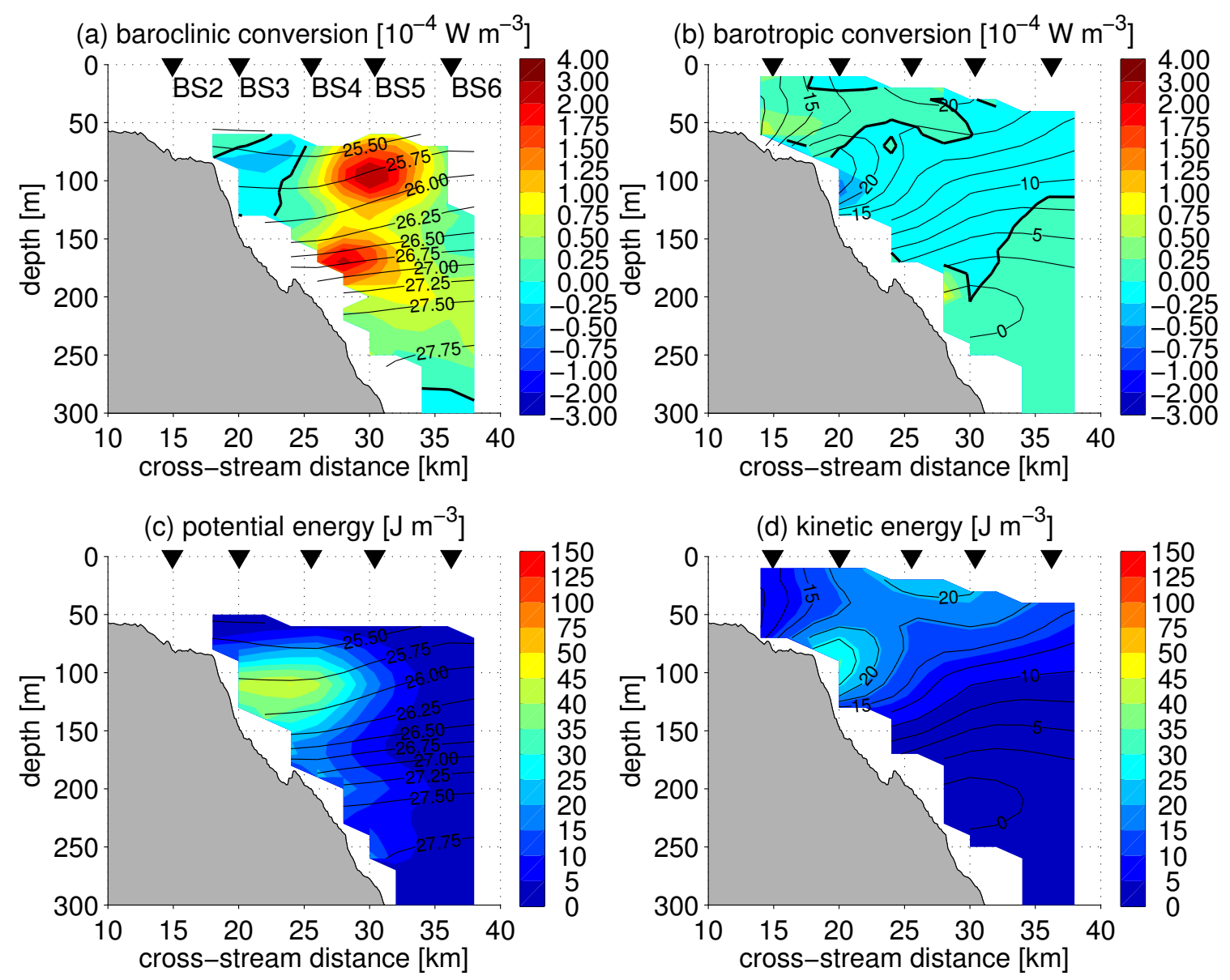

Figure 2-12: Energetics of the Western Arctic shelfbreak current advecting Chukchi Summer Water in 2003. Quantities plotted are the same as in Figure 2-11. 

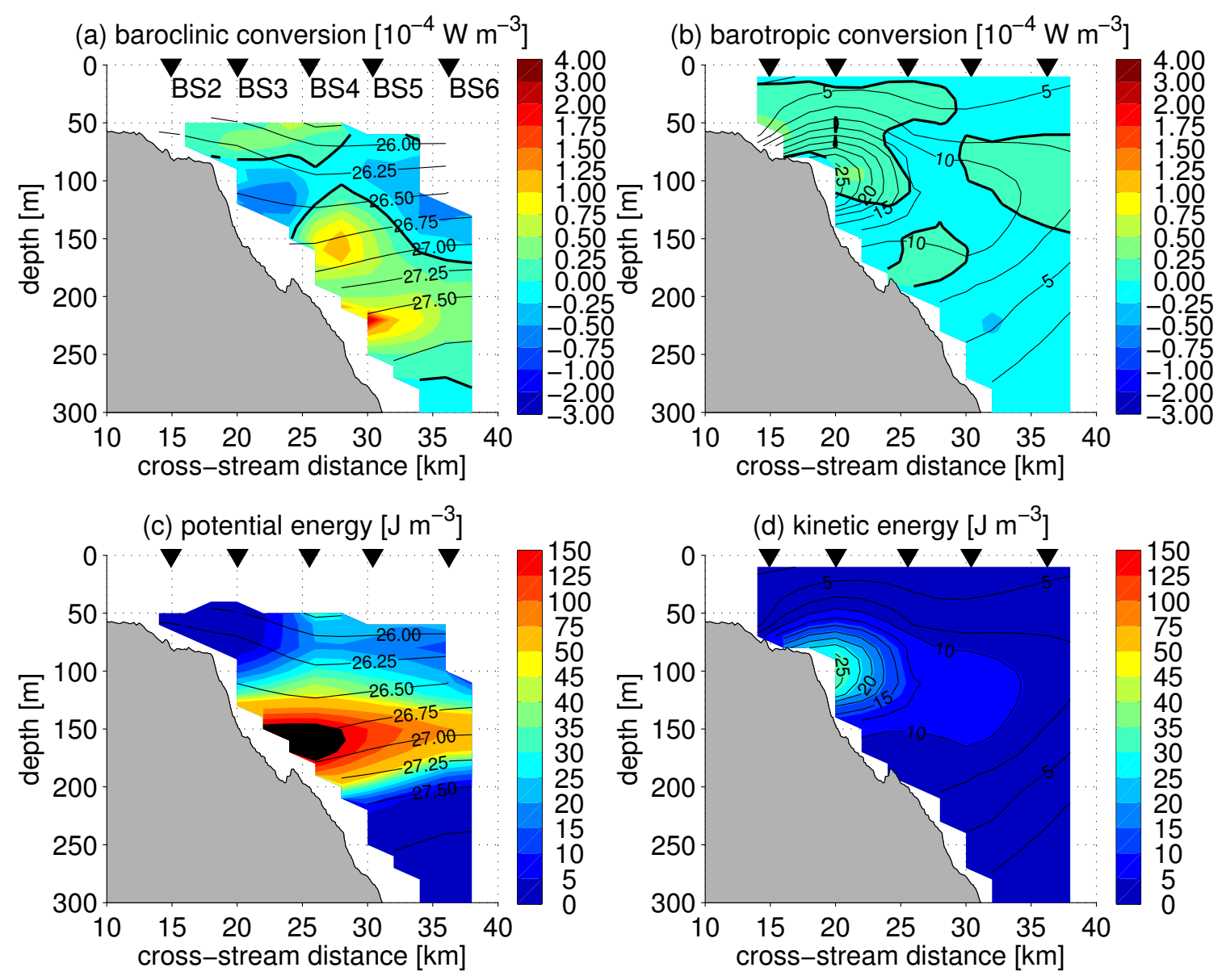

Figure 2-13: Energetics of the Western Arctic shelfbreak current advecting Pacific Winter Water in 2003. Quantities plotted are the same as in Figure 2-11. Panels (a,b) are adapted from Spall et al. (2008). 
that the ACW configuration of the Western Arctic shelfbreak current in 2002 was subject to a mixed instability.

Not surprisingly, the spatial distribution of mean kinetic energy for the ACW state in 2002 corresponds closely to the mean alongstream velocity and is well captured by the array. However, the mean available potential energy is largest near the edge of the sampled region. In order to assess the impact of this data gap, we computed the available potential energy and kinetic energy for two summertime CTD transects of the shelfbreak current during the ACW phase (Figure 2-8 shows the hydrography during the second crossing). During the two crossings the total energy as computed from the moorings accounted for $102 \%$ and $76 \%$, respectively, of the energy computed using the ship sections. While the latter are synoptic snapshots which are expected to differ from longer term means such as presented in Figure 2-11, it suggests that the energy estimates from the moorings account for significantly more than half of the total energy. This is mainly due to the fact that while the top $50 \mathrm{~m}$ contain very buoyant water, this buoyant water is not completely confined within the shelfbreak current and is therefore not associated with strong horizontal density gradients.

Since the mean hydrographic and velocity structure of the ACW in 2003 is qualitatively similar to 2002 , it is expected that the energetics would be similar as well. As shown in Table 2.2, both the baroclinic and barotropic conversion are again positive; however, the baroclinic conversion is not statistically different from zero.

The energetics of the CSW configuration of the shelfbreak current in 2003 are shown in Figure 2-12. As in the ACW case, there is strong baroclinic conversion in the region where the isopycnals are sloping most strongly upward and the sum (see Table 2.2) is significantly positive. By contrast, the barotropic conversion in this state has no pronounced structure and its sum is not statistically different from zero. This is consistent with the fact that this configuration also does not fulfill 
Table 2.2: Length of time period $\left(T_{d}\right)$ and mean velocity $(\bar{U})$ in the shelfbreak current, baroclinic mean-to-eddy energy conversion $(C)$, barotropic mean-to-eddy energy conversion $(T)$, total mean potential energy $(P)$, total mean kinetic energy $(K)$, exponential time scale of energy loss $\left(T_{e}\right)$, and exponential distance scale of energy loss $\left(L_{e}\right)$ are given for the four Pacific Summer Water time periods and the Spall et al. (2008) Pacific Winter Water time period. Values are given with their standard errors taking into account the cross-correlation between the time series at the individual grid points, but not accounting for systematic errors. Some of the conversions are not statistically significant. In those cases, the derived time and distance scales have not been calculated, but are rather marked as "n/a".

\begin{tabular}{|c|c|c|c|c|c|c|c|c|}
\hline & $T_{d}$ & $\bar{U}$ & $C$ & $T$ & $P$ & $K$ & $T_{e}$ & $L_{e}$ \\
\hline & {$[$ days $]$} & {$\left[\mathrm{m} \mathrm{s}^{-1}\right]$} & {$\left[\mathrm{W} \mathrm{m}^{-1}\right]$} & {$\left[\mathrm{W} \mathrm{m}^{-1}\right]$} & {$\left[10^{6} \mathrm{~J} \mathrm{~m}^{-1}\right]$} & {$\left[10^{6} \mathrm{~J} \mathrm{~m}^{-1}\right]$} & {$[$ days $]$} & {$[\mathrm{km}]$} \\
\hline ACW2002 & 35 & $0.29 \pm 0.05$ & $180 \pm 78$ & $102 \pm 34$ & $184 \pm 31$ & $120 \pm 20$ & $12 \pm 4$ & $313 \pm 115$ \\
\hline ACW2003 & 29 & $0.28 \pm 0.04$ & $148 \pm 270$ & $43 \pm 21$ & $775 \pm 126$ & $188 \pm 28$ & $\mathrm{n} / \mathrm{a}$ & $\mathrm{n} / \mathrm{a}$ \\
\hline CSW2003 & 29 & $0.20 \pm 0.04$ & $192 \pm 65$ & $2 \pm 12$ & $162 \pm 31$ & $102 \pm 14$ & $10 \pm 4$ & $169 \pm 74$ \\
\hline CSW2004 & 15 & $0.25 \pm 0.05$ & $108 \pm 106$ & $-56 \pm 36$ & $155 \pm 35$ & $93 \pm 20$ & $\mathrm{n} / \mathrm{a}$ & $\mathrm{n} / \mathrm{a}$ \\
\hline PWW2003 & 57 & $0.17 \pm 0.02$ & $55 \pm 51$ & $-11 \pm 8$ & $449 \pm 98$ & $65 \pm 7$ & $94 \pm 90$ & $1388 \pm 1332$ \\
\hline
\end{tabular}

Rayleigh's necessary criterion for barotropic instability on a beta plane. Accordingly, we conclude that the CSW configuration of the shelfbreak current is baroclinically unstable. We note that the estimate of the potential energy for this case is more robust than for the ACW case as the bias due to the data gap is smaller. With a shorter and more intermittent record for CSW in 2004, the baroclinic conversion is marginally positive and the barotropic conversion is in fact negative (implying some energy transfer into the mean kinetic energy.) While quantitively not as robust as in 2003, this still supports the conclusion that the CSW configuration is baroclinically unstable.

Spall et al. (2008) concluded that the PWW configuration in 2003 was baroclinically unstable. For comparison purposes, the energy conversions for that case are included in Table 2.2 and shown in Figure 2-13. Estimates of the mean kinetic and available potential energy (computed here) are added. As noted by Spall et al. (2008), the net barotropic conversion is small and the baroclinic conversion is positive. How- 
ever, the magnitude of the baroclinic conversion $\left(55 \pm 51 \mathrm{~W} \mathrm{~m}^{-1}\right)$ is only about $25 \%$ of that for the ACW state in 2002 and the CSW state in 2003. This means that the PWW configuration in 2003 is less unstable, and hence the cross-stream property fluxes are diminished. Correspondingly, the mean available potential energy for the PWW case is larger (by more that a factor of two) than for the two summer configurations of the current.

Using a numerical model of the Winter Water configuration of the Western Arctic shelfbreak current (whose energetics were similar to those measured for the 2003 PWW case), Spall et al. (2008) concluded that the shelfbreak current was the source of the cold-core, anti-cyclonic eddies observed in the southern Canada Basin. While it is beyond the scope of the present study to implement a numerical model, we can nonetheless make inferences with some degree of confidence based on the calculated energetics of the two summertime configurations of the jet. It is likely that the mixed instability of the ACW shelfbreak jet will lead to the formation of warm-core, surfaceintensified eddies of the type reported by Pickart and Stossmeister (2008) (such eddies are present in unpublished data as well). Similarly, baroclinic instability of the CSW shelfbreak current should produce warm-core, mid-depth anti-cyclones, also observed by Pickart and Stossmeister (2008). Although the ACW and CSW configurations of the current are present for only about one month each, one might expect that their strong baroclinic conversion rates should result in a substantial offshore flux of Alaskan Coastal Water and Chukchi Summer Water. This is consistent with the common occurrence of these water masses throughout the Western Arctic (e.g. Steele et al., 2004). 


\subsubsection{Decay Distances and Downstream Fate}

The above information on the energetics of the shelfbreak current at the location of the mooring array makes it possible to infer some aspects of how the current should evolve as it continues to flow eastward along the continental slope. It is of high interest to determine whether or not the current stays intact and flows into the Canadian Arctic Archipelago - or onward to Fram Strait - versus rapidly spinning down and thereby fluxing its properties into the interior Arctic. Mountain (1974) addressed this issue using synoptic hydrographic measurements of the Western Arctic shelfbreak current to the east of Pt. Barrow and concluded that the jet should lose its momentum over a distance of $O(100 \mathrm{~km})$. Here we use the mooring time series data to investigate the energy budget of the three configurations of the shelfbreak current (ACW, CSW, and PWW).

Before using the data to estimate the time scale over which the current loses its signal, we present a framework for the baroclinic decay using a simple scaling argument. In particular, we use the scale for the cross-stream eddy density flux as derived by Spall (2004):

$$
\overline{\rho^{\prime} v^{\prime}} \approx \alpha \bar{u} \Delta \rho
$$

Here $\alpha$ is a constant non-dimensional scaling factor, $\bar{u}$ is the mean baroclinic alongstream velocity of the shelfbreak current, and $\Delta \rho$ is the density difference between the current and interior. This difference, divided by a typical width of the current ( $\left.L^{y} \approx 20 \mathrm{~km}\right)$, scales as the horizontal density gradient:

$$
\frac{\Delta \rho}{L^{y}}=\bar{\rho}_{y} .
$$

The time rate of change of the potential energy is the baroclinic conversion as 
defined in (2.5). Hence:

$$
\frac{d P}{d t}=-C=-g \overline{\rho^{\prime} v^{\prime}} \frac{\bar{\rho}_{y}}{\bar{\rho}_{z}}
$$

Noting that $\rho$ as used in (2.3) is the same as $\Delta \rho$ in (2.8), we can use (2.3) and (2.7) to substitute $\overline{\rho^{\prime} v^{\prime}}$ and $\bar{\rho}_{z}$ in $(2.9)$ :

$$
\frac{d P}{d t}=-C \approx-\alpha \frac{\bar{u}}{L^{y}} P=-\frac{1}{T_{e}} P
$$

Here we have identified $T_{e}=\frac{L^{y}}{\alpha \bar{u}}$ as an exponential decay time in the solution to (2.10). The interpretation is that, following the flow, after a time $T_{e}$ only $1 / \mathrm{e}$ of the mean available potential energy is left in the shelfbreak current. This is due to the coupling between available potential energy and baroclinic conversion: as the potential energy decreases there is less energy that the conversion can draw from and therefore it becomes smaller as well.

The above argument assumes that the velocity in the shelfbreak current $\bar{u}$ remains constant. However, as the total energy in the current decreases, the velocity will also decrease representing a higher order effect that lengthens the decay time. However, the decay distance will not be affected by this because, as the flow weakens, so does the conversion rate, and these two effects offset each other. This is seen by computing the decay distance, making use of the solution to (2.10):

$$
L_{e}=\bar{u} \cdot T_{e}=\frac{L^{y}}{\alpha}
$$

While providing a framework for the baroclinic decay of the current, we are unable to evaluate (2.11) to compute $L_{e}$ because $\alpha$ is an unknown constant. We can, however, estimate the baroclinic decay distances directly from the mooring data, simply by computing the quotient $\frac{P}{C}$ (which by $(2.10)$ is roughly equal to $T_{e}$ ) and multiplying 
this by the mean flow $\bar{u}$. Note, however, as seen by the above scaling, that this length scale does not represent a complete draining of the available potential energy from the current, but rather an e-folding decrease.

A scaling similar to (2.7) does not exist for the cross-stream eddy momentum flux, so we cannot derive a similar framework for the barotropic decay. However, there is also a coupling between the kinetic energy and the barotropic conversion suggesting that the qualitative behavior should be exponential to lowest order. Therefore, we consider the baroclinic and barotropic decays together in our estimates below. The reader should keep in mind, however, that this estimate only takes into account energy loss due to mesoscale instabilities; there are clearly other processes impacting the fate of the shelfbreak current. In the next subsection we discuss some of these other factors and assess their importance.

We now proceed to estimate the approximate exponential decay times (defined as $\frac{P+K}{C+T}$ ) and associated decay distances from the mooring array data. For the cases when the conversion rates are statistically significant, we have computed the decay times and, using typical advective velocities of the current (defined as an average over the fastest 40 grid points which comprise roughly $15 \%$ of the domain), converted these into distances. The results are shown in Table 2.2. For the ACW state in 2002, for which the shelfbreak current was both baroclinically and barotropically unstable, the sum of the energies divided by the sum of the conversions leads to a decay time of $12 \pm 4$ days, which is about a third of the duration for which that current state was observed. Based on the mean velocity in the core of the shelfbreak current $\left(\approx 0.3 \mathrm{~m} \mathrm{~s}^{-1}\right)$, this corresponds to a distance of about $300 \mathrm{~km}$ beyond the array site. For the CSW state in 2003 (the other case for which the energy conversion rate estimates were statistically significant), the computed decay time is $10 \pm 4$ days. With a slower mean velocity of $\approx 0.2 \mathrm{~m} \mathrm{~s}^{-1}$, this implies an even shorter decay distance of 


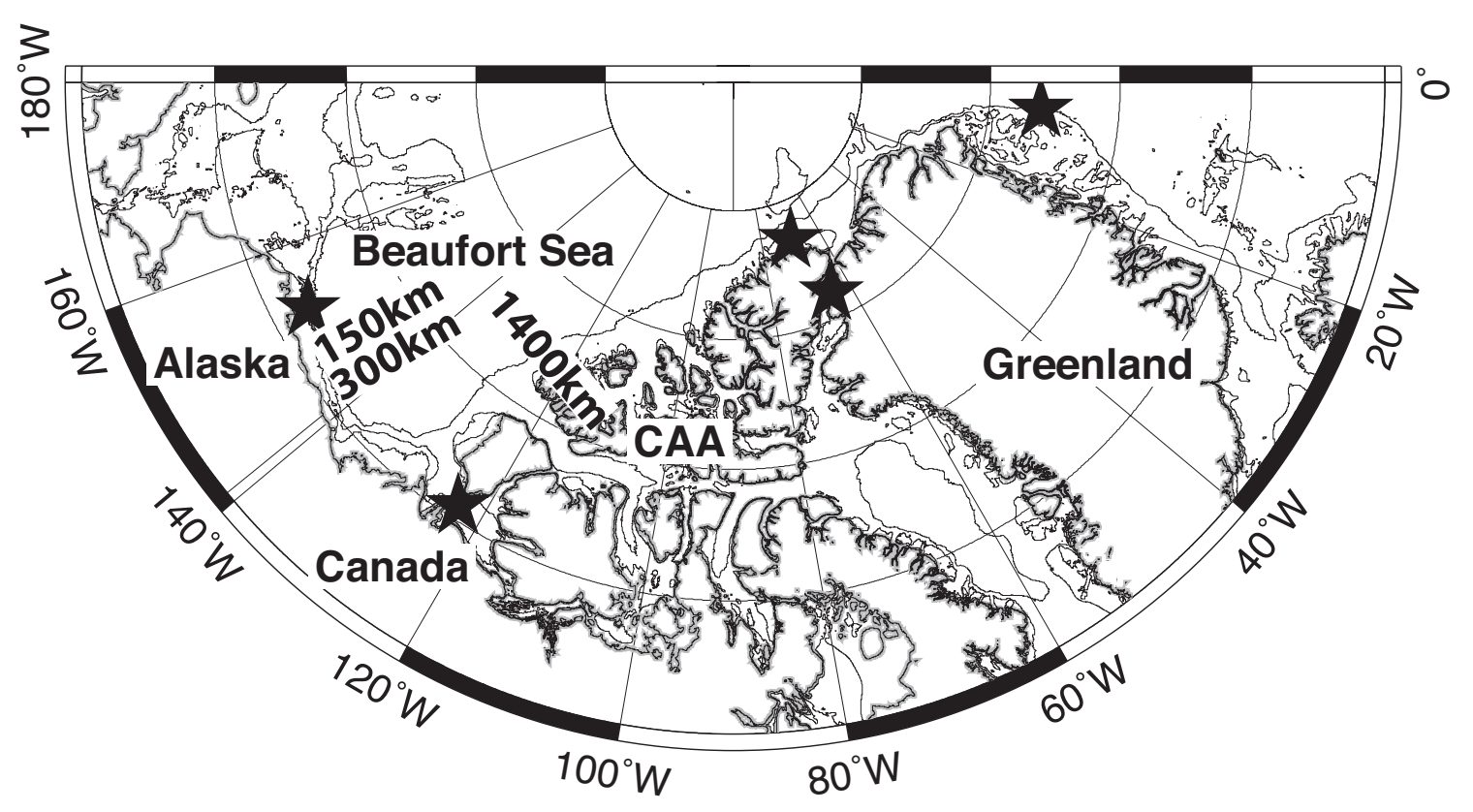

Figure 2-14: Map of the Arctic Ocean with the 0 m, 50 m, $200 \mathrm{~m}$, and $1000 \mathrm{~m}$ isobaths drawn. The black stars indicate locations mentioned in the text: the mooring array at $152^{\circ} \mathrm{W}$ north of Alaska; Amundsen Strait $(\approx 850 \mathrm{~km})$; the Switchyards region north of Ellesmere Island ( $\approx 2600 \mathrm{~km})$; Nares Strait between Ellesmere Island and Greenland; and Fram Strait east of Greenland $(\approx 3600 \mathrm{~km})$. Distances are measured from the mooring array following the shelfbreak. Elevation data are from Jakobsson et al. (2008).

order $150 \mathrm{~km}$. In contrast to these relatively short $O(100 \mathrm{~km})$ decay distances for the two Summer Water configurations of the shelfbreak current, the PWW state in 2003 decays over a substantially longer distance of roughly $1400 \mathrm{~km}$ (decay time of three months), although the error estimate is larger as well. We note that these same dynamics probably hold in the $\approx 80 \mathrm{~km}$ between Barrow Canyon and our mooring array site at $152^{\circ} \mathrm{W}$, but that the stability characteristics of the current in the shallow Chukchi Sea are likely different. Therefore, the present analysis does not address the question for how the current gets from Bering Strait to Barrow Canyon.

To put these estimates into context, we show maps (Figures 2-1 and 2-14) which 
mark each of the three decay distances. As seen, the Winter Water configuration of the current reaches the region of the Canadian Arctic Archipelago, but is still a long distance from the northern tip of Greenland and Nares Strait. By contrast, the estimated decay distance for the ACW state in $2002(300 \mathrm{~km})$ is less than the distance to the Alaska-Canada border. As such, based on the energetics of the two summertime configurations of the shelfbreak current, it is unlikely that warm Pacific Water should enter the Canadian Arctic Archipelago as a well defined shelfbreak current.

\subsubsection{Limitations of Distance Estimates}

There are several limitations to the above distance estimates. Intrinsic to this calculation is the assumption that the instabilities have reached their maximum amplitude by $152^{\circ} \mathrm{W}$ and continue to extract energy from the current in the same qualitative way as measured at the array. If instead the instabilities continue to grow downstream of the array, the energy extraction would be faster meaning that our decay distances are overestimates. It is also possible that the flow could stabilize farther downstream (i.e. cease to lose energy) in which case our decay distances would be underestimates. We have also assumed that there is no re-entrainment of Pacific Water from offshore during the eddy formation process that might re-establish the density gradient and its associated potential energy. Additionally it has been assumed that there is no other source of buoyant water to the current; beyond $135^{\circ} \mathrm{W}$ the freshwater from the Mackenzie River might need to be taken into account. We note further that the bathymetry has been assumed uniform in the alongstream direction. While this is reasonable along the North Slope of Alaska, in the Canadian Beaufort the continental slope becomes significantly steeper. Also, it is not obvious how the shelfbreak current 
will negotiate the entrance to Amundsen Strait (the first passage into the Canadian Arctic Archipelago).

There is a large-scale pressure gradient between the Pacific and Atlantic (e.g. Woodgate and Aagaard, 2005) that drives the throughflow through the Arctic Ocean. However, this pressure gradient does not influence the precise lateral flow patterns by which the Pacific-origin water progresses from Bering Strait to the Canadian Arctic Archipelago and Fram Strait (e.g. via the shelfbreak current or the transpolar drift). This is why we neglect pressure work as an energy source to the evolution of the Pacific Water transport in the shelfbreak current.

We have also neglected friction in the above analysis, which will spin down the current as well. Bottom friction might be especially important for the case of the bottom-intensified CSW and PWW cases. However, buoyancy shutdown in the bottom boundary layer tends to counteract the effect of friction by reducing the bottom stress to zero, which can allow boundary currents to persist for long distances (e.g. MacCready, 1994). Brink and Lentz (2010) developed a scaling for the time in which buoyancy shutdown is achieved. Using appropriate values for the Beaufort Slope, we find that this should occur rapidly (order of a day). This implies that bottom friction should be negligible for the longer time evolution of the Western Arctic shelfbreak current. Frictional spin down by the ice is another factor which may be at work, particularly for the surface-intensified ACW state. However, in recent decades the ice concentration along the Alaskan Beaufort Slope has become near zero over much of the late-summer/early-fall.

Finally, perhaps the most important limitation to the above analysis is the neglect of wind (recall that periods of wind-forcing were excluded from the time series used in the study). In particular, winds may on their own either increase or decrease the potential energy (by changing isopycnal slopes) and kinetic energy (by changing flow 
velocities). Part of our motivation to focus on the current structure in the absence of wind is that the combined case of external wind forcing and internal mesoscale dynamics is difficult to address. As such, our goal was to isolate the latter with the hope of achieving an incremental, but significant, improvement in the understanding of this aspect of the shelfbreak current system.

\subsection{Discussion}

The present study has used high-resolution mooring array data at $152^{\circ} \mathrm{W}$ from the summers of 2002-04 to investigate the structure, transport, and dynamics of the Western Arctic shelfbreak current when it advects Pacific Summer Water in the absence of winds. The jet has two distinct configurations which respectively advect the two major Summer Water masses. The Alaskan Coastal Water (ACW) configuration is a surface-intensified shelfbreak current advecting strongly stratified warm and fresh water; it is the extension of the Alaskan Coastal Current that flows through Bering Strait and along the west coast of Alaska in the Chukchi Sea. This configuration of the jet is both baroclinically and barotropically unstable and is estimated to exponentially decay due to the formation of surface-intensified warm-core eddies over a distance of roughly $300 \mathrm{~km}$. The Chukchi Summer Water (CSW) configuration is a bottom-intensified shelfbreak current transporting weakly stratified, less-warm and fresh water that originates in the Bering and Chukchi Seas. It is baroclinically unstable and is estimated to exponentially decay due to formation of mid-depth intensified warm-core eddies over a distance of roughly $150 \mathrm{~km}$.

The calculated volume transports at $152^{\circ} \mathrm{W}$ show that, in the mean, between $10 \%$ and $20 \%$ of the Pacific Summer Water entering Bering Strait reaches the Beaufort Sea as a shelfbreak current. However, in the absence of wind, both configurations of the 
jet transport on the order of $0.5 \mathrm{~Sv}$ to the east. For completeness, we also considered the Pacific Winter Water configuration of the jet studied earlier by Spall et al. (2008). This is a weakly stratified, bottom-intensified current advecting newly-formed Winter Water near the freezing point. It is also baroclinically unstable, but is estimated to decay more slowly over an exponential distance of roughly $1400 \mathrm{~km}$.

Our study has demonstrated that the Western Arctic shelfbreak current is an important conduit of Pacific Summer Water downstream of the Chukchi Sea outflow points. Furthermore, its mesoscale dynamics largely dictate the cross-stream flux of freshwater and heat into the interior which consequently impact the maintenance of the halocline, sea-ice melt, and the freshwater reservoir of the Beaufort Gyre. According to our energetics analysis, the mean-to-eddy transfer of energy is so strong that neither of the summer configurations of the current should persist far into the Canadian Beaufort Sea before spinning down. By contrast, the winter configuration seems able to flow into the region of the Canadian Arctic Archipelago (Figure 2-1). There are, however, some additional aspects to consider in this regard.

Tracer measurements have detected the presence of Pacific Winter Water in both Nares Strait and Fram Strait (e.g. Jones et al., 2003). This means that either a boundary current provides water to both of these exit points or there is transport of the Pacific Winter Water in the interior basin (e.g. the transpolar drift). If the transport occurs via a boundary current, this would suggest that the above exponential decay distance estimate for the PWW case may be an underestimate. To date there have been two observational studies near the shelfbreak north of the Canadian Arctic Archipelago. Using a combination of CTD sections and current meter records, Newton and Sotirin (1997) revealed a bottom intensified eastward flow along the shelfbreak (roughly $200 \mathrm{~m}$ deep) in the Lincoln Sea north of Ellesmere Island at the northeastern tip of the archipelago. However, a more recent field program to the 
west of Nares Strait (the "Switchyards" study; Steele, pers. comm. 2010) found little evidence of a shelfbreak current. It should be noted that in both these studies the cross-stream resolution of measurements is arguably too coarse to properly resolve a shelfbreak current. As such, at this point the observational evidence is inconclusive as to the existence of a Pacific Water boundary current in this region.

There are additional reasons, however, to suspect that the PWW shelfbreak jet does not reach either Nares Strait or Fram Strait. In order for a shelfbreak current to follow a direct path along the shelfbreak from Pt. Barrow to the Switchyards region, it would have to flow past several entrances to the archipelago that are deeper than $200 \mathrm{~m}$. This raises the question of whether the current would flow into these channels, and perhaps back out again, or whether it would "jump" such a channel and continue unimpeded along the shelfbreak. Chapman (2003) investigated the conditions under which these two scenarios occur, and found that a relevant factor was the advective distance in a pendulum day (speed of the current divided by the Coriolis frequency) compared to the geometrical dimensions of the channel. By thermal wind, this ratio of the advective distance to the geometrical dimension is related to the width of the current, which was the primary parameter investigated by Sutherland and Cenedese (2009) in a similar study. Amundsen Strait is the first channel into the archipelago that the Western Arctic shelfbreak current encounters. The width of the channel is roughly $90 \mathrm{~km}$ and the radius of curvature at its western side is roughly $60 \mathrm{~km}$. Using typical scales of the shelfbreak current at $152^{\circ} \mathrm{W}$ (noting that these will be overestimates as the current is decaying due to mesoscale instabilities as discussed above), we estimate that both the advective distance and the width of the current are roughly $10 \mathrm{~km}$. This implies that the shelfbreak current would enter Amundsen Strait rather than taking a more direct route across the mouth of the channel.

According to our scaling analysis then, the presence of the different openings to 
the Canadian Arctic Archipelago drastically increases the effective distance between Barrow Canyon and the Switchyards location along the shelfbreak of the Beaufort and Lincoln Seas. As such, it seems unlikely that the PWW configuration of the jet (and even less so the ACW and CSW configurations) can stay intact all the way to Nares Strait and beyond to Fram Strait. This in turn implies that there are other pathways of Pacific Water feeding these exit points. In this regard we mention the recent model study of Nguyen et al. (2011) who conclude that the majority of the Pacific Water transport to the northeastern part of the archipelago is accomplished in the transpolar drift. Also, the pan-Arctic model of Aksenov et al. (2011) shows westward flow along the shelfbreak north of the archipelago.

Finally, it is important to keep in mind that our study uses data from a limited time period (2002-04). In light of the pronounced interannual variability in the Arctic system (e.g. associated with the Arctic Oscillation), it is likely that our results are not representative for every summer. For example, the recent study of Watanabe (2011) suggests that during the latter part of the decade, the summertime shelfbreak jet was weak or non-existent. Using a numerical model in conjunction with satellite data, Watanabe (2011) compared the shelfbreak jet dynamics in 2003, when the winds over the Chukchi Sea were predominantly northwesterly (due to low pressure over the Beaufort Sea), to 2007 with persistent easterly winds (due to high pressure over the Beaufort Sea). They concluded that the westerly winds enhanced the flux of Pacific Summer Water in the shelfbreak jet during the earlier time period, while easterly winds in 2007 transported much of the Summer Water to the west in the Chukchi Sea. The latter scenario resulted in cross-shelfbreak Ekman transport of the Summer Water rather than the formation of a shelfbreak current.

Investigation of the NCEP atmospheric reanalysis fields (Kalnay et al., 1996), as well as measured QuikSCAT winds (Naderi et al., 1991) and surface wind mea- 
surements at Barrow Airport (Climate-Radar Data Inventories, 2010), showed that during the time period of the mooring array (2002-04) typical atmospheric conditions in summer consisted of low pressure over the Beaufort Sea leading to westerly winds. By contrast, the summers of 2007-09 generally consisted of high pressure over the Beaufort Sea leading to easterly winds in this region. From summer 2008 onwards, a mooring at location BS3 (in the center of the shelfbreak jet) has been maintained as part of another field program. Interestingly, the hydrographic time series from July 2008 to August 2009 showed no presence of Alaskan Coastal Water. Based on the above analysis for 2002-04, this mooring should have measured warm ACW within this year-long time frame. While the absence of ACW in 2008-09 is consistent with the assertion of Watanabe (2011) that the summertime shelfbreak jet is diminished or absent under persistent easterly forcing, this requires more in-depth analysis using the additional mooring data.

\subsection{Acknowledgments}

The authors would like to thank K. Brink, M. Spall, M. Steele and R. Woodgate for helpful discussions and suggestions. T. Weingartner and R. Woodgate provided access to additional SBI mooring data and M. Steele provided access to the Switchyards hydrographic sections. This work was supported by National Science Foundation grants OCE-0726640, OPP-0731928, and OPP-0713250. 


\section{Chapter 3}

\section{A Case Study of Denmark Strait Overflow Water Cyclones from a Cross-stream Mooring Array}

\subsection{Abstract}

The East Greenland shelf and slope south of Denmark Strait is an important crossroads of the global ocean circulation. In the surface layer warm subtropical water recirculates and joins the southward flowing cold Arctic origin water. Below this, dense Denmark Strait Overflow Water (DSOW), originating in the Nordic Seas, entrains ambient water in the Irminger basin as it descends to form the Deep Western Boundary Current. The variability in this region is dominated by energetic DSOW cyclones propagating equatorward from Denmark Strait and the spilling of dense water off the East Greenland shelfbreak. In order to study these processes, a highresolution profiling mooring array was deployed from summer 2007 to summer 2008. We investigate different aspects of the mean flow and dominant variability. In the 
mean, there is a bottom intensified alongstream flow on the upper slope of $0.4 \mathrm{~m} / \mathrm{s}$, with a significant nearly barotropic offshore component of $0.05 \mathrm{~m} / \mathrm{s}$. The range of variability in both components is $\mathrm{O}(0.25 \mathrm{~m} / \mathrm{s})$.

Three DSOW cyclones which passed by the array in September 2007 are studied in detail. Their structure is in agreement with previous modeling studies suggesting that they were formed due to vortex stretching. The radius of the eddies, defined as the distance from the center to where the force balance changes from dominantly cyclostrophic to geostrophic, is between $4 \mathrm{~km}$ and $8 \mathrm{~km}$. On the offshore side of the cyclones the height of the DSOW plume is taller by 100-200 $\mathrm{m}$ than in the absence of cyclones. The overflow plume flow there, however, is always equatorward. By contrast, in the middle layer on the offshore side of a cyclone, the flow is poleward up to $0.3 \mathrm{~m} / \mathrm{s}$. The three cyclones are located at different depths on the continental slope, representing a variation in their center positions of more than $20 \mathrm{~km}$. Consequently their modulation of the surface East Greenland/Irminger front varied considerably. The spilling of dense water off the shelf during the period of the case study is also investigated. Both spilling due to a DSOW cyclone ("Type II spilling") and unrelated to DSOW cyclones ("Type I spilling") is shown.

\subsection{Introduction}

\subsubsection{Overview of Region}

The Irminger Sea is at the confluence of many globally important circulations. Gulf Stream origin warm and salty Atlantic water is transported into the Nordic Seas as well as south of Iceland and southwards along the East Greenland shelfbreak in the Irminger Current (IC). Cooling and evaporation in the Nordic Seas leads to 
the formation of dense water which then leaves the region through the Faroe Bank Channel, across the Iceland-Scotland Ridge, and through the Denmark Strait. The latter source is the largest of the three overflows and the resulting water mass is called Denmark Strait Overflow Water (DSOW). Cold and fresh Arctic origin water flows through the Fram Strait and southwards along the East Greenland shelfbreak in the East Greenland Current (EGC) and onwards through Denmark Strait. Figure 1 of Curry and Mauritzen (2005) summarizes this circulation scheme. Runoff from Greenland contributes to the very fresh East Greenland Coastal Current (EGCC) along the relatively steep coast of East Greenland (Sutherland and Pickart, 2008).

The EGC and IC in combination are the origin of the shelfbreak current that flows equatorward along the western North Atlantic margin and eventually terminates near Cape Hatteras (Fratantoni and Pickart, 2003). This is the rim current to the subpolar gyre circulation. The EGC is relatively cold and fresh while the IC is warm and salty so that there is a strong lateral gradient of temperature and salinity that is easily detected. The density difference, on the other hand, is much smaller with only slightly lighter water on the EGC side.

Figure 3-1 shows a schematic of the circulation in the area of this study and also the location of the mooring array used in this study. The mooring location coincides with the hydrographic sections used in Pickart et al. (2005a) and Brearley et al. (2012) and a close-up is shown in Figure 3-2.

\subsubsection{Denmark Strait}

Arctic origin water transported by the deep portion of the EGC (Rudels et al., 2002) as well as dense water formed during open ocean convection in the Nordic Seas (Våge et al., 2011) constitute Denmark Strait Overflow Water (DSOW). The flow of DSOW 


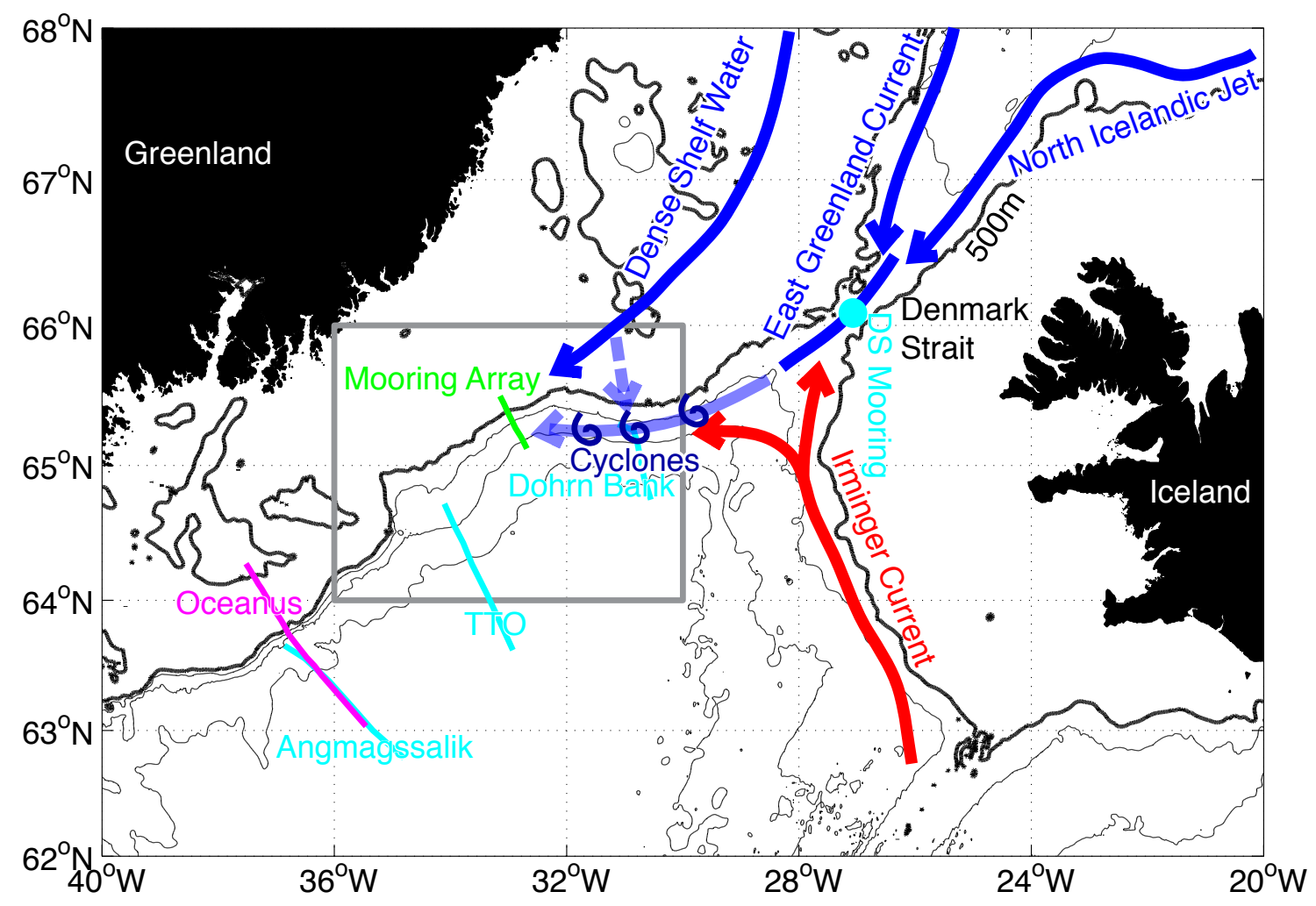

Figure 3-1: Map of the study region. Greenland and Iceland as well as the $500 \mathrm{~m}$ (thick line), $1000 \mathrm{~m}, 1500 \mathrm{~m}$, and $2000 \mathrm{~m}$ isobaths are shown. The mooring array (green line) is at $33^{\circ} \mathrm{W}$ across the shelfbreak. The $R / V$ Oceanus cruise 369 (purple line) crosses the shelfbreak around $37^{\circ} \mathrm{W}$. The locations of the three Lowestoft mooring arrays (Dickson and Brown, 1994) and the mooring in Denmark Strait are shown in cyan. The gray box outlines the region of Figures 3-2 and 3-13. 


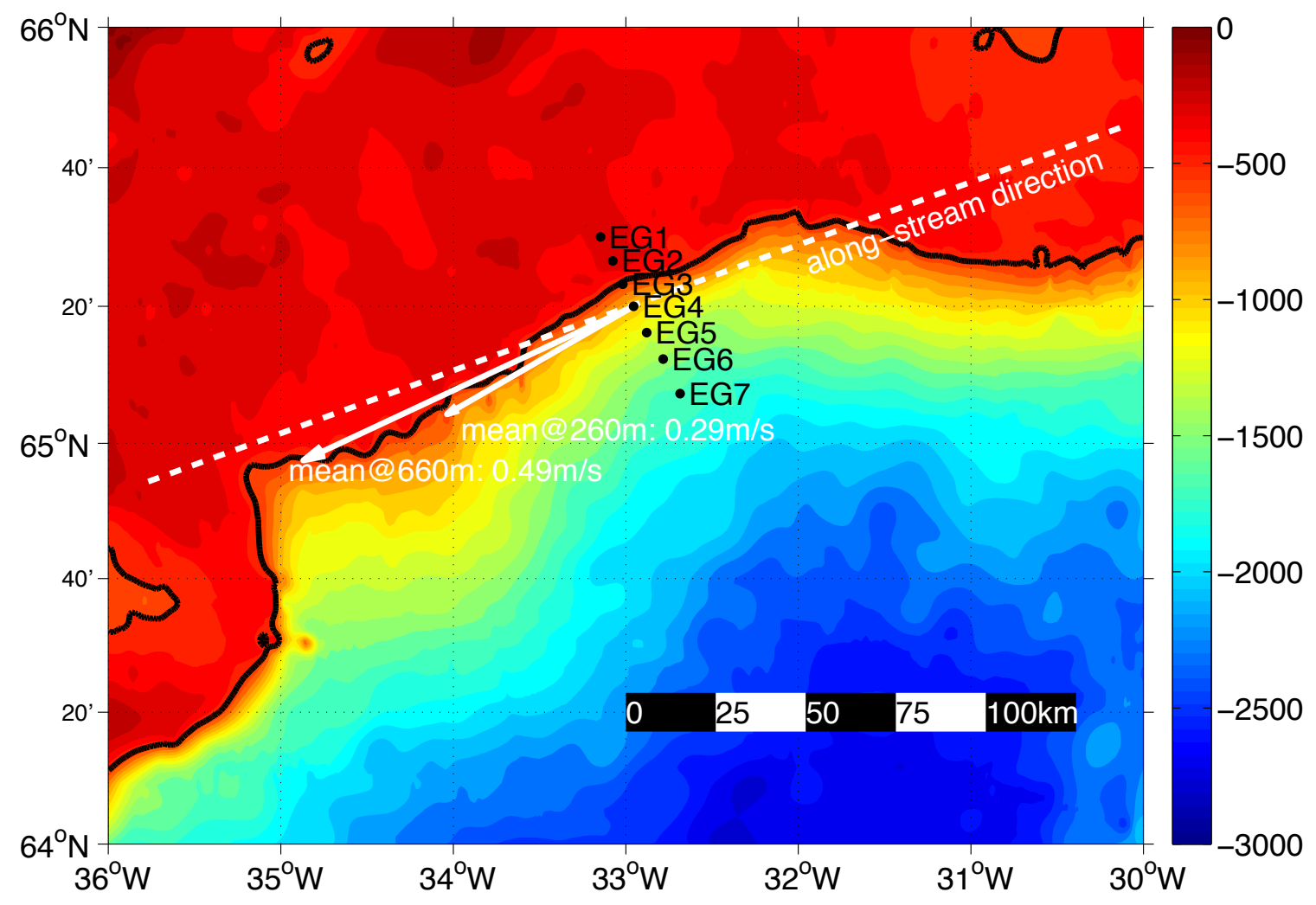

Figure 3-2: Close-up of the bathymetry (in meters) of the region of the mooring array. The individual moorings are named and a scale bar for the horizontal distances is shown in the bottom right. The alongstream direction used in this study is indicated by a white dashed line. Year-long mean velocities at mooring EG4 in $894 \mathrm{~m}$ of water have been calculated (see Section 3.4) and the vectors at $260 \mathrm{~m}$ and $660 \mathrm{~m}$ water depth are shown here as white arrows. 
through Denmark Strait is part of a complex circulation pattern in the strait.

In the 1960s an attempt was made to measure the volume transport through Denmark Strait (Worthington, 1969). 30 current meters were deployed, but only one returned satisfactory data, indicating flows as fast as $1.4 \mathrm{~m} / \mathrm{s}$. As such, this was an impressive demonstration of the energetic environment of the Denmark Strait and its impact on mooring equipment. While many technical and scientific advances have been made since, to this day this part of the world's ocean is a challenging environment for moored observations.

Recent transport estimates by Girton et al. (2001) from seven rapid high-resolution hydrographic surveys indicated a volume flux of $2.7 \pm 0.6 \mathrm{~Sv}$ (standard error at $67 \%$ confidence) for water denser than $27.8 \mathrm{~kg} / \mathrm{m}^{3}$ which is the boundary isopycnal commonly used to delimit DSOW (Dickson and Brown, 1994). It was also found that the flow in the strait has a significant barotropic component and that the front dividing Arctic and Atlantic waters is nearly vertical.

Models suggest that overflow water transport across the Greenland-Iceland-Scotland sills varies on multi-year time-scales, driven by the replenishing capacity of the upstream dense water reservoir, as well as on annual and shorter time scales associated with the wind stress curl around Iceland (Köhl et al., 2007). In an attempt to devise a monitoring system for Denmark Strait, Macrander et al. (2007) argue that two to three well-positioned ADCPs and pressure inverted echo sounders at the Denmark Strait sill could be used to capture $80 \%$ of the transport and its variability. Based on work by Hoyer and Quadfasel (2001), Haine (2010) shows the direct relation between overflow transport across the Denmark Strait sill and the sea surface height signal. While current satellite altimeter measurements are not sufficient to monitor the overflow transport based on this relation, the next generation altimeter - the Surface Water and Ocean Topography (SWOT) wide-swath altimeter (Durand et al., 
2010) - should be.

\subsubsection{Steady Models of the Overflow South of the Strait}

In their seminal paper, Price and O'Neil Baringer (1994) developed a stream tube model to predict the water mass changes between the sill and the final adjusted water depth of an overflow water. As motivation they refer to the world's four most prominent overflows (Filcher Ice Shelf in the Weddell Sea, Denmark Strait, Faroe Bank Channel, and the Strait of Gibraltar) and note that the densest source water of the four (Mediterranean outflow) actually results in the lightest final product and vice versa. This points to the importance of mixing and entrainment in the downstream pathway. Their stream tube model is steady and has one spatial dimension (downstream distance). The plume is characterized by its density, width, height, velocity, and bottom depth. The bottom slope as a function of downstream distance is provided from bathymetric surveys, and a constant density profile of the ambient water is included. As the plume has a negative buoyancy anomaly, it starts to descend the slope and gets deflected to the right (in the Northern Hemisphere) by the Coriolis force to form a geostrophically adjusted flow along the isobaths. Bottom drag and entrainment stress from Kelvin-Helmholtz instabilities at the top of the plume remove momentum from the plume and allow for its slow continual descent. A geostrophic Froude number (equivalent to a bulk Richardson number) is used to diagnose when entrainment occurs. A result of this simple model is that there are only a small number of regions of enhanced entrainment, associated with an increase in the bottom slope, that account for the majority of the entrainment. For much of the rest of their pathways, the overflow plumes exhibit negligible entrainment. In addition to the above physics, the pressure and temperature dependence of sea water's com- 
pressibility is included. These steady physics allow the model to predict successfully the ordering of the final density of the four major overflows. This is an important achievement, but it should also be clear that the neglect of temporal variability represents a serious misrepresentation of oceanic conditions in the highly energetic and variable East Greenland slope region.

Since the small scale processes parameterized by Price and O'Neil Baringer (1994) are crucial for deep water formation and are subgrid scale in all current and as well as all near- and far-future climate models, a climate process team was formed to increase the speed of implementation of the results of Price and O'Neil Baringer (1994) into global climate models. Danabasoglu et al. (2010) describe the overflow parametrization as it has been implemented at the Denmark Strait and Faroe Bank Channel in the Community Climate System Model version 4 (CCSM4). Significant improvements in the global coupled climate model are achieved: Deep water is formed and a deep ocean circulation is present. Both of these features were missing in previous generation models. However, it should be noted that this parameterization is a steady stream tube model that does not include any temporal variability. Hence it may well be that this overflow parameterization produces the right —or less incorrect-results for the wrong reasons making it questionable for applications in a changing climate. Therefore it is crucial to improve the understanding and representation of the physical processes involved and, in particular, their temporal variability.

\subsubsection{DSOW Eddies and Cyclogenesis Mechanisms}

The above mentioned steady models of the overflow plume neglect temporal, crossstream, as well as small and medium scale alongstream variability. However, a number of observations have shown energetic variability in the properties of the overflow 
water. Girton and Sanford (2003) analyzed a $140 \mathrm{~km}$ long transect along the axis of the DSOW plume pathway sampled with expendable temperature, salinity, and velocity probes. It is the only quasi-synoptic view of the downstream evolution of the overflow plume. The transect reveals a variation in overflow water layer thickness ranging from $40 \mathrm{~m}$ to $400 \mathrm{~m}$ over an observed distance of roughly $20 \mathrm{~km}$. A region of marked increase in entrainment is identified about $125 \mathrm{~km}$ south of the sill. Similar to the results of the steady models, this is found to be related to an increased bottom slope.

Rather than showing a steady overflow plume, this alongstream variation is the manifestation of DSOW eddies. They are tall cyclonic vortices that are ubiquitous on the East Greenland slope south of Denmark Strait (Bruce, 1995). The synoptic variability is dominated by their presence.

The most comprehensive treatment to date of available observational data and theory regarding DSOW cyclones is presented by Bruce (1995). It analyzes satellite infrared SST images (an example of which is reproduced in Figure 3-3) of the eddymodulated East Greenland Current/Irminger Current surface hydrographic front and combines it with previously published in-situ data (surface drifter data, deep current measurements, a small number of CTD sections, and laboratory experiments) to produce a consistent interpretation of the cyclonic features. It is noted that these features will not only have a significant impact on the overflow water, but also on the intermediate and surface layers. Quantitive statistics of the DSOW cyclones are presented, and consequently this study is the standard reference for all modeling studies that have been undertaken since. The mean (from roughly 50 realizations) eddy diameter was found to be $34 \mathrm{~km}$ (with individual realizations ranging from $20 \mathrm{~km}$ to $40 \mathrm{~km}$ ). The mean eddy separation was found to be $54 \mathrm{~km}$, and it is estimated that, at a mean advective speed of the East Greenland boundary current system of 
$0.27 \mathrm{~m} / \mathrm{s}$, an eddy would pass by a fixed point on the slope every 2.3 days. These numbers are based on SST images and the sample size is 46 for the mean diameter and 54 for the mean eddy separation. It is conceivable that not all eddies present during the study time were measured from the SST images. Additionally, the heavy cloud cover may lead to systematic biases in the eddy statistics estimates. Therefore, it is hard to quantify what the statistical confidence of the mean values of Bruce (1995) is.

Krauss (1996) reports on a brief study of DSOW eddies that used satellite tracked drifters drogued at $100 \mathrm{~m}$. The study revealed intense cyclonic eddies with a core diameter of $\approx 20 \mathrm{~km}$ along the East Greenland shelfbreak between $\approx 32^{\circ} \mathrm{W}$ and $42^{\circ} \mathrm{W}$, likely in solid-body rotation, thereby supporting the conclusions of Bruce (1995). Swirl velocities in the eddies reach $0.5 \mathrm{~m} / \mathrm{s}$ south of Denmark Strait and decrease to $0.15 \mathrm{~m} / \mathrm{s}$ near Cape Farewell. It is also suggested that the eddy propagation speed exceeds the mean flow speed by $\approx 0.1-0.3 \mathrm{~m} / \mathrm{s}$.

Smith (1976) was the first to put forward the notion of baroclinic instability as an explanation for the strong peak of variability in the overflow plume at a period of a couple of days. A number of subsequent studies (e.g. Jungclaus et al. (2001) who make a comparison to atmospheric frontal cyclogenesis and Swaters and Flierl (1991)) have added details building on the notion of baroclinic instability being responsible for the formation of DSOW eddies.

Hydraulic control has been shown to be active at Denmark Strait in observations reported by Nikolopoulos et al. (2003). The numerical model of Käse et al. (2003) reproduces the circulation and succeeds in placing the location of hydraulic control $100 \mathrm{~km}$ downstream of the sill and in generating eddies at intervals of 1-3 days. The hydraulic jump and eddy generation result in a transition from a mostly barotropic flow to a mostly baroclinic bottom-trapped equatorward flow. Käse et al. (2003) 


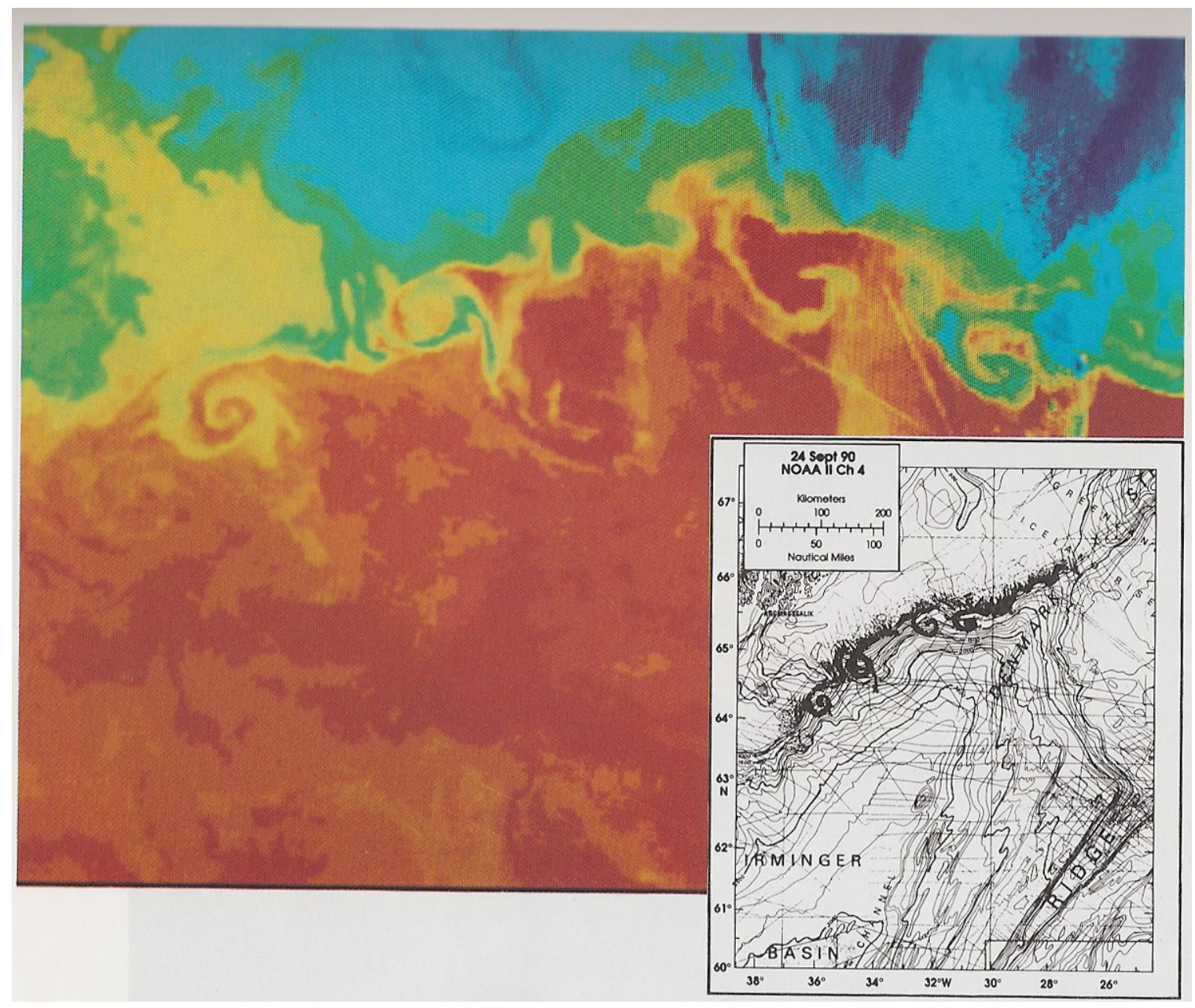

Figure 3-3: SST image by Bruce (1995) showing a number of overflow eddies through their modulation of the EGC/IC surface front. Figure is from Bruce (1995). 
note that the observed cyclonic sense of rotation of the eddies can only be due to a generation mechanism involving an active layer above the overflow water. Their model has eddy generation occurring in a region with bottom depths of 600-800 m, producing an eddy spacing of about $100 \mathrm{~km}$. The propagation speed of the eddies in the numerical model is $\approx 0.4 \mathrm{~m} / \mathrm{s}$, about half of the long gravity wave speed predicted from the parameters in the study. They also establish a relation between maximum plume thickness and maximum SSH anomaly.

It is important to note that many more cyclones are observed than anti-cyclones, and baroclinic instability does not explain this difference. This motivated Spall and Price (1998) to investigate an alternate explanation of eddy formation, in particular that of vortex stretching. Spall and Price (1998) present a detailed numerical study of the formation and downstream evolution of the Denmark Strait cyclones and note that two things are special about the Denmark Strait outflow. First, the outflow through the strait is comprised of three water masses of distinct densities. At the surface is fresh, cold and relatively light EGC water, and at sill depth there is the overflow of very cold and dense DSOW. In between there is an outflow of Arctic Intermediate Water (AIW) in the density range of $27.7-27.85 \mathrm{~kg} / \mathrm{m}^{3}$ that has not been cooled as much as the overflow water. As such, the Denmark Strait can be identified as a three-layer outflow. All these water masses are confined to a depth of $650 \mathrm{~m}$ (sill depth) leading to a higher stratification than in the ambient environment. The second observation about the Denmark Strait system noted by Spall and Price (1998) is that, downstream of the strait, the flow becomes extremely energetic over a shorter horizontal distance than the distance that would correspond to one wavelength based on the eddy size. In addition, as shown by Bruce (1995), the eddies are predominantly cyclonic.

As the three water masses move southward beyond the sill, the water column 
height increases. Potential vorticity is conserved in the absence of non-adiabatic processes. The evolution downstream of the sill is as follows and is also summarized in Figure 3-4. At the sill $(650 \mathrm{~m})$, there is no relative vorticity. As the water depth increases, the different layers of water are stretched and the relative vorticity becomes positive (cyclonic) to conserve PV. Since the EGC water and DSOW are mainly constrained to the surface and bottom respectively, the majority of the stretching will occur in the intermediate AIW layer. Hence, the strongest cyclonic vorticity occurs in the intermediate layer. A stretching of this layer by the same amount as its original height leads to a relative vorticity as large as the planetary vorticity and Rossby numbers of order 1 .

\subsubsection{The Region Between Denmark Strait and Cape Farewell}

A high resolution shipboard conductivity/temperature/depth (CTD) and vessel-mounted acoustic Doppler current profiler (VMADCP) section across the East Greenland shelf and slope at $32^{\circ} \mathrm{W} 65^{\circ} \mathrm{N}$ was analyzed by Pickart et al. (2005a). In addition to the well-known and expected equatorward flows in the surface intensified EGC/IC front and the bottom-intensified DSOW at the base of the continental slope, another equatorward flow was found to exist high up on the slope at a depth of around 400-600 m. Pickart et al. (2005a) named this current the "East Greenland Spill Jet". Peak speeds in this realization of the Spill Jet are $0.65 \mathrm{~m} / \mathrm{s}$. It was hypothesized and then subsequently shown from observations (Brearley et al., 2012) that there is dense water passing through Denmark Strait on the shelf in addition to the region of the sill. It is hypothesized that this water subsequently gets advected across the shelfbreak by some process and adjusts on the upper slope forming a strong along-isobath flow that is bottom intensified. Richardson numbers in the Spill Jet were measured and deter- 


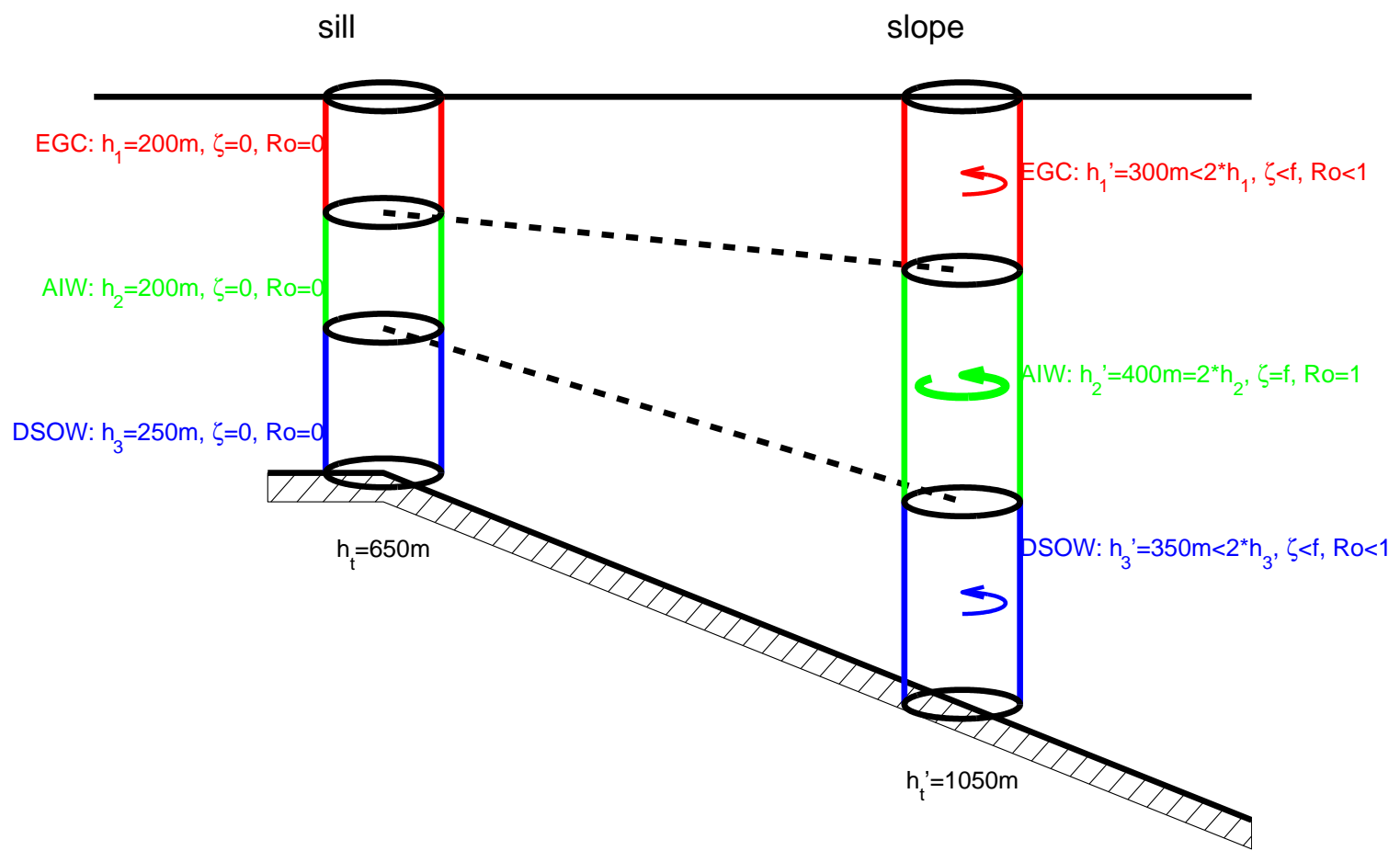

Figure 3-4: Cartoon of the stretching process leading to the generation of cyclonic vorticity. Potential vorticity is conserved: $P V=\frac{f}{h}=\frac{f+\zeta}{h^{\prime}}$. From the Denmark Strait (left of cartoon, total depth $h_{t}=650 \mathrm{~m}$ ) to a place (e.g. the location of the mooring array) along the East Greenland slope (right of cartoon, $h_{t}^{\prime}=1050 \mathrm{~m}$ ), all three layers outflowing Denmark Strait are stretched. However, the strongest stretching occurs in the middle AIW layer leading to a relative vorticity of $f$ and $R o \approx 1$ there. 
mined to be low, suggestive of active mixing at that location. Pickart et al. (2005a) motivated the mooring array that the current study is based upon.

Brearley et al. (2012) present three more occupations of the section analyzed by Pickart et al. (2005a). Compared to the mooring array, the hydrographic surveys provide a higher spatial resolution, but the velocity data are limited to absolute geostrophic velocity estimates. Since the system commonly exhibits Rossby numbers around unity, these geostrophic velocities may be significantly different from the full velocity field. The four sections in Brearley et al. (2012) all look different with a significant $(\approx 10 \mathrm{~km})$ horizontal displacement of the alongstream velocity maximum. This points to a strongly variable and energetic system. The vorticity structure (stably stratified with negative potential vorticity in the domain) is suggestive of the presence of symmetric instability which exchanges water in vertical overturning cells, moving dense fluid beneath light fluid (Haine and Marshall, 1998). The growth rate of the symmetric instability is estimated to be on the order of an hour to a few hours. Richardson numbers in the Spill Jet on the upper slope and in the DSOW are presented and suggest strong Kelvin-Helmholtz mixing. It is noted that the density contrast of the EGC/IC front is dominated by the temperature contribution near the mooring array site of the present study, but dominated by salinity near Cape Farewell. Brearley et al. (2012) argued that this qualitative change could be due to double diffusive mixing which is shown to be strongly favored in the CTD sections presented.

A regional numerical model study investigating the circulation along the East Greenland slope in general, and near the mooring array site in particular, is reported in Magaldi et al. (2011). The time period of the numerical study is summer 2003. This adds a spatial and temporal context to the CTD transects of Pickart et al. (2005a) and Brearley et al. (2012). A large variability with periods of 0.1-10 days is noted. 
The southward Spill Jet transport is estimated as $4.9 \pm 1.7 \mathrm{~Sv}$ (at $67 \%$ confidence). The Spill Jet's vorticity structure shows it to be unstable with peak Rossby numbers of $\approx 2-3$. It is argued that there are two distinct mechanisms by which the dense water is fluxed from the shelf to the continental slope where it forms the Spill Jet. The first scenario (called Type I) is a local perturbation of the EGC/IC that results in an instability horizontally moving dense water from the shelf to the slope. The second scenario (Type II), which accounted for more than half of the spilling events in the model, is associated with the passage of DSOW cyclones which span the full water column. The leading edges of these eddies are associated with offshore flow transporting dense water across the shelfbreak.

The pathway of the dense water along the East Greenland slope and the corresponding entrainment in this region has been widely studied. Dickson and Brown (1994) give the classical estimates of deep water volume fluxes. In order to be able to quantify the overflow water transport, they define the overflow water as being denser than $27.8 \mathrm{~kg} / \mathrm{m}^{3}$. This definition has been widely used since. Note, however, that Brearley et al. (2012) found water of this density high up on the slope, suggesting that it might not have passed through the trough of the strait. The criterion of 27.8 of Dickson and Brown (1994) is based on the reasoning that this water is still dense enough to sink to the deep ( $>2000 \mathrm{~m}$ ) North Atlantic, thereby contributing to North Atlantic Deep Water formation. Dickson and Brown (1994) quote a combined overflow volume across Denmark Strait and Faroe Bank Channel of 5.6 Sv, while the dense water transport around Cape Farewell was reported as $13.3 \mathrm{~Sv}$. This points to the fact that a sizable amount of entrainment has occurred along the pathways. A long-term UK program maintained three "Lowestoft" current meter arrays spaced 150 km apart: the Dohrn Bank Array, the "TTO" Array, and the Angmagssalik Array (see Figure 3-1 for their locations). At least one year of data from each of them is 
presented in Dickson and Brown (1994) detailing the downstream evolution of the overflow plume. However, these arrays only measured the deep part of the flow, terminating $1000 \mathrm{~m}$ or less above the ocean floor. The Angmagssalik Array has been more or less continuously occupied for 25 years.

The DSOW plume becomes warmer and less dense between Denmark Strait and Cape Farewell. As such, warm and light ambient water in the Irminger Sea (Irminger Water) is entrained either through vertical diapycnal fluxes associated with internal wave breaking or through lateral mesoscale eddy heat/density fluxes. The nearbottom mooring temperature and velocity data presented by Dickson and Brown (1994) are revisited by Voet and Quadfasel (2010) to compute turbulent lateral eddy heat fluxes into the overflow plume. Eddy temperature fluxes of $\approx 0.5-1 \mathrm{~K} \mathrm{~cm} / \mathrm{s}$ are found, which translate into a warming rate of $0.1 \mathrm{~K} / 100 \mathrm{~km}$. Hence these mesoscale features can explain about half of the total warming between Denmark Strait and Cape Farewell. Note that since the Lowestoft arrays did not cover the middle and upper water column and only some had salinity sensors, this study was only able to determine the eddy heat fluxes explicitly and hence had to infer the eddy density fluxes. Also, the structure above the overflow plume could not be investigated. Voet and Quadfasel (2010) show a month-long timeseries in which an eddy feature can be distinguished, but it is not discussed in detail; instead the statistical mean effect of the eddies is described.

\subsubsection{Cape Farewell Region}

The flow around Cape Farewell has been studied by a combined French-UK mooring array deployed during 2004-2006. Data from the French portion, consisting of point current meters and temperature sensors from the mid shelf to the $2070 \mathrm{~m}$ isobath, 
suggested a mean transport of the combined EGC/IC of $17.3 \pm 1.0 \mathrm{~Sv}$ (standard error at $98 \%$ confidence) (Daniault et al., 2011a). The seasonal variability is small, but synoptic peak-to-peak amplitudes are large (up to $30 \mathrm{~Sv}$ ). Winds over the Irminger Sea are well correlated with the transport. Daniault et al. (2011b) combines surface geostrophic velocities from satellite altimetry in the years 1992-2009 with the 20042006 mooring record to determine a longer term transport estimate of $19.5 \mathrm{~Sv}$ for the EGC/IC.

Bacon and Saunders (2010) analyzed data from the combined French and UK mooring arrays at Cape Farewell across the Deep Western Boundary Current below $\approx 1500 \mathrm{~m}$. The mean transport of water colder than $3^{\circ} \mathrm{C}$ (comparable to a density criterion of 27.8) is estimated as $7.8 \pm 0.8 \mathrm{~Sv}$ (standard error at $67 \%$ confidence). This is significantly less than the estimate presented by Dickson and Brown (1994) at this location. Bacon and Saunders (2010) also elucidated the magnitude of the variability in the DWBC. Its overall standard deviation is $2.9 \mathrm{~Sv}$ with a de-correlation timescale of 4-10 days, and the majority of the variability is in the 10-50 day band.

Based on several hydrographic sections along the East Greenland slope and near Cape Farewell, Lauderdale et al. (2008) use an internal wave strain-based parameterization to conclude that about half of the volume entrainment into the DSOW plume occurs within the first $\approx 150 \mathrm{~km}$, while the rest occurs in the next $\approx 1000 \mathrm{~km}$ to Cape Farewell. This is in agreement with Voet and Quadfasel (2010). Lauderdale et al. (2008) also find a secondary increase in the mixing and entrainment strength south of Cape Farewell associated with a local topographic feature (the Eirik Ridge) and an increase in bottom roughness. 


\subsubsection{Motivation and Outline of the Chapter}

The Denmark Strait overflow along with the Faroe-Bank Channel overflow provides the dense water that replenishes the North Atlantic Deep Water (NADW). Together with Antarctic Bottom Water, NADW occupies $80 \%$ of the oceans' volume. It is a crucial element of the meridional overturning circulation and its associated meridional heat transport. This is important to maintaining the pole-to-equator temperature difference. Since our human society is adapted to its current value, the precise value and the likely future evolution of this pole-to-equator difference is of great societal importance.

The amount of entrainment south of Denmark Strait determines the final density of NADW as well as its relative density - and hence depth level - relative to other intermediate and deep water masses. This entrainment happens in a very energetic region that in particular has a large synoptic variability associated with the passage of DSOW cyclones. Even if the cyclones are not the main source for turbulence leading to entrainment, they will certainly affect the detailed physics leading to entrainment. To date, DSOW cyclones have not been studied extensively and in particular their full-water column structure has not been observed.

In order to enhance our understanding of the flow at the East Greenland slope including the Spill Jet and DSOW cyclones, a full-water column mooring array was deployed across the outer shelf and slope in 2007-2008 (Figure 3-2). This was the first such array downstream of Denmark Strait. The chapter begins with a description of this data set. The mean flow on the upper slope is then presented along with a discussion of the range of observed water mass characteristics and the structure and expression of the EGC/IC front. A shipboard CTD section through the center of a DSOW cyclone is presented. The main body of work is devoted to the detailed 
description of three DSOW cyclones sampled during the early part of the deployment period. General characteristics are presented, and differences and similarities between the three cyclones are discussed. Finally, evidence is presented that spilling of dense water occurs at the shelfbreak during the time period that the eddies pass by the array. The insights gained from the detailed description of these three DSOW eddies will then be used in a later study to examine the eddy ubiquity and mean structure in the year-long record.

\subsection{Data}

\subsubsection{Mooring Array}

The mooring array on the East Greenland shelf and slope consisted of seven moorings named consecutively from EG1 (inshoremost mooring) to EG7 (offshoremost mooring). It was planned to obtain measurements of the hydrography and velocity structure for 13 months at the best feasible resolution in space and time. Figure 3-5 shows the setup that was utilized and deployed from 5 September 2007 to 4 October 2008. Details on the mooring array can be found in Appendix A. Here we briefly summarize the salient aspects of the array and the instruments used. A number of problems arose due in part to the extremely energetic environment on the East Greenland slope. We discuss these problems and the steps employed to overcome them.

Each of the moorings consisted of a nylon jacketed wire between an anchor on the ocean floor and a steel buoyancy sphere at $100 \mathrm{~m}$ water depth. Coastal Moored Profilers (CMPs on EG1-4) and McLane Moored Profilers (MMPs on EG5-7) traversed the wire twice a day (00UTC and 06UTC) measuring temperature, conductivity, and 


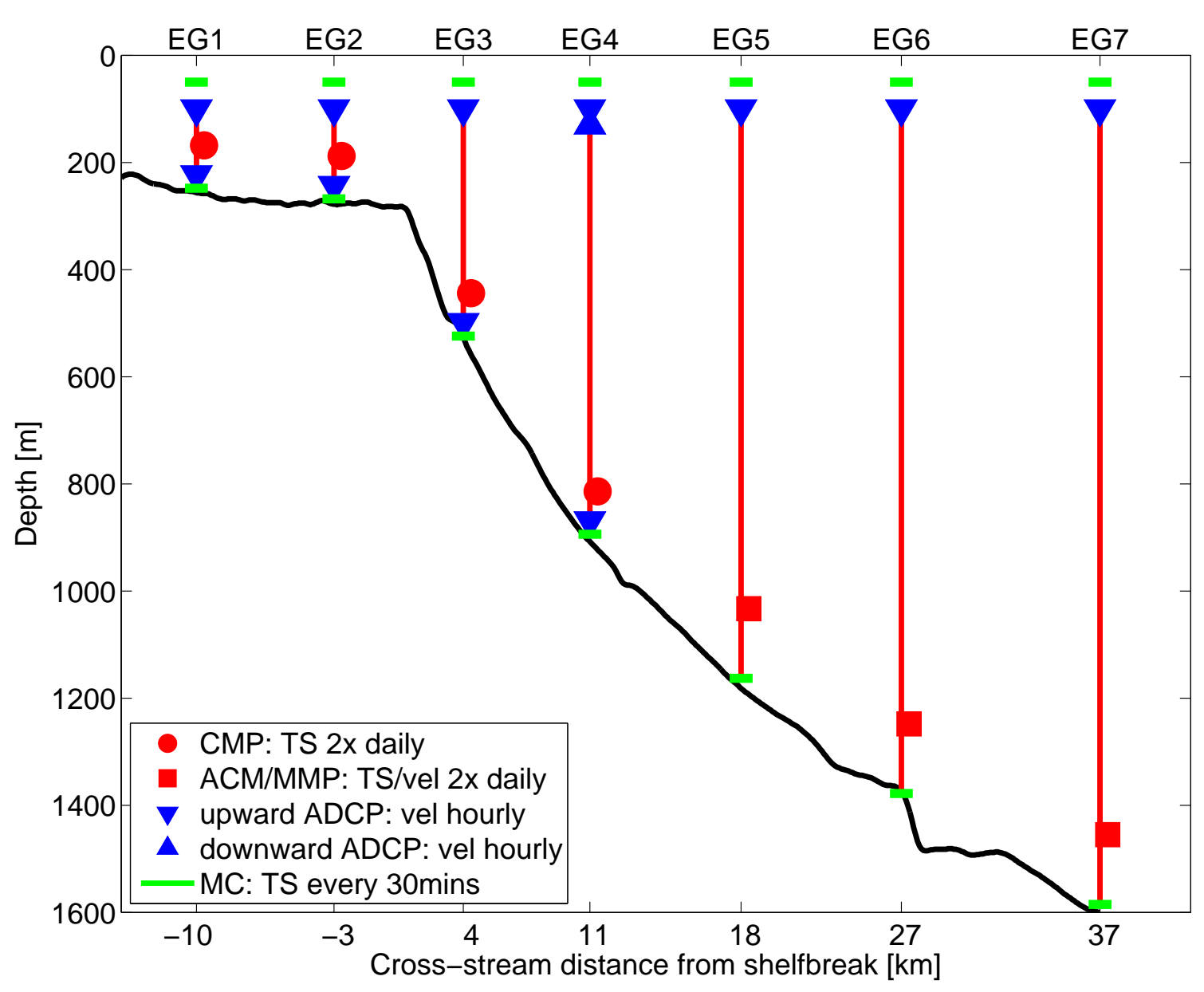

Figure 3-5: Sideview of the East Greenland mooring array. The different instruments and their sampling schedules are explained in the legend. The CMPs and MMPs crawled along the part of the mooring wire that is shown in red here. The bottom depth along the mooring line is shown in black. The acronyms are as follows: CMP: Coastal Moored Profiler, ACM: Acoustic Current Meter, MMP: McLane Moored Profiler, ADCP: Acoustic Doppler Current Profiler, MC: Microcat. 
pressure, as well as velocity (only on the MMPs). MMPs are described in Morrison et al. (2000) and CMPs are a simplified version built in-house at WHOI that lack the velocity measuring capability. Velocity was also measured hourly with upward looking ADCPs at $100 \mathrm{~m}$ on all of the moorings and upward looking ADCPs near the bottom on moorings EG1-4, with an additional downward looking ADCP on EG4 at $100 \mathrm{~m}$. Half hourly measurements of temperature, conductivity, and pressure were also obtained from microcats near the ocean floor and on a $47 \mathrm{~m}$ long wire extending buoyantly above the steel spheres.

Instrument drift and failure presented some minor complications, while the use of steel spheres and stronger than expected velocities presented a set of more difficult complications. Since the steel spheres contained hard and soft iron, they were both permanently magnetized and also became magnetized in the Earth's magnetic field. The upward looking ADCPs were mounted directly onto the steel spheres and their compasses were therefore contaminated by the spheres' magnetic filed. Theory regarding compasses on steel ships (National Geospatial-Intelligence Agency, 2004) as well as a direct comparison of measured flow directions to measurements below the steel spheres (from ADCPs or MMPs) were used to correct this effect on the measured flow directions from the upward looking ADCPs. The effect was relevant in the sense that before the correction, the mean of the flow direction was shifted by more than $45^{\circ}$ and its standard deviation was less than half as big as the actual standard deviation.

The velocities regularly exceeded $1 \mathrm{~m} / \mathrm{s}$ throughout large parts of the water column, while speeds of $1.5 \mathrm{~m} / \mathrm{s}$ were not uncommon. The resulting horizontal force exerted onto the mooring wires led to blowdowns of the spheres that at times exceeded $500 \mathrm{~m}$. A stronger blowdown is related to stronger flow between the spheres and the bottom. Unfortunately, the shape and direction of the velocity profile is un- 
known and therefore a numerical calibration of the blowdown depth to the columnintegrated flow speed is impossible. During blowdowns, the profilers either were not able to profile at all and returned a point measurement at the location at which the profiler was stuck, or were able to complete only part of the planned vertical profile. Additionally, the pressure sensors on the top microcats went beyond their rated range during blowdowns. The resulting pressure records could be corrected as long as the depth was less than about $520 \mathrm{~m}$. The timeseries of the microcats and the upward looking ADCPs are therefore not at a constant depth as planned. The aluminum tubes providing buoyancy for the top microcats broke on all the moorings during blowdown events sometime during the deployment period. Consequently, the remaining portions of the microcat records were $47 \mathrm{~m}$ below the spheres rather than $47 \mathrm{~m}$ above. In addition, the bottom mounted ADCPs tilted beyond the range of their tilt sensors $\left(\approx 23^{\circ}\right)$ during the larger blowdown events, causing gaps in the velocity data. Vertical velocities measured by the ADCPs are smaller than the noise level and therefore not meaningful.

Tidal constituents $\mathrm{O}_{1}$ (25.82 hours), $\mathrm{K}_{1}$ (23.93 hours), $\mathrm{M}_{2}$ (12.42 hours), and $\mathrm{S}_{2}$ (12.00 hours) with combined amplitudes of up to $25 \%$ of the standard deviation of the full velocity records were removed from the records at EG1-3; tidal amplitudes at EG4 were less than $0.03 \mathrm{~m} / \mathrm{s}$ and less than $0.01 \mathrm{~m} / \mathrm{s}$ at EG5-7 and therefore negligible compared to the typical variability in the records. The principal axis directions at different moorings and different depths vary by up to $10^{\circ}$. We chose to consider one consistent alongstream direction based on the principal axis of all the mooring data. This was applied to the whole array in order not to introduce local convergences. The mean alongstream direction of $-160^{\circ} \mathrm{T}$ (i.e. west-southwestward) also coincides with the average direction of the shelfbreak topography in the study region. Subsequently, we will refer to this west-southwestward direction as positive alongstream, and to the 
south-southeastward direction (i.e. downslope) as positive cross-stream.

The final working data set is made up of timeseries of potential temperature, salinity, potential density, and alongstream and cross-stream velocity that are intermittent, but explicitly defined in space and time. A detailed assessment of the most likely and maximum errors of these quantities is given in Appendix A.

\subsubsection{Synoptic CTD Data}

Synoptic CTD data are also used in the study. In particular, $R / V$ Oceanus voyage 369 collected a number of high-resolution CTD sections on the East Greenland shelf and slope perpendicular to the shelfbreak in August 2001. Here we use a CTD section $250 \mathrm{~km}$ downstream of the mooring array that crosses the shelfbreak at $63^{\circ} 49^{\prime} \mathrm{N}$, $36^{\circ} 51^{\prime} \mathrm{W}$ (see Figure 3-1). It is the CTD section closest to the array that shows a DSOW cyclone. The occupation of the part of the section on the shelf took 9 hours on August 6, 2001, and the part on the slope took 20 hours on August 7. Pickart et al. (2005a) describe instrument calibration, processing, and accuracy of the CTD sections occupied during the cruise.

\subsubsection{Satellite SST data}

Two satellite sea surface temperature (SST) images are used in this study. They are Level 2 products of the MODIS Aqua satellite on September 24th, 2007. The first image is from 0430UTC while the second is a composite from 0605UTC and 0610UTC. MODIS is the Earth Observing System (EOS) Moderate Resolution Imaging Spectrometer. The processing steps for the Level 2 product are documented in Brown and Minnett (1999) and the data were downloaded from http://www.nodc.noaa.gov/ SatelliteData/ghrsst/accessdata.html. 
The spatial resolution of the infrared satellite measurements at nadir is $1 \mathrm{~km}$ and the Level 2 product takes advantage of this full resolution without smoothing in space and time. Since infrared radiation does not penetrate clouds, and the study region is generally very cloudy, these two images are the only ones available within two days of their acquisition time. The Level 2 product contains a preliminary bad data detection flag. This captures both possible clouds and data pixels with temperatures strongly different from their surrounding pixels. Unfortunately, this rejects the pixels in the vicinity of the high SST gradient region associated with the East Greenland Current/Irminger Current surface front. Since this is the region of particular interest, and the change in $\mathrm{SST}$ of $\approx 8^{\circ} \mathrm{C}$ (from $\approx 0-2^{\circ} \mathrm{C}$ in the EGC to $\approx 8-10^{\circ} \mathrm{C}$ in the $\mathrm{IC}$ ) is real, we devised an adjusted cloud cover rejection routine as follows. Cloud tops are much colder than $-2^{\circ} \mathrm{C}$, the coldest reasonable ice-free SST. Hence, scattered clouds result in spots of super cold satellite-measured temperatures surrounded by a region of transitional temperatures where both sea-surface and cloud-top emitted infrared radiation reaches the spectrometer. Therefore, regions of continuous or spotty super cool temperatures were manually removed leaving mostly continuous regions of temperatures in the $-2-12^{\circ} \mathrm{C}$ range, reasonable for ice-free $\mathrm{SST}$ in the study region. No further adjustments than removal of entire regions of the domain with questionable data were applied.

\subsection{Mean Velocity on the Slope and its Dominant Variability}

Before presenting the case study of three Denmark Strait cyclones, we first discuss aspects of the mean flow and variability at a location on the mid continental slope. 
This provides valuable context for the synoptic variability associated with the passage of the eddies. As mentioned in Section 3.3, the mooring blowdown resulted in non-random data dropout with larger flow speeds systematically missing from the records. Therefore, a mean of the available data is an underestimate of the true mean. However, mooring EG4, at a bottom depth of $894 \mathrm{~m}$ (Figure 3-5) had the downward looking ADCP below the sphere which means that velocities were measured in the middle of the water column even during blowdowns. The upper water column above $250 \mathrm{~m}$ and the lower water column below $670 \mathrm{~m}$ are not covered during all of the blowdowns, but between $260 \mathrm{~m}$ and $660 \mathrm{~m}$ more then $90 \%$ (>97\% between $340 \mathrm{~m}$ and $560 \mathrm{~m}$ ) of the planned hourly measurements were obtained. A linear interpolation in time was used to replace the remaining small percentage of missing data to obtain a continuous timeseries.

Figure 3-6 shows the mean, standard deviation, and standard error (at 67\% confidence level) of the alongstream and cross-stream velocities at mooring EG4 during all times (with and without DSOW cyclones). The mean flow at two depth levels is also shown with current vectors in Figure 3-2. Due to the year-long record length and the relatively short auto-correlation time scale of about 20 hours, the standard errors are more than an order of magnitude smaller than the standard deviations and hence the means are statistically different from zero at all depths. It can be seen that the mean alongstream flow increases from around $0.3 \mathrm{~m} / \mathrm{s}$ to around $0.5 \mathrm{~m} / \mathrm{s}$ between $300 \mathrm{~m}$ and $700 \mathrm{~m}$. The Spill Jet shown by Pickart et al. (2005a), Brearley et al. (2012), and Magaldi et al. (2011) also displays such a bottom intensified flow, hence this year-long mean record on the East Greenland slope is consistent with the Spill Jet paradigm. To emphasize this point, we reproduce the mean velocity section of Magaldi et al. (2011) in Figure 3-7. It can be seen that mooring EG4 is in the model simulated Spill Jet and that the amplitude as well as the increase in alongstream 


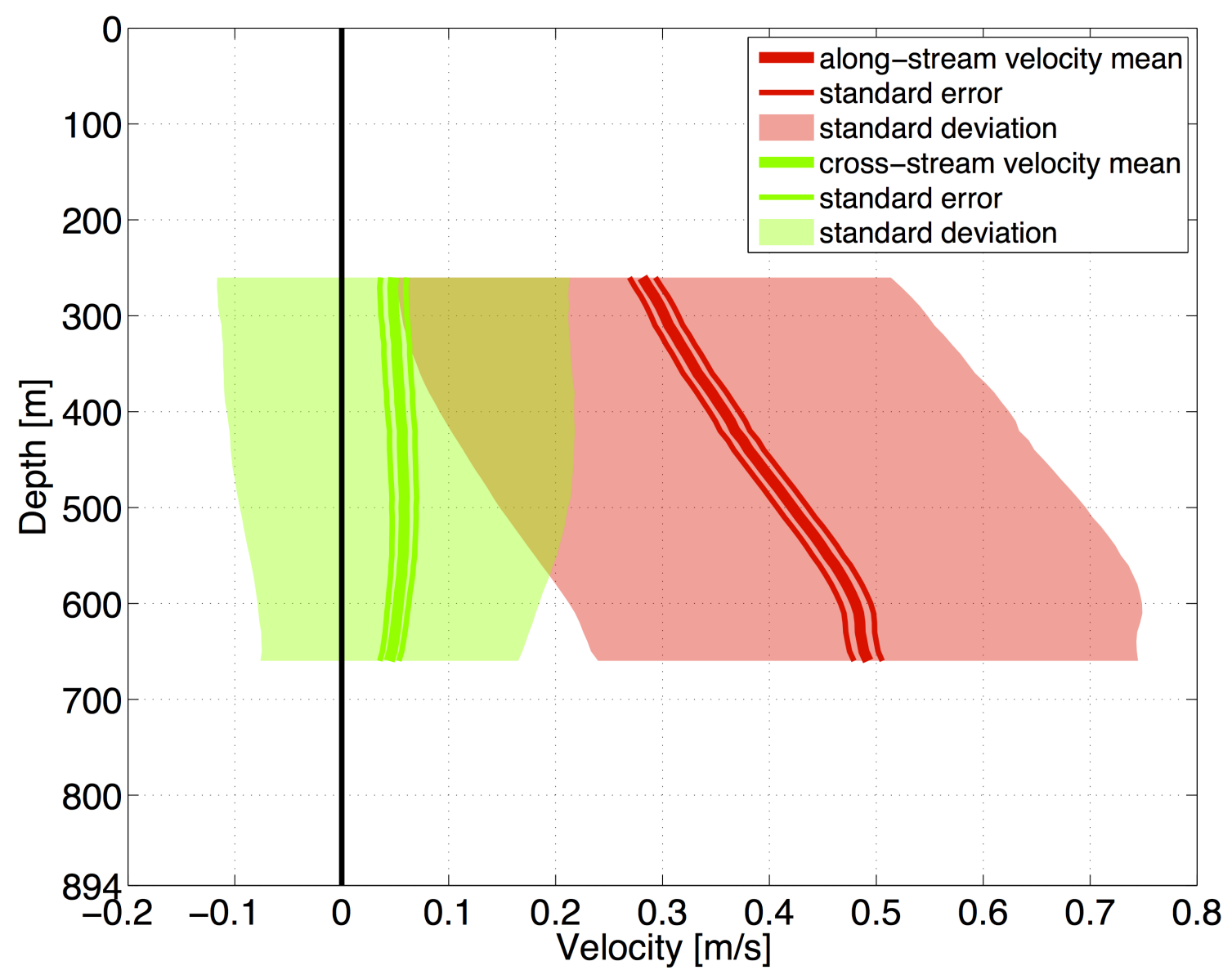

Figure 3-6: Mean, standard error (at 67\% confidence level), and standard deviation of the velocity at EG4. Alongstream flow is shown in red and cross-stream flow in green. The water depth at the mooring is $894 \mathrm{~m}$. Statistics are presented only at depths where more than $90 \%$ of the hourly measurements between 05-Sep-2007 and 05-Sep-2008 were obtained. The standard deviation is smaller than its mean for the alongstream velocity, while it is larger than the mean for the cross-stream velocity. Due to the length of the record, the standard error is more than an order of magnitude smaller than the standard deviation such that both the alongstream and the crossstream mean velocities are statistically significantly different from zero at all water depths. 
velocity with depth is consistent with the mean velocity of Magaldi et al. (2011). The mean absolute geostrophic velocity from four CTD sections presented by Brearley et al. (2012) (their Figure 5) shows the same increase with depth, but exhibits amplitudes up to $1.4 \mathrm{~m} / \mathrm{s}$ which is more than twice as large as the mean found from the mooring array or the numerical model of Magaldi et al. (2011). However, the system is significantly ageostrophic and the geostrophic calculation Brearley et al. (presented by 2012) therefore (Subsection 3.7.1) overestimates the true fluid velocities reported by Magaldi et al. (2011) and shown here (Figure 3-6). The standard deviation of the velocity at EG4 (Figure 3-6) is of the same order of magnitude as, but smaller than the mean. This indicates downstream flow during the majority of the time although flow-reversals also occur on occasion.

The mean cross-stream flow is positive with little vertical variation. While this is indicative of a mean offshore flow of water, it should be noted that the strength of the variability is quite large. We note also that the strong alongstream velocities make the actual mean value of the cross-stream velocity strongly dependent on the angle by which the alongstream direction is defined. As discussed in Section 3.3, this determination may at least locally have an error of up to $10^{\circ}$. Overall, we interpret the mean cross-stream flow as being predominantly due to the offshore transport feeding the Spill Jet with a contribution from the down-slope motion of DSOW in this region. However, the cross-stream flow is clearly episodic in nature.

The bottom density record at mooring EG4 measured a mean potential density of $27.75 \mathrm{~kg} / \mathrm{m}^{3}$. Only about $16 \%$ of the time was the density greater than $27.8 \mathrm{~kg} / \mathrm{m}^{3}$. Consistent with Brearley et al. (2012), this suggests that the region mostly occupied by DSOW is deeper than $900 \mathrm{~m}$. DSOW is present at these depths of around $900 \mathrm{~m}$, but most of the time the water is less dense. The mean alongstream velocities measured at EG4 are more than twice as big as the mean alongstream velocity $10 \mathrm{~km}$ 


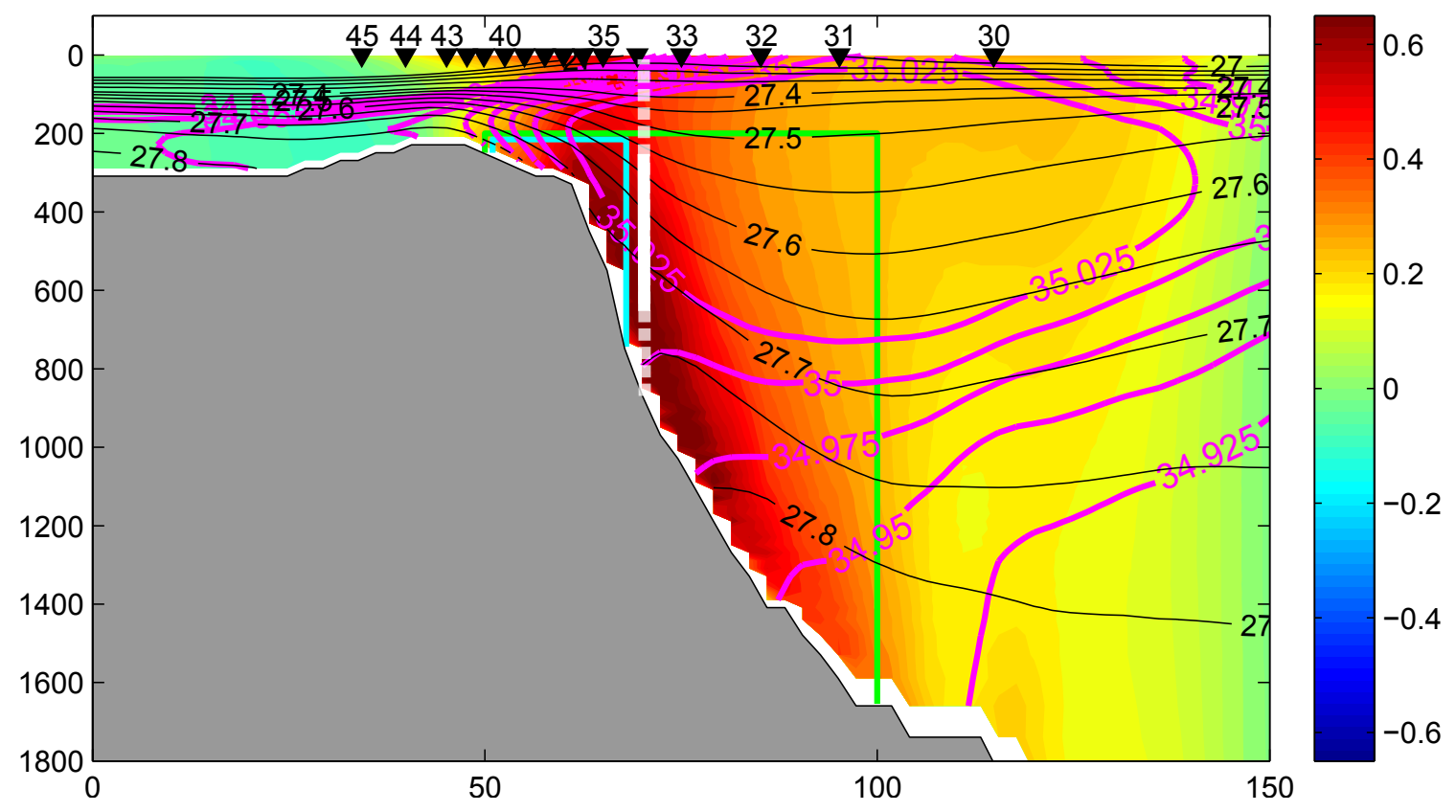

Figure 3-7: Mean velocity (color in $\mathrm{m} / \mathrm{s}$ ), potential density (black contours in $\mathrm{kg} / \mathrm{m}^{3}$ ), and salinity (magenta contours) at the Pickart et al. (2005a) Spill Jet section and mooring array line from the numerical model of Magaldi et al. (2011). The location of mooring EG4 in $894 \mathrm{~m}$ water depth near $70 \mathrm{~km}$ cross-stream distance is shown for reference. The solid white line indicates the region of robust mooring velocity estimates while the dashed white line indicates partial coverage. The figure has been adapted from Magaldi et al. (2011). 
inshore of the shelfbreak reported at EG1 by Harden et al. (2012). On the shelf, the velocity veered strongly offshore with depth reaching offshore velocities of $0.15 \mathrm{~m} / \mathrm{s}$ in the mean at $232 \mathrm{~m}$. Harden et al. (2012) interpreted this as the velocities on the shelf leading to spilling of dense water. The situation at EG4 is different. Smaller cross-stream velocities occurs over a greater vertical distance leading to comparable offshore volume transports. As the spilled water adjusts near the bottom, its alongstream velocity increases, possibly explaining the bottom intensification of the alongstream flow at EG4.

In order to assess the barotropic part of the variability, Figure 3-8 presents autocorrelations of the depth-mean alongstream and cross-stream velocity at EG4. The auto-correlation of the cross-stream velocity has a zero-crossing at 7 hours and the strongest anti-correlation at 14 hours. This contrasts with the longer auto-correlation timescale of the alongstream velocity of 21 hours for the zero-crossing and 32 hours for the minimum correlation. The cross-correlation of the alongstream and crossstream velocities has two significant local extrema with a positive correlation of 0.3 at a positive lag of 10 hours and a negative correlation of -0.2 at a negative lag of 7 hours. Note that these lags are similar to and shorter than the auto-correlation time scale of the cross-stream velocity. This means that positive (offshore) cross-stream flow leads the positive (downstream) alongstream flow by 10 hours. Also, positive (downstream) alongstream flow leads negative (onshore) cross-stream flow by 7 hours. As such the progression is offshore flow followed 10 hours later by downstream flow followed 7 hours later by onshore flow. As suggested by Harden et al. (2012) and as discussed below in Section 3.9, this is the statistically significant manifestation of the passage of Denmark Strait Overflow Water cyclones. As a cyclone translates toward the mooring array, EG4 will first detect the leading edge associated with a strong offshore component due to the azimuthal (rotational) velocity component of the 


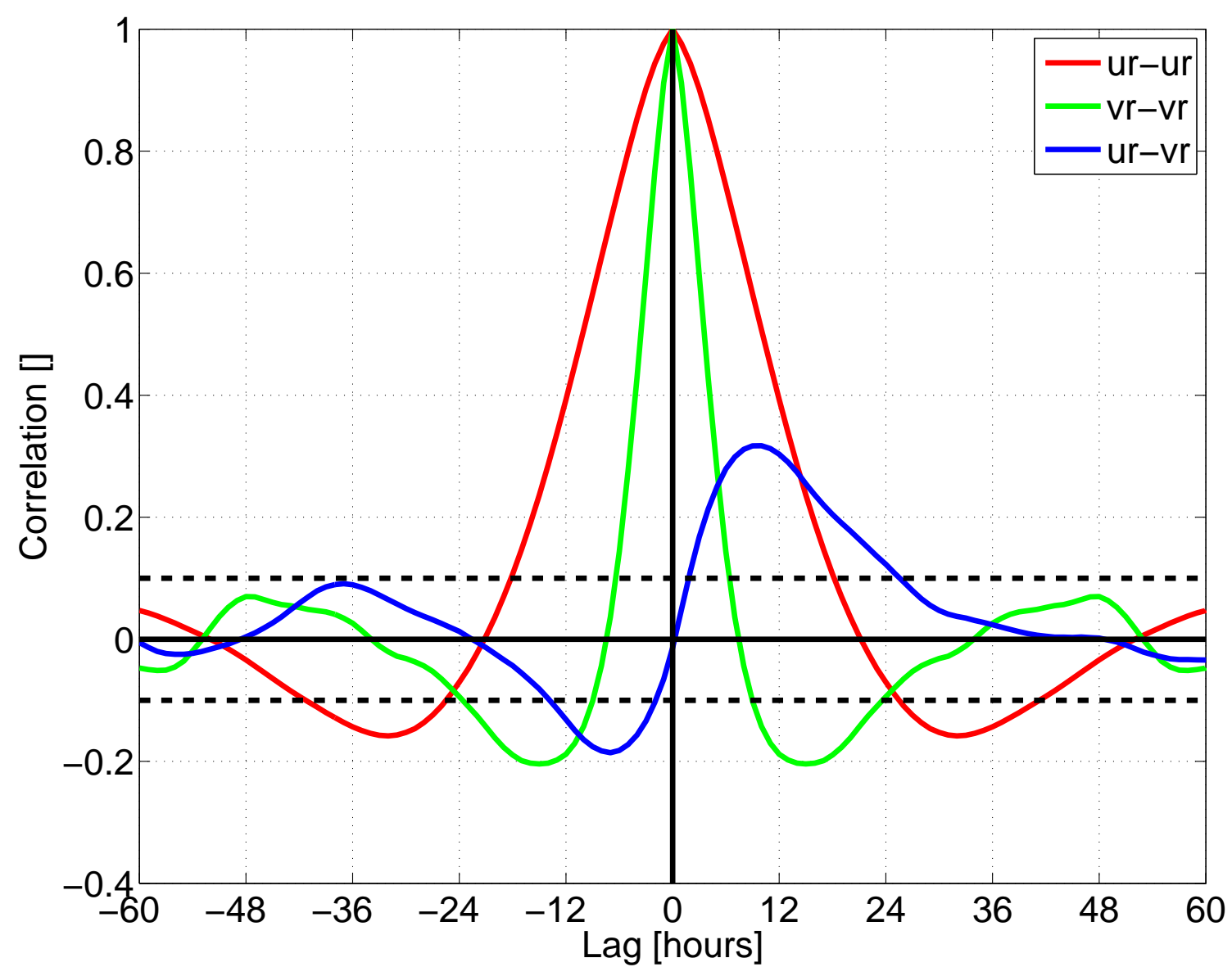

Figure 3-8: Auto-correlation of depth-mean (260-660 m) alongstream (red) and crossstream (green) EG4 velocity timeseries as well as cross-correlation (blue) of the two timeseries. The black lines at +0.1 and -0.1 indicate the noise level of the correlation at lags greater than 4 days. Correlations inside of these bounds are statistically not different from zero. Statistically, a positive alongstream (downstream) anomaly is preceded 10 hours earlier by a positive cross-stream (offshore) anomaly and succeeded 7 hours later by a negative cross-stream (onshore) anomaly. 
cyclone. Then the alongstream velocity associated with the downstream translation of the eddy at a speed higher than the mean flow dominates during the central time of eddy passage. Finally, the mooring measures the trailing edge of the eddy associated with onshore flow. The bidirectional (onshore and offshore) nature of the cross-stream velocities associated with the eddy results in the auto-correlation time of the crossstream velocity to be shorter than the typical duration of an eddy passage and leads to the negative side-lobes at 15 hours when the alongstream velocity is still positively auto-correlated. The fact that the alongstream velocity is positive during an entire eddy passage leads to the longer auto-correlation time scale comparable to the eddy passage time.

\subsection{Range of Observed Temperatures and Salinities}

The calibrated temperature and salinity data from the mooring array provides a statistically robust estimate of the water mass presence along the East Greenland slope during the deployment in 2007-2008. The two inner most moorings occasionally recorded cold (down to the freezing temperature) and fresh (down to 33.4) Polar Surface Water (Sutherland and Pickart, 2008) that correspondingly has a very low density $\left(\approx 26.8 \mathrm{~kg} / \mathrm{m}^{3}\right)$. The deepest measurements in the mooring record of this water type were at $140 \mathrm{~m}$ depth which is more than $100 \mathrm{~m}$ above the bottom on the shelf. Excluding this near-surface water type and focusing on processes happening below $100 \mathrm{~m}$ depth collapses all the measurements onto the T-S plot in Figure 3-9. Here we consider all the available individual measurements without accounting for when they were recorded in space or time.

Two endmembers are clearly defined from this T-S plot: the cold and intermediate salinity Denmark Strait Overflow Water and the warm and salty Irminger Water. The 


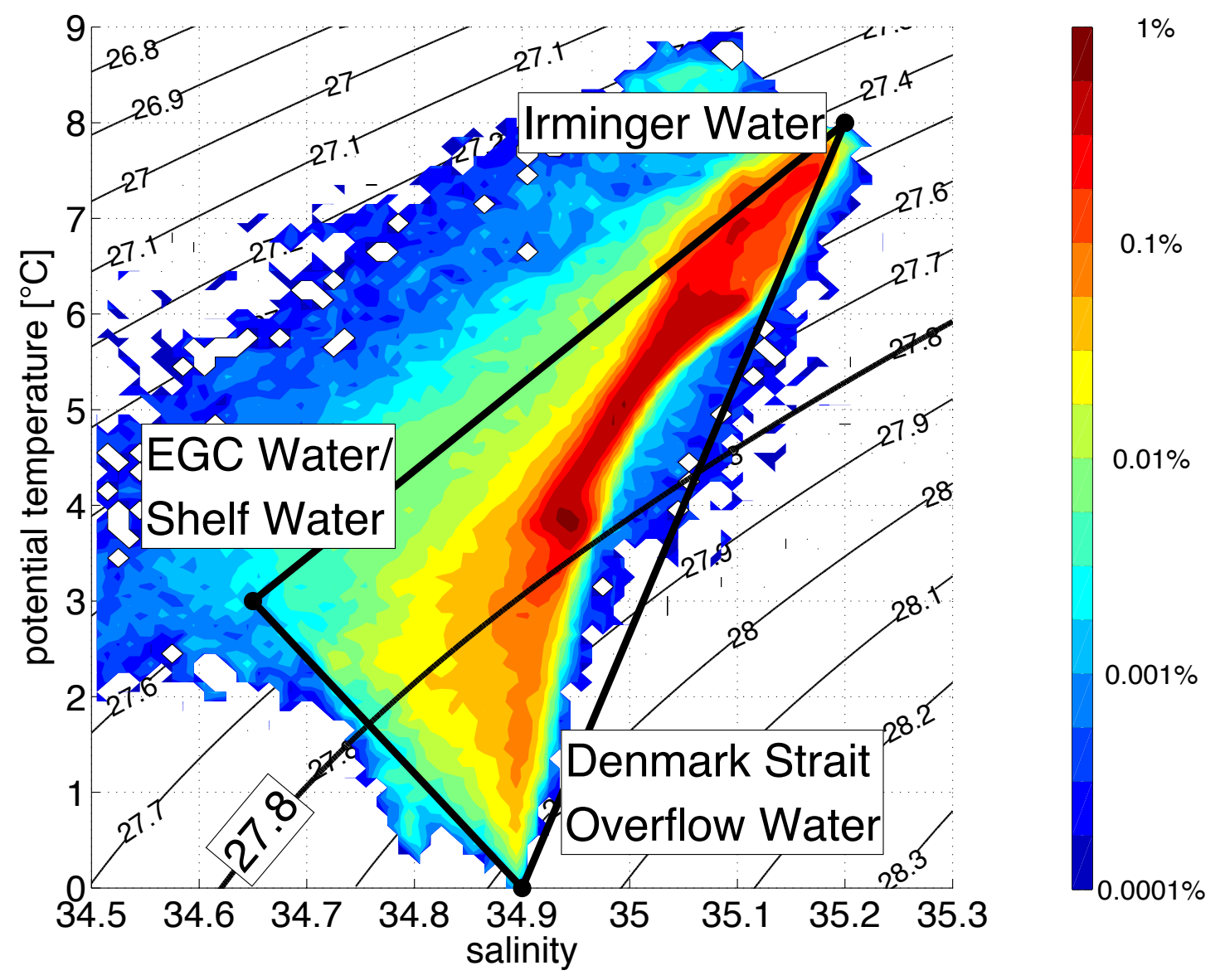

Figure 3-9: Frequency plot of potential temperature versus salinity for all measurements obtained by the mooring array below $100 \mathrm{~m}$ water depth. The width of T-S boxes are 0.01 salinity units by $0.1^{\circ} \mathrm{C}$. Note that the color scale is logarithmic. The three major endmembers are highlighted as well as direct mixing lines between them. Table 3.1 lists their properties. The classical density cut-off for Denmark Strait Overflow Water of 27.8 is also shown.

Table 3.1: T-S characteristics of the three endmembers identified from all measurements obtained by the mooring array below $100 \mathrm{~m}$ water depth. Note that these endmembers are solely based upon this mooring data set (as shown in Figure 3-9).

\begin{tabular}{|c|c|c|c|}
\hline Endmember name & pot. temperature $\left[{ }^{\circ} \mathrm{C}\right]$ & salinity [ ] & pot. density $\left[\mathrm{kg} / \mathrm{m}^{3}\right]$ \\
\hline \hline Irminger Water & 8 & 35.20 & 27.43 \\
\hline EGC Water / Shelf Water & 3 & 34.65 & 27.61 \\
\hline Denmark Strait Overflow Water & 0 & 34.90 & 28.03 \\
\hline
\end{tabular}


third component is fresh with intermediate temperature, but is less well defined and is likely a combination of water in the East Greenland Current and water on the shelf. The temperature and salinity values as well as the corresponding density identified for the three endmembers are given in Table 3.1. It should be noted that few of the observations fall outside a direct mixing combination of these sources. Therefore, most of the observations can uniquely be described as a combination of the three source water masses and this can be used to identify the level of entrainment.

Essentially no water colder than $0^{\circ} \mathrm{C}$ was measured and the salinity of the coldest water is 34.9. This is in contrast to measurements near the Denmark Strait sill that indicate water as cold as $-0.5^{\circ} \mathrm{C}$ with salinities around 34.86 in 2007-2008 (Jochumsen et al., 2012). In other words, there is always at least some entrainment into the overflow water between Denmark Strait and the mooring array. The traditional bound for DSOW of a potential density of $27.8 \mathrm{~kg} / \mathrm{m}^{3}$ (compare Dickson and Brown, 1994) is also shown in Figure 3-9, indicating that a significant portion of the water measured by the array is DSOW. The near-bottom record at the most seaward mooring in $1585 \mathrm{~m}$ water depth in fact never detected water lighter than $27.8 \mathrm{~kg} / \mathrm{m}^{3}$.

\subsection{Characteristics of the EGC/IC Front}

Very cold and fresh surface water of the East Greenland Current resides on the East Greenland shelf. The EGC water has temperatures around $0-2^{\circ} \mathrm{C}$ with salinities of $\approx 34$. This leads to a very strong property contrast with the offshore Irminger Sea surface waters that have a temperature of $>8^{\circ} \mathrm{C}$ and a salinity of $>35$. The horizontal density gradient by geostrophy is associated with a surface intensified southwestward flowing current: the East Greenland/Irminger Current.

In Section 3.9, we will focus on a case study over a five day period during low 

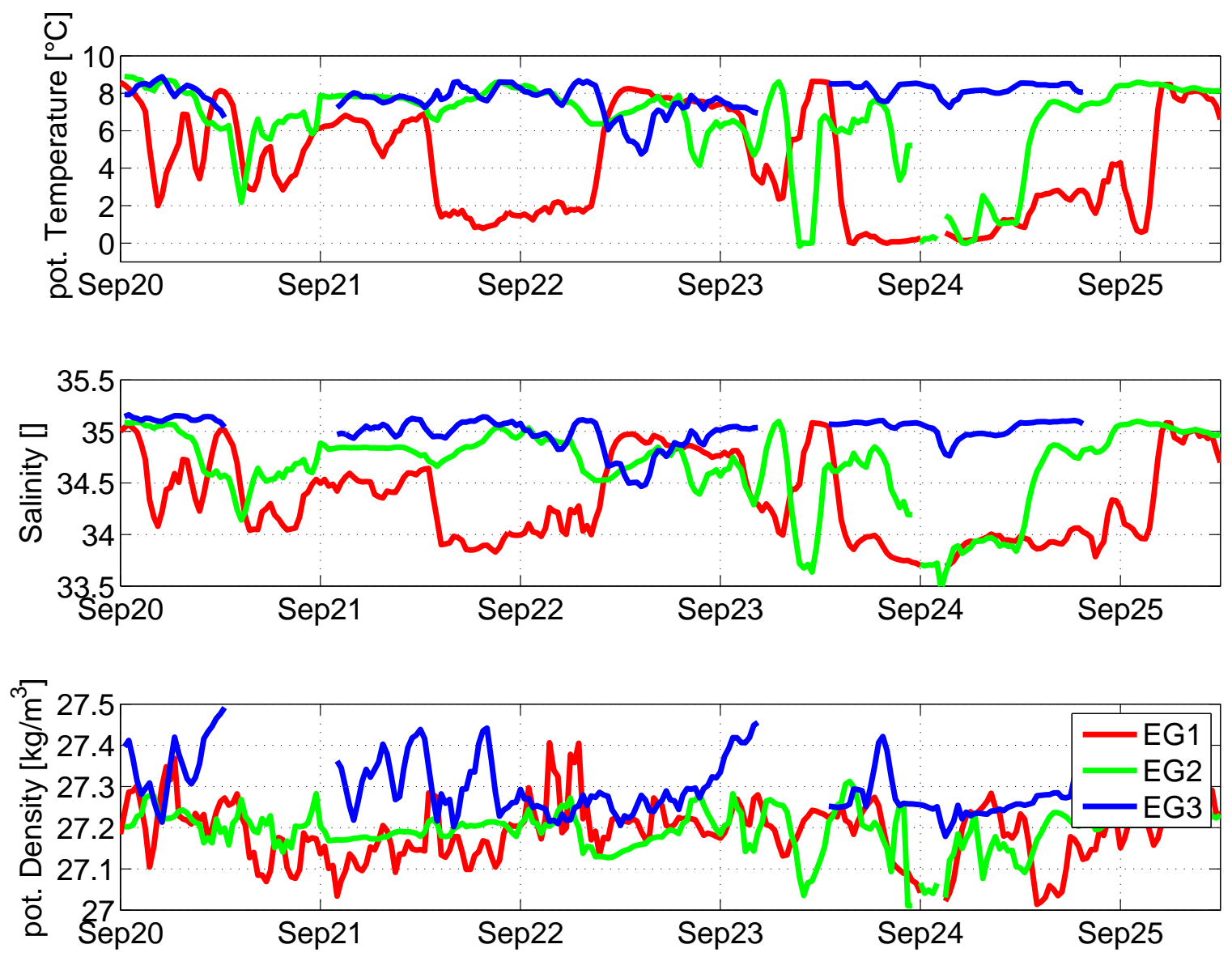

Figure 3-10: Timeseries of potential temperature, salinity, and potential density of the top microcats of the moorings EG1-3 in 2007. The depth of the measurements is 50-80 $\mathrm{m}$ for EG1 and EG2 and 80-120 m for EG3. Gaps in the EG3 record are due to the mooring being blown down below $120 \mathrm{~m}$. 
wind conditions in late September 2007. We will describe the structure of DSOW cyclones present during that time period. As an example of the general behavior of the EGC/IC front and in order to be able to refer back to its particular behavior during that time period in Section 3.9, we show in Figure 3-10 the timeseries recorded at the top microcats of the three most shoreward moorings during the case study timeperiod. These measurements were obtained between $50 \mathrm{~m}$ and $120 \mathrm{~m}$ depth and the observed variability is mainly due to horizontal property gradients being advected past the moorings rather than due to the moorings moving vertically and sampling vertical property gradients. It can be seen that for some time, only the most shoreward mooring (EG1) is located in cold and fresh water. During other times (e.g. the first half of September 24th), both the first and second mooring reside in cold, fresh water. This can be interpreted as horizontal shifts in the position of the EGC/IC front. If the moorings detect cold, fresh water, they are on the EGC side of the front. These frontal motions can be caused by meanders, eddies, and frontal instabilities. Figure 3-10 also shows the potential density. Since the temperature/salinity variability is largely density compensated, the variability of the density is mainly determined by processes other than lateral shifts of the front.

Considering the year-long record yields hydrographic records around $150 \mathrm{~m}$ depth, based on an endmember decomposition using the three water masses in Table 3.1, mooring EG1 (10 km inshore of the shelfbreak) was in EGC water (defined as the EGC endmember exceeding $50 \%$ volume concentration) for more than $50 \%$ of the year-long deployment. Mooring EG2 (3 km inshore of the shelfbreak) was in IC water for $65 \%$ of the time. $10 \mathrm{~km}$ offshore of the shelfbreak, mooring EG4 was in EGC water for only $10 \%$ of the time. Consistent with previous studies (e.g. Bruce, 1995), this indicates that the EGC/IC front on average is in the vicinity of the shelfbreak.

The shape of the EGC/IC front can also be seen in Figure 3-3 and in Figure 3- 
13 (discussed in Subsection 3.9.1) that shows a snapshot of sea surface temperature along the East Greenland shelf. The cold onshore side is the EGC water and the warm offshore side is Irminger Water. The images reveal that the front is contorted. Two of the contortions in Figure 3-13 may be associated with DSOW cyclones.

\subsection{Theoretical Considerations Regarding Eddies on a Slope}

\subsubsection{Gradient Wind Balance}

Finite amplitude eddies are flow structures that have a core and a swirling motion around the center. Atmospheric hurricanes are well-known and well-studied examples of this. Depending on the distance from the core, different dominant forces balance. The three major forces are:

1. Pressure gradient force

2. Coriolis force

3. Centrifugal acceleration (related to the curvature of the trajectory)

There are two limits. At large radii, the centrifugal acceleration is smaller than the other two forces and the pressure gradient force balances the Coriolis force. This is the geostrophic balance and the azimuthal velocity decreases proportional to the inverse of the radius from the vortex center. At small radii, the Coriolis force may be small compared to the other forces and the pressure gradient force is balanced by the centrifugal acceleration. This is the cyclostrophic balance. If the flow is in solid body rotation, then the azimuthal velocity increases proportional to the radius from the 
vortex center. The situation where all three forces are of similar order is the gradient wind balance (e.g. Marshall and Plumb, 2007; van Heijst, 2010).

If the gradient flow is fast, the Rossby number can reach unity, in which case the velocities will differ from what they would be for geostrophically balanced flow $(R o<<1)$. We seek to understand by how much they differ. The force balance between centrifugal force, Coriolis force, and pressure gradient force in radial coordinates is:

$$
\frac{v_{a}^{2}}{r}+f v_{a}=\frac{1}{\rho_{0}} \frac{\partial p}{\partial r}
$$

Here $v_{a}$ is the azimuthal velocity and $r$ is the outward radial coordinate. At low Rossby numbers, the right hand side is the geostrophic velocity $v_{G}$ times $f$ yielding:

$$
\frac{v_{a}^{2}}{r}+f v_{a}=f v_{G}
$$

Evaluating this at a typical radius $R$ :

$$
\frac{v_{a}}{v_{G}} \frac{v_{a}}{R f}+\frac{v_{a}}{v_{G}}-1=0
$$

Here we identify the angular frequency $\omega=\frac{v_{a}}{R}$ (azimuthal velocity divided by the radius) divided by the Coriolis frequency $f$ as the Rossby number $\epsilon^{\prime}=\frac{v_{a}}{R f}$. This yields:

$$
\begin{aligned}
\frac{v_{a}}{v_{G}} \epsilon^{\prime}+\frac{v_{a}}{v_{G}}-1 & =0 \\
\frac{v_{a}}{v_{G}} & =\frac{1}{1+\epsilon^{\prime}}
\end{aligned}
$$


In the limit of small Rossby numbers, eq. (3.5) shows that the azimuthal velocity is equal to the geostrophic velocity, i.e. the flow is in geostrophic balance as expected. However, as the flow becomes more ageostrophic (and the Rossby number increases), the azimuthal velocity becomes smaller than the geostrophic velocity. At Rossby numbers of order unity $\left(\epsilon^{\prime}=1\right)$, it follows that:

$$
\frac{v_{a}}{v_{G}}=\frac{1}{2} \text { for } \epsilon^{\prime}=1
$$

This shows that at $R o \approx 1$, the actual peak azimuthal velocity is significantly weaker than what would be expected from geostrophic balance. In fact, it is reduced about half of the geostrophic velocity. As pointed out in Section 3.4, this may explain the difference of a factor of approximately two between the velocities reported in Brearley et al. (2012) and Magaldi et al. (2011).

The radius at which the azimuthal velocity is maximal can be used as one metric to define the horizontal extent of an eddy. This radius can be found from a plot of radius versus azimuthal velocity. At small Rossby numbers (weak velocities) solid body rotation (at small radii) and geostrophic balance (at large radii) are expected. Then fitting can be applied to the $v_{a}(r)$ curve with a linear fit at small radii and an inverse fit at large radii. The radius of the eddy would be where the two fits cross. This technique has been used in several studies (e.g. Timmermans et al., 2008).

Other metrics for eddy size might include the radius at which the azimuthal velocity has fallen off by an order of magnitude compared to its maximum value thereby indicating that the influence of the eddy on the velocity field is small.

We estimate the distance where the Rossby number is 1 for typical scales found in the mooring array data as shown later. Here we simply establish the order of magnitude of the size of an eddy. For an azimuthal velocity of $0.5 \mathrm{~m} / \mathrm{s}$, the radius 
becomes:

$$
R=\frac{v_{a}}{f \epsilon}=\frac{0.5 \mathrm{~m} / \mathrm{s}}{1.3 * 10^{-4} \mathrm{~s}^{-1} * 1} \approx 4 \mathrm{~km}
$$

If the advective alongstream flow is assumed to be $0.75 \mathrm{~m} / \mathrm{s}$ (a value that is common during the presence of DSOW cyclones as shown in Subsection 3.9.3 below), then a feature will have been advected by $4 \mathrm{~km}$ in a time of less than 2 hours. So, in this parameter range, if an eddy center passes right over a stationary instrument, then the instrument would record the region of maximum column-integrated velocity (eddy radius where $R o \approx 1$ ) at one time and about 2 hours later it would record the center of the vortex where the azimuthal velocity vanishes leaving only the advective velocity of the eddy. As shown in Section 3.4 and as we will show later, this time scale of only a few hours for the passage of a vortex is quite consistent with what is found from the data in the mooring array even though $R o=1$ is an overestimate of the eddy strength.

\subsubsection{Eddy Structure Predicted by Spall and Price (1998)}

From their simple vortex stretching mechanism and associated numerical model, Spall and Price (1998) make some predictions of what the flow along the pathway of the outflow water should look like. We briefly review the predictions here as our case study presented below will verify some of the predicted features. Figure 3-11 shows the velocities in the middle and lower layer of the numerical model of Spall and Price (1998).

The flow field can be interpreted as the superposition of a mean advective southward motion along the slope and the velocities associated with the eddies. The eddies that can be seen in the intermediate layer at distances 295, 270, and $225 \mathrm{~km}$ have in common that the downstream velocity is strongly positive on the onshore (left) side 
Middle Layer (AIW)

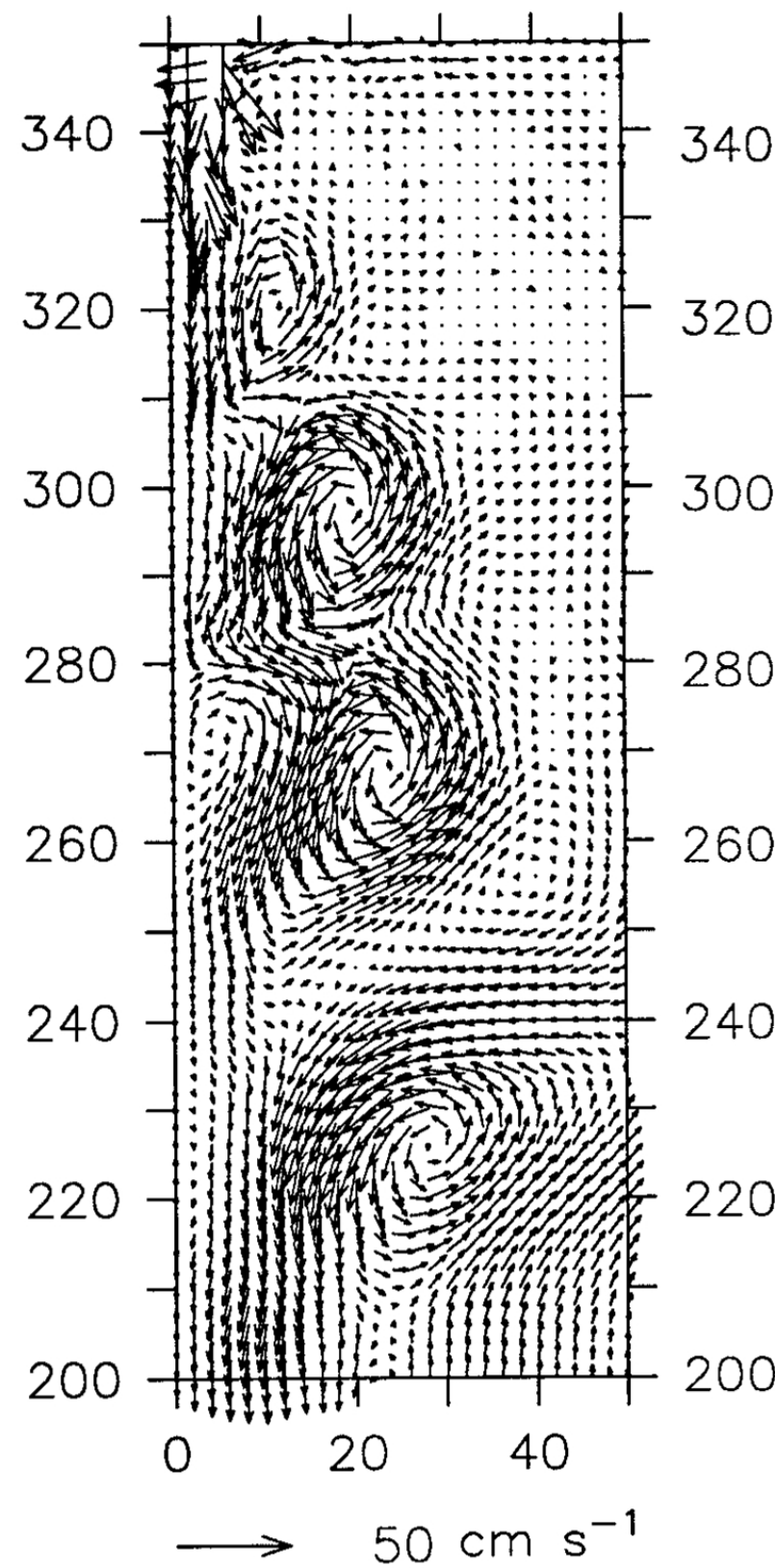

Lower Layer (DSOW)

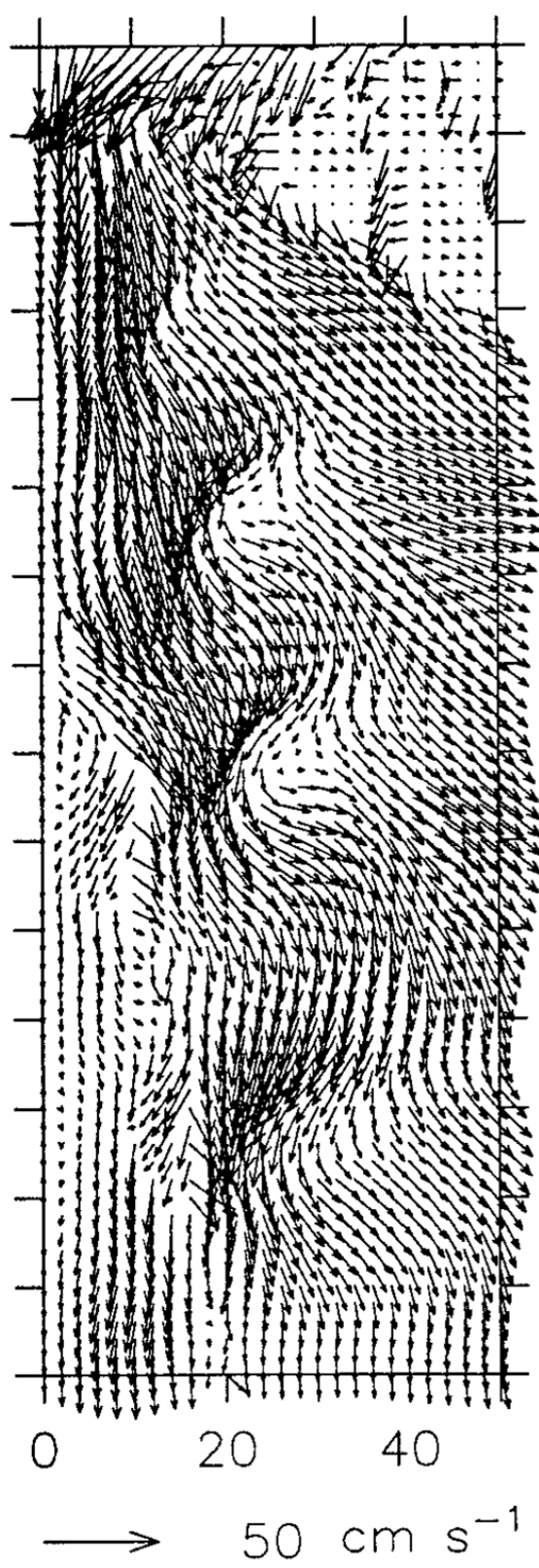

Figure 3-11: Numerical model results of Spall and Price (1998). The velocities in the middle (Arctic Intermediate Water) layer are shown on the left and the velocities in the lower (DSOW) layer are on the right. Figures from Spall and Price (1998). 
of the center of the eddy where the swirl velocity superposes with the relatively slow mean velocity in the intermediate layer. In contrast, the offshore side of the eddies exhibits northward velocities which are a result of the fact that the swirl velocity is stronger than the mean velocity.

The situation is quite different in the lower layer. Since the DSOW has been stretched less, the original sill transport is distributed over a smaller vertical distance than for the AIW layer and therefore the mean velocity in the overflow layer is much stronger. This results in the fact that no poleward velocities are observed in the lower layer. However, the velocities on the inshore side of the eddies are strongly enhanced compared to the mean while they remain small but positive on the offshore side. An overflow layer thickness of more than $200 \mathrm{~m}$ exists in the eddy center, while it is between $50 \mathrm{~m}$ and $100 \mathrm{~m}$ in between the eddies. This means that the intermediate AIW layer is actually thinner by about $100 \mathrm{~m}$ in the eddy center than in the surrounding water.

As such, the predicted water column structure of an eddy is as follows: On the offshore side the lower layer is thicker by $\approx 100 \mathrm{~m}$ with a relatively low stratification due to stronger stretching. Its velocity is small, but equatorward. The transition to the intermediate layer above is abrupt as the velocity veers poleward and the density changes to the AIW properties over a small vertical distance (we note that this small vertical distance may, however, be due to the fact that Spall and Price (1998) used a layer model; in a continuously stratified case, this distance may be much greater). The onshore side exhibits enhanced equatorward flow in both layers. It should, however, be noted that spilling of dense water off the shelf is not included in the model of Spall and Price (1998) and it is therefore expected that the actual structure at the onshore side of DSOW cyclones is more complicated than in the model. 


\subsection{Shipboard Section through a DSOW Cyclone}

The data available from the mooring array helps to confirm the structure of DSOW cyclones, but it is not resolved well enough in space and time to allow the construction of a cross-stream section of the detailed structure of the cyclones.

Four high-resolution CTD sections were occupied across the East Greenland shelf and slope along the Spill Jet section which is where the mooring array of this study was located. As it happened, the presence of DSOW cyclones was not obvious in any of the sections (Brearley et al., 2012). However, a CTD section occupied by $R / V$ Oceanus in 2001 about $250 \mathrm{~km}$ downstream of the Spill Jet section (see Subsection 3.3.2 for a description of the data and Figure 3-1 for its location), did capture and resolve a DSOW cyclone near its center. Figure 3-12 presents this section.

The station spacing near the shelfbreak and the upper slope is $5 \mathrm{~km}$ which is finer than many other such surveys, but still only marginally resolves the pertinent features. In Section 3.9, we show that this is about the size of the radius of DSOW cyclones. Around the center of the cyclone, the station spacing is $\approx 10 \mathrm{~km}$. The velocity in Figure 3-12 is the absolute geostrophic velocity computed from the density field and referenced to de-tided vessel mounted ADCP data (see Pickart et al. (2005a) for details of the processing). As discussed in Subsection 3.7.1, geostrophy likely overestimates the velocities in the large Rossby number cyclone. Important ageostrophic effects are likely present in the system, but the shipboard section cannot measure them. The absolute geostrophic velocity section nonetheless is the best in-situ realization of a DSOW cyclone. Hence, while noting the limitations to the velocity estimates, we present them here for illustrative purposes.

In the center of the eddy the $27.8 \mathrm{~kg} / \mathrm{m}^{3}$ isopycnal is raised by almost $400 \mathrm{~m}$ compared to its depth $30 \mathrm{~km}$ offshore, leading to a bottom DSOW layer of about 


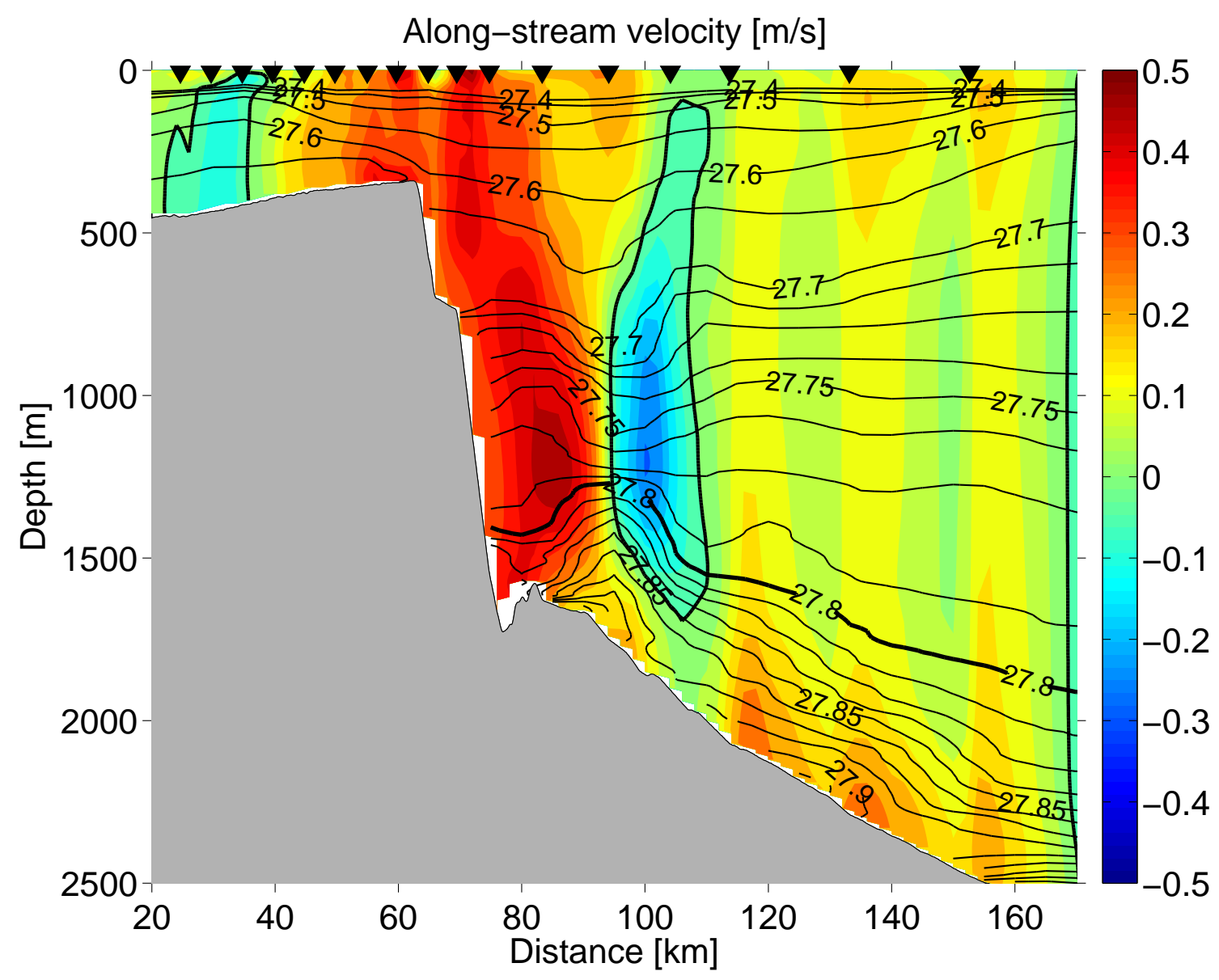

Figure 3-12: Hydrographic section through the center of a DSOW cyclone approximately half way between the mooring array and Cape Farewell. Data are from $R / V$ Oceanus cruise 369 in 2001 and the station locations are indicated by inverted black triangles at the top. Isopycnals are shown in black contours and absolute geostrophic velocity is shown in color. The vessel mounted ADCP reached to less than $500 \mathrm{~m}$ and the absolute geostrophic velocity below that exceeds the actual velocity field in that significant ageostrophic parts of the flow are not included. 
$500 \mathrm{~m}$. Meanwhile, the $27.75 \mathrm{~kg} / \mathrm{m}^{3}$ isopycnal is depressed by about $200 \mathrm{~m}$. This leads to a strong increase in stratification between these two isopycnals. This is related to the remnant highly stratified Arctic Intermediate Water flowing southward out of Denmark Strait that has been stretched since Denmark Strait, but is still more stratified than the ambient Irminger Water. The associated strong isopycnal slopes result in the two relative symmetric (when subtracting the mean and advective alongstream flow) lobes of the azimuthal flow on the order of $0.4 \mathrm{~m} / \mathrm{s}$. Note, however, the limitations of these amplitude estimates. The vertical extent of the lobes is more than $500 \mathrm{~m}$.

The azimuthal flow is superimposed on the EGC/IC mean flow as well as the selfadvection speed that in combination are around $0.1-0.2 \mathrm{~m} / \mathrm{s}$. The DSOW extends into the center of the cyclone and is even advected by the upstream flow on the offshore side. The $27.85 \mathrm{~kg} / \mathrm{m}^{3}$ isopycnal roughly traces the 0 contour of alongstream velocity and there is strong downstream flow of up to $0.25 \mathrm{~m} / \mathrm{s}$ in the dense overflow plume layer below. As a result, the vertical shear on the offshore side is large. A secondary velocity maximum likely due to the EGC/IC exists just offshore of the shelfbreak at a depth of around $400 \mathrm{~m}$. The general flow pattern in the absence of the cyclone in this section therefore is a combination of the EGC/IC and the DSOW flow as well as possibly the Spill Jet. Note that the Spill Jet presence has been investigated at the mooring array site, but so far has not been studied farther downstream.

The continental slope is very steep and drops by $\approx 1000 \mathrm{~m}$ over a horizontal distance of $\approx 10 \mathrm{~km}$ (at $\approx 65-75 \mathrm{~km}$ cross-stream distance), so the bottom slope there is $\alpha \approx 1 / 10$. The vertical extent of the cyclone is also on the order of $1000 \mathrm{~m}$, but its horizontal extent is more than $30 \mathrm{~km}$. This means that the aspect ratio of the cyclone is flatter and the cyclone sees the continental slope as a vertical wall more than the bottom boundary. The stratification exceeds $1.3^{*} 10^{-3} \mathrm{~s}^{-1}$ for the density difference 
of $\approx 0.1 \mathrm{~kg} / \mathrm{m}^{3}$ between about $800 \mathrm{~m}$ and $1400 \mathrm{~m}$. With the Coriolis frequency of $1.3^{*} 10^{-4} \mathrm{~s}^{-1}$, this means that, the Burger number $B u=\alpha \frac{N}{f}$ is $\approx 1$. This Burger number of order unity shows more quantitatively that for the propagation of this cyclone, the continental slope can be considered to approach the situation analogous to a side wall (e.g. Huthnance, 1978).

While Figure 3-12 serves as a nice visualization of the qualitative structure of DSOW cyclones, it should be noted that the location of this observation is different from where the mooring array was located. In particular, the shelf is deeper at the location of the CTD section and the continental slope down to $\approx 1700 \mathrm{~m}$ is steeper. In addition, the water has travelled a greater distance from Denmark Strait. This means that it may have stretched further in the vertical thereby increasing its vertical extent. It may also have mixed further and spun down partially while redistributing momentum to the outside of the cyclone thereby widening its extent horizontally. This could explain the observed diameter of about $20 \mathrm{~km}$ which is greater than the $\approx 12 \mathrm{~km}$ found at the mooring array (see Section 3.9). However, it should be noted that the horizontal sampling is not sufficient to precisely determine the size of the cyclone.

While many aspects of DSOW cyclones such as their radius, vertical extent, and center location vary, they are qualitatively similar. Section 3.9 presents detailed observations located at the centers and offshore sides of DSOW cyclones. In Figure 3-12, these locations would be around $95 \mathrm{~km}$ and $110 \mathrm{~km}$ cross-stream distance respectively. 


\subsection{Case Study of Three DSOW Cyclones in Septem- ber 2007}

This section describes the nature and characteristics of three different Denmark Strait

Overflow Water cyclones that propagated along the East Greenland slope between 21 and 24 September 2007. Several aspects identified to be crucial parts of the structure of DSOW cyclones are presented in progression.

\subsubsection{Detection from SST}

Figure 3-13 shows a sea surface temperature image obtained by the MODIS Aqua satellite on September 24th, 2007 at 0605Z. It can be seen that the EGC/IC front roughly tracks the shelfbreak. However, there are also strong modifications to the sea surface temperature field. Two of these were identified to possibly be related to Eddies 1 and 2 of this study described below. At the time of the SST image these eddies were downstream of the mooring array, but as will be shown in the next subsection, they had a clear expression in the mooring array prior to the time of the image. We assume that the eddies continued to be advected by the mean flow as well as by their self-advection between the time when they were present at the mooring array and when we see their supposed signature in the SST image. Estimates for the translation velocity based on this are given below. Due to the generally thick cloud cover in this region the infrared sensor on the satellite was not able to obtain clear sky images most of the time. In fact, aside from another image 105 minutes prior to the one presented in Figure 3-13, there were no clear sky observations within six days of this observation.

Eddy 1 is seen as an elongated spiral like structure with an $\mathrm{SST}$ around $6^{\circ} \mathrm{C}$ which 


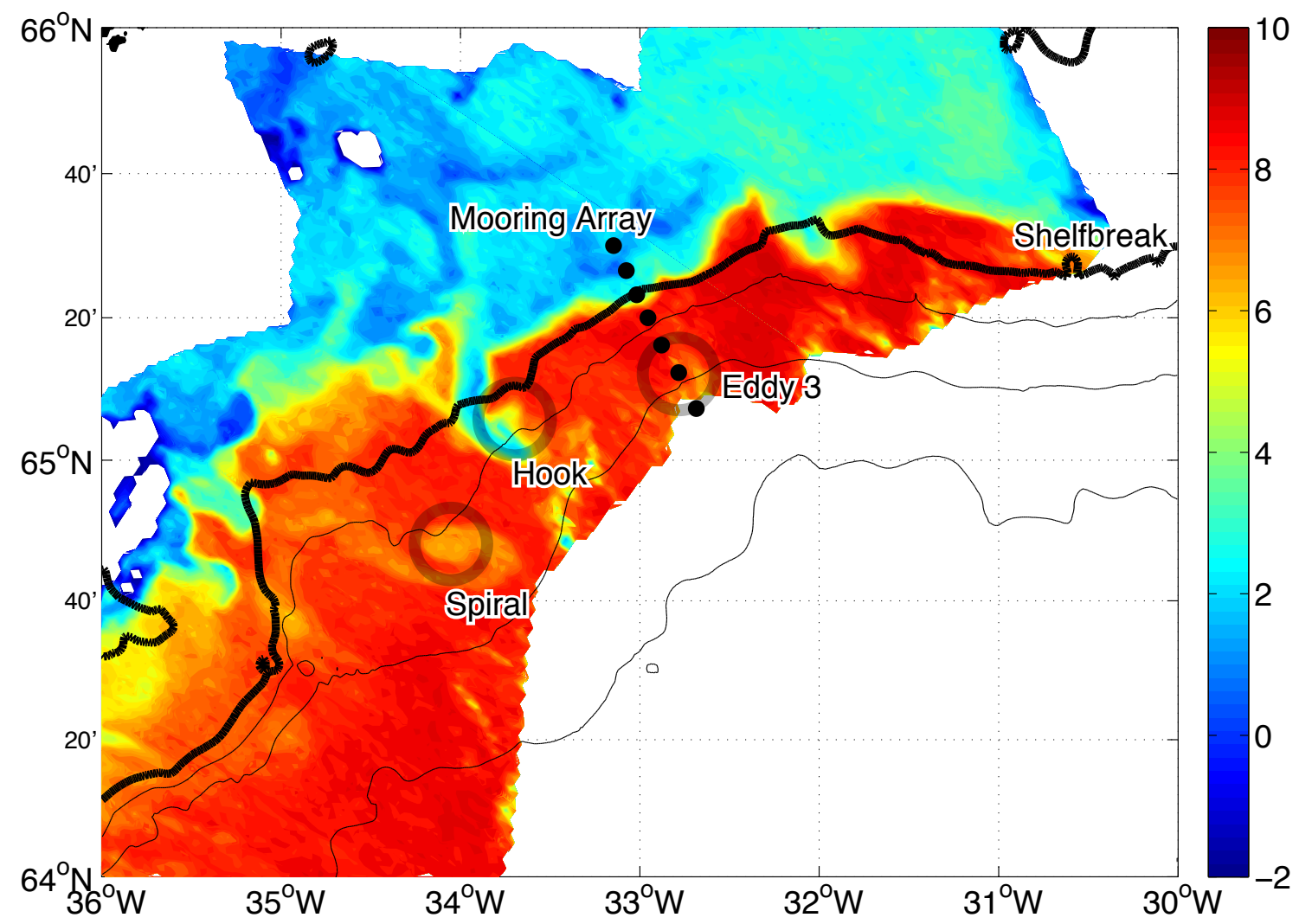

Figure 3-13: MODIS Aqua sea surface temperature $\left[{ }^{\circ} \mathrm{C}\right]$ on Sep24 0605Z. The domain corresponds to the gray box of Figure 3-1. White areas indicate cloud cover. The $500 \mathrm{~m}$ isobath (approximately the shelfbreak) is shown as a thick line and the $1000 \mathrm{~m}$, $1500 \mathrm{~m}$, and $2000 \mathrm{~m}$ isobaths are shown as thin lines. The seven moorings are shown by the black dots ranging from EG1 on the northwest to EG7 in the southeast. Note for scale that the distance between moorings EG1 and EG7 is $47 \mathrm{~km}$. The locations of the three eddies were determined assuming that they propagate along their isobaths at a constant alongstream velocity. These eddy locations are shown with gray circles: Eddy 1 is inferred to be near the spiral and eddy 2 near the hook. 
is colder than the ambient water and is centered roughly on the $1100 \mathrm{~m}$ isobath. This eddy has likely drawn cold EGC water off the shelf and into the ambient Irminger Water. As this thin streak of $\approx 2^{\circ} \mathrm{C}$ water mixed with the surrounding ambient warm Irminger Water, its temperature rose to the $\approx 6^{\circ} \mathrm{C}$ observed in the spiral.

Eddy 2 is seen as a "hook" of cold water advected from the shelf that has reached the $1000 \mathrm{~m}$ isobath at the time of the SST image. The hook has a curvature that is consistent with cyclonic circulation around an eddy center at $\approx 900 \mathrm{~m}$ depth. This is consistent with an eddy at the mooring array 21 hours prior to the SST image. The center of Eddy 2 is about $46 \mathrm{~km}$ from the mooring array (along the $900 \mathrm{~m}$ isobath) leading to a mean translational velocity of about $0.61 \mathrm{~m} / \mathrm{s}$. The hook might be an earlier stage in the development of the SST disturbances than the spiral. As the water encircles the eddy center and has time to mix, its thermal signal likely becomes less distinct.

We have also indicated on Figure 3-13 the presence of another eddy, Eddy 3, situated near the $1400 \mathrm{~m}$ isobath close to the mooring array. We will demonstrate below that this is a DSOW cyclone that is clearly identifiable in the mooring data record. Note, however, that there is essentially no discernible signature in the SST image. Even though Eddy 3 likely has a near-surface velocity expression, this surface circulation simply advects warm Irminger Water. Eddy 3 is about $27 \mathrm{~km}$ from the shelfbreak (compared to about $11 \mathrm{~km}$ for Eddy 2) so that it is apparently too far away from the EGC/IC surface front to modulate it.

The fact that Eddy 3 has no SST signature is an important result which is in contrast to Bruce (1995) who assumed that all DSOW cyclones propagating along the East Greenland slope would be visible as frontal disturbances in SST. Also different from Bruce (1995), we show that DSOW cyclones are present at differing locations across the slope. 


\subsubsection{Detection from the Mooring Array}

As mentioned in the previous subsection, the three eddies highlighted in the SST image were also detected in the mooring record. As a cyclone passes by the mooring array, the velocities associated with the feature will be recorded at the moorings. In general, the total velocity can be thought of as the sum of the time mean alongstream velocity, the advective velocity with which the eddy is propagating, and the eddy associated swirl velocities (the azimuthal velocity in a frame of reference that is moving with the eddy). The center of a cyclone can either pass right over a mooring, or the mooring can be located to the right or left of the track of the center. Depending on whether the mooring samples inside of the radius of the cyclone, different velocity scenarios can be predicted. The eddy radius here is defined as the transition region where the azimuthal velocity is at its maximum. Recall that inside of the eddy radius, the azimuthal velocity increases with distance from the center, while it decreases outside.

There are two different scenarios for the progression of the strength of the azimuthal velocity and they are summarized in Figure 3-14. If the mooring never samples inside of the eddy radius (black lines in Figure 3-14), then the progression is as follows:

- As the mooring gets closer to the center, the azimuthal velocity increases.

- At the point of closest encounter (still outside of the eddy radius), the azimuthal velocity has a local maximum.

- As the mooring gets farther away from the center, the azimuthal velocity decreases.

If, on the other hand, the mooring measures inside of the eddy radius (green lines in 


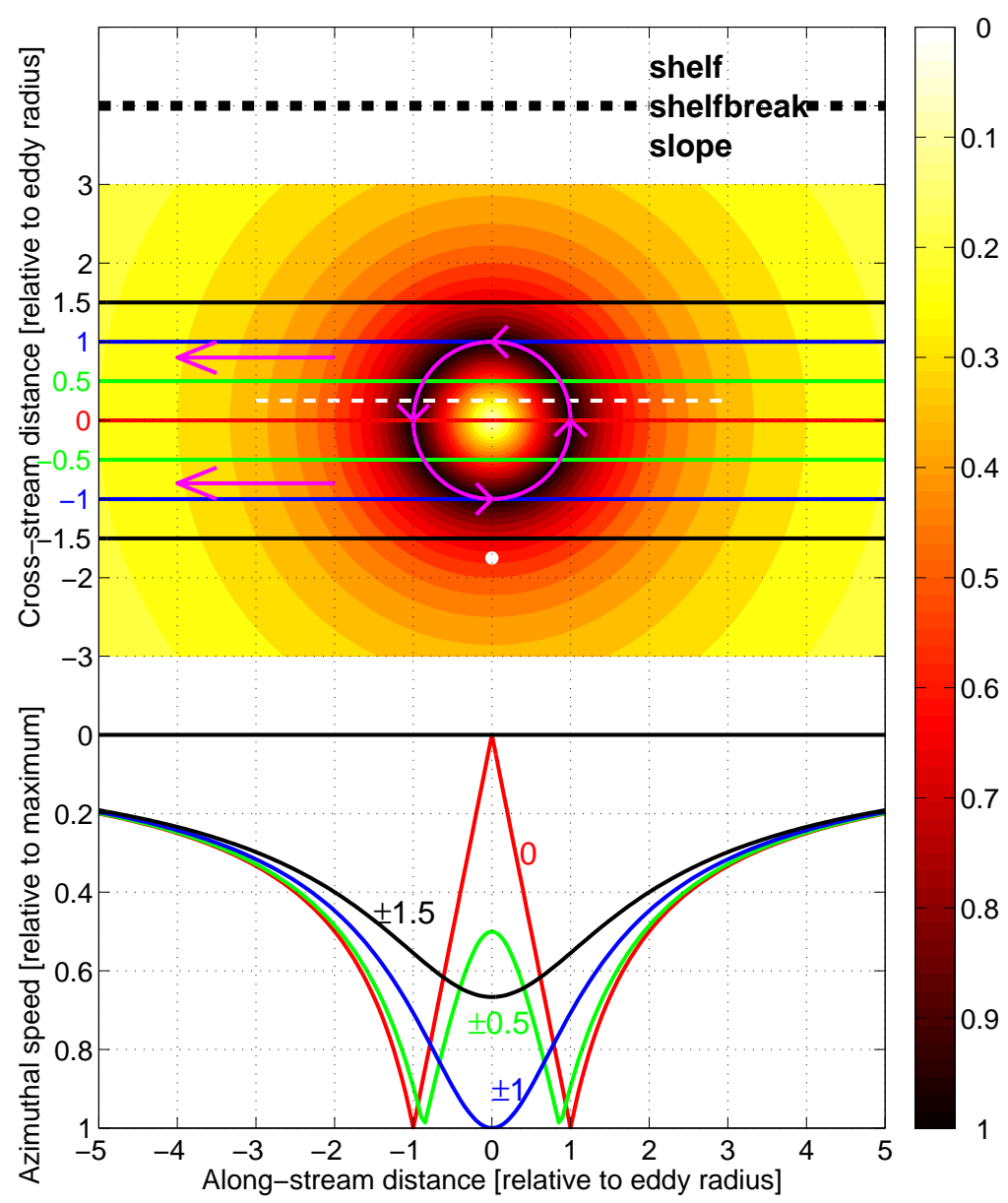

Figure 3-14: Cartoon of the strength of the azimuthal velocity for an idealized circularly symmetric barotropic eddy. Here we assume that the eddy is in solid body rotation and the azimuthal velocity is proportional to the radius up to a radius of 1. Outside of a radius of 1 , the eddy is assumed to be in geostrophic balance and the azimuthal velocity is proportional to the inverse of the radius. Note that this step-change of the force balance as well as the perfect circular symmetry is obviously an oversimplification of the situation on the East Greenland slope. The azimuthal velocity is shown in colored contours and the sense of rotation is indicated in magenta. Its translation with the shelfbreak to its right is indicated in magenta as well. The locations of four representative cross-stream locations at a minimum radius of $0,0.5$, 1 , and 1.5 are shown and the azimuthal velocity along those sections is shown in the bottom half of the figure. The orientation of this is purposefully chosen to compare to the timeseries shown in Figure 3-15a. Note that the qualitative shape of the sections of azimuthal velocity does not depend on the exact scaling (proportional and inversely proportional) as long as there is a core with decreasing azimuthal velocities. Hence this cartoon is instructive even if the scaling is not that simple. The approximate location of the timeseries near the eddy center presented in Subsection 3.9.3 is shown in white as well as the approximate location of the profiles on the offshore side presented in Subsection 3.9.4. 
Figure 3-14), then the following progression occurs:

- As the mooring gets closer to the center, the azimuthal velocity increases.

- As the mooring gets to the eddy radius, the azimuthal velocity reaches a local maximum.

- Inside of the eddy radius, in solid body rotation, the azimuthal velocity decreases.

- At the point of closest encounter, the azimuthal velocity reaches a local minimum. If the point of closest encounter is actually the eddy center (red line in Figure 3-14), then the azimuthal velocity there is zero.

- With increasing distance from the center, the azimuthal velocity increases.

- At the eddy radius, the azimuthal velocity again reaches a local maximum. If the eddy is perfectly symmetric, the amplitude of that local maximum is the same as the previous local maximum.

- Outside, in geostrophic balance, the azimuthal velocity again decreases.

Note that for a symmetric eddy without a wake the advective velocity associated with the eddy only increases to the point of closest encounter and then decreases. As a result of this progression, the column-integrated velocity seen at the moorings will either only have a single local maximum if the mooring is outside of the eddy radius, or it will have two local maxima and a local minimum at the point of closest encounter in between. Note, however, that due to the translational velocity of the eddy, the total velocity will not decrease to the mean velocity even if the azimuthal velocity is zero for a center observation of a mooring. 

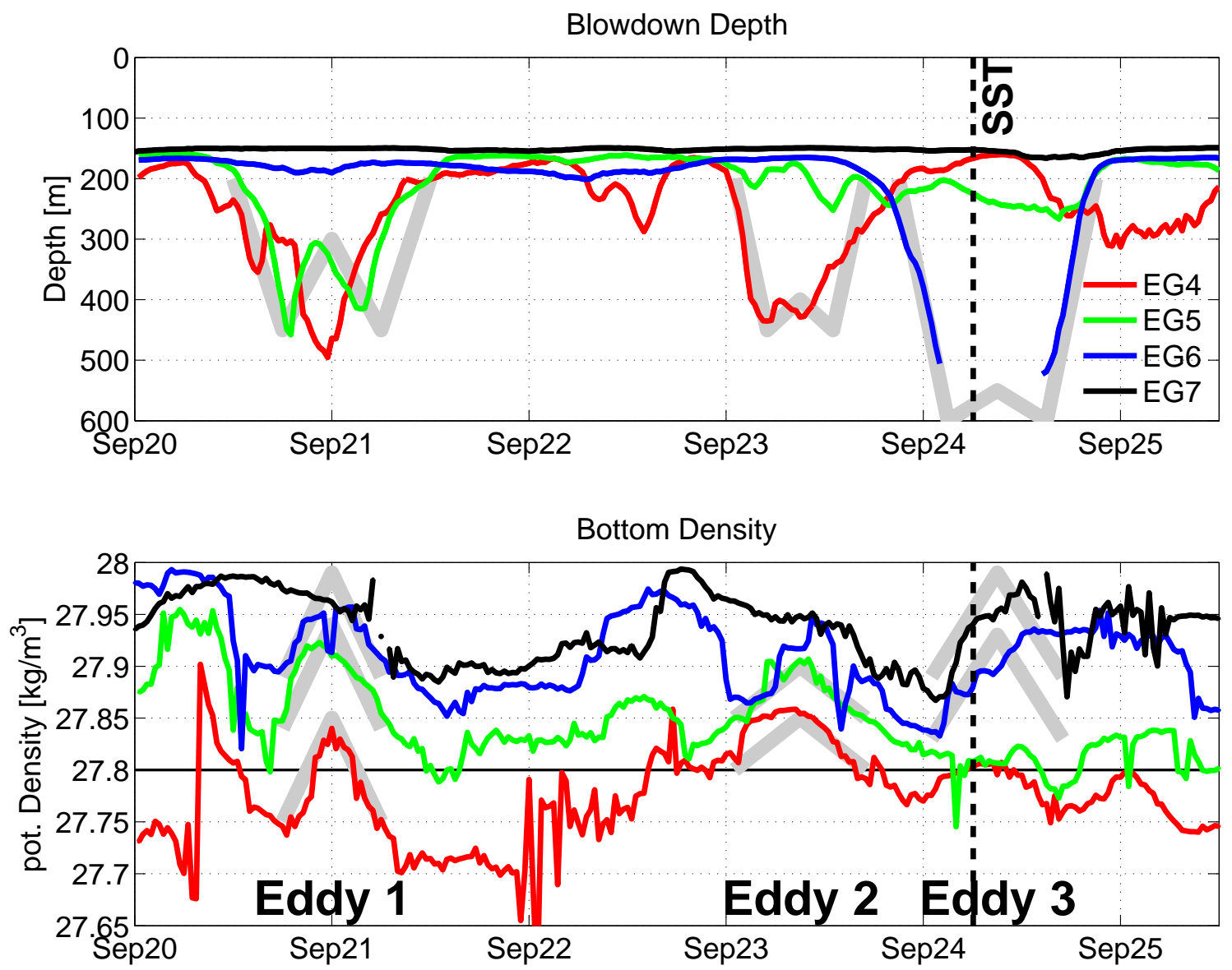

Figure 3-15: Timeseries of the depth of the top microcats (top panel: a) and the potential density at the bottom microcats (bottom panel: b) of the moorings EG4-7. The idealized response that would be expected in the records is overlaid in thick gray for the three eddies of the case study. The $27.8 \mathrm{~kg} / \mathrm{m}^{3}$ isopycnal delimiting DSOW and the time of the SST image (Figure 3-13) on Sep24 0605Z are highlighted. 
As described in Section 3.3, the moorings were not able to record velocities throughout the water column in the presence of strong flow associated with the eddies. However, the mooring blowdown corresponds directly to the column-integrated velocity. Therefore, we can use the blowdown depth, as shown in Figure 3-15a, as a proxy for column-integrated velocity. The idealized expected response to the eddies in the blowdown timeseries is overlaid in gray on Figure 3-15a. Referring again to this figure, on September 21st mooring EG5 encountered a near center hit of the cyclone that has been identified above as Eddy 1. In contrast, EG4 only exhibits a single local maximum in blowdown depth (i.e. column-integrated velocity). EG6 also has a weak maximum in blowdown depth at this time, which is consistent with a significant, but not very strong increase of column-integrated velocity compared to the mean flow. Consequently, our interpretation of the signal at these four moorings is that EG5 was near the center of Eddy 1 on September 21st at 00Z, EG4 was close to but outside of the eddy radius, and EG6 was outside of its eddy radius. This establishes the distance between EG4 and EG6 of $16 \mathrm{~km}$ as a firm upper bound for twice the radius of Eddy 1. In other words, we infer that the eddy radius of Eddy 1 was smaller than $8 \mathrm{~km}$.

Eddy 2 in Figure 3-15a on September 23rd results in a double local maxima signature at EG4 and, to a much smaller degree, at EG5. The amplitude of the intermediate recovery at EG4 is relatively weak indicating that the mooring did not get very close to the center of the eddy. Therefore, the interpretation is that Eddy 2 passed in between moorings EG4 and EG5 on September 23rd at 09Z, but closer to EG4 than EG5. From additional information at EG3, we conclude that the center was closer to mooring EG5 than to EG3. Finally, on September 24th, EG6 displayed the strongest observed blowdown which went beyond the range of the pressure sensor on the microcat. The neighboring EG5 and EG7 moorings did not show strong 
Table 3.2: Table with properties of the three eddies studied in this case study. The way these values are determined is described in the text.

\begin{tabular}{|c|c|c|c|c|c|}
\hline Name & Time of center & Centered on & Centered on & Influenced moorings & Radius \\
\hline \hline Eddy 1 & Sep21 00Z & EG5 & $1150 \mathrm{~m}$ & EG4-EG6 & $5 \mathrm{~km}$ \\
\hline Eddy 2 & Sep23 09Z & EG4 & $900 \mathrm{~m}$ & EG3-EG5 & $8 \mathrm{~km}$ \\
\hline Eddy 3 & Sep24 09Z & EG6 & $1400 \mathrm{~m}$ & EG5-EG7 & $5 \mathrm{~km}$ \\
\hline
\end{tabular}

blowdowns. Therefore, we do not know how close EG6 was to the center of Eddy 3, but a partial recovery associated with being inside the eddy radius as indicated by the gray idealized graph is consistent with the available data. If no recovery had occurred, the radius of Eddy 3 would be much less than half the distance between EG5 and EG6 and the distance between EG6 and EG7, i.e. less than $4 \mathrm{~km}$. These determined eddy locations and the associated times of passage are summarized in Table 3.2.

Figure 3-15b presents the bottom potential density records at the four outermost moorings. They are from less than $10 \mathrm{~m}$ above the bottom and are therefore not affected by blowdowns. The increased mean density at each site is due to the fact that the moorings are located on the continental slope with EG4 at $894 \mathrm{~m}$ being the shallowest and EG7 at $1585 \mathrm{~m}$ the deepest. The centers of the eddies contain water that is anomalously dense, consistent with the notion of them being DSOW cyclones. In particular, the density at moorings EG4-6 increases by about $0.1 \mathrm{~kg} / \mathrm{m}^{3}$ in the roughly 6 hours associated with the arrival of Eddy 1 and then it decreases almost symmetrically thereafter. The idealized response at the three moorings is overlaid in gray in Figure 3-15b. Note that even for EG4, located on the inshore side of Eddy 1, the bottom density increased above $27.8 \mathrm{~kg} / \mathrm{m}^{3}$, indicating that there was DSOW as high up on the slope as the $900 \mathrm{~m}$ isobath. Eddy 2 has a smaller amplitude increase in density at EG4 and EG5 that is spread over a slightly longer time period. This signal is less clear at EG6 and EG7 does not have an increase and subsequent decrease. The 
density at EG4 again is indicative of DSOW presence. Consistent with the blowdown depth record, Eddy 2 influences EG4 and EG5, but has no effect farther offshore. Finally, Eddy 3 is associated with an increase in density at EG6 and EG7. However, contrary to the idealized expected response, the densities do not decrease as clearly thereafter. This means that there are likely other processes present that influence these records in addition to the passage of an idealized eddy. Note that EG4 and EG5 do not or only barely exceed $27.8 \mathrm{~kg} / \mathrm{m}^{3}$. Hence, Eddy 3 is seaward of the $1200 \mathrm{~m}$ isobath (depth of EG5).

With the good agreement between the blowdown depth and bottom density timeseries, we have therefore established the feasibility of identifying DSOW cyclones from these records. That the eddies identified here are indeed DSOW cyclones and that they are consistent with our idealized conception is demonstrated in the following subsections. In particular, we present data from two different cross-stream locations with respect to the cyclones. Figure 3-14 schematically shows these locations as white symbols with respect to the cyclone itself and the shelfbreak. Our aim is to give the reader a view of the structure and water mass characteristics of the eddy center and its offshore side.

\subsubsection{Center of Eddy}

Figure 3-16 shows a timeseries of velocity from mooring EG5 which was near the center of Eddy 1 when it passed the mooring array. This mooring had an upward looking ADCP on the top sphere and a profiling acoustic current meter sampling the remainder of the water column. Here we show the ADCP data which are more complete. The mooring blowdown can be clearly seen in the depth coverage of the ADCP velocity measurements (compare to Figure 3-15a). As the eddy is encountered, 
the alongstream velocities increase from $\approx 0.25 \mathrm{~m} / \mathrm{s}$ to $\approx 0.75 \mathrm{~m} / \mathrm{s}$, reaching a local maximum at the eddy radius of Eddy 1 . At the same time there are strong offshore velocities of $\approx 0.5 \mathrm{~m} / \mathrm{s}$ that correspond to the azimuthal velocities of the cyclone.

As highlighted in the figure, the elapsed time from when the mooring samples the eddy radius to when it samples the closest approach to the center of the cyclone is about 3 hours. The alongstream velocity at this time is roughly $0.5 \mathrm{~m} / \mathrm{s}$ though it could be greater at depth. Assuming that the eddy is circular, this means that the eddy radius (computed as translational velocity times time) is about $5 \mathrm{~km}$. Note that this is consistent with the conclusion from the mooring blowdown analysis where it was shown that the eddy radius is less than $8 \mathrm{~km}$ for Eddy 1 .

At the center of the cyclone, the alongstream velocity has decreased to $\approx 0.25 \mathrm{~m} / \mathrm{s}$ with an almost vanishing cross-stream velocity, indicative of the fact that the mooring is in close proximity to the center of the vortex. Towards the trailing edge of the eddy, the signature is less clear because there are small onshore velocities as well as some offshore directed currents. At the same time, the alongstream velocity increases to almost $1 \mathrm{~m} / \mathrm{s}$ and retains those strengths for a longer period of time than at the leading edge.

The Spill Jet hypothesis discussed in Pickart et al. (2005a) and Magaldi et al. (2011) can explain the asymmetry in the eddy shape observed at EG5. As the leading edge of the eddy moves along the slope, the offshore velocity component draws water off the shelf. Since this water is denser than the ambient water at the same depth, it is prone to descend and mix. This process is termed "spilling". During the subsequent adjustment its alongstream velocity increases. This additional (likely not symmetric) alongstream velocity component could explain the observed alongstream velocity signature that seems to be more than the simple signature of a symmetric eddy. We note, however, that our measurements of Eddy 1 only cover the upper part 


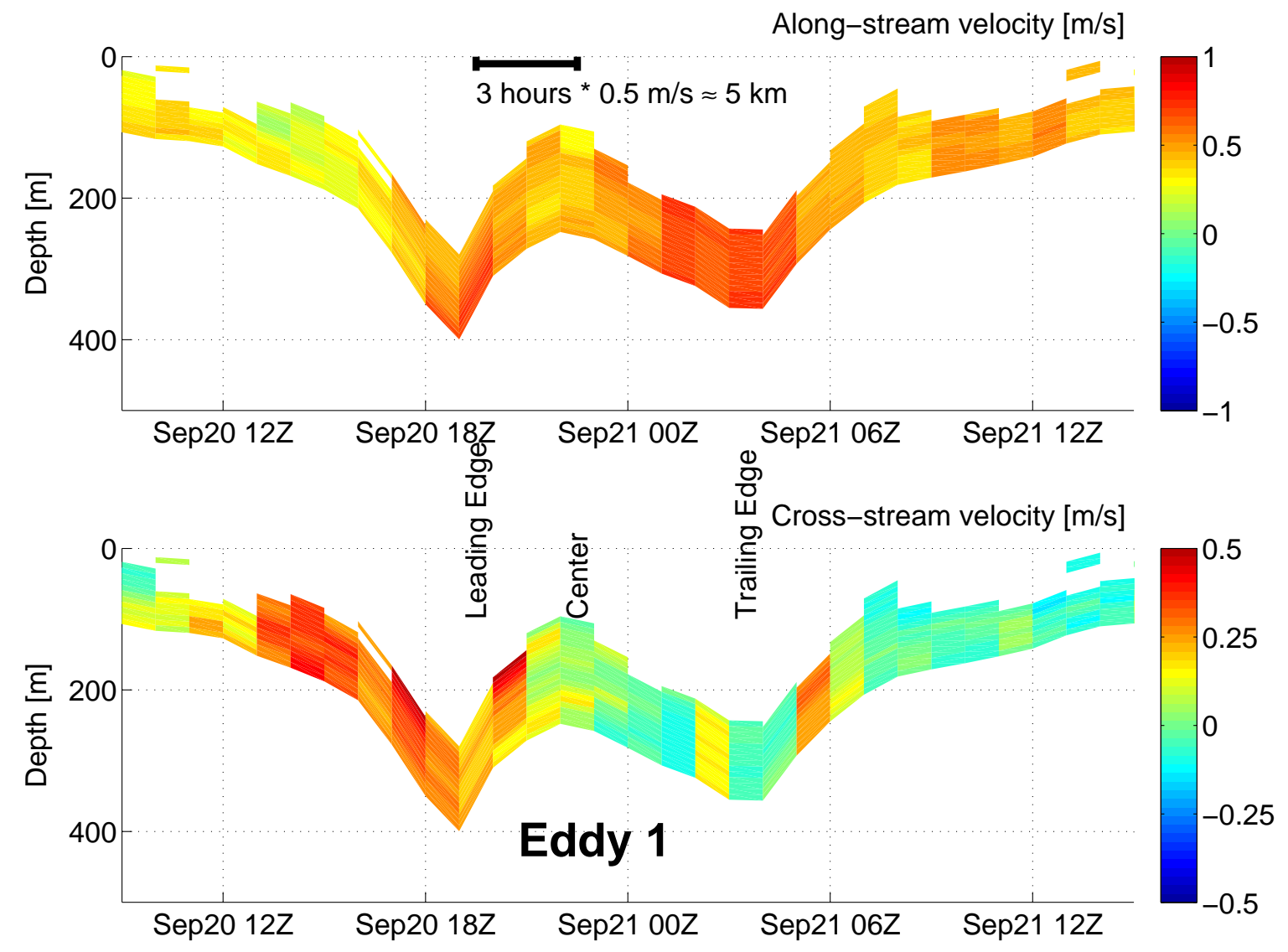

Figure 3-16: Alongstream (upper panel) and cross-stream (lower panel) velocity timeseries at mooring EG5. Note the different scales for alongstream and cross-stream velocity. The water depth at EG5 is $1163 \mathrm{~m}$ and the vertical axis therefore only covers the upper part of the water column. This is due to the fact that the data here is only from the upward looking top ADCP on the mooring. Eddy 1 is centered on Sep20 $21 \mathrm{Z}$. 
of the water column while the adjusted water is likely mainly below our measurements.

Eddy 2 was higher up on the continental slope, centered on EG4 at the $900 \mathrm{~m}$ isobath. Figure 3-17 shows the timeseries in proximity to the passage of the center of this eddy. Note that the blowdown recovery towards the center of the eddy is not as pronounced and we therefore infer that the center of Eddy 2 passed a small distance offshore of EG4.

The progression of velocity for Eddy 2 is similar to that of Eddy 1 . The leading edge has strong offshore velocities exceeding $0.5 \mathrm{~m} / \mathrm{s}$ in the middle water column with somewhat smaller velocities near the bottom. This is consistent with the idealized picture that assumes the strongest eddy swirl velocities to be in the middle water column rather than near the bottom. Note that we cannot determine whether the azimuthal velocities increase or decrease toward the surface. The alongstream velocities are smaller in the beginning with a somewhat bottom intensified signature. Near the center, the velocity varies weakly with depth and exceeds $0.75 \mathrm{~m} / \mathrm{s}$. Similar to Eddy 1, the time between the passing of the leading edge and the center again is about 3 hours. However, the larger alongstream velocity during this time results in a slightly larger estimate for the radius of Eddy 2 of about $8 \mathrm{~km}$ (as opposed to less than $8 \mathrm{~km}$ for Eddy 1).

The strongest alongstream flows occur some time after the center of the eddy. Between $400 \mathrm{~m}$ and the bottom, the alongstream velocity is $1 \mathrm{~m} / \mathrm{s}$. This asymmetry is similar to Eddy 1 and might be due to spilling, but could also be caused by other processes. For example, the eddy might have a wake that follows the eddy. It is not until after the passage of the eddy radius that the spilled water in the upper part and the lower part of the record flows onshore, first at low and then at increasing amplitudes. In the middle of the water column (around $500 \mathrm{~m}$ depth), however, the offshore flow persists for longer. This could be the signature of symmetric instabil- 


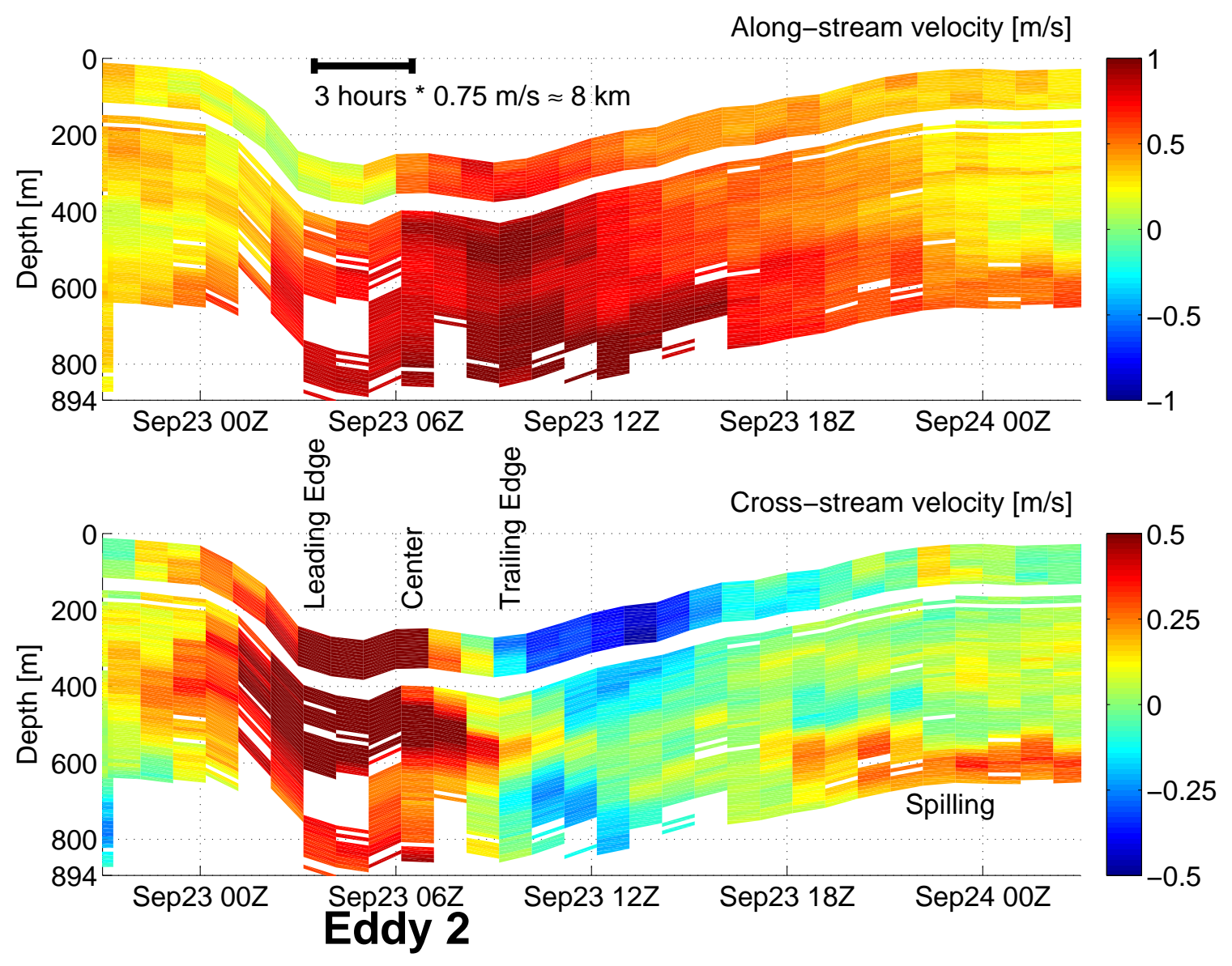

Figure 3-17: Alongstream (upper panel) and cross-stream (lower panel) velocity timeseries at mooring EG4. Note the different scales for alongstream and cross-stream velocity. The vertical axis covers the full water depth at mooring EG4. Eddy 2 is centered on Sep23 06Z. The Type I spilling of dense water at the end of the record (coincident with Eddy 3) is discussed in Section 3.10. 
ities associated with the adjustment of spilled water. More details on the possible symmetric instabilities will be discussed in Section 3.10.

Interestingly, the largest onshore velocities are reached more than 6 hours after the passage of the eddy center, with velocities between $0.25 \mathrm{~m} / \mathrm{s}$ and $0.5 \mathrm{~m} / \mathrm{s}$ above $400 \mathrm{~m}$ depth. Note that the progression of these events is consistent with the horizontal motion of the EGC/IC front as described in Section 3.6. As seen in Figure 3-10, near the center of Eddy 2 at the mooring array, the front is found offshore of EG2 indicative of a fast and efficient offshore motion of water originally on the shelf. Then, coinciding with the strong onshore flow at EG4, the front is observed to be back inshore of EG2.

\subsubsection{Offshore Side of Eddy}

As shown in Figure 3-12 and also described by Spall and Price (1998) (compare Figure 3-11), the offshore side of DSOW cyclones is characterized by different flow regimes in the lower DSOW layer versus the middle of the water column. The DSOW layer exhibits equatorward (downstream) flow, but the overlying intermediate water column experiences the poleward (upstream) flow associated with the azimuthal velocity of the cyclone.

Figure 3-18 shows profiles obtained at mooring EG6 in $1378 \mathrm{~m}$ deep water. The gray profiles are within 4 days of the passage of Eddy 1 . They give a scale for the mean and variability encountered at the mooring site. We present this rather than a mean value of the properties over a particular time period, because, as mentioned in Section 3.3, the moored profilers had systematic data dropouts due to mooring blowdown during strong current events. As such, any mean would be biased by disregarding those times.

All the profiles that sampled to the bottom encountered the DSOW layer (denser 

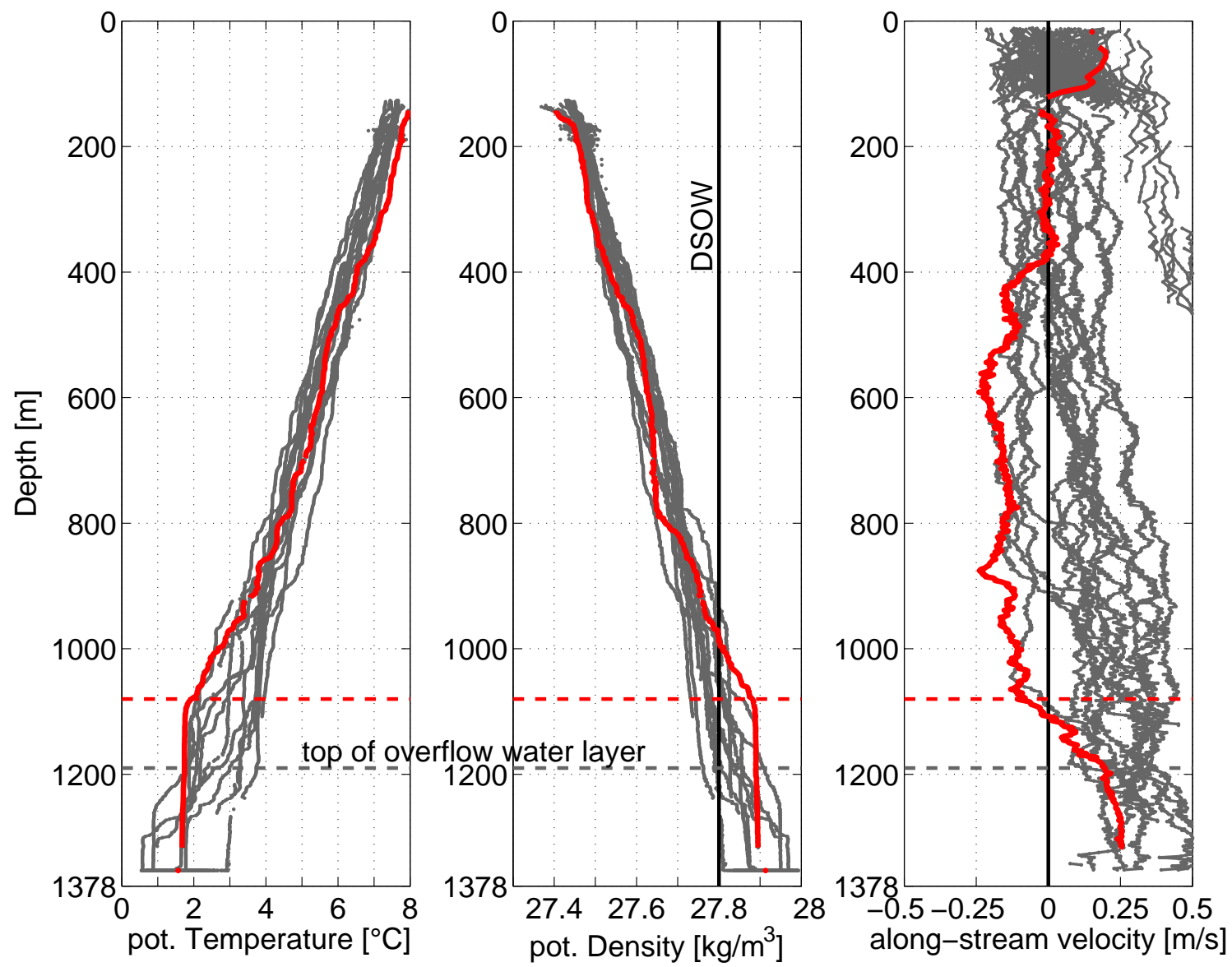

Figure 3-18: Profiles of pot. temperature, pot. density, and alongstream velocity at mooring EG6 near the time period of Eddy 1. The red profiles are on Sep21 00Z and the gray profiles are within plus/minus four days of that time. The height of the overflow layer in the mean is indicated by the dashed line. During the presence of Eddy 1 (red profile), the bottom DSOW layer height (red dashed line) is increased and there is a flow reversal in the middle water column. 
than $27.8 \mathrm{~kg} / \mathrm{m}^{3}$ ), generally crossing it around $1190 \mathrm{~m}$ depth (or about $200 \mathrm{~m}$ above the bottom). This is highlighted in the figure as the approximate top of the overflow water layer (gray dashed line). Generally there is some indication of a weakly stratified bottom mixed layer. Except for a few of the profiles, the flow is generally downstream below about $600 \mathrm{~m}$ with some more variation encountered above.

The red profile in Figure 3-18 corresponds to the time when the center of Eddy 1 was identified at mooring EG5 some $9 \mathrm{~km}$ (or greater than the eddy radius) inshore. It can be seen that the bottom DSOW layer is increased in height by more than $100 \mathrm{~m}$ to a total thickness of almost $300 \mathrm{~m}$. This layer is extremely well-mixed as can be seen from the fact that both temperature and density are essentially uniform. Using the observed change in density and velocity over the observed $\Delta z=240 \mathrm{~m}$ of the overflow layer of $\Delta \rho=0.015 \mathrm{~kg} / \mathrm{m}^{3}$ and $\Delta u=0.37 \mathrm{~m} / \mathrm{s}$ respectively, we can estimate the gradient Richardson number:

$$
R i=\frac{N^{2}}{S^{2}}=-\frac{g}{\rho_{0}} \frac{\Delta \rho}{\Delta z} /\left(\frac{\Delta u}{\Delta z}\right)^{2} \approx \frac{9.81 \mathrm{~m} / \mathrm{s}^{2}}{1027 \mathrm{~kg} / \mathrm{m}^{3}} \frac{0.015 \mathrm{~kg} / \mathrm{m}^{3}}{240 \mathrm{~m}} /\left(\frac{0.35 \mathrm{~m} / \mathrm{s}}{240 \mathrm{~m}}\right)^{2} \approx 0.25
$$

Here $N$ is the buoyancy frequency and $S$ is the shear. The estimate is close to the critical value of $R i=1 / 4$ and is suggestive of the fact that the layer is entraining fluid from above by Kelvin-Helmholtz instability.

The top of the overflow layer is very well defined even though the density there is still in excess of $27.8 \mathrm{~kg} / \mathrm{m}^{3}$. The stratification in the middle layer above is stronger than in the ambient surrounding water as can be seen from the greater change in density over a shorter vertical distance. This is perhaps the remnant signature of the more highly stratified Arctic Intermediate Water in Denmark Strait. Most importantly, the alongstream velocity is reversed with upstream flow of up to $0.25 \mathrm{~m} / \mathrm{s}$ over more than $400 \mathrm{~m}$ depth which is consistent with the expected eddy structure. 
The cross-stream velocity (not shown) is zero in the overflow layer and has a slight onshore component above, indicative that this profile may be slightly to the trailing side of the cyclone. The velocity in the overflow layer is downstream (though at a smaller amplitude than at other times). Due to the increased layer thickness, the downstream DSOW flux is stronger than in the absence of the cyclones.

Figure 3-19 presents profiles at mooring EG7 (bottom depth of $1585 \mathrm{~m}$ ) around the time of the passage of Eddy 3. Here the DSOW layer generally covers about $200 \mathrm{~m}$ above the bottom. The red profiles that were obtained offshore of the center of Eddy 3 show an increase in layer thickness of almost $200 \mathrm{~m}$ so that there is DSOW in the bottom $400 \mathrm{~m}$. This overflow layer is not as well mixed as the one observed during Eddy 1 . The upper part of the DSOW layer has a relatively weak stratification, but the lower half shows some increase in density corresponding to a decrease in temperature. This non-zero stratification is similar to the structure of bottom mixed layers observed far downstream in the Deep Western Boundary Current (Pickart, pers. comm. 2012) as well as to numerical simulations by D'Asaro et al. (2011) who find that boundary layers within symmetrically unstable fronts exhibit stratification and turbulence at the same time. The increase of the DSOW layer thickness by almost the same value as its background value is clearly an order one variation due to the cyclone. This compares well with the transect taken by Girton et al. (2001) who also found an order one variability. The downstream as well as offshore $(\approx 0.3 \mathrm{~m} / \mathrm{s})$ flow in the stratified part of the overflow layer is indicative of an advancing and descending plume. Around $1400 \mathrm{~m}$ depth, the velocity turns slightly onshore while the alongstream velocity goes to zero.

Dramatic gradients indicate the top of the overflow layer. The density decreases by almost $0.1 \mathrm{~kg} / \mathrm{m}^{3}$ and the alongstream velocity goes from zero to an upstream velocity of $0.25 \mathrm{~m} / \mathrm{s}$ over a vertical distance of only about $40 \mathrm{~m}$. Due to the large 

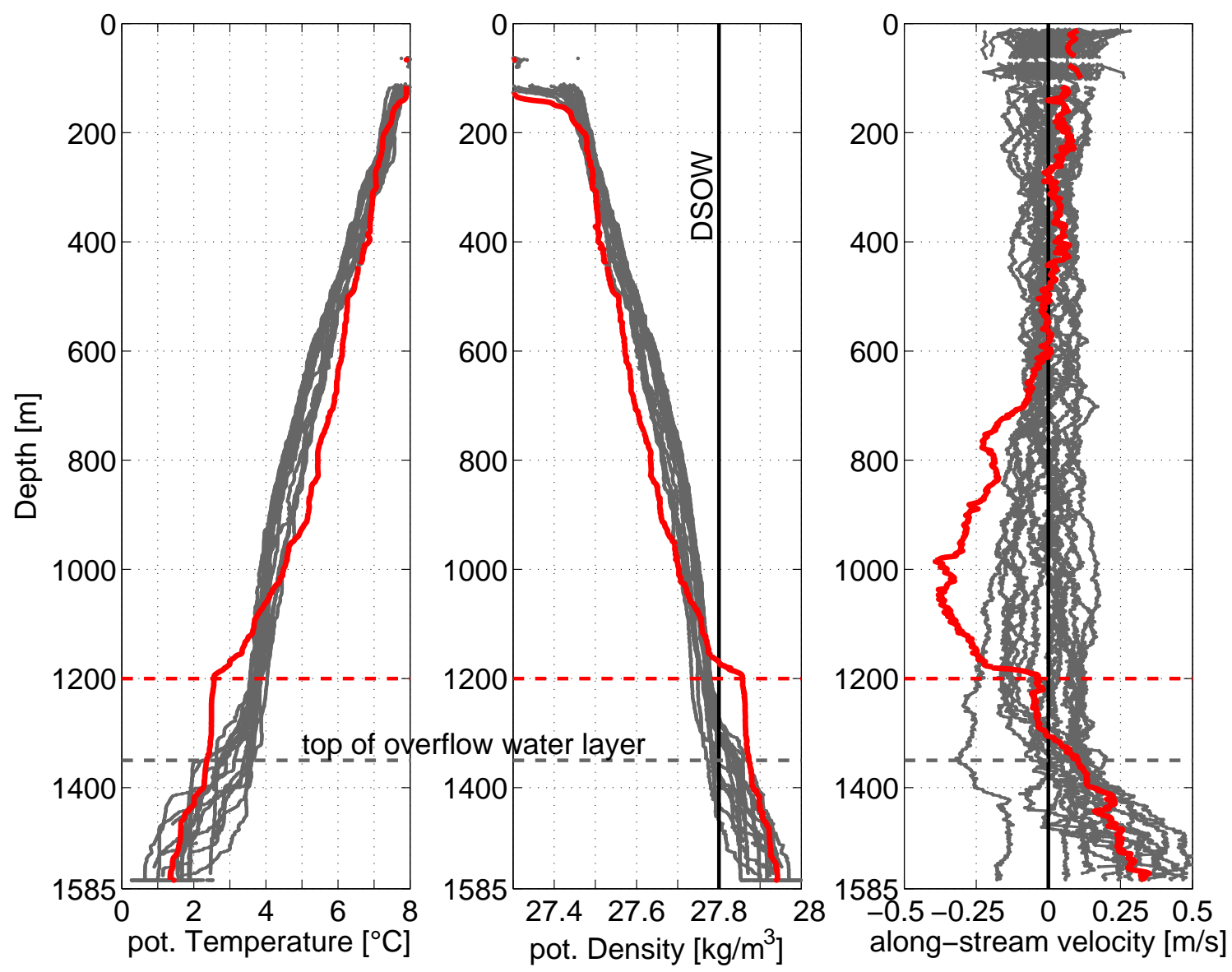

Figure 3-19: Profiles of pot. temperature, pot. density, and alongstream velocity at mooring EG7 near the time period of Eddy 3. The red profiles are on Sep24 06Z and the gray profiles are within plus/minus four days of that time. During the presence of Eddy 3 (red profile), the bottom DSOW layer height is increased and there is a flow reversal in the middle water column. 
density jump, the Richardson number there is $\approx 3 / 4$ which suggests that the top of this layer is eroding less than in the case of Eddy 1. It should be noted that this is different from Eddy 1 which has more of a gradual transition into the middle AIW layer as observed on its offshore side.

The intermediate layer clearly exhibits the expected structure associated with a DSOW cyclone. A higher than ambient stratification between $1150 \mathrm{~m}$ and $700 \mathrm{~m}$ is coincident with an upstream flow with a mid-depth maximum of $0.4 \mathrm{~m} / \mathrm{s}$. Above this intermediate layer the velocity is again near zero.

While it would be nice to present a similar analysis of the water mass and flow structure on the onshore side of these DSOW cyclones, this is not possible due to data restrictions. In particular, the flows in this region are so energetic that there were instrument malfunctions (as described in Section 3.3). The available measurements on the upper slope in fact are too far away in space or time to show the structure of the eddies. However, in addition to the flow associated with the cyclones, other currents were measured on the upper slope. In particular, the spilling of dense water off the shelf occurred during the time period of the case study. These observations are described next.

\subsection{Evidence for Spilling}

Dense water resides on the shelf south of the Denmark Strait as shown by Brearley et al. (2012). Magaldi et al. (2011) suggested that the spilling of this water off the shelf may be due to the passage of DSOW cyclones (termed Type II events) or due to generic instabilities or small scale variability in the vicinity of the shelfbreak (termed Type I events). Here we present evidence for the two different types of spilling events. The first event (Type II) occurred due to the passage of Eddy 2, while the second 
event (Type I) coincidentally occurred near the time that Eddy 3 passed the array, but was not due to the eddy itself.

\subsubsection{A Type II spilling event}

Eddy 2 passed the mooring array with its center about $11 \mathrm{~km}$ from the shelfbreak and on its leading edge displayed strong offshore velocities throughout the water column and to the shelfbreak. This is suggested by the hook of cold water in the SST image (Figure 3-13) as well as the velocity record at mooring EG4 (Figure 3-17). There are also offshore velocities inshore of the shelfbreak at mooring EG2 exceeding $0.3 \mathrm{~m} / \mathrm{s}$ in the bottom $100 \mathrm{~m}$. As the eddy passes, both moorings EG3 and EG4 (seaward of the shelfbreak) are blown down, so no hydrographic profiles are available. However, the top microcat on EG4 was able to obtain a measurement around $400 \mathrm{~m}$ depth near the center of Eddy 2. As shown in Figure 3-20, T-S values more than $3{ }^{\circ} \mathrm{C}$ colder and 0.25 fresher than commonly observed at this depth are found during the presence of Eddy 2. This is evidence for shelf-origin water. In fact, an endmember decomposition according to Table 3.1 shows that the shelf water concentration in the mean is around $35 \%$ at this depth. During the passage of Eddy 2, the shelf water concentration increased to between 50\% and 80\%, while the Irminger Water concentration decreased accordingly. This hydrographic and velocity evidence suggests that, along the leading edge of Eddy 2, spilling of dense shelf water occurred. The offshore velocity in the Eulerian mooring view at this time was at values in excess of $0.3 \mathrm{~m} / \mathrm{s}$ for about 6 hours indicating a cross-stream displacement of about $6 \mathrm{~km}$. Hence water could not have come from the shelfbreak to mooring EG4 in that amount of time. However, as the water gets advected along with the cyclone, it experiences the offshore velocities for much longer and can therefore make it from the shelf to $11 \mathrm{~km}$ offshore where it is 
observed. Since the spilling was triggered by a DSOW cyclone, we classify it as a Type II spilling event following the classification of Magaldi et al. (2011).

\subsubsection{A Type I spilling event}

Eddy 3 passed the mooring array about $27 \mathrm{~km}$ seaward of the shelfbreak and, given its radius of less than $8 \mathrm{~km}$, it is unlikely that it has more than a small effect on the shelfbreak. In fact, the velocities measured at mooring EG4, roughly half way between the eddy center and the shelfbreak, indicate near-zero alongstream velocities during the passage of Eddy 3. If Eddy 3 were to impact mooring EG4, the eddy's onshore side would lead to larger than average rather than lower than average alongstream velocities there. So it is clear that whatever happened at the shelfbreak at this time was not due to Eddy 3, but just coincidentally occurred at the same time. As we show below, spilling of dense shelf water happens at this time, and following Magaldi et al. (2011), this is classified as Type I spilling, i.e. spilling due to generic instabilities of the flow at the shelfbreak rather than a passing DSOW cyclone.

About 14 hours before the passage of Eddy 3, the offshore velocities just inshore of the shelfbreak at mooring EG2 increase markedly in the bottom $150 \mathrm{~m}$, reaching up to $0.35 \mathrm{~m} / \mathrm{s}$ (not shown). This starts to advect dense shelf water (exceeding $27.75 \mathrm{~kg} / \mathrm{m}^{3}$ ) across the shelfbreak. About three hours later the bottom offshore velocities on the upper slope drastically increase up to $0.5 \mathrm{~m} / \mathrm{s}$ at mooring EG3 (Figure 3-21, near Sep23 19Z). For nearly 6 hours the bottom $50 \mathrm{~m}$ of the water column on the upper slope flows strongly downslope. The offshore velocities farther down the slope at

mooring EG4 correspondingly increase (Figure 3-17, near the same time). While the maximum flow there occurs about 100-200 m deeper than at EG3, it may have detached from the bottom and is conceivably actually about $200 \mathrm{~m}$ above the bottom. 

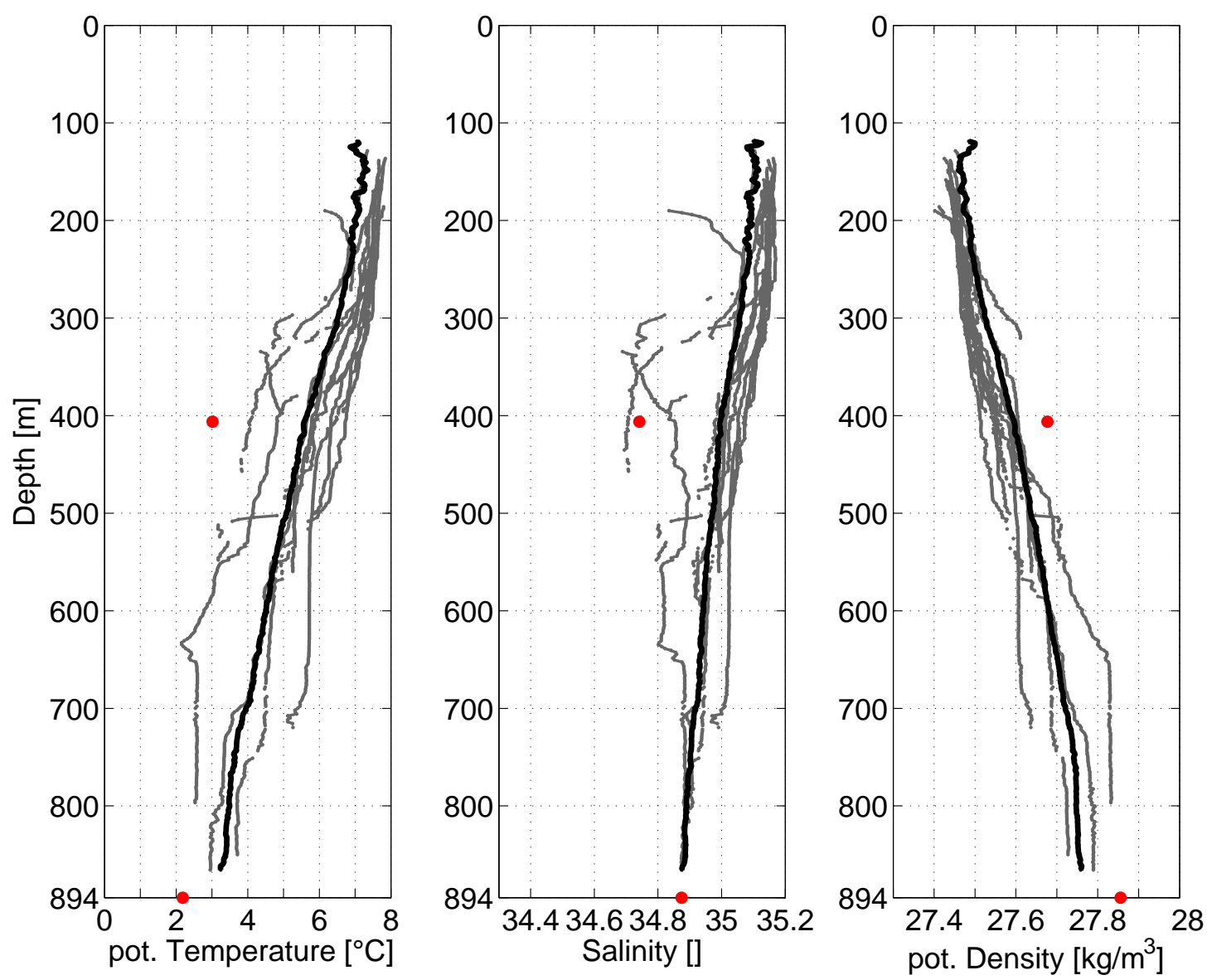

Figure 3-20: Profiles of pot. temperature, salinity, and pot. density at mooring EG4. The gray profiles are within plus/minus four days of Sep23 06Z (near center of Eddy 2). The black profiles are the four months record mean profiles. Measurements from the blown-down top microcat and the bottom microcat at EG4 on Sep23 06Z are shown with red dots. 

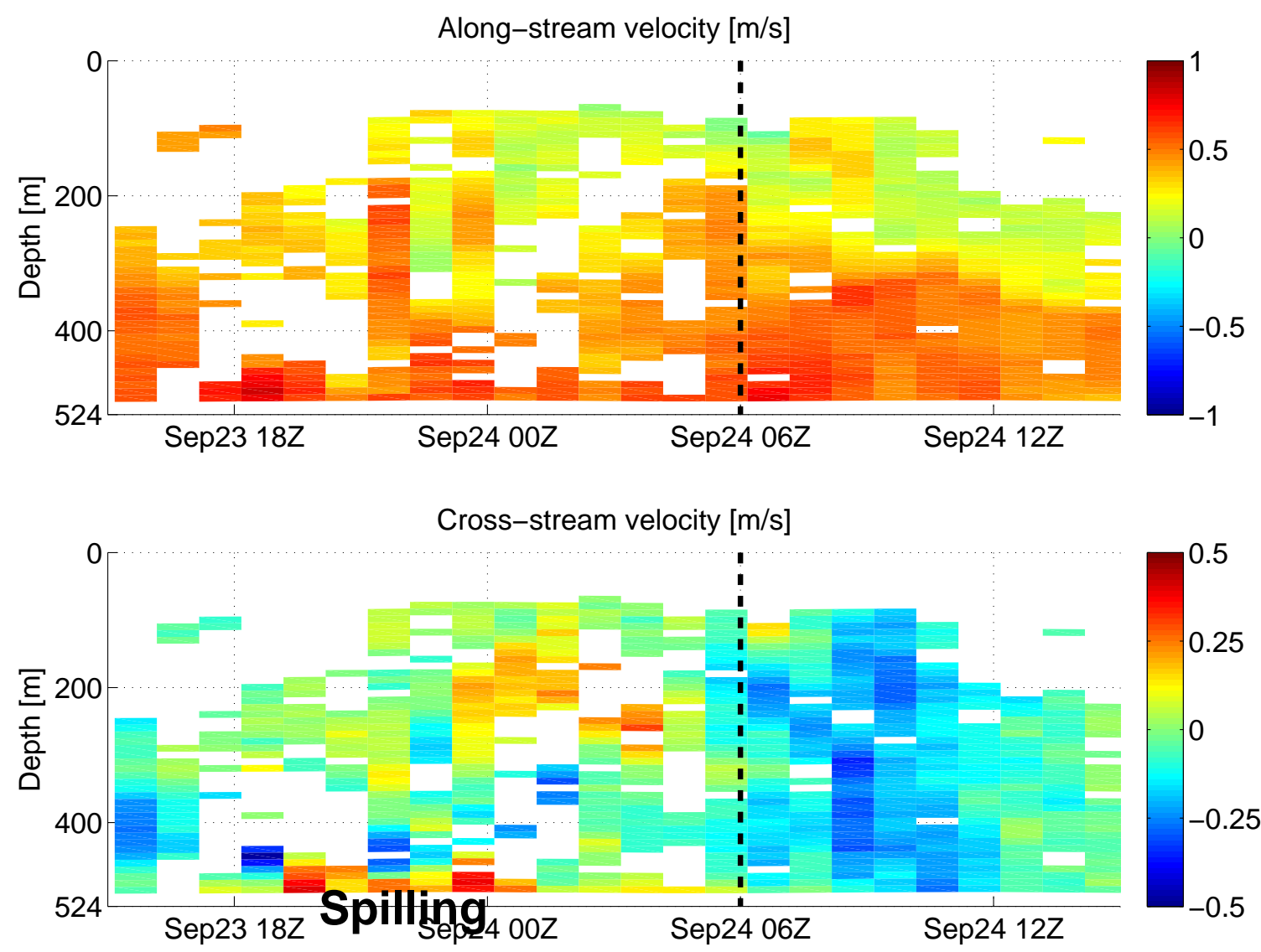

Figure 3-21: Alongstream (upper panel) and cross-stream (lower panel) velocity timeseries at mooring EG3. Note the different scales for alongstream and cross-stream velocity. The spilling event characterized by strongly enhanced offshore velocities in the bottom 50 m occurs from about Sep23 19Z to Sep24 01Z. The time of the hydrographic profile presented in Figure 3-22 is highlighted with a dashed line. The reason for data dropout in the middle water column (white areas) is not clear, but may be related to increased error velocities associated with enhanced turbulence. 
This could be due to the spilled water equilibrating at a density horizon within the ambient water at which point it possibly spreads laterally through the water column rather than flowing along the bottom.

Further evidence for the spilling comes from the bottom microcat record on mooring EG3 that shows a decrease in salinity to values less than 34.75 which is actually the lowest value encountered during the case study presented in this chapter. An endmember decomposition determines this to be more than $75 \%$ shelf water. At this time the potential temperature at the bottom of all moorings is actually within a narrow $2-3{ }^{\circ} \mathrm{C}$ band meaning that the horizontal gradients are mainly sustained by salinity differences. A vertical profile that sampled this spilled water was taken about 5 hours after the strongest downslope near-bottom velocities subsided at mooring EG3. This is shown as the red profile in Figure 3-22 and exhibits a nearly $200 \mathrm{~m}$ thick somewhat mixed bottom layer (from $300 \mathrm{~m}$ to $500 \mathrm{~m}$ depth). There is, however, marked fine-scale variability in the profile suggestive of turbulent conditions. The temperature and salinity are also lower than the ambient water and the shelf water endmember percentage in that mixed layer is elevated near $50 \%$ compared to the value of $35 \%$ observed otherwise.

As can be seen in Figure 3-21, in the layer immediately above the near-bottom offshore flow, there is an indication of onshore flow. This is consistent with the structure expected from symmetric instability. As discussed by Brearley et al. (2012), symmetric instability is the fastest process adjusting the spilled water to its new environment with growth timescales of around 1-2 hours. Therefore it is likely to be the initial process at work. During a symmetric instability, due to continuity, there can be no net volume flux across the slope. In other words, in response to the sinking in the bottom layer there must be a comparable upslope transport in the layer above or in horizontal proximity. The observed onshore velocities above the bottom layer 

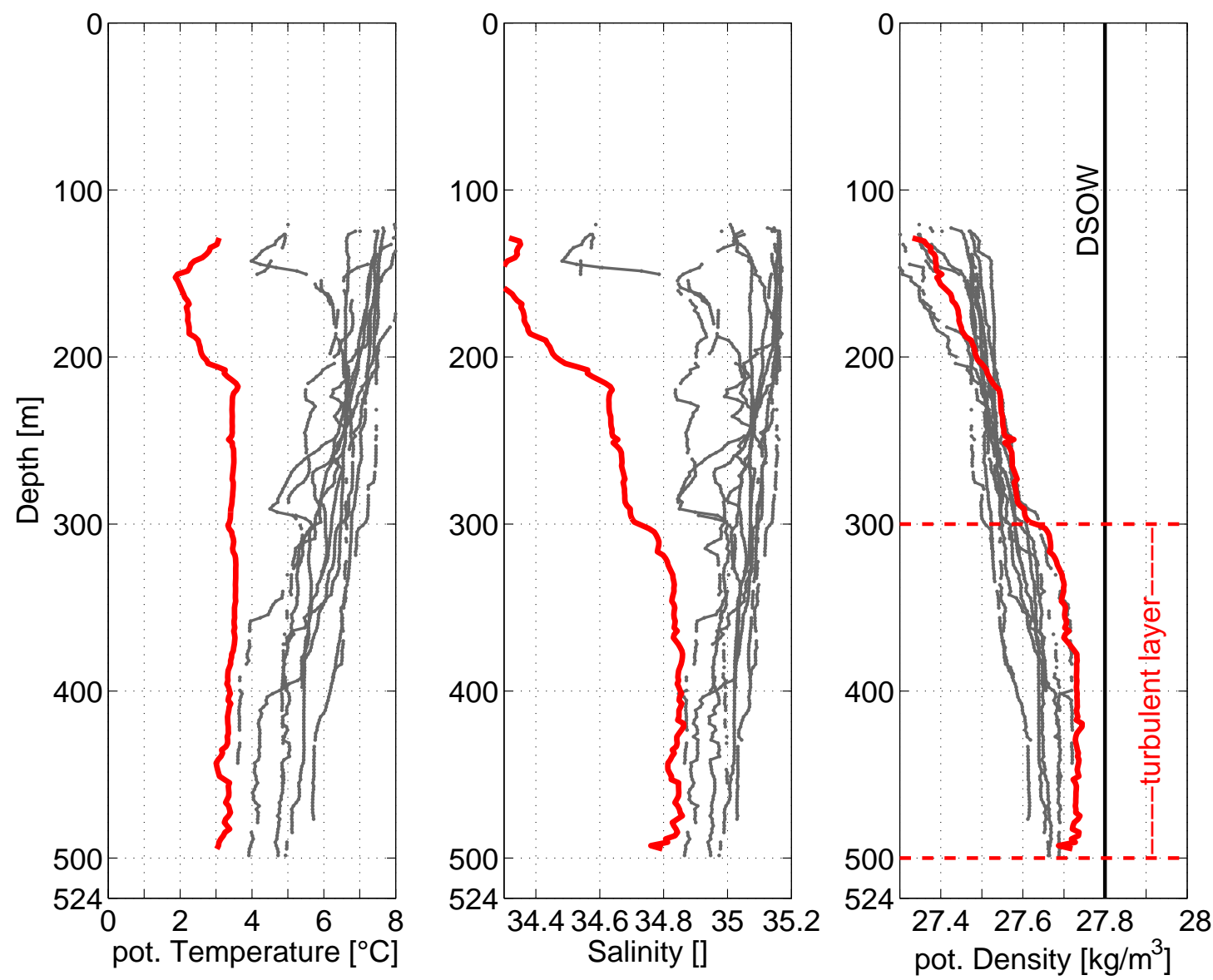

Figure 3-22: Profiles of pot. temperature, salinity, and pot. density at mooring EG3. The red profiles are on Sep24 06Z (3 hours prior to Eddy 3) and the gray profiles are within plus/minus four days of that time. 
in Figure 3-21 are consistent with this notion. Note that during this time there is a comparatively large number of data drop outs. While the exact reason for this is not known, it is likely due to data rejection in response to large error velocities. ${ }^{1}$ This is suggestive of strong spatial gradients and/or large temporal variability in the region of the missing data, which in turn is consistent with symmetric instability resulting in enhanced levels of turbulence as well as the strong observed flows. Figure 3-21 suggests that the region of strong turbulence extends at least $200 \mathrm{~m}$ above the bottom. Hence it can help explain the well-mixed bottom layer observed on Sep24 06Z (shown in Figure 3-22). The lowest $50 \mathrm{~m}$ of that profile also indicate static instability, but it is not clear whether that is real or due to the fact that the profiler took those measurements over a time period of about 10 minutes.

Unfortunately, the moored profiler on mooring EG3 was one of the first instruments in the mooring array to fail and only worked until early October 2007. Therefore, the total number of spilling events recorded by the profiler is limited. This will make it hard to assess how frequently well-mixed layers like the one shown in Figure 3-22 occur as a result of spilling.

During the time period of the case study presented in this chapter, there is evidence for at least two more spilling events, though they were not measured as completely as the two examples described above. About 30 hours before the Type II event and then again roughly 24 hours after the Type I event, strong offshore velocities at mooring EG4 were registered. Some of the low temperature and salinity profiles shown in Figure 3-20 are associated with these offshore velocities, indicating the presence of

\footnotetext{
${ }^{1}$ For an upright ADCP, error velocities can occur if there are large horizontal velocity gradients or strong temporal variability during the measurement averaging time. In this case different beams of the ADCP at different times will insonify water flowing at different speeds leading to differing beam velocities and correspondingly large error velocities. For a tilted ADCP, vertical gradients in velocity can have the same effect. The inclination of the ADCP on EG3 for the time period in question was about $10^{\circ}$.
} 
spilled water from the shelf.

\subsection{Discussion}

In this chapter we have presented some of the pertinent features of DSOW cyclones by focusing on a case study of the three eddies that passed by the mooring array in September 2007. The general structure of the observed DSOW cyclones agrees with previous modeling studies such as Spall and Price (1998). In particular, the center inside of the radius of maximum azimuthal velocities, where ageostrophic effects play a leading order role, is $4-8 \mathrm{~km}$. The present analysis suggests that the strongest velocities of up to $0.5 \mathrm{~m} / \mathrm{s}$ in the cross-stream direction are found in the middle part of the water column which has undergone the strongest stretching. The bottom layer of DSOW flows equatorward and is up to $200 \mathrm{~m}$ thicker than in the absence of cyclones.

It was shown that there is a remarkable lateral variation in the pathways of the cyclones. Eddy 2 was located $\approx 11 \mathrm{~km}$ from the shelfbreak in $900 \mathrm{~m}$ deep water, while Eddy 3 was $\approx 27 \mathrm{~km}$ from the shelfbreak at $1400 \mathrm{~m}$ depth. A survey of the year-long mooring record has also found cyclones as far up the slope as EG3 at $4 \mathrm{~km}$ and $530 \mathrm{~m}$ depth and also as far down slope as mooring EG7 at $37 \mathrm{~km}$ and $1600 \mathrm{~m}$ depth. Bruce (1995) assumed that all of the cyclones travel at a similar depth and impact the SST signature of the EGC/IC front in a similar way. This assumption made it possible to infer eddy statistics from the signature observed in the SST record. However, Eddy 3 has no discernible SST signature because the surface velocities associated with it advect only warm Irminger Sea water around. This means that the study by Bruce (1995) misses DSOW cyclones similar to Eddy 3 and that the resulting statistics are therefore biased. For example, the eddy frequency will be higher if the 
additional eddies are included and the propagation velocity may be different if there is a systematic difference in propagation speed between eddies closer to and farther away from the shelfbreak. The inferred eddy propagation speed may also be different if the cyclones and the SST disturbance actually do not travel along with each other.

The variation in cross-stream locations of the eddies also suggests that the cyclones have differing vertical heights as they occupy all or part of a water column that ranges in height from roughly the Denmark Strait sill depth to more than twice this height. For comparison, the southernmost eddy of the numerical study by Spall and Price (1998) shown in Figure 3-11 is located at roughly 1600 m water depth. For the model sill depth of $1000 \mathrm{~m}$, this implies a total water column height increase of $60 \%$. It should be noted that this does not imply that the entire water column was stretched by $60 \%$, but rather that the middle layer likely increased in thickness by more than this while the top and bottom layers stretched to a lesser degree. This then leads to a middle layer stretching of $\approx 100 \%$ associated with Rossby numbers of order one. In our case, Eddy 2 resides in $900 \mathrm{~m}$ of water. Compared to the Denmark Strait sill depth of $650 \mathrm{~m}$, this implies a water column height increase of 40\%. Again taking into account that there is more stretching in the middle layer, it is feasible that the observed strong flow in Eddy 2 is due to vortex stretching qualitatively similar to the process described by Spall and Price (1998). It is, however, possible that the water did not flow through the deepest part of Denmark Strait at $650 \mathrm{~m}$. If, for example, it passed the sill at $600 \mathrm{~m}$, this would increase the water column stretching in the case of Eddy 2 to $50 \%$. For Eddy 3, the water column height increase is $115 \%$. Its structure as observed in Figure 3-19 is suggestive of the fact that it no longer is strictly barotropic. As the lower and middle layers descend, water above it may be replaced from the side rather than through stretching of the existing water. This would again lead to a consistent picture with order $100 \%$ stretching in the middle layer and lower 
values above and below.

It has been suggested that transport of DSOW and hence and the rate of deep water formation may be monitored from the SST and SSH signatures of DSOW cyclones (Haine, 2010). However, current generation SSH measurements do not resolve DSOW cyclones. Also, given that the relation between DSOW cyclones and SST disturbances is not clear, monitoring them from SST will not be straightforward and will require knowledge of how many and what kind of cyclones are missed in the SST record as well as how the two records relate to each other. Furthermore, the extent to which DSOW cyclones will have an impact on the SST expression of the EGC/IC front is likely time dependent. The surface expression of this front has interannual variability associated with changes in transport of the EGC and IC. There are also differences in the frontal intensity in winter due to sea-ice and generally colder offshore water temperatures. Therefore, it will not be possible to determine a single cross-stream location inshore of which DSOW cyclones have a discernible SST expression and offshore of which they do not. Additionally, this is complicated by the fact that cloud-free views of the East Greenland slope are only realized on a small number of days.

Spilling of dense water off the shelf was also documented during the time period of the case study. Both types of spilling events identified by Magaldi et al. (2011) were observed: a Type II event due to the passage of a cyclone (Eddy 2), and a Type I event triggered by an instability of the shelfbreak circulation. The entire year-long mooring record will have to be used in order to shed further light on these aspects, as well as to estimate how representative the three eddies in the case study are. Furthermore, documenting the frequency and horizontal distribution of the cyclones will add important context to the study of Bruce (1995). The cyclone speeds, strengths, and the transport associated with them will also need to be quantified from the longer 
time period data set.

\subsection{Acknowledgments}

Creation of the MODIS satellite data sets is credited to the NASA Ocean Biology

Processing Group (OBPG), the NASA Jet Propulsion Laboratory (JPL), and the University of Miami Rosenstiel School of Marine and Atmospheric Science (RSMAS). 


\section{Chapter 4}

\section{Mean Structure and Statistics of}

\section{Denmark Strait Overflow Water}

\section{Cyclones}

\subsection{Abstract}

Using data from a mooring array deployed across the East Greenland shelfbreak and slope $280 \mathrm{~km}$ downstream of Denmark Strait, we investigate the characteristics and dynamics of Denmark Strait Overflow Water cyclones. The cyclones pass by the array on average every two days and dominate the variability of the boundary current system. Their depth distribution is centered around the $900 \mathrm{~m}$ isobath while the overflow water transport in the background Deep Western Boundary Current is mainly achieved farther down the continental slope. There is no seasonality to either their frequency or their location on the slope. A composite cyclone was constructed using the year-long data set. This revealed that, on average, the features self-propagate at approximately $0.45 \mathrm{~m} / \mathrm{s}$ and are also advected by the depth-mean flow of $0.27 \mathrm{~m} / \mathrm{s}$, 
leading to a total propagation speed of $0.72 \mathrm{~m} / \mathrm{s}$. The velocity field of a typical cyclone is a Gaussian eddy with a radius of $7.8 \mathrm{~km}$ and a peak azimuthal speed of $0.22 \mathrm{~m} / \mathrm{s}$. In its core, the feature has a bottom density anomaly of $0.07 \mathrm{~kg} / \mathrm{m}^{3}$, containing Denmark Strait Overflow Water. The influence of the cyclones on the sea surface temperature (SST) field was investigated using satellite data. We find that disturbances to the shelfbreak SST front appear to propagate significantly slower than the underlying cyclones suggesting that SST imagery may be unsuitable for accurately tracking the subsurface eddies. In the absence of cyclones, we can explicitly determine the dominant component of the mid-slope background flow to be the East Greenland Spill Jet (it is also present when cyclones pass the array). This is a year-round feature transporting 2-4 Sv of shelf-origin dense water equatorward.

\subsection{Introduction}

The meridional circulation both in the atmosphere and ocean (with the exception of the South Atlantic) brings heat from low latitudes to high latitudes. The oceanic northward heat transport in the North Atlantic is achieved by the warm Gulf Stream in combination with the cold southward return flow of North Atlantic Deep Water (NADW) in the Deep Western Boundary Current (DWBC). The major regions of dense water formation renewing NADW in the northern North Atlantic are shown in Figure 4-1. Open ocean deep convection in the Labrador Sea (Lazier et al., 2002) and the Irminger Sea (Pickart et al., 2003) forms the lighter component of NADW. Warm Gulf Stream origin water enters the Nordic Seas west of Norway and east of Iceland. It circulates around the perimeter of the Nordic Seas (Norwegian Sea, Greenland Sea, Iceland Sea) and cools and densifies along that path (Mauritzen, 1996). Local convection north of Iceland has also been shown to form dense water (Våge et al., 2011). 

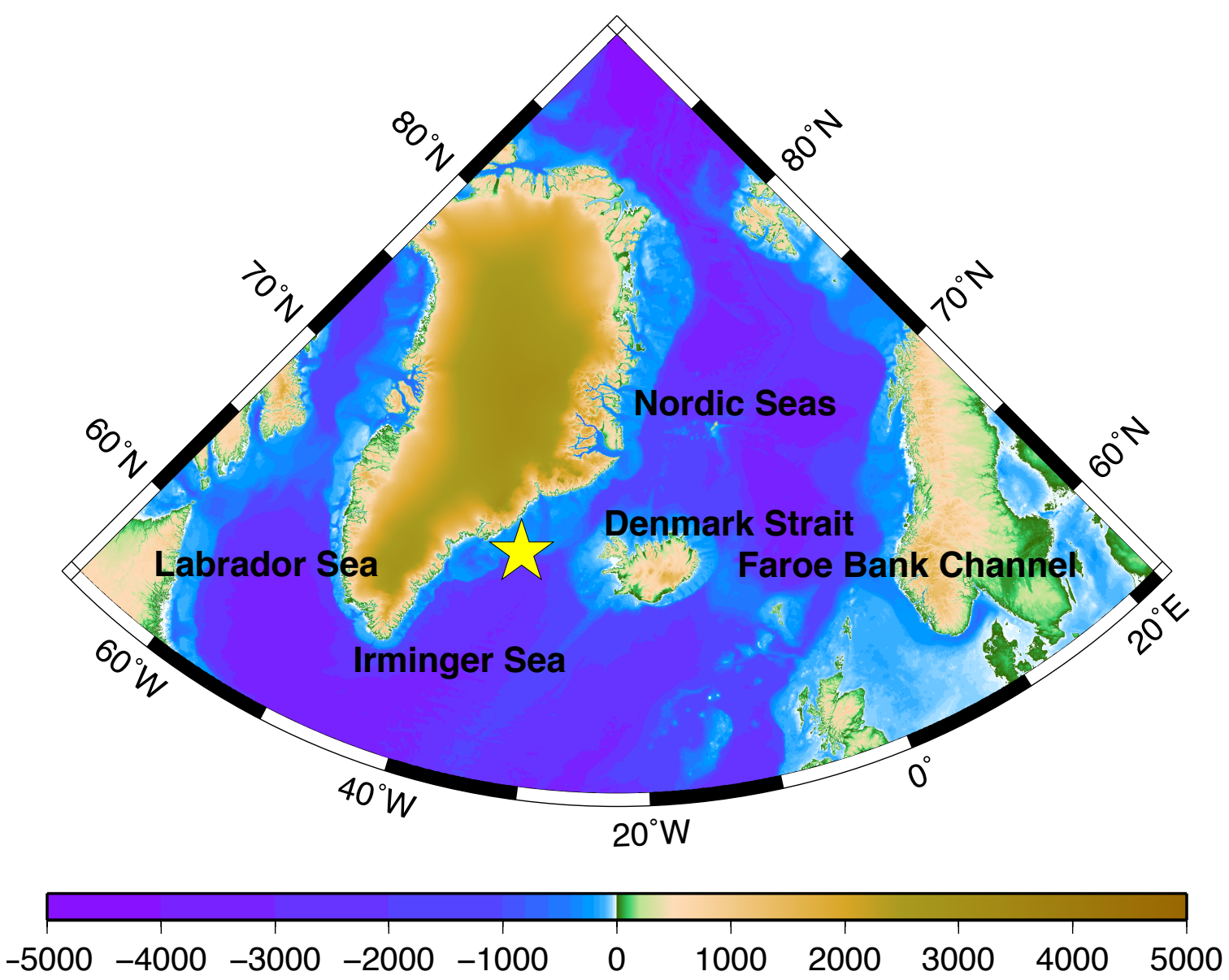

Figure 4-1: Elevation map (ETOPO Ice 1min grid) of the North Atlantic and the Nordic Seas. Seas and sills mentioned in the text are named. The location of the mooring array used in this study is marked with a yellow star.

The dense waters then overflow the deepest parts of the Greenland-Scotland Ridge in the Denmark Strait and the Faroe Bank Channel, forming the lower component of the NADW.

Denmark Strait exhibits striking mesoscale variability with flow speeds as fast as $1.4 \mathrm{~m} / \mathrm{s}$ (Worthington, 1969) over a timescale of a few days (e.g. Macrander et al., 2007). The features moving through the strait have been referred to as boluses and it is to be expected that there is some expression of them in the form of eddies south of the strait. The densest portion of the outflow from Denmark Strait (sill depth of 
$650 \mathrm{~m}$ ) is called Denmark Strait Overflow Water (DSOW). South of the sill it is denser than the ambient water at that depth and hence it sinks. As it descends, it accelerates and entrains ambient water reducing its density (Price and O'Neil Baringer, 1994). Since it is still dense enough to contribute to the dense component of NADW, water with potential density exceeding $27.8 \mathrm{~kg} / \mathrm{m}^{3}$ has traditionally been defined as DSOW south of Denmark Strait along the East Greenland slope (e.g. Dickson and Brown, 1994).

During its descent from the sill, the DSOW layer thickness as well as the layer thicknesses of the overlying water increase. Potential vorticity is conserved in the absence of frictional effects and mixing. Therefore, an increase in the water column height generates positive relative vorticity. This vortex stretching mechanism leads to cyclone formation. These cyclones are named "DSOW cyclones" because of the water in their core. The vortex stretching mechanism is illustrated in Figure 3-4 and also discussed in detail in Subsection 3.2.4.

Girton et al. (2001) observed the initial formation and descent of the DSOW cyclones just south of the sill. The subsequent evolution along the East Greenland slope was studied with an idealized numerical model by Spall and Price (1998) and with realistically configured simulations by Käse and Oschlies (2000) and Magaldi et al. (2011). However, observational studies to date have been limited to the one presented in Chapter 3 and to two surface-based studies. Krauss (1996) used the tracks of three surface drifters drogued at $100 \mathrm{~m}$ depth to identify three cyclonic features that moved southward along the East Greenland slope. One of the drifters remained in the cyclone for 8 loops. The velocity field of that eddy was explained as the sum of a background mean flow of $\approx 0.2 \mathrm{~m} / \mathrm{s}$, an eddy propagation of $\approx 0.3 \mathrm{~m} / \mathrm{s}$ near $65^{\circ} \mathrm{N}$ that slowed to $\approx 0.1 \mathrm{~m} / \mathrm{s}$ at $63^{\circ} \mathrm{N}$, and a rotational velocity component. The measurements suggested a Gaussian eddy with a peak azimuthal velocity (at 
$100 \mathrm{~m}$ depth) of $0.3 \mathrm{~m} / \mathrm{s}$ at a radius of $10 \mathrm{~km}$. The second observational study is by Bruce (1995) who used sea surface temperature (SST) images, such as Figure 3-3, to track disturbances ("hooks", "spirals", etc). Based on 33 observations, Bruce (1995) found that the features propagated at a mean speed of $0.27 \mathrm{~m} / \mathrm{s}$ with a mean radius of $17 \mathrm{~km}$. It was inferred that the time between consecutive eddies was 2.3 days on average. Bruce (1995) then compared the structures in SST with theoretical and laboratory studies and argued that the SST disturbances are the surface signature of the DSOW cyclones. Therefore, he identifies the statistics of the tracked features to be the statistics of DSOW cyclones on the East Greenland slope. These values have since become the "canonical" parameters of DSOW cyclones. They are, for example, used to estimate the performance of numerical models in that region.

The boundary current system along the East Greenland continental slope consists of three distinct components in addition to the variable flow associated with the DSOW cyclones. The East Greenland Current/Irminger Current is a surfaceintensified flow associated with the horizontal density gradient between the Arcticorigin water on the shelf and the warm North Atlantic-origin water in the interior Irminger Sea (Brearley et al., 2012). The East Greenland Spill Jet is a bottomintensified flow on the upper slope that is comprised of dense waters that "spill" off the shelf south of Denmark Strait and subsequently adjust to form a southward current (Pickart et al., 2005a). Finally, the Deep Western Boundary Current is the near-bottom southward flow that transports the densest part of the NADW (Dickson and Brown, 1994). Interestingly, mooring observations at Cape Farewell (the southern tip of Greenland) have found no sign of mesoscale variability similar to that of DSOW cyclones (Daniault et al., 2011a; Bacon and Saunders, 2010). This suggests that the DSOW cyclones spin-down and break up during their transit along the East Greenland slope. 
The formation of NADW is of global importance determining the flow and its properties in the world's oceans at depths below $\approx 1500 \mathrm{~m}$. Both the meridional heat transport and the medium term export ("sequestration") of climate relevant gases such as carbon dioxide are strongly affected by NADW renewal rates. As described above, the formation is essentially a two step process that begins with atmospheric cooling and densification at the surface and continues with the descent of the dense water to the deep northern North Atlantic and its modification along that pathway. The amount of entrainment of ambient ocean water into the dense water overflow plume determines the final properties of the newly formed NADW. As such, it is of high importance to quantify the processes that dictate the evolution of the flow during its adjustment south of the strait.

In order to better understand the nature of the flow along the East Greenland slope, including the Spill Jet and the DSOW cyclones, a mooring array was deployed approximately $280 \mathrm{~km}$ southwest of Denmark Strait for a year-long period. It is the aim of this chapter to untangle these flow features and to describe the dominant part of the variability of the system: the DSOW cyclones. This then allows us to isolate the Spill Jet and will contribute to our evolving understanding of the boundary current system and its impact on the entrainment and NADW formation.

\subsection{Methods}

This study employs the same mooring array that was used in Chapter 3. The data set has been described in detail in Section 3.3 and a cross-sectional view of the mooring array is shown in Figure 3-5. Because of the unexpectedly large velocities encountered during the deployment, all of the moorings exhibited significant (at times exceeding $400 \mathrm{~m}$ ) blow downs. During these conditions, the bottom ADCPs and the moored 
profilers did not function. However, the ADCPs mounted on the top floats of the moorings did record data, although deeper than their intended 0-100 m range. In addition, the downward looking ADCP on the top of mooring EG4 (water depth of $900 \mathrm{~m}$ ) was functional during these events. This provides a timeseries of velocity in the middle water column (between $260 \mathrm{~m}$ and $660 \mathrm{~m}$ depth) at EG4 that is essentially complete (less than 3\% data drop out). In addition, the bottom microcats continued to record temperature and salinity. As demonstrated in Chapter 3, the high velocities are due to the presence of DSOW cyclones.

We developed a methodology for identifying when and where DSOW cyclones passed the mooring array. This was done using all timeseries available at moorings EG3 to EG7 within a graphical user interface (GUI) programmed in MATLAB (for a screenshot see Figure 4-2). The timeseries were visually inspected in two-day segments and the time of passage of a DSOW cyclone was identified as a continuous variable, while the location was identified as a discrete variable that could take 15 discrete bin values: onshore of EG3, near EG3, offshore of EG3, onshore of EG4, near EG4, and so on up to offshore of EG7. The fact that the number of eddies identified to be in the extreme bins (onshore of EG3 and offshore of EG7) accounts for less than 5\% of all identified eddies suggests that these discrete bins essentially span the locations at which DSOW cyclones pass the mooring array.

The manual eddy detection scheme consisted of the following decision elements whose motivation is directly derived from the findings in Chapter 3. The first two elements are required for a cyclone identification, and the last three elements provide ancillary information.

1. A reversal in the cross-stream velocity from strongly offshore to strongly onshore is required for an eddy to be identified. The time of the eddy passage is chosen 


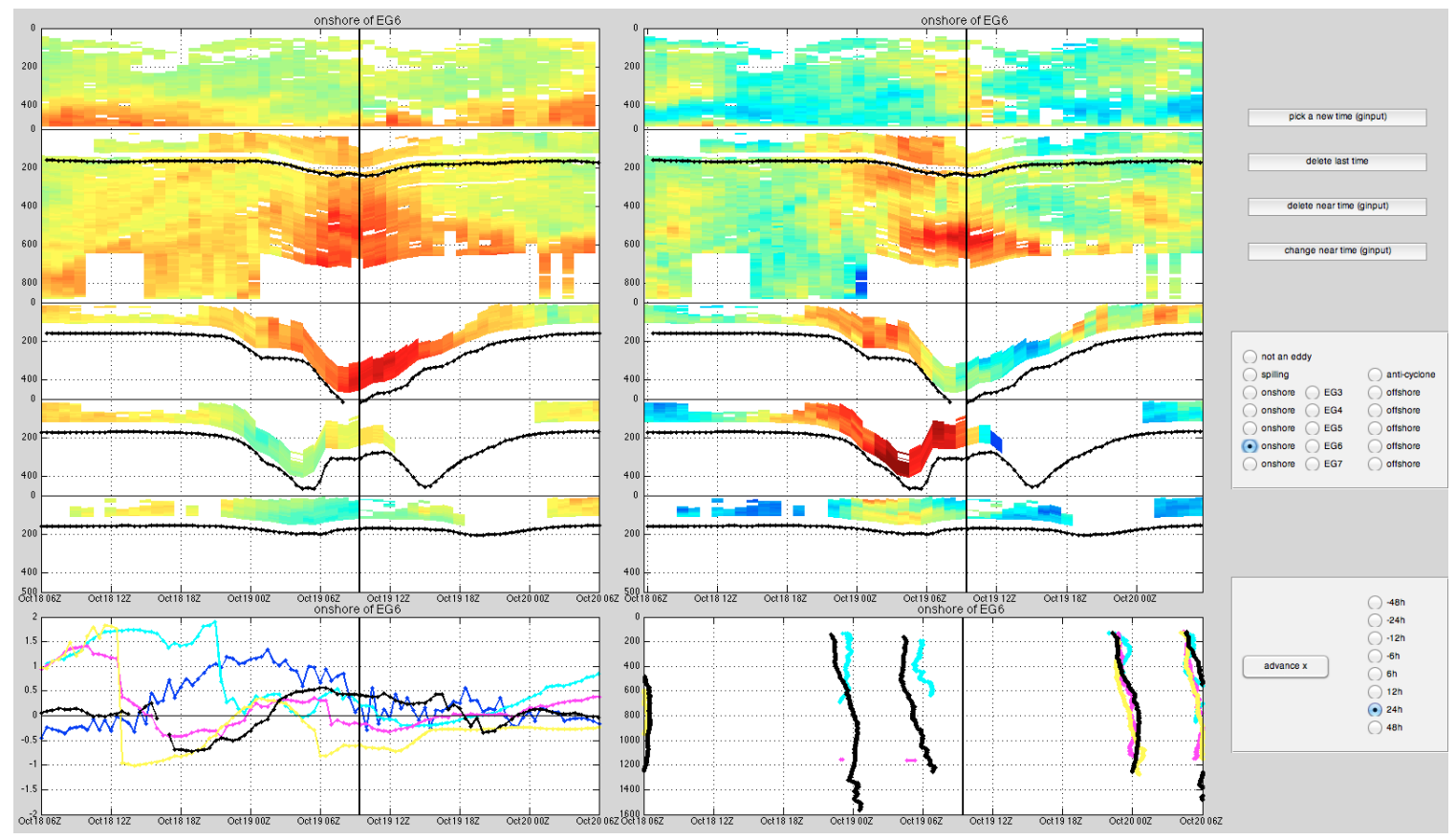

Figure 4-2: Screenshot of the eddy identification scheme using a Graphical User Interface programmed in MATLAB. The top left shows ADCP alongstream velocities at moorings EG3 (on top) to EG7 (on bottom) (red is $1 \mathrm{~m} / \mathrm{s}$, blue is $-1 \mathrm{~m} / \mathrm{s}$ ). Top right shows the corresponding cross-stream velocities (red is $0.5 \mathrm{~m} / \mathrm{s}$, blue is $-0.5 \mathrm{~m} / \mathrm{s}$ ). These are records similar to the ones shown in Figures 3-16 and 3-17. The black lines in both panels show the depth of the top microcat on the respective mooring. The bottom left panel shows the bottom potential temperature anomaly from the respective mooring record mean (compare to Figure 3-15). Bottom right panel shows profiles of potential density anomaly from the respective depth mean potential density at the respective mooring. Color coding in the two bottom panels is as follows: EG3: blue, EG4: cyan, EG5: magenta, EG6: yellow, EG7: black. A DSOW cyclone was identified to pass the array on Oct 19 10Z onshore of EG6 and is denoted by a vertical black line. 
to be the time when the cross-stream velocity reverses at the mooring closest to the eddy center (as defined from the other criteria below).

2. An increase in the downstream (positive alongstream) velocity is required for an eddy to be identified. Such an increase is indicative that the mooring in question is located near or onshore of the eddy center.

3. Vertical mooring motion (blow down) is a proxy for column-integrated speed. A double maximum in mooring motion indicates that mooring in question is near the center of the eddy inside of the radius of solid body rotation where the azimuthal velocity decreases toward the center of the eddy. A single maximum in mooring motion indicates that the respective mooring is near the edge of the eddy.

4. A decrease in downstream (positive alongstream) velocity at a mooring indicates that the mooring is offshore of the eddy center.

5. An increase and subsequent decrease in near-bottom potential density indicates the time of the passage of the eddy. The same inference is made from a decrease and subsequent increase in near bottom potential temperature.

The timing of the passage of the cyclones could be determined with the hourly resolution of the ADCPs. Therefore the time when each of the cyclones passed the array is known to within \pm 1 hour.

It should be noted that using these criteria and the full set of mooring array data makes it possible to place all of the 190 identified eddies unambiguously in no more than two cross-stream location bins. The final placement into one of those two bins was ambiguous at times, with different criteria pointing to different locations. This 
Table 4.1: Identification of the part of an eddy that mooring EG4 measures for different locations in the cross-stream direction where the center of the eddy passes the mooring array.

\begin{tabular}{|l|l|l|l|}
\hline $\begin{array}{l}\text { Location of eddy } \\
\text { relative to } \\
\text { moorings }\end{array}$ & $\begin{array}{l}\text { Where a measurement } \\
\text { at EG4 lies relative } \\
\text { to the eddy }\end{array}$ & $\begin{array}{l}\text { Cross-stream distance } \\
\text { relative to center } \\
\text { of mean eddy }\end{array}$ & $\begin{array}{l}\text { Number of } \\
\text { eddies } \\
\text { observed }\end{array}$ \\
\hline \hline near EG3 & near offshore edge of eddy & $6.6 \mathrm{~km}$ & 17 \\
\hline offshore of EG3 & offshore of eddy center & $4.4 \mathrm{~km}$ & 11 \\
\hline onshore of EG4 & just offshore of eddy center & $2.2 \mathrm{~km}$ & 33 \\
\hline near EG4 & at eddy center & $0 \mathrm{~km}$ & 33 \\
\hline offshore of EG4 & just onshore of eddy center & $-2.6 \mathrm{~km}$ & 10 \\
\hline onshore of EG5 & onshore of eddy center & $-5.3 \mathrm{~km}$ & 14 \\
\hline near EG5 & near onshore edge of eddy & $-7.9 \mathrm{~km}$ & 18 \\
\hline offshore of EG5 & onshore of eddy & $-10.7 \mathrm{~km}$ & 8 \\
\hline onshore of EG6 & onshore of eddy & $-13.5 \mathrm{~km}$ & 9 \\
\hline near EG6 & far onshore of eddy & $-16.3 \mathrm{~km}$ & 17 \\
\hline
\end{tabular}

should be considered as part of the uncertainty in the resulting location of the eddy as determined from this procedure.

The distance between neighboring moorings increases from $7 \mathrm{~km}$ on the upper slope to $10 \mathrm{~km}$ in deeper water. Since each DSOW cyclone center was uniquely placed into one of the 15 bins, the locations of the cyclone passages are known to within $2-3 \mathrm{~km}$ in the cross-stream direction. From a different perspective, we can consider what aspects of the passing cyclones an observer located at EG4 would see. The measurements at EG4 will then be a record of those specific aspects of the passing cyclones. For each eddy passage location, Table 4.1 shows where measurements at EG4 are relative to that passing. This information is used to construct a composite DSOW cyclone in Section 4.5. 


\subsection{Statistics}

In the 395 days of mooring array data, 190 cyclonic eddies were visually identified. Their cross-stream distribution is peaked around $y=10 \mathrm{~km}$ in the vicinity of EG4 at a water depth of $900 \mathrm{~m}$ (Figure 4-3). The eddy count decreases steeply in the onshore direction, and the histogram is consistent with the notion that there are no cyclones at or inshore of the shelfbreak. The distribution decreases less quickly in the seaward direction, and there are still eddy occurrences as far offshore as $40 \mathrm{~km}$ near mooring EG7 in 1600 m water depth. However, the shape of the distribution implies that the population of eddies offshore of the last bin is very small. The majority of the DSOW cyclones are near the $900 \mathrm{~m}$ isobath which implies a descent of $250 \mathrm{~m}$ from the $650 \mathrm{~m}$ deep Denmark Strait sill. This corresponds to a vortex stretching of $40 \%$ which would lead to the generation of a relative vorticity of $0.4 f$ in the absence of frictional effects.

While there are short-term trends, as happens for the running mean of any random function, there are no longer term trends to the cross-stream location of the eddy passage (Figure 4-4). In particular, there is no apparent seasonal signal to the eddy location. The separation time between consecutive eddies ranges from near zero to 8 days with a mean of 2.1 days, although the two extreme scenarios are rare (Figure 4-5). The first scenario corresponds to the situation when a cyclone passes far onshore (around EG3) and at nearly the same time, another cyclone passes far offshore (around EG7). The second scenario corresponds to extended periods with no cyclones at all. As with the cross-stream distribution of the cyclones, the cyclone separation timeseries (Figure 4-4) does not exhibit any longer term trends and no seasonality. The atmospheric forcing in this region has a large seasonal signal with strong storms in fall and winter and relatively light winds in summer. The fact that 

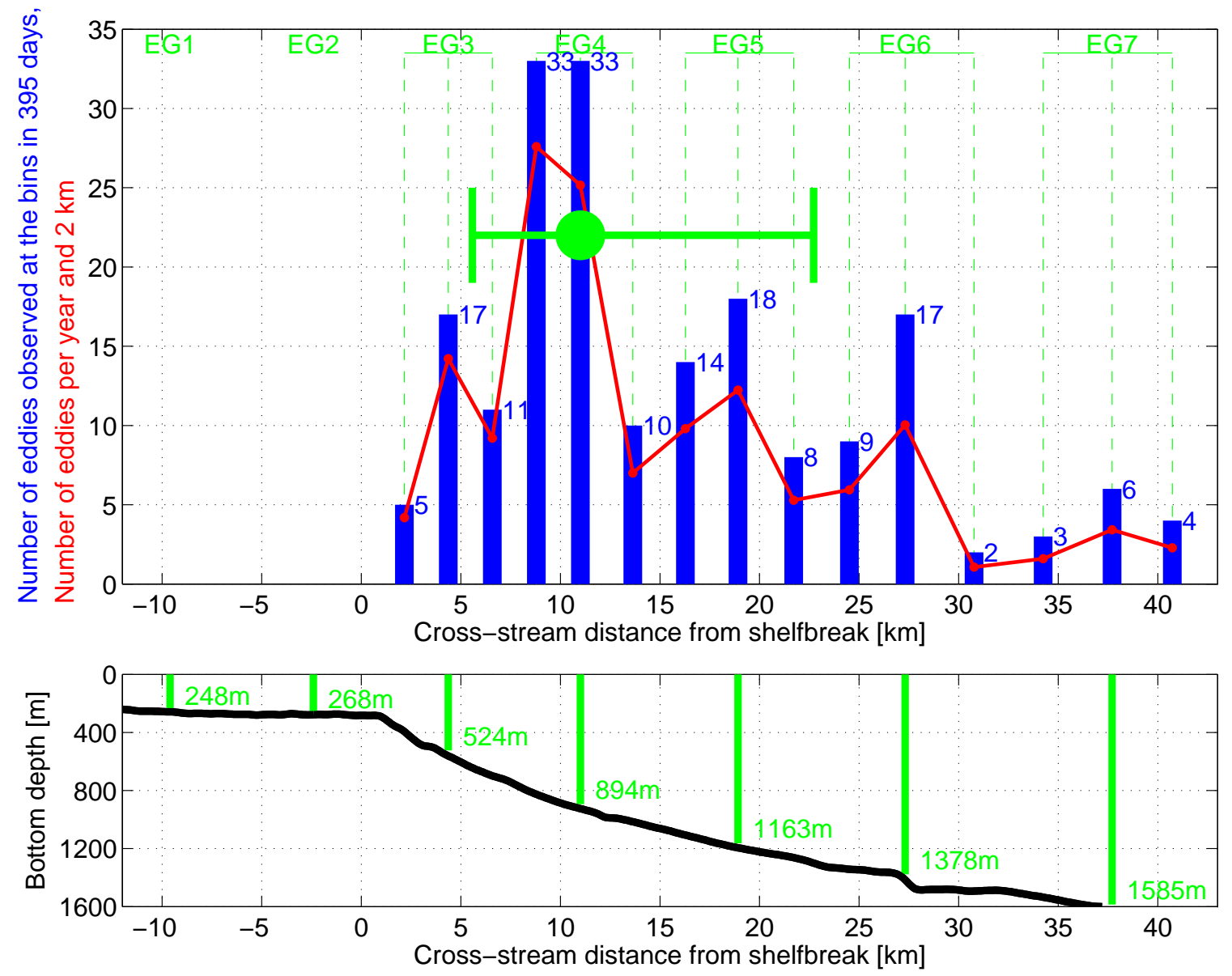

Figure 4-3: Top panel: Histogram of cross-stream distribution of the 190 identified eddies. The three bins (onshore, near, and offshore) that are related to each mooring are shown with the dashed green lines. The blue bars are a histogram of the 190 eddies identified in 395 days in the bins that become wider in the offshore direction. The red line normalizes the histogram to 1 year (365 days) and $2 \mathrm{~km}$ cross-stream distance. Bottom panel: Cross-stream bottom depth profile. Mooring locations are highlighted. 
the DSOW cyclone statistics show no resemblance of this seasonality implies that they are not influenced by the atmosphere, and that the dynamics of their formation and propagation is a purely oceanic phenomenon.

On average an eddy passes by the array every other day which means that they are a ubiquitous feature of the flow in this region. The separation time of 2.1 days is close to the 2.3 days that was computed by Bruce (1995) using SST data. However, the separation time in that study was computed as the distance between consecutive eddies $(54 \mathrm{~km})$ divided by the translational speed $(0.27 \mathrm{~m} / \mathrm{s})$. As we will show in the next section, Bruce (1995) appears to significantly underestimate the actual in-situ translational speed of the DSOW cyclones. Therefore the agreement between the two separation time estimates is coincidental.

\subsection{Composite Cyclone}

As mentioned in Section 4.3, the only complete velocity timeseries returned by the array is in the middle water column at mooring EG4. Fortuitously, the vast majority of DSOW cyclones passed the array in the vicinity of EG4 (Figure 4-3). We now describe a statistical method that maps out the full three dimensional velocity structure of a composite DSOW cyclone using only the EG4 data.

The data at EG4 capture different parts of the passing cyclones depending on their proximity to the mooring (see Table 4.1 for a listing of those distances). In a statistical sense, there is a structure that represents the mean of all the eddies that passed at a particular water depth while eddies farther onshore and offshore are going to be different in some sense (e.g. the degree of vertical stretching). We assume that such changes in characteristics are weak over the cross-stream distance spanned by an eddy (shown below to be approximately $15 \mathrm{~km}$ ). Hence our measurements at EG4 are 

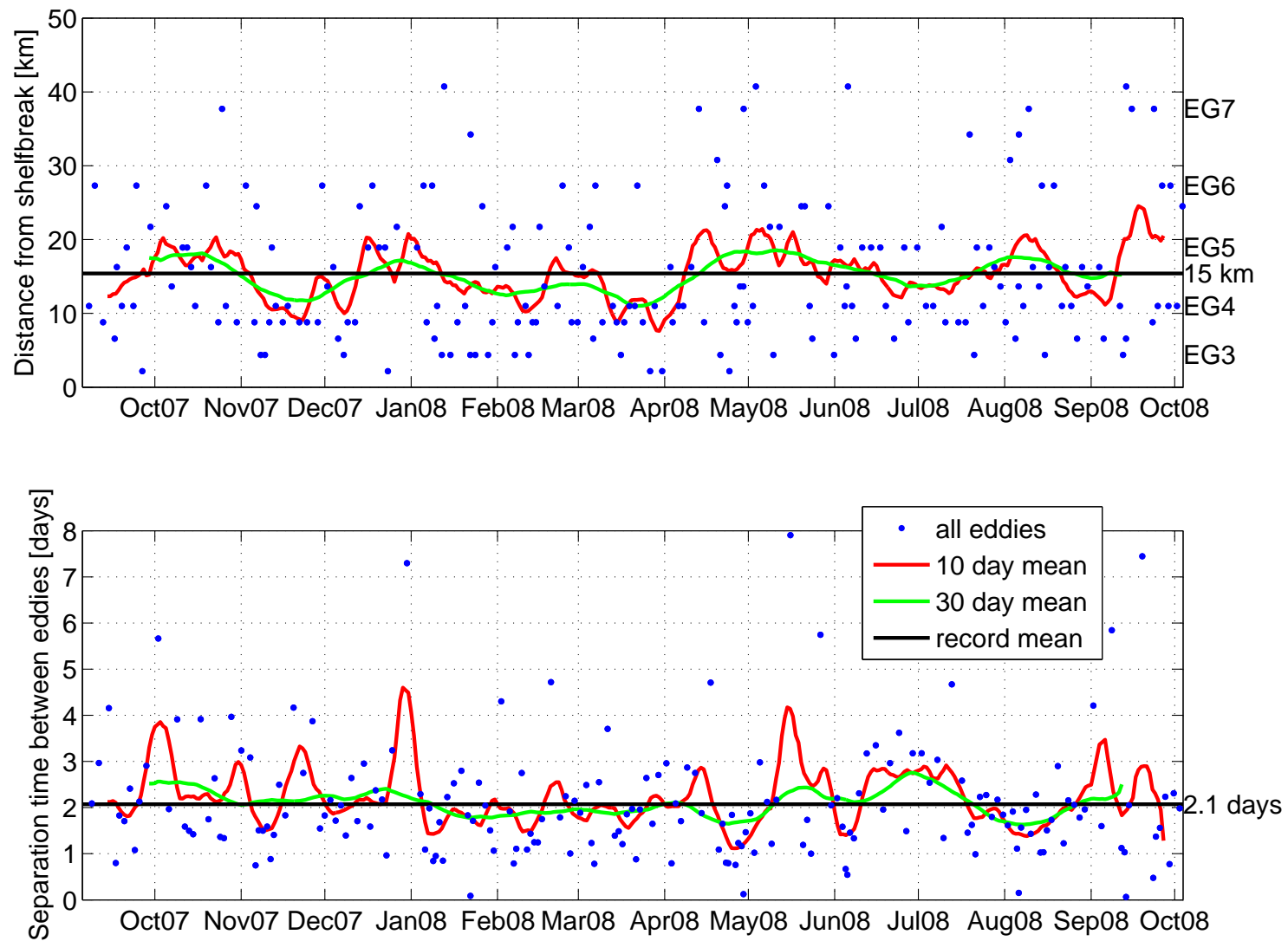

Figure 4-4: Timeseries of the 190 identified eddies. Top panel shows the location at which the eddies (blue dots) were found in the cross-stream direction. Note that the location is quantized to the same bins that are shown in Figure 4-3. Red and green lines are running mean values over 10 days and 30 days respectively. The record mean of $15 \mathrm{~km}$ is shown in black and corresponds to a water depth of about $1050 \mathrm{~m}$. Bottom panel shows the time between successive eddies passing the array with the record mean being 2.1 days. Note that there are no seasonal trends in either of the two statistics shown. 


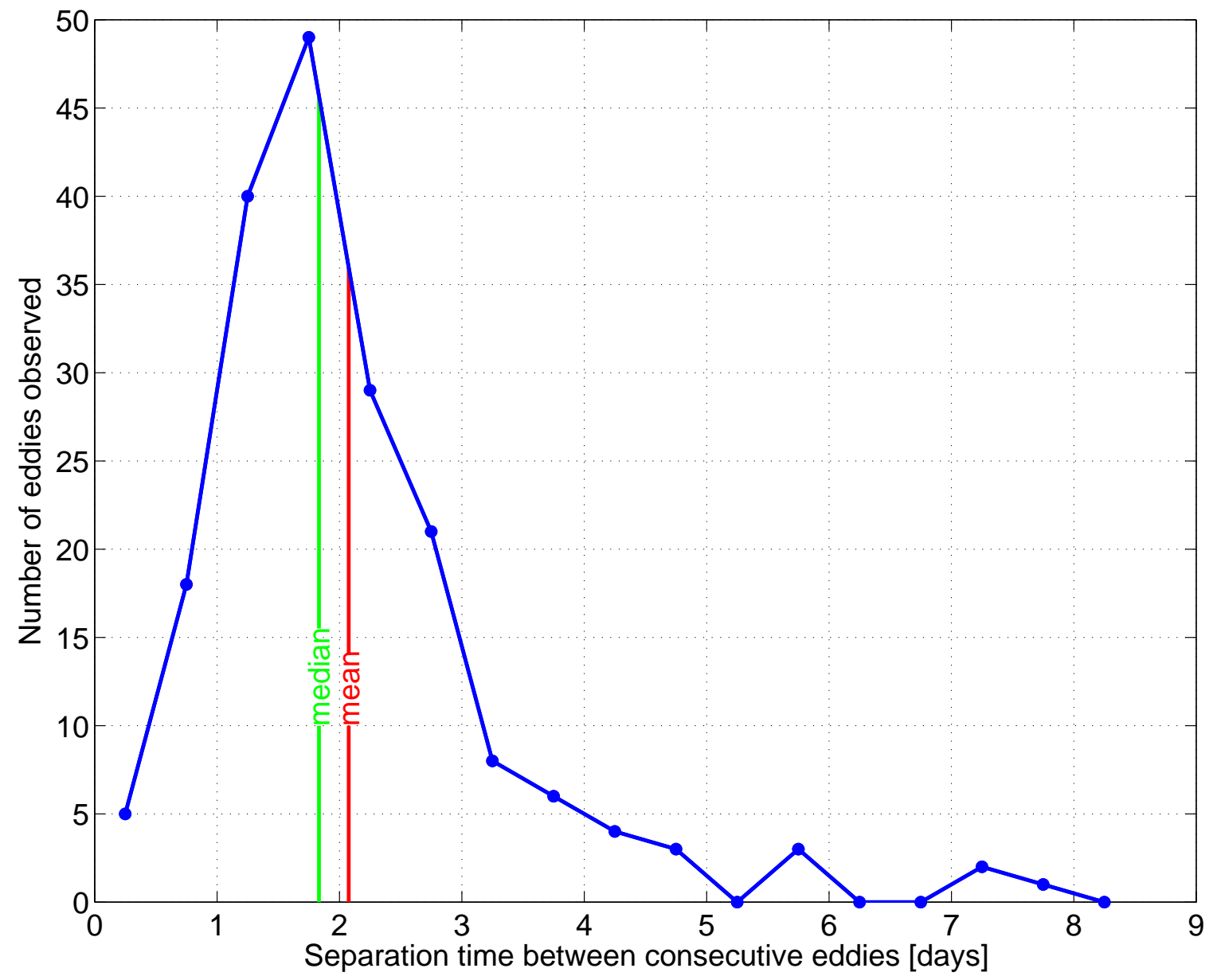

Figure 4-5: Histogram of separation times between consecutive eddies. Times are binned to $\pm 1 / 4$ day of the shown time. The mean of 2.1 days and the median of 1.8 days of the distribution is also shown. 
taken to represent slices through this mean structure at different horizontal distances from the center. Based on this assumption of slow cross-stream variation, we now composite the mean structure of DSOW cyclones in the vicinity of mooring EG4.

\subsubsection{Depth Mean Structure of the Composite Cyclone}

We start with the depth mean velocity field of the composite cyclone in the middle part of the water column, between $260 \mathrm{~m}$ and $660 \mathrm{~m}$, where the velocity measurements are complete. In the next subsection we will examine the vertical structure of the typical DSOW cyclone. Figure 4-6 shows the depth mean velocity field in a top down view with the center of the cyclone at $(0,0)$. The observer is situated on the East Greenland shelf looking offshore, so that the mean flow and the cyclone translation are towards the right. Bins in the cross-stream direction are averages from all the eddies that passed at that particular offset from EG4 as outlined in Table 4.1. The alongstream distance was resolved as the temporal offset with respect to the time when the eddy passed the mooring array. Times are indicated at the top of the plot with negative values corresponding to times preceding the arrival of the eddy

center. We used the propagation velocity of the eddy (which we derive in detail below) to transform the temporal measurements into alongstream distance, plotted on the horizontal axis. Color shows the depth mean speed in each bin and the black lines indicate the vector velocity. The white line near $-11 \mathrm{~km}$ corresponds to the approximate location of the shelfbreak in this transformed coordinate system.

This full velocity field is the sum of four different components which we determine in the following. The first component is the background mean flow that is also present in the absence of DSOW cyclones. The next is the velocity with which the fluid in the cyclone propagates. As this fluid propagates along the East Greenland slope, it 
$(u, v)$ : Depth mean $(260 \mathrm{~m}-660 \mathrm{~m})$ velocity $[\mathrm{m} / \mathrm{s}]$
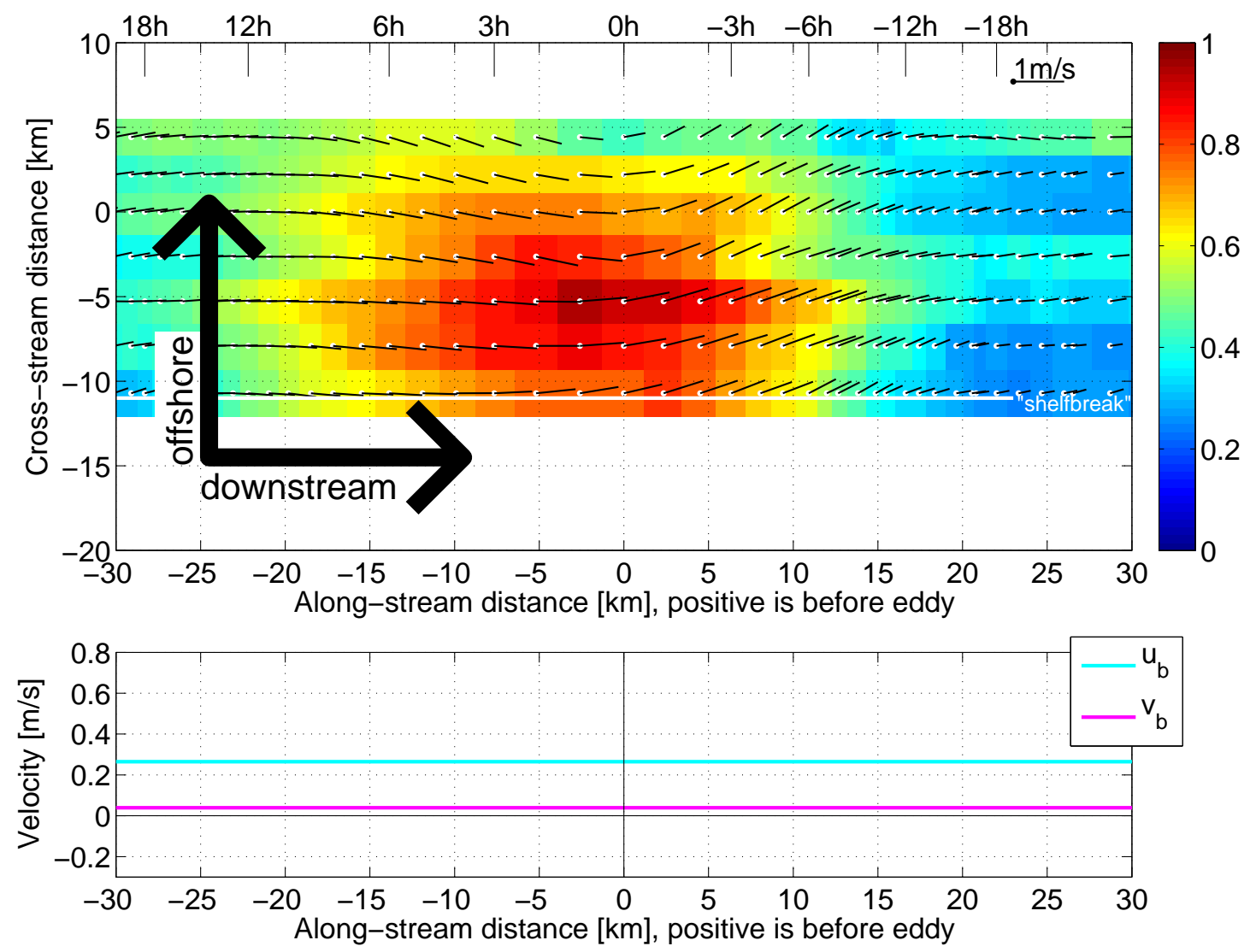

Figure 4-6: $(u, v) 260 \mathrm{~m}-660 \mathrm{~m}$ depth mean velocity of the composite cyclone: Top panel shows a top down view of the total velocity field during the cyclone passage. The center of the cyclone is located at the origin $(0,0)$. The color of the bins is the speed and the black lines show the vector velocity with a $1 \mathrm{~m} / \mathrm{s}$ scale bar in the top right corner. Refer to the text for the construction of this field. We sequentially decompose this full velocity field into its components. The first two velocity components are shown in the bottom panel: the background alongstream $u_{b}$ and the background cross-stream $v_{b}$ velocities in absence of DSOW cyclones. 
induces a velocity in the ambient fluid and this is the third velocity component. This also contains any motions in the wake of the cyclone. The final component is the azimuthal flow around the cyclone center. The available data allows us to constrain the background velocity $\left(u_{b}, v_{b}\right)$ which is uniform in space. The second and third velocity components have a full along-stream and cross-stream structure. Unfortunately, the available data only allows us to determine the along-stream structure of these combined two velocity components. We call this velocity associated with the translation of the cyclone and the induced velocity co-translational velocity and only determine its lowest order structure $u_{c}(x)$-the along-stream component which is a function of the along-stream distance $x$. Finally, we determine the azimuthal velocity as a function of the radius from the center of the cyclone. At each location, it has a component that is directed into the alongstream direction and a component directed into the cross-stream direction: $\left(u_{a}(r), v_{a}(r)\right)$. The above components are all considered to be depth mean quantities. The vertically varying component of the background flow $u_{b}^{\prime}(z)$ and the vertically varying components of the azimuthal flow $\left(u_{a}^{\prime}(r, z), v_{a}^{\prime}(r, z)\right)$ are determined in Subsection 4.5.2 below.

There is significant flow well before and after the passage of a cyclone, associated with the mean flow of the East Greenland/Irminger Current as well as the Spill Jet (Pickart et al., 2005a). The influence of the DSOW cyclone extends for less than 18 hours before and after its center passage (Figure 4-6). About 140 days (roughly $35 \%$ of the velocity record) are more than 18 hours away from the center of a DSOW cyclone passing anywhere by the mooring array. The depth mean background flow in the alongstream direction is $u_{b}=0.27 \mathrm{~m} / \mathrm{s}$, and $v_{b}=0.04 \mathrm{~m} / \mathrm{s}$ directed offshore. These components are shown in the bottom panel of Figure 4-6. We will discuss the full cross-stream and depth structure of the background flow in the absence of DSOW cyclones in more detail in Section 4.7. 

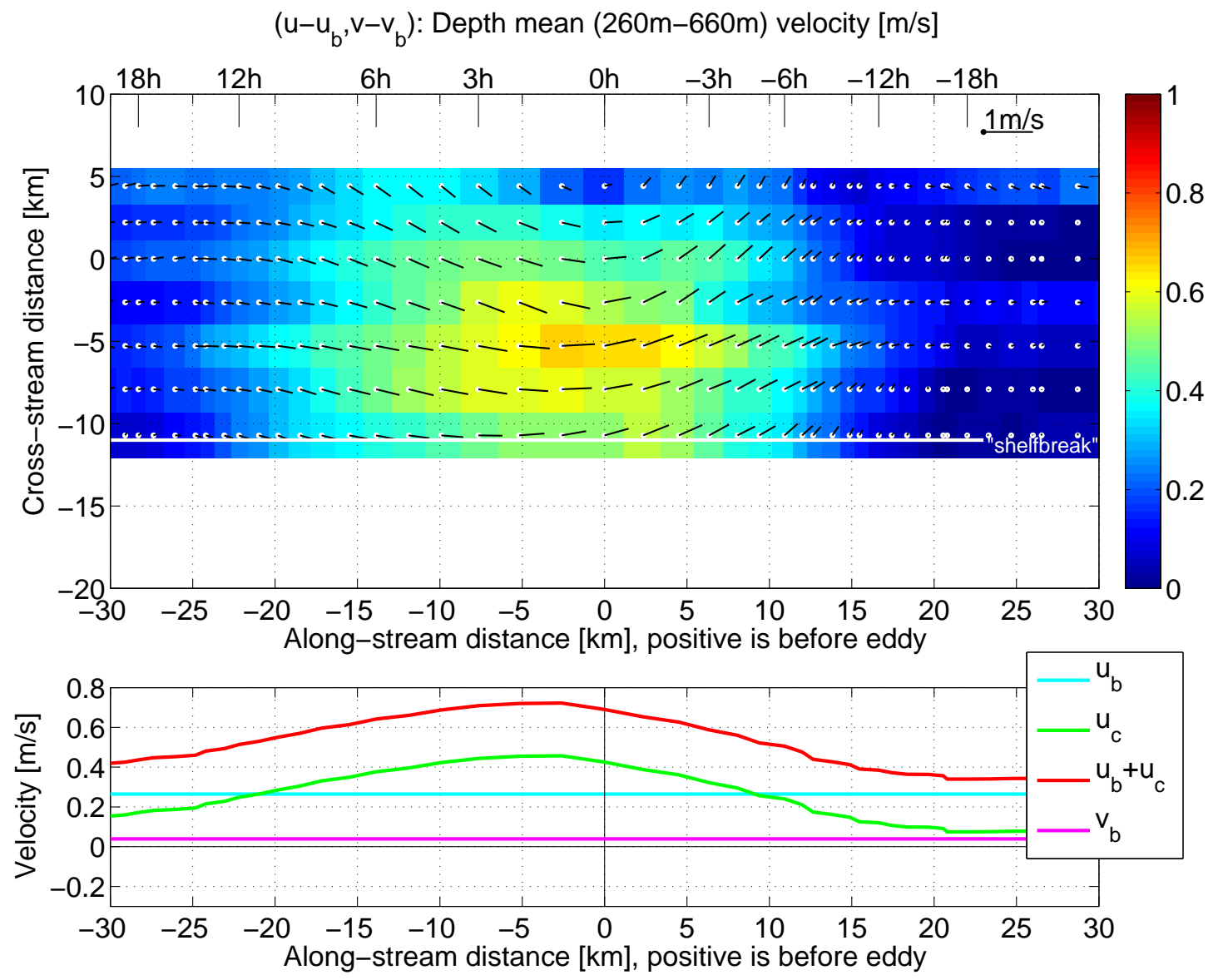

Figure 4-7: $\left(u-u_{b}, v-v_{b}\right) 260 \mathrm{~m}-660 \mathrm{~m}$ depth mean velocity in the top panel. Bottom panel: co-translational velocity $u_{c}(x)$ of the cyclone with respect to the background mean flow (green) as well as the co-translational velocity $u_{b}+u_{c}(x)$ of the cyclone with respect to the bottom (red). 
Subtracting $\left(u_{b}, v_{b}\right)$ from the full flow field reveals the velocity structure of the eddy with respect to the background mean flow (Figure 4-7). On its onshore side (negative cross-stream distance), the positive translational velocity and the positive azimuthal velocity superpose resulting in the observed strongly positive down-stream velocity. On its offshore side, the positive translational velocity and the negative azimuthal velocity result in very weak downstream flow. Along the center slice of the cyclone $(y=0)$, the alongstream velocity is only due to the translation of the fluid inside of the cyclone and to the motion that is induced in the ambient fluid that needs to make way for the passing cyclone. In particular, the azimuthal velocities of the eddy do not contribute to the co-translational velocity $u_{c}(x)$ along $y=0$. The same is true for the cross-stream average over an area that is symmetric around $y=0$. In order to decrease the noise level of the estimate of $u_{c}(x)$, we average the velocities in each temporal offset bin between $y=-6 \mathrm{~km}$ and $y=6 \mathrm{~km}$ to obtain the profile of the co-translational velocity $u_{c}(x)$ shown in green in the bottom panel of Figure 4-7.

Away from the cyclone there is very weak flow with essentially no structure. The co-translational velocity increases from near zero before the cyclone until it reaches a maximum of $0.45 \mathrm{~m} / \mathrm{s}$ about $2.5 \mathrm{~km}$ downstream of the center of the cyclone decreasing thereafter (but not back down to zero). We assume that the maximum approximately corresponds to the translational velocity of the cyclone with respect to the mean flow and determine it to be $u_{t}=0.45 \mathrm{~m} / \mathrm{s}$. This is consistent with the model of an isolated self-advecting eddy that could be envisioned as a vertical cylinder ("pipe") being dragged through a fluid. The alongstream flow is due to the translation of a circularly symmetric feature, to the induced motion in the ambient fluid and to the advective motion in the wake of the feature. As the wake will only be present behind the cyclone, the velocities there are stronger than in front of the cyclone and the velocity structure is not symmetric around the cyclone center. Since DSOW 
cyclones are not step discontinuities in properties (such as a dragged pipe would be), the co-translational velocity has to ramp up to and down from its center value in some smooth fashion as can be observed in Figure 4-7. The detailed theoretical prediction for what $u_{c}(x)$ should be for a baroclinic Gaussian eddy on a $\beta$-plane with stratification is complicated and beyond the scope of the present work. Therefore, we only note that the three main qualitative elements of $u_{c}(x)$ agree between our observations and the expected structure: near zero velocity at great distances from the cyclone, nearly constant translational velocity in the small approximate solid body core near the center of the cyclone advecting fluid with the cyclone at this nearly constant velocity, and a smooth ramp up/down of the induced motion in the domain of influence of the cyclone in the ambient fluid.

The co-translational velocity is expected to be non-divergent:

$$
\nabla \cdot \overrightarrow{u_{c}}=\frac{\partial u_{c}}{\partial x}+\frac{\partial v_{c}}{\partial y}+\frac{\partial w_{c}}{\partial z}=0
$$

The order of magnitude of $\frac{\partial u_{c}}{\partial x}$ is $\approx 1-2^{*} 10^{-5} \mathrm{~s}^{-1}$. With the Rossby number $\approx 0.2$ (as shown below), this means that this component of the divergence is $\lesssim R_{0} * f$. While we are not able to determine the cross-stream velocity $v_{c}$ or the vertical velocity $w_{c}$ from the available measurements, we can infer their order of magnitude assuming that they balance the along-stream divergence. If the flow around the cyclone is horizontal, the order of magnitude of the cross-stream velocity would be be $\approx 0.05-0.1 \mathrm{~m} / \mathrm{s}$ over a length scale of $\approx 5 \mathrm{~km}$ for the fluid to pass around the cyclone in Taylor columns. However, a vertical velocity of $\approx 3-6^{*} 10^{-3} \mathrm{~m} / \mathrm{s}$ over a height of $300 \mathrm{~m}$ would also balance the along-stream divergence and could facilitate the isopycnal displacement shown in Figure 4-21 below.

The self-advection mechanism of a DSOW cyclone is consistent with the propaga- 
tion of a finite amplitude, non-linear topographic Rossby wave. The restoring force for a topographic Rossby wave is the change in potential vorticity experienced as a vortex column migrates into deeper or shallower water. For long waves, the linear topographic Rossby wave speed is (Pedlosky, 2003):

$$
c=-\beta R_{d}^{2}=\frac{f_{0}}{H_{0}} \frac{d H}{d y} R_{d}^{2}
$$

where $R_{d}$ is the internal Rossby radius, $\beta=\frac{d f}{d y}=\frac{-f_{0}}{H_{0}} \frac{d H}{d y}$ is the topographic $\beta, f$ the Coriolis frequency, and $H_{0}$ the mean water depth of the isobath along which the topographic Rossby wave propagates. We take $H_{0}$ as the bottom depth of EG4 (900 m), and estimate the slope as the difference in water depth between EG3 and EG5 $(650 \mathrm{~m})$ divided by their separation $(14 \mathrm{~km})$. There are different ways to estimate the internal Rossby deformation radius $R_{d}$ depending on the presumed depth of the fluid that partakes in the motion. Considering a mean stratification $N=2.3^{*} 10^{-3} 1 / \mathrm{s}$ (Figure 4-20) over the full water column $H=900 \mathrm{~m}$ yields an upper estimate of the Rossby radius $R_{d}=\frac{N H}{f}$ of $\approx 16 \mathrm{~km}$. If on the other hand we consider the bottom density anomaly $\Delta \rho=0.1 \mathrm{~kg} / \mathrm{m}^{3}$ (Figure 4-11) to be responsible for motions over the vertical distance of the isopycnal displacement $h=300 \mathrm{~m}$ (Figure 4-21), we obtain a lower estimate $R_{d}=\frac{1}{f} \sqrt{\frac{\Delta \rho}{\rho} g h}$ of $\approx 4 \mathrm{~km}$ (here $g$ is the acceleration due to gravity) or $R_{d}=\frac{1}{f} \sqrt{\frac{\Delta \rho}{\rho} g H} \approx 7 \mathrm{~km}$ if we consider the motions to be present across the full water column depth $H$. As shown below, the approximate radius of the cyclones is $8 \mathrm{~km}$ which is why we take $R_{d}=8 \mathrm{~km}$ as an intermediate estimate in order to find the scale of the topographic Rossby wave speed of $\approx 0.45 \mathrm{~m} / \mathrm{s}$, while we stress the large uncertainty in this estimate. This estimated wave speed is similar to our observational estimate of the self-advection velocity with respect to the mean flow $u_{t}$. There will be a significant $O(1)$ correction factor that is due to the difference between linear 
wave dynamics and the non-linear finite amplitude vortex dynamics of the DSOW cyclones. Nonetheless, the order of magnitude agreement suggests that the restoring force associated with the deflection of a vortex column can account for the observed self-advection.

Another process leading to self-advection of isolated vortices on a sloping bottom invokes a mirror vortex behind the topography (i.e. on the other side of the wall if the sloping bottom is considered as a wall). The self-advection velocity due to this process is weaker than the maximum azimuthal velocity of the vortex. As shown below, the maximum azimuthal velocity of the DSOW cyclones is $0.22 \mathrm{~m} / \mathrm{s}$, and therefore this process cannot be responsible for the observed translational velocity.

The sum of the translational velocity with respect to the mean flow, $u_{t}$, and the background mean velocity, $u_{b}$, is the velocity with which the cyclone translates with respect to the bottom. It reaches a maximum of $0.72 \mathrm{~m} / \mathrm{s}$ (Figure $4-7$ ). The sum of the background velocity $u_{b}$ and the co-translational velocity $u_{c}(x)$ is the velocity of a fluid parcel with respect to the bottom and this is the velocity that was used to transform time with respect to center passage into alongstream distance in all the figures and computations of this chapter.

Next we remove both the background mean flow and the co-translational velocity to reveal only the cyclonic flow of the eddy (Figure 4-8). One sees that there is no flow at the center and that it increases radially from there outward before decreasing again. Three concentric circles are shown for visual guidance. It is clear that the majority of the flow is tangential to those circles as would be expected for an azimuthal flow.

When plotted as a function of radius, the azimuthal velocities nicely reveal the structure of an eddy (Figure 4-9). While there is obvious scatter due to random noise, a smoothed $1 \mathrm{~km}$ running mean of the azimuthal velocities shows a very clear signal. Starting from zero, the swirl speed increases nearly linearly, reaches a maximum near 


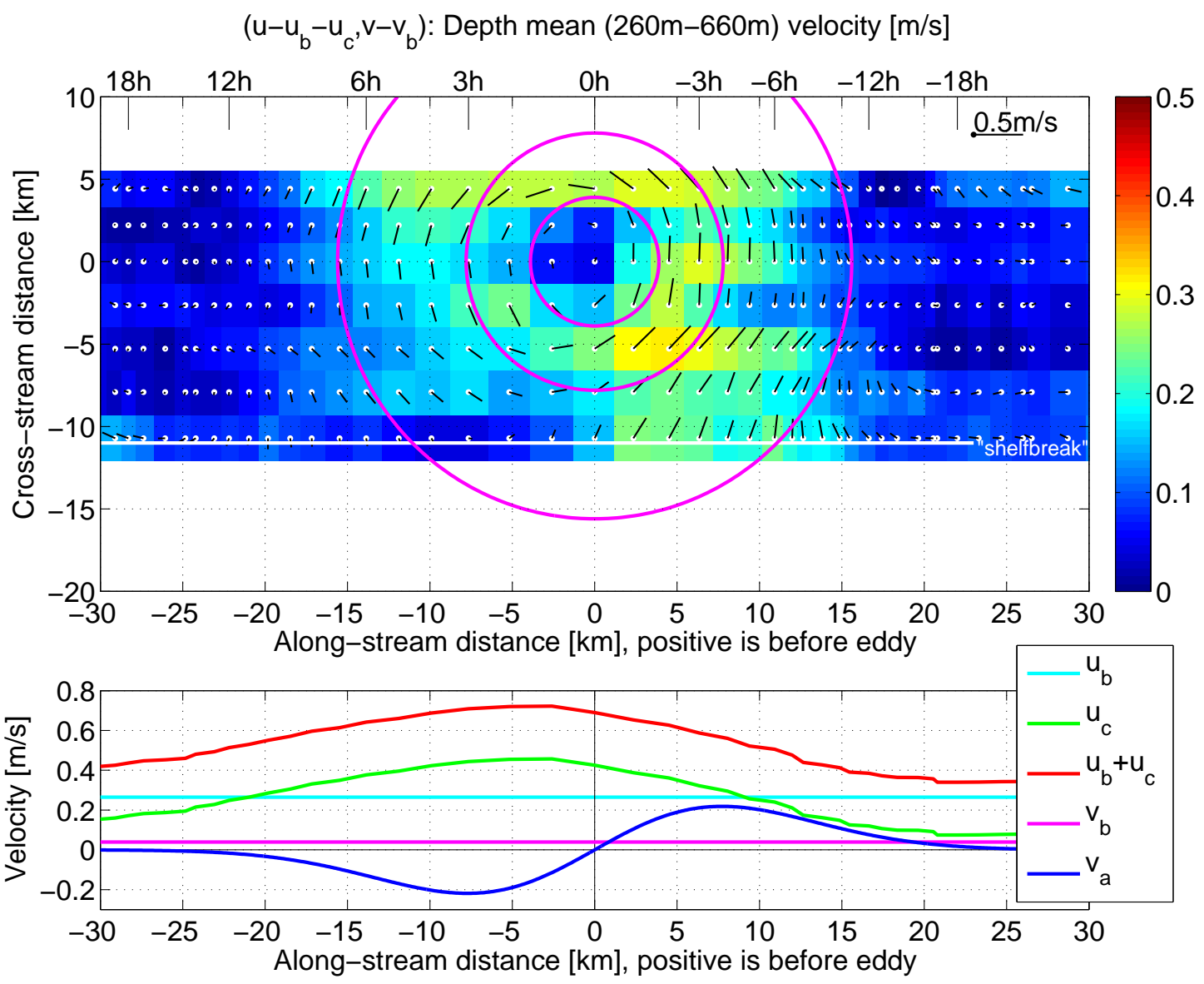

Figure 4-8: $\left(u-u_{b}-u_{c}, v-v_{b}\right) 260 \mathrm{~m}-660 \mathrm{~m}$ depth mean velocity in the top panel. Note that the color scale and the vector velocity scale have been reduced to $0.5 \mathrm{~m} / \mathrm{s}$. The concentric circles have radii $0.5 R_{0}, R_{0}$, and $2 R_{0}$ where $R_{0}=7.8 \mathrm{~km}$. Bottom panel: Cross-steam azimuthal velocity of the Gaussian eddy fit from Figure 4-9 shown in blue. 


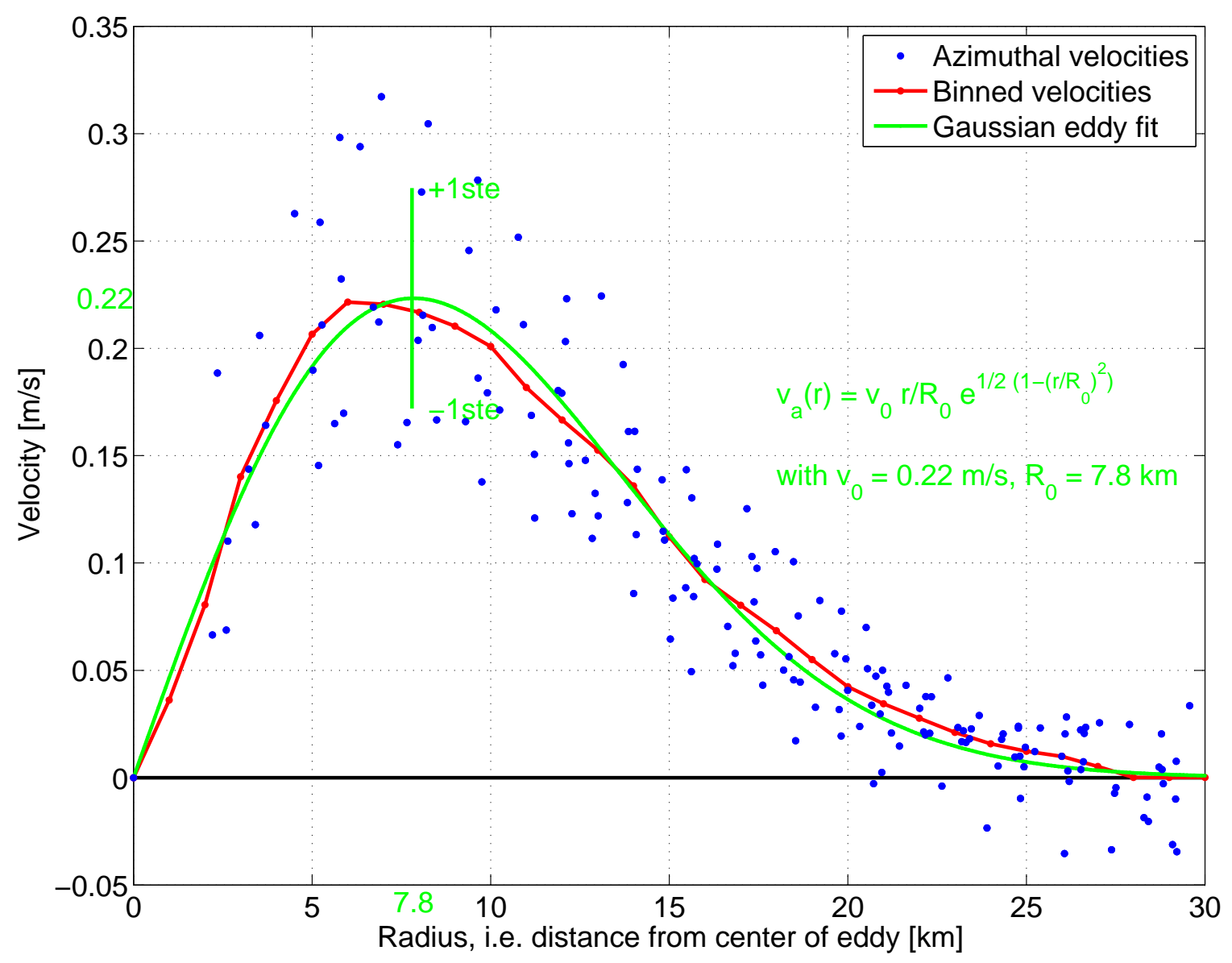

Figure 4-9: Azimuthal velocities defined as the azimuthal component relative to the center $(0,0)$ of the depth mean of $\left(u-u_{b}-u_{c}, v-v_{b}\right)$ plotted versus the radius. Each blue dot corresponds to one bin (colored rectangular box) in Figure 4-8. The red curve is a smoothed $1 \mathrm{~km}$ running mean of the blue dots and the green curve is a least squares fit of a Gaussian eddy model to the red curve. The equation of the fit is given and results in a maximum azimuthal velocity of $0.22 \mathrm{~m} / \mathrm{s}$ and a radius of $7.8 \mathrm{~km}$. We estimate the uncertainty from the standard deviations of the azimuthal velocities estimated from each individual passing cyclone. The minimum number of degrees of freedom is the 10 cyclones passing offshore of EG4 (compare Figure 4-3). The standard deviation divided by the square root of the minimum number of degrees of freedom is the standard error. It is about $23 \%$ and is shown with the vertical green bar. 
$6 \mathrm{~km}$ and then decreases smoothly to near zero around 25-30 km. A simple Rankine vortex (velocity proportional to the radius up to a distance and then inversely proportional to the radius) which results from an isolated step discontinuity in potential vorticity reproduces the linear increase due to solid body rotation near the center, but is not a good model farther out as it does not decrease quickly enough. In contrast, a Gaussian eddy which results from a smooth PV anomaly is an excellent model as can be seen from the green fit in Figure 4-9. A Gaussian eddy is the following model:

$$
v_{a}(r)=v_{0} \frac{r}{R_{0}} e^{\frac{1}{2}\left(1-\left(\frac{r}{R_{0}}\right)^{2}\right)}
$$

The azimuthal velocity increases nearly linearly up to a radius $R_{0}$ where it smoothly reaches its maximum velocity $v_{0}$. Beyond that radius, the decrease is Gaussian (proportional to $\left.e^{-r^{2}}\right)$. The eddy only has vanishingly small amplitudes beyond three radii. Unlike the Rankine vortex, the influence of the Gaussian eddy is well bounded. The fit shown in Figure 4-9 leads an eddy radius $R_{0}=7.8 \mathrm{~km}$ and a peak azimuthal depth mean velocity $v_{0}=0.22 \mathrm{~m} / \mathrm{s}$. This velocity profile will be used in Subsection 4.5 .4 to infer the pressure field associated with DSOW cyclones.

The Rossby number $R o=\frac{v_{a}}{f \cdot R_{0}}$ for these fitted parameters at $r=R_{0}$ is $\approx 0.22$, which indicates that in the mean these eddies are mostly geostrophic, but ageostrophic effects are important. In particular, a geostrophic velocity calculation would estimate the maximum azimuthal velocity at $r=R_{0}$ to be $v_{G}=v_{a}\left(1+\epsilon^{\prime}\right) \approx 1.22 v_{a}$ or $\approx 0.27 \mathrm{~m} / \mathrm{s}$ (compare Subsection 3.7.1). The geostrophic calculation would hence lead to a slight overestimate of the peak azimuthal speed. It should also be noted that the descent from $650 \mathrm{~m}$ at the Denmark Strait sill to $900 \mathrm{~m}$ at the array site leads to a vortex stretching of $250 \mathrm{~m}$ or $\approx 40 \%$. This predicts a relative vorticity of $0.4 f$ and a Rossby number $R o=\frac{\zeta}{f}$ of 0.4 . Considering that frictional effects will lead to some 


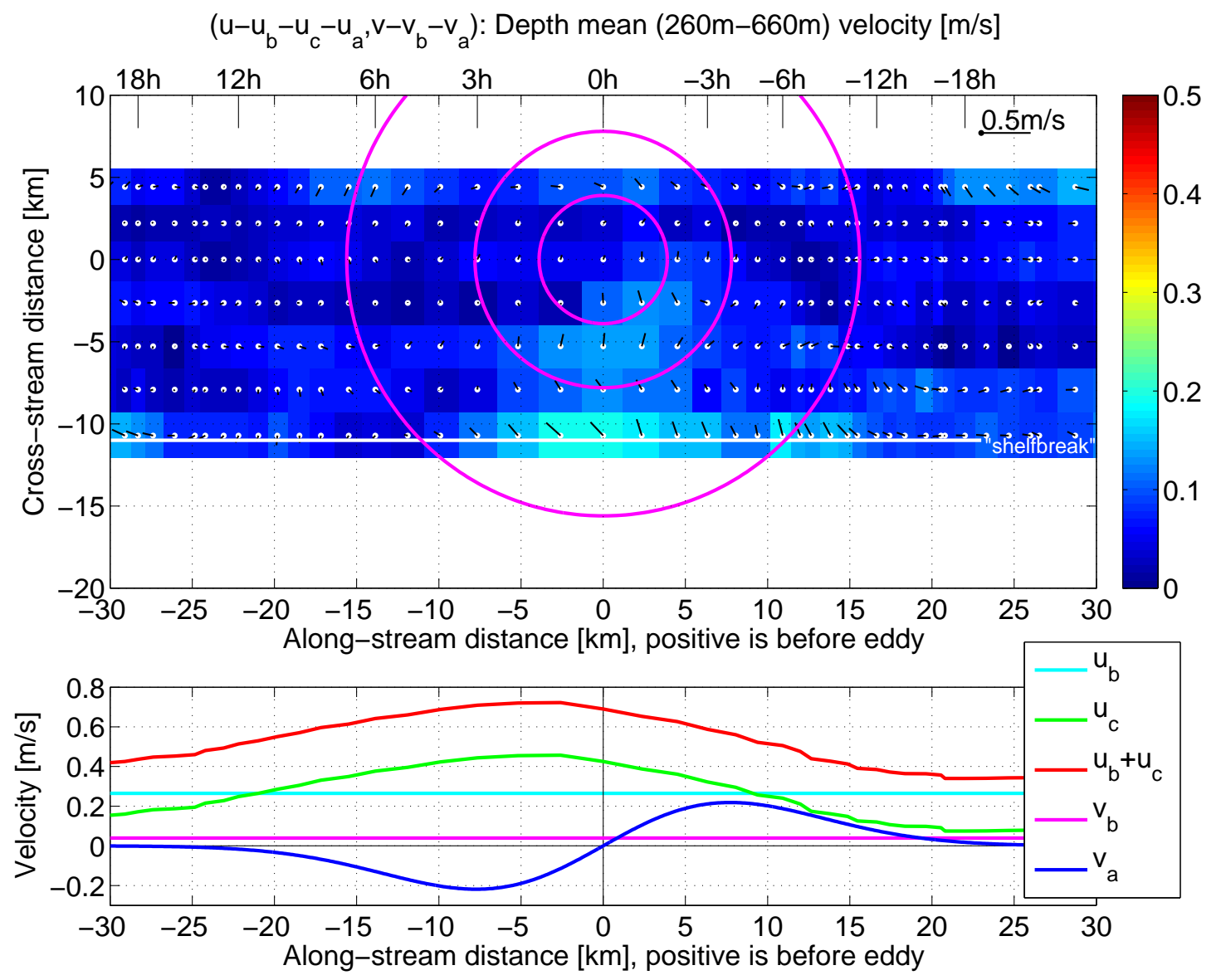

Figure 4-10: $\left(u-u_{b}-u_{c}-u_{a}, v-v_{b}-v_{a}\right) 260 \mathrm{~m}-660 \mathrm{~m}$ depth mean velocity in the top panel. Note that the color scale and the vector velocity scale have been reduced to $0.5 \mathrm{~m} / \mathrm{s}$. This plot shows the weak residual field after all identified components have been removed from the depth mean velocity field.

loss of relative vorticity, this means that the observed cyclones are not inconsistent with having been generated by vortex stretching. The depth mean azimuthal velocity fit is also reproduced in the bottom panel of Figure 4-8.

After removing the background flow, the co-translational velocity, and the azimuthal velocity of the cyclone, the residual velocities are weak (less than $0.1 \mathrm{~m} / \mathrm{s}$ ) with very little structure (Figure 4-10). This demonstrates that we have successfully decomposed the depth mean velocity field associated with DSOW cyclones into the components shown in the lower panel of Figure 4-8. The only structure that is appar- 
ent in the residual field is at greater cross-stream offsets $(y=5 \mathrm{~km}$ and $y=-10 \mathrm{~km})$. Recall that we assumed that the eddy variation in the cross-stream direction is weak. At greater cross-stream offsets this does not hold as well and likely accounts for the greater noise there.

EG4 was also equipped with a microcat that measured temperature and salinity near the bottom. Within a radius of about $5 \mathrm{~km}$ from the center of the composite cyclone, the bottom density exceeds $27.8 \mathrm{~kg} / \mathrm{m}^{3}$ (Figure 4-11). This indicates the presence of Denmark Strait Overflow Water in the core of the cyclones and hence the naming "DSOW cyclones" is appropriate. It is important to note that while overflow water is present at $900 \mathrm{~m}$ (depth of EG4) when the cyclones pass by, it is found only much deeper down the slope in the background flow. This also points to the fact that there is trapped fluid inside of the cyclone which is different from what would be expected for the passage of a linear topographic Rossby wave. Note that the passage of both a linear wave and a cyclone starts with offshore directed velocities. In the absence of trapped fluid, these velocities would bring lighter fluid from higher up on the continental slope to the depth of EG4. On the trailing edge, the onshore velocities would bring denser fluid up to the depth of EG4. In other words, the observed increase in density in the center of the cyclone is the opposite of what would be expected in the absence of trapped fluid.

The dense fluid could only be trapped and passively advected by the cyclonic velocity field if the maximum azimuthal velocity was greater than the translational velocity (e.g. Flierl, 1981). With the maximum observed azimuthal velocity of $0.22 \mathrm{~m} / \mathrm{s}$ and the translational velocity of $0.45 \mathrm{~m} / \mathrm{s}$, this is clearly not given. Therefore, there the pressure fields of the dense water anomaly and the cyclonic velocity have to be dynamically linked resulting in their propagation at the same velocity. We will return to the reasons for this in Subsection 4.5.4 below. 
$\left(u-u_{b}-u_{c}, v-v_{b}\right)$ : Depth mean $(260 m-660 m)$ velocity [m/s] and Bottom density anomaly $\left[\mathrm{kg} / \mathrm{m}^{3}\right]$
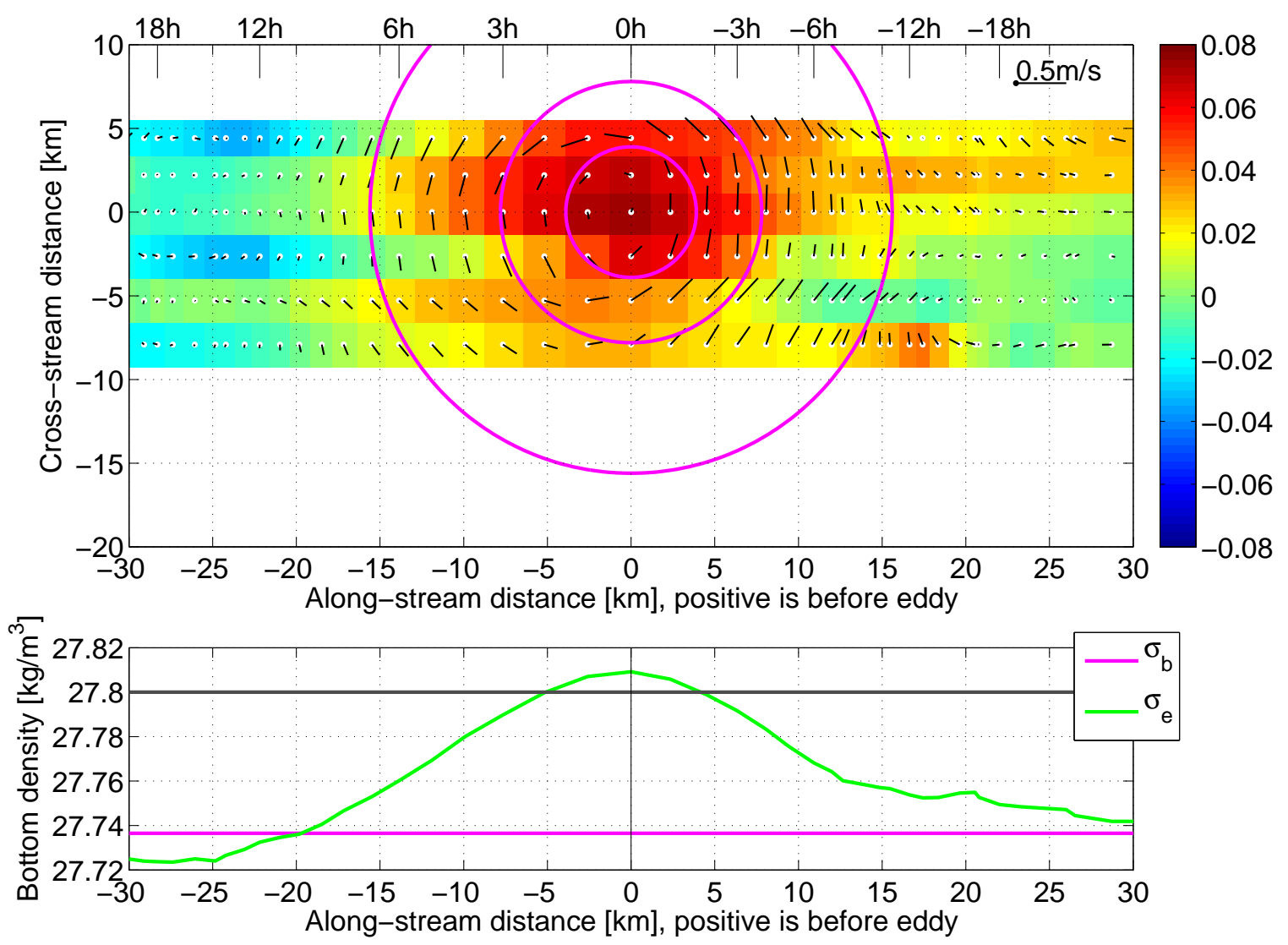

Figure 4-11: Top panel: Bottom density anomaly with respect to the background bottom density of $\sigma=27.735 \mathrm{~kg} / \mathrm{m}^{3}$ shown in color. This field is constructed in a similar way as the velocity fields were constructed. The velocity field $\left(u-u_{b}-u_{c}, v-v_{b}\right)$ shows the azimuthal flow as in Figure 4-8. Bottom panel: Background bottom density at EG4 more than 18 hours away from any DSOW cyclone is shown in magenta and bottom density along the center slice of the cyclone $(y=0)$ is shown in green. Note that the density in the center exceeds $27.8 \mathrm{~kg} / \mathrm{m}^{3}$, the classical definition for DSOW. 


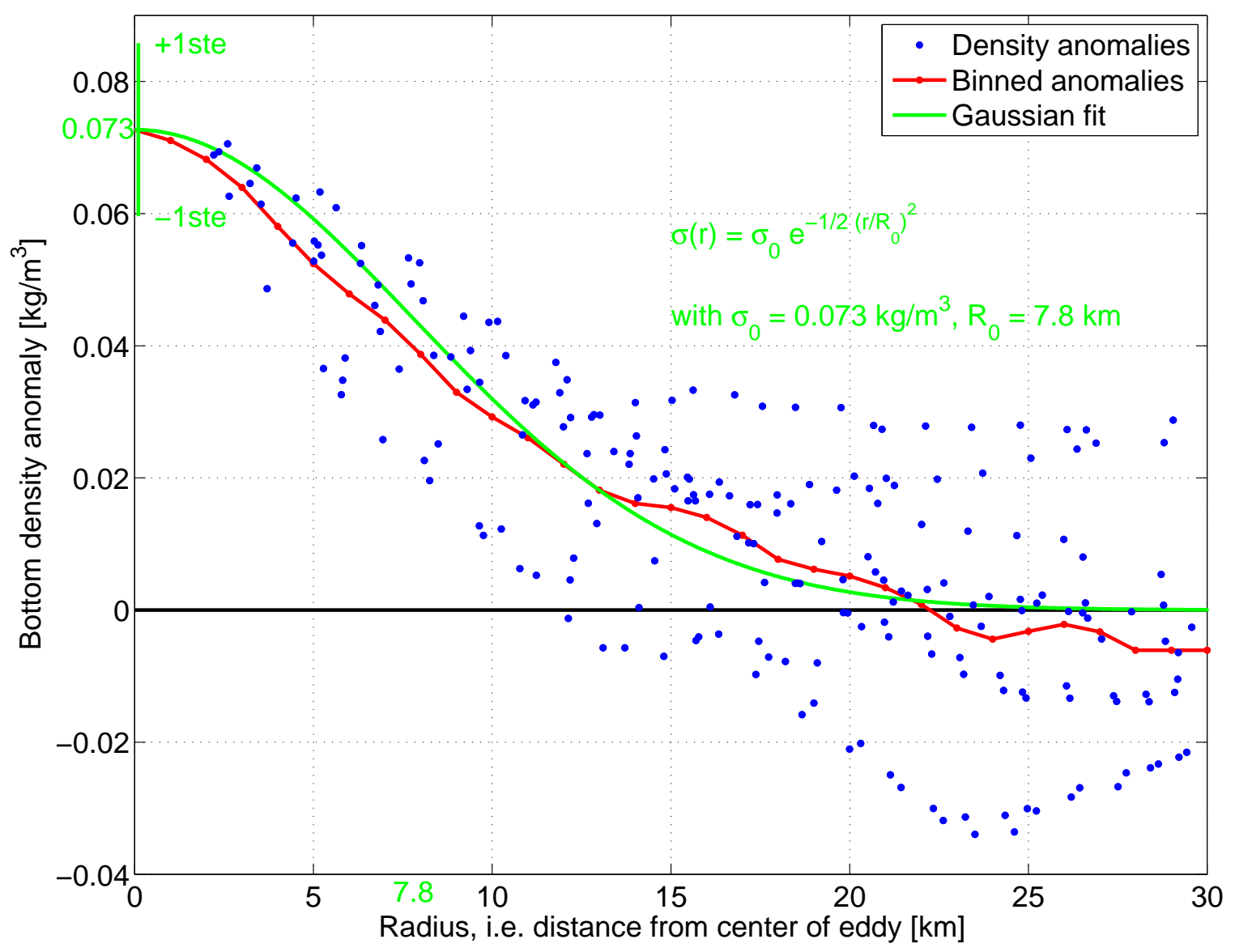

Figure 4-12: Bottom density anomaly from Figure 4-11 as a function of radius. A Gaussian with an amplitude of $0.073 \mathrm{~km} / \mathrm{m}^{3}$ and a radius of $7.8 \mathrm{~km}$ is fitted to the binned anomalies. We estimate the uncertainty from the standard deviations of the bottom densities measured by each individual passing cyclone. The minimum number of degrees of freedom is the 10 cyclones passing offshore of EG4 (compare Figure 4-3). The standard deviation divided by the square root of the minimum number of degrees of freedom is the standard error. It is about $18 \%$ and is shown with the vertical green bar. 
In Section 4.7 we discuss the cross-stream structure of the density field in the absence of cyclones. When plotted as a function of radius (Figure 4-12), the bottom density anomalies display a clear signature that is well approximated by a Gaussian fit:

$$
\sigma(r)=\sigma_{0} e^{-\frac{1}{2}\left(\frac{r}{R_{0}}\right)^{2}}
$$

The radius $R_{0}=7.8 \mathrm{~km}$ is the same as for the Gaussian eddy fit and the maximum density anomaly at the origin is $\sigma_{0}=0.073 \mathrm{~kg} / \mathrm{m}^{3}$.

In summary, the depth mean composite Denmark Strait Overflow Water cyclone is advected by the background mean flow of $0.27 \mathrm{~m} / \mathrm{s}$ in the downstream direction and $0.04 \mathrm{~m} / \mathrm{s}$ in the offshore direction. Consistent with the propagation of a topographic Rossby wave, it appears to self-advect with respect to the mean flow at $0.45 \mathrm{~m} / \mathrm{s}$ along the isobaths and also $0.03 \mathrm{~m} / \mathrm{s}$ downslope. The azimuthal velocity structure of the composite DSOW cyclone is well approximated by a Gaussian eddy with a maximum azimuthal velocity of $0.22 \mathrm{~m} / \mathrm{s}$ at a radius of $7.8 \mathrm{~km}$. In its core, the cyclone contains DSOW that is $0.07 \mathrm{~kg} / \mathrm{m}^{3}$ denser than the water present during the background flow.

\subsubsection{Vertical Structure of the Composite Cyclone}

We now proceed to analyze the vertical structure of the mean cyclone. It should be kept in mind, however, that the velocity data above $260 \mathrm{~m}$ and below $660 \mathrm{~m}$ are more sparse, and as such, the results are not as robust.

The mean flow in the absence of DSOW cyclones increases with depth in the middle of the water column (Figure 4-13). It is about $0.1 \mathrm{~m} / \mathrm{s}$ slower than if all the times (with and without DSOW cyclones) are considered (Figure 3-6). A simple linear fit (Figure 4-13) to this profile gives a constant shear of $4.6^{*} 10^{-4} \mathrm{~s}^{-1}$ and a top-to-bottom velocity difference of $0.41 \mathrm{~m} / \mathrm{s}$. The profile reaches $0.47 \mathrm{~m} / \mathrm{s}$ at $900 \mathrm{~m}$ 


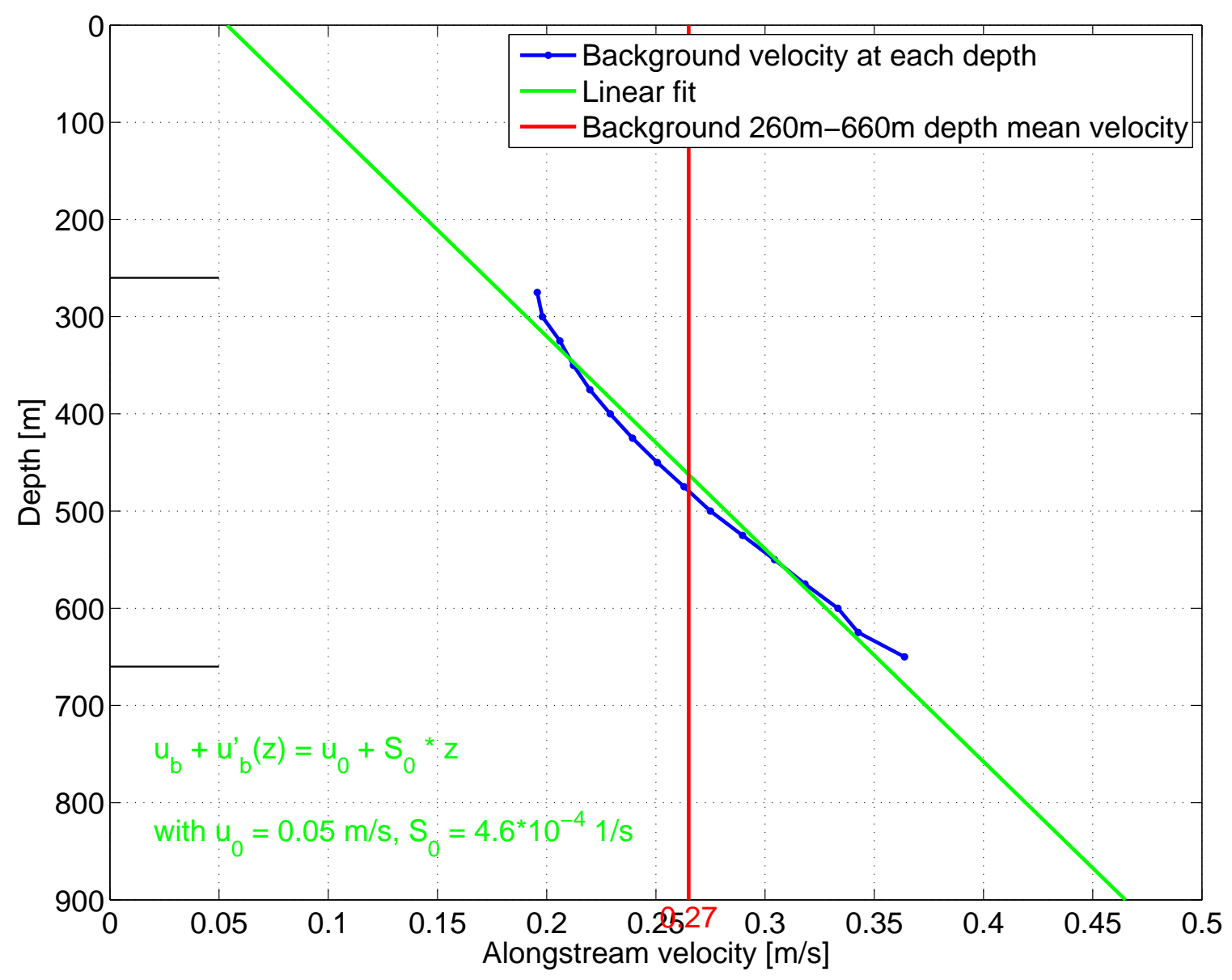

Figure 4-13: Vertical structure of the background alongstream velocity (more than 18 hours from any cyclone center). The alongstream velocity in the middle water column was measured without bias (blue line). A linear fit (constant shear) is shown in green. The depth mean $u_{b}$ is also shown in red. The depth dependent structure of the mean flow $u_{b}^{\prime}$ is defined as the green fit minus the red depth mean such that the depth mean of $u_{b}^{\prime}$ is approximately zero. 


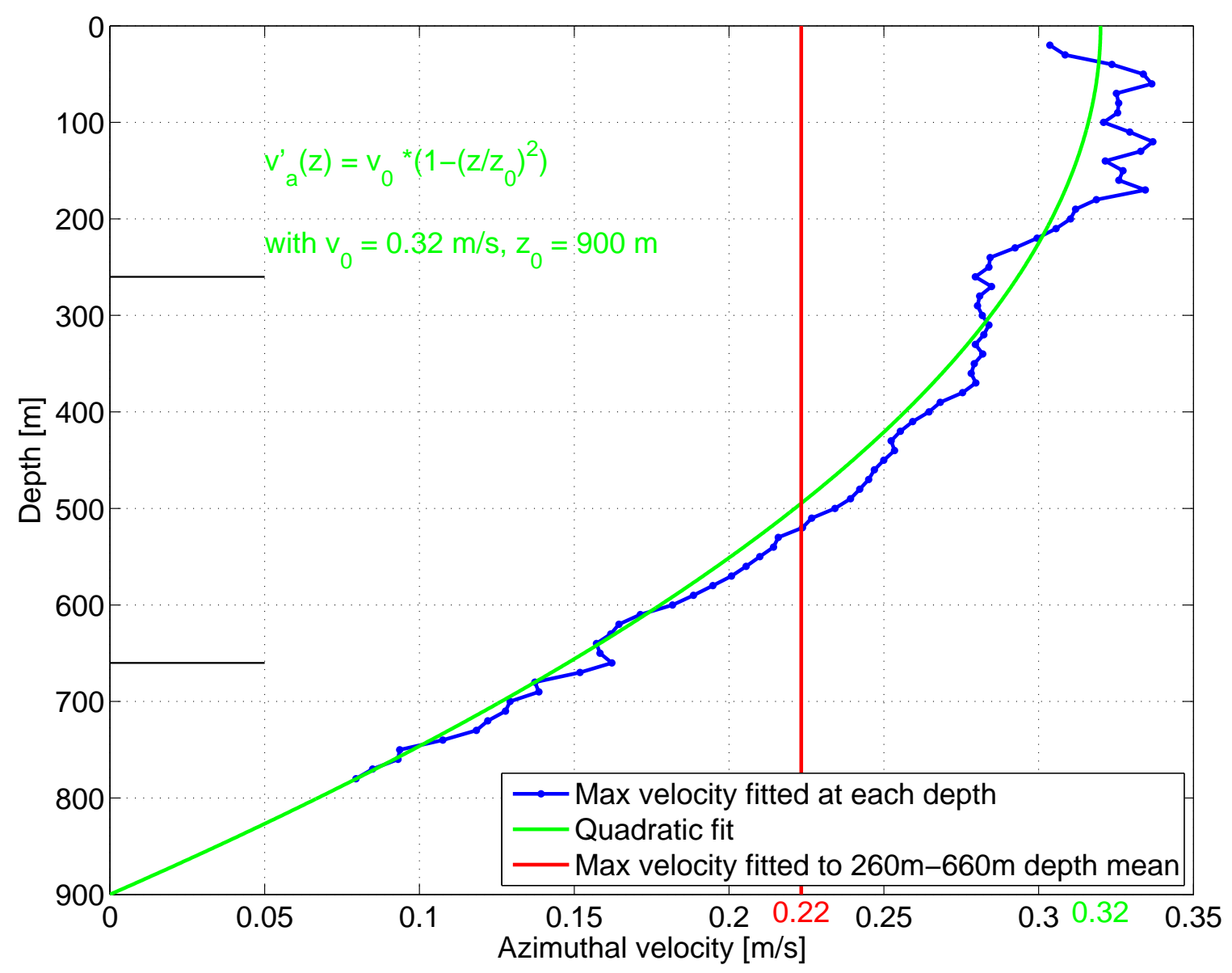

Figure 4-14: Maximum azimuthal velocity as a function of depth. A Gaussian eddy with a radius of $7.8 \mathrm{~km}$ was fitted to the azimuthal velocity components of $\left(u-u_{b}-\right.$ $\left.u_{b}^{\prime}-u_{c}, v-v_{b}\right)$ at each depth. The fitted velocity amplitudes as a function of depth are shown in blue and a quadratic fit for the velocity as a function of depth is shown in green. This fit implies a shear that is linearly increasing with depth.

near the bottom (our observations do not extend into the bottom boundary layer). Again noting that the accuracy is much lower near the bottom, the constant shear profile is the best fit to the data and hence we take it as the vertical structure of the mean flow $u_{b}^{\prime}$.

To determine the vertical structure of the composite eddy, a Gaussian eddy fit to the azimuthal component of the velocities was applied for each $10 \mathrm{~m}$ depth bin in the same way that it was done for the depth mean structure (Figure 4-9). While 
there was close to no variation (less than $0.5 \mathrm{~km}$ ) in the fitted radius $R_{0}$ from top to bottom, there was a substantial difference in the amplitude $v_{0}$. Therefore, the same calculation was repeated, but with the radius fixed to the depth mean $R_{0}=7.8 \mathrm{~km}$. The fitted azimuthal velocities near the surface are around $0.3 \mathrm{~m} / \mathrm{s}$ and much stronger than the velocities below $700 \mathrm{~m}$, where they are around $0.1 \mathrm{~m} / \mathrm{s}$ (Figure 4-14). A quadratic fit with zero velocity at the bottom and zero vertical shear at the top fits the data very well. This implies that DSOW cyclones in our study region are surface intensified in velocity with a maximum azimuthal velocity of $0.32 \mathrm{~m} / \mathrm{s}$ at the surface.

It should be noted that this is different from the model results of Spall and Price (1998) and the vortex stretching hypothesis (compare Figure 3-4) that predict middepth intensified cyclonic flow due to the strongest vortex stretching occurring in the middle of the water column. However, it compares well with the laboratory and theoretical results of Whitehead et al. (1990) who described a lens of dense bottom water that was propagating westward with an overlying cyclonic vortex. Furthermore, the DSOW cyclone shown in Figure 3-12 that was sampled $250 \mathrm{~km}$ downstream of the mooring array exhibits a mid-depth maximum in azimuthal velocity as found in Spall and Price (1998). However, this cyclone has descended to about $1800 \mathrm{~m}$ and its velocity maximum is around $1000 \mathrm{~m}$ depth, or roughly $800 \mathrm{~m}$ above the bottom. In that regard it compares well with our composite DSOW cyclone that resides in much shallower water but still has its velocity maximum about the same height $(\approx 900 \mathrm{~m})$ above the bottom. In other words it may have previously been at the surface and then been capped by Irminger Water.

In the case study of Chapter 3, we presented alongstream sections of velocity for two cyclones (Figures 3-16 and 3-17), but we were not able to quantitatively decompose the sections into their velocity components. For comparison, we also present a similar view of the composite DSOW cyclone (Figure 4-15; note that the horizontal 
u: Cross-stream $(-6 \mathrm{~km}-6 \mathrm{~km})$ mean of alongstream velocity $[\mathrm{m} / \mathrm{s}]$

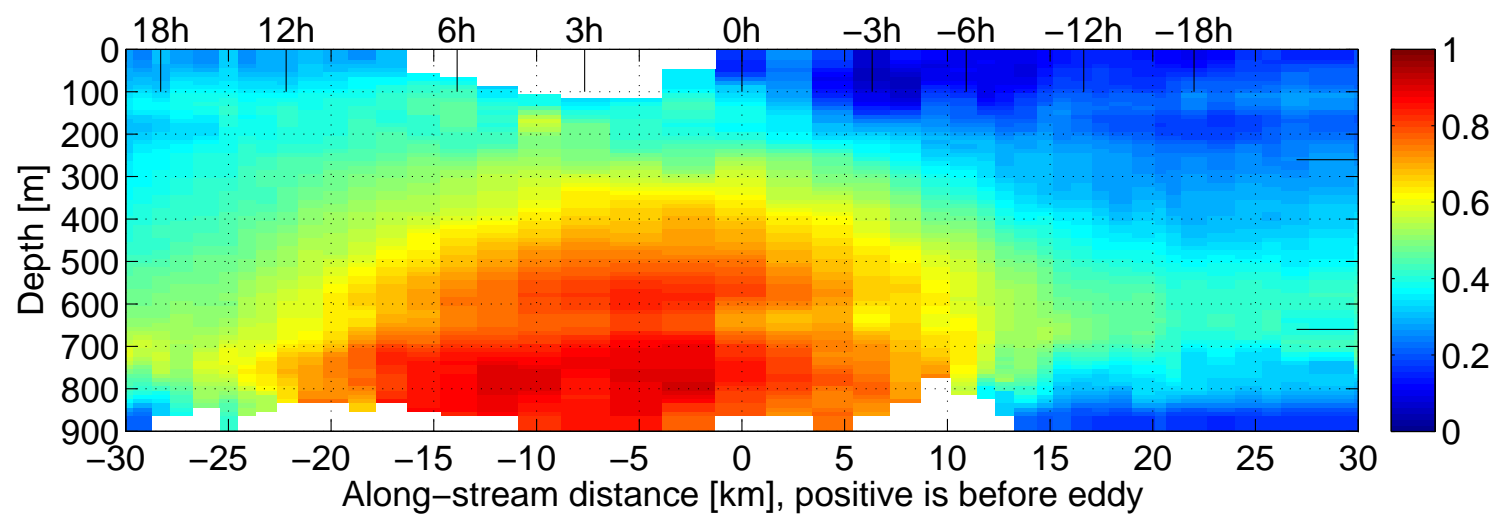

v: Cross-stream $(-6 \mathrm{~km}-6 \mathrm{~km})$ mean of cross-stream velocity $[\mathrm{m} / \mathrm{s}]$

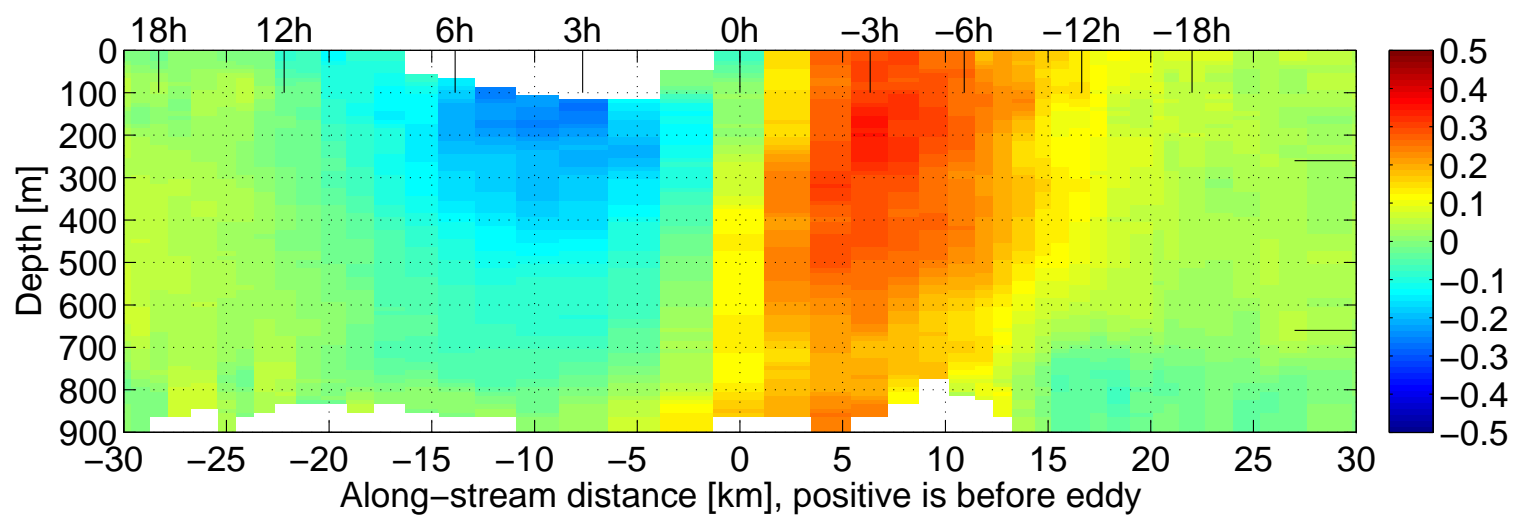

Figure 4-15: Alongstream section of the cross-stream $(y=-6 \mathrm{~km}$ to $y=6 \mathrm{~km})$ average of the full measured velocity field $(u, v)$ of the composite eddy. All of the velocity components discussed above are present. 
axis is distance rather than time). All of the velocity components discussed above can be seen in the alongstream section. The vertically sheared mean flow $u_{b}+u_{b}^{\prime}$ and the eddy co-translational velocity $u_{c}$ with its peak in the wake just behind the eddy center dominate the alongstream velocity signature. The cross-stream velocity is dominated by the azimuthal velocity $v_{a}+v_{a}^{\prime}$ and its surface intensified signature is quite clear (Figure 4-15). The qualitative and quantitative agreement between the two case study eddies and the composite eddy is remarkable and suggests that the two eddies near EG4 and EG5 of the case study are relatively typical specimens of DSOW cyclones. The residual velocity field after all the above identified components have been removed has very little structure (Figure 4-16). There is a somewhat increased offshore flow inside of the cyclone (at radii less than $5 \mathrm{~km}$ ). Also there are quite pronounced negative alongstream velocities at depths below about $750 \mathrm{~m}$ which is related to the strongly sheared background alongstream velocities that have been removed with values exceeding $0.45 \mathrm{~m} / \mathrm{s}$ at the bottom. As pointed out in the fit that led to this constant shear profile (compare Figure 4-13), this area is not well constrained by data and the available information there is likely biased by the instrument with which it was recorded. ${ }^{1}$ Therefore, it is likely that this feature in the residual field is due to the biased data coverage rather than to the physics of the system. The residual field has been constructed under the assumption that the co-translational velocity of the composite cyclone $u_{c}$ does not have a depth dependence. The residual field does not show any structure suggesting that this assumption is incorrect. This implies that the cyclones do not get sheared apart during their propagation along the East Greenland

\footnotetext{
${ }^{1}$ The upward looking ADCP on the bottom of EG4 only recorded in extremely weak flow conditions. If in fact the velocities in the first $200 \mathrm{~m}$ above the bottom were moderate, the weaker part of the distribution would have been measured while the stronger part of the distribution would not have been measured as the flow was too strong for the upward looking ADCP, but not strong enough to be picked up by the downward looking ADCP. This would lead to an underestimate of the actual velocities in that region.
} 


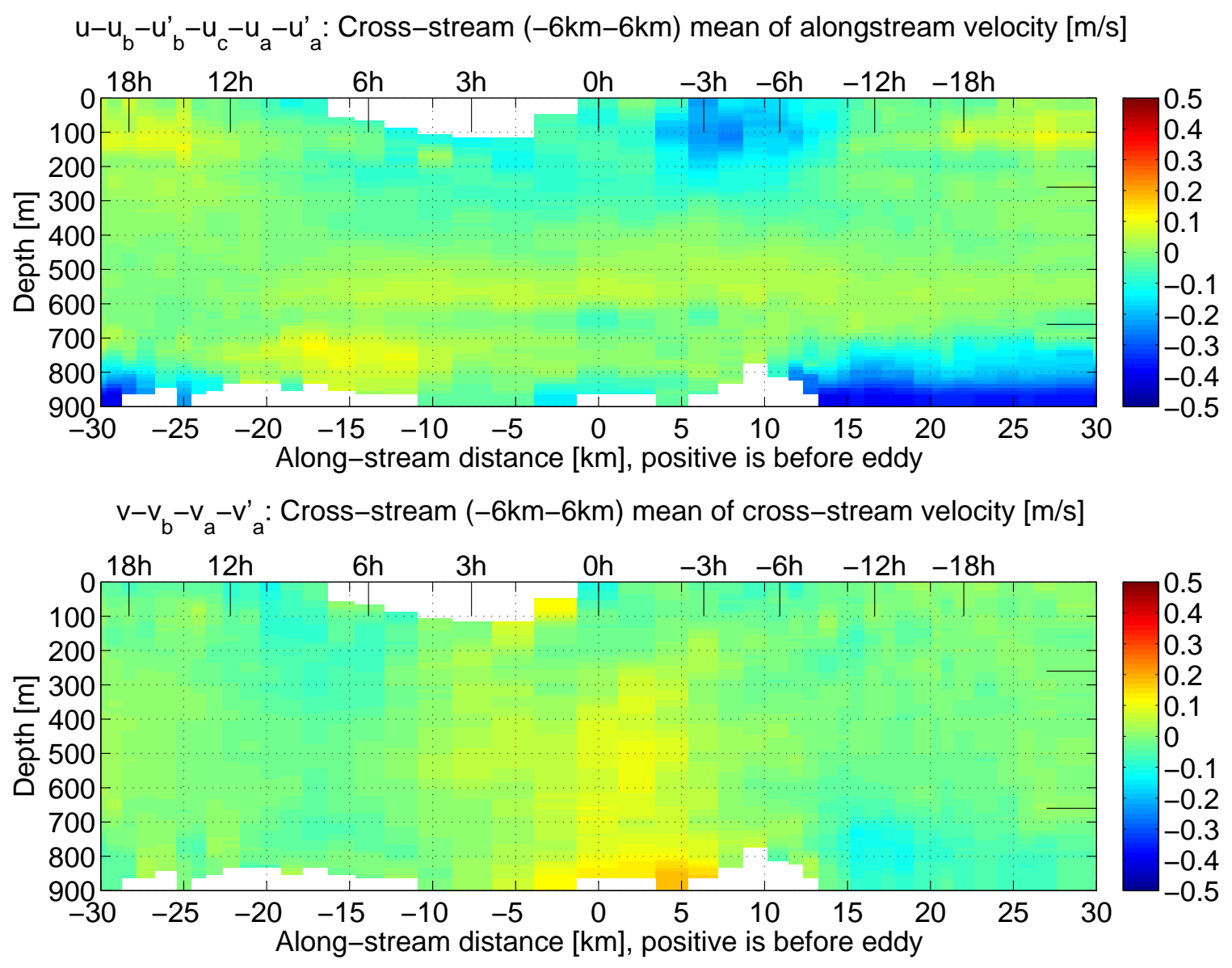

Figure 4-16: Alongstream section of the cross-stream $(y=-6 \mathrm{~km}$ to $y=6 \mathrm{~km})$ average of the residual velocity field $\left(u-u_{b}-u_{b}^{\prime}-u_{c}-u_{a}-u_{a}^{\prime}, v-v_{b}-v_{a}-v_{a}^{\prime}\right)$ of the composite eddy. All the above identified velocity components have been removed to obtain this residual.

slope.

The moored profilers measuring hydrography were not able to perform full depth profiles in the presence of the large velocities encountered inside of the DSOW cyclones. However, on the offshore side of the cyclones, the upstream directed azimuthal velocity leads to a relatively weak total velocity (compare Figure 4-6) and the profilers can perform comparatively well. This allows us to composite the density structure at $\mathrm{a} \approx 7-10 \mathrm{~km}$ horizontal offset from the cyclone center (Figure 4-17). Along the slice through the offshore side of the eddy, the density strongly increases near the bottom. 
The isopycnals denser than $\approx 27.7 \mathrm{~kg} / \mathrm{m}^{3}$ are raised by more than $200 \mathrm{~m}$ during the passage of the cyclones compared to the ambient conditions. In contrast, the depths of the overlying isopycnals are only weakly affected and this leads to a significant increase of the stratification in the middle water column (around $600 \mathrm{~m}$ depth).

The individual density profiles presented in Figure 4-17 were accompanied by velocity measurements at the same vertical resolution. This makes them suitable for the calculation of the Richardson number $R i$ as defined in Equation (3.8). A fourth order Buttwerworth filter with a cutoff wavelength of $60 \mathrm{~m}$ in the vertical was used to smooth the noisy profile data. $R i<1 / 4$ indicates that the fluid is unstable with respect to Kelvin-Helmholtz instabilities. Since the smoothing removed some of the extremely low values, we rather looked for $R i<1$ to indicate the likely presence of Kelvin-Helmholtz instabilities. There are occurrences of low $R i$ at all depths and all times with respect to the passage of the cyclones (Figure 4-18). On the offshore side of DSOW cyclones, there seems to be little change in the occurrence of low Ri. This is indicative of the fact that the flow along the East Greenland slope is often subject to Kelvin-Helmholtz instabilities. This strongly facilitates active mixing and entrainment and may play a role in the qualitative transformation of the flow structure along the East Greenland slope from the mooring array location to Cape Farewell (Brearley et al., 2012).

\subsubsection{Cross-stream Variation of Cyclones}

Most of the cyclones pass the array near EG4 (Figure 4-3) where we have good velocity data and were therefore able to perform the above analysis. We have also assumed that the eddy statistics vary slowly in the cross-stream direction. We now evaluate this assumption using the available data. Reliable velocity data inside of cyclones 


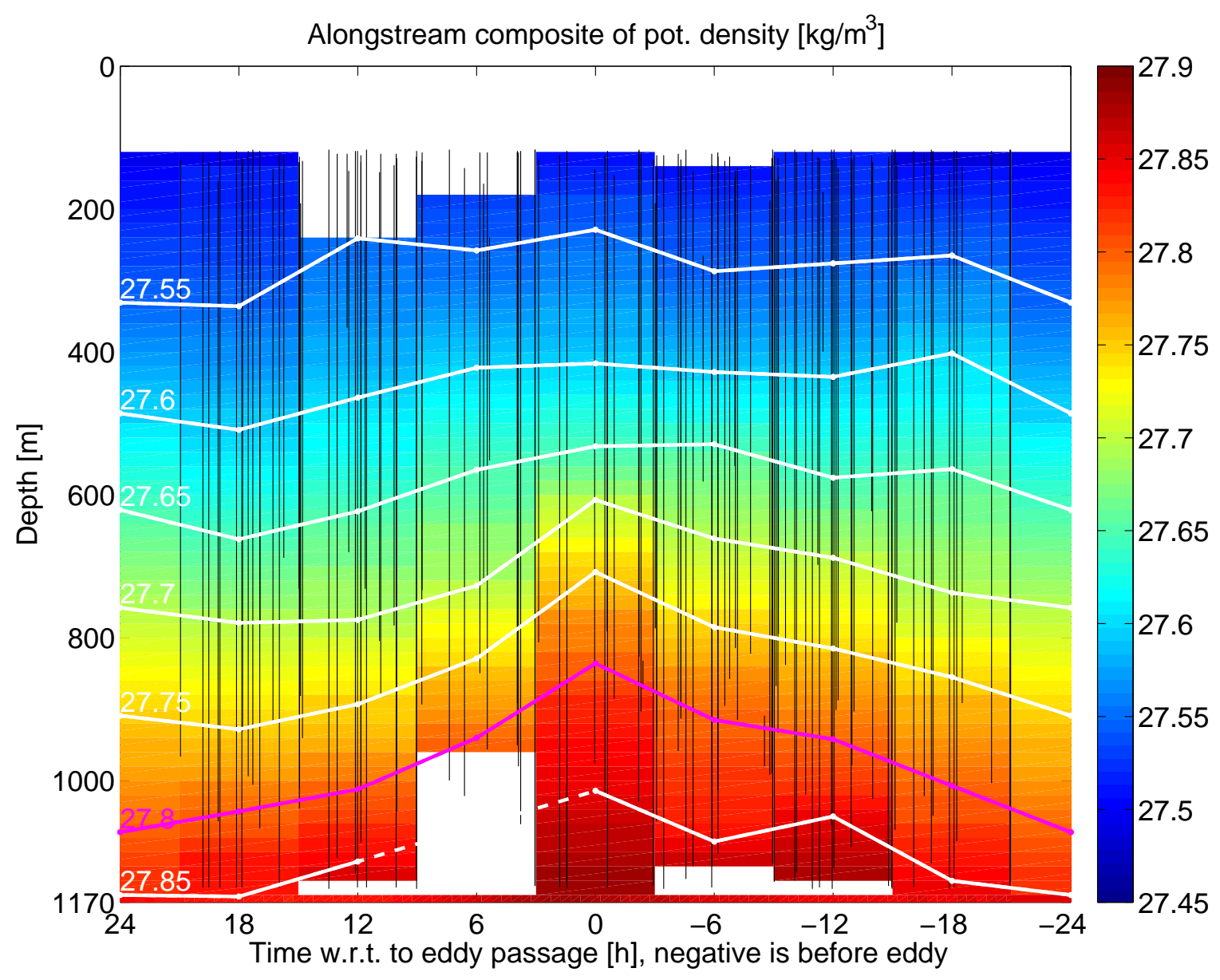

Figure 4-17: Alongstream section of potential density $\left[\mathrm{kg} / \mathrm{m}^{3}\right]$ at EG5 during the passage of 66 cyclones near and onshore of EG4. The $\mathrm{x}$-axis is time with respect to the time when the cyclone passes EG4. This data shown here is $\approx 7-10 \mathrm{~km}$ from the location where the cyclone centers pass the mooring array. The location in space and time of the individual profiles is shown as black lines. These profiles were averaged over bins spanning $20 \mathrm{~m}$ in the vertical and 6 hours in time. The density in the bins is shown in color and isopycnals are shown in white (magenta for $27.8 \mathrm{~kg} / \mathrm{m}^{3}$ ). 


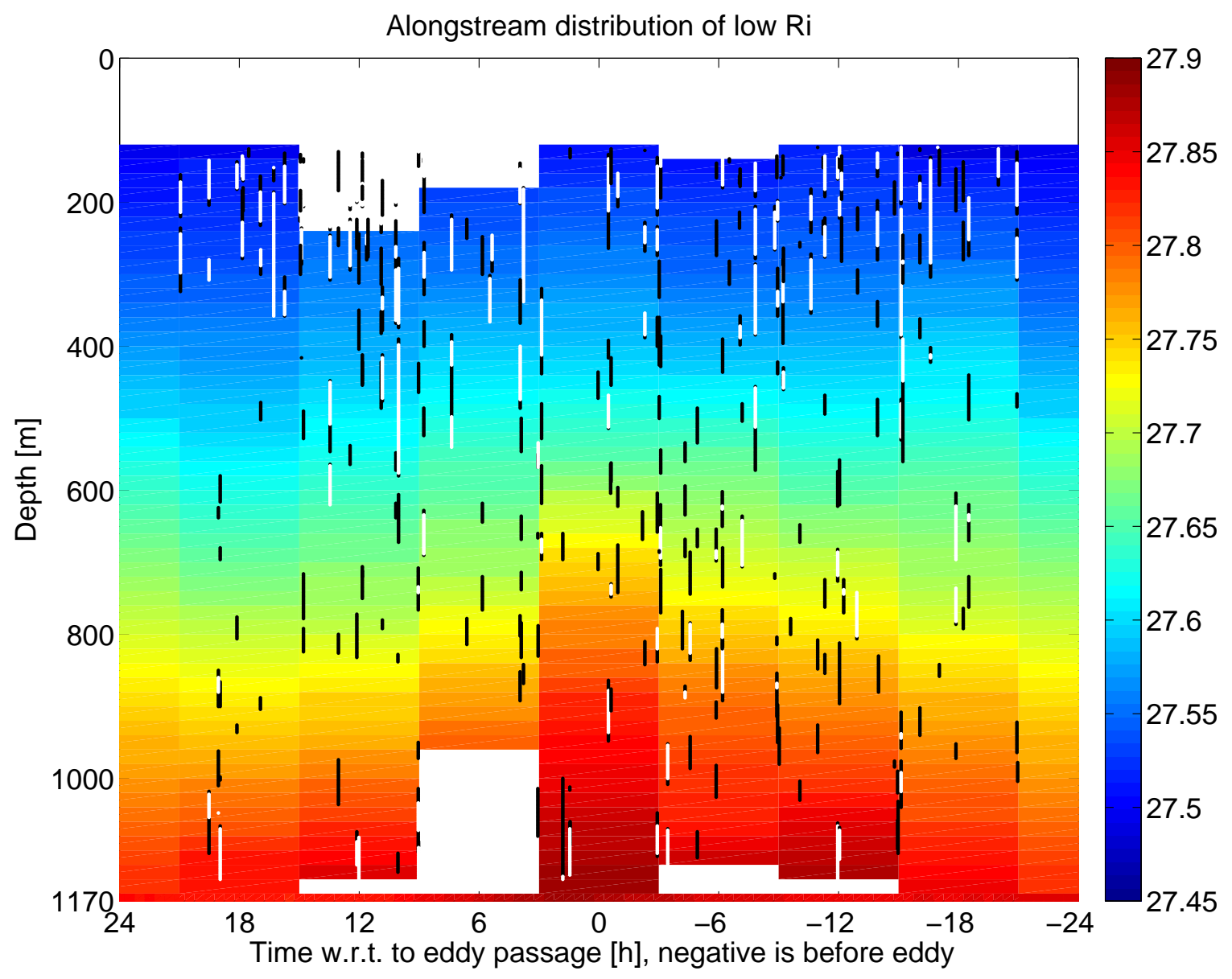

Figure 4-18: Alongstream section of the occurrence of low Richardson numbers. $R i<$ $1 / 4$ are shown in white and $1 / 4<R i<1$ are shown in black. The distribution of the profiles (Figure 4-17) needs to be considered for the interpretation of these low $R i$ occurrences. The potential density shown in color is the same as in Figure 4-17. 
only exists at EG4 and we can therefore not directly compare the velocity structure of eddies at other locations to the ones near EG4. However, bottom temperature and salinity measurements are available at all moorings both inside and outside of the cyclones.

We present the bottom density and bottom temperature conditions at the five moorings on the continental slope both in the absence of cyclones ( $\geq 18$ hours from any cyclone) and within the core of the cyclones (Figure 4-19). For each mooring, this is defined as the average of all density/temperature measurements that were obtained within an hour of the time that the cyclone center passed onshore, near, or offshore of that mooring.

Salinity variations in the overflow water have only a weak effect on the density (compare Figure 3-9 and Dickson and Brown, 1994), and hence temperature variations are a good proxy for density variations. Since the salinity sensor on the bottom of EG3 failed, we cannot present density, but our qualitative statements can be supported from temperature. As the bottom depth across the slope increases, so does the bottom density. Hence it is most effective to consider anomalies between the background state and the times of cyclone presence. It is found that this increase is quite similar for the first three moorings (roughly from the shelfbreak to $20-25 \mathrm{~km}$ offshore). Recall that this region accounts for nearly $80 \%$ of the DSOW cyclones. This implies that the majority of DSOW cyclones have a similar impact on the near-bottom hydrography. The anomalies decrease farther offshore (at the last two moorings) as the bottom densities indicate the presence of overflow water there all the time. Since DSOW cyclones pass at those depths less often, the total impact that they have on the circulation there is much weaker than higher up on the slope. 

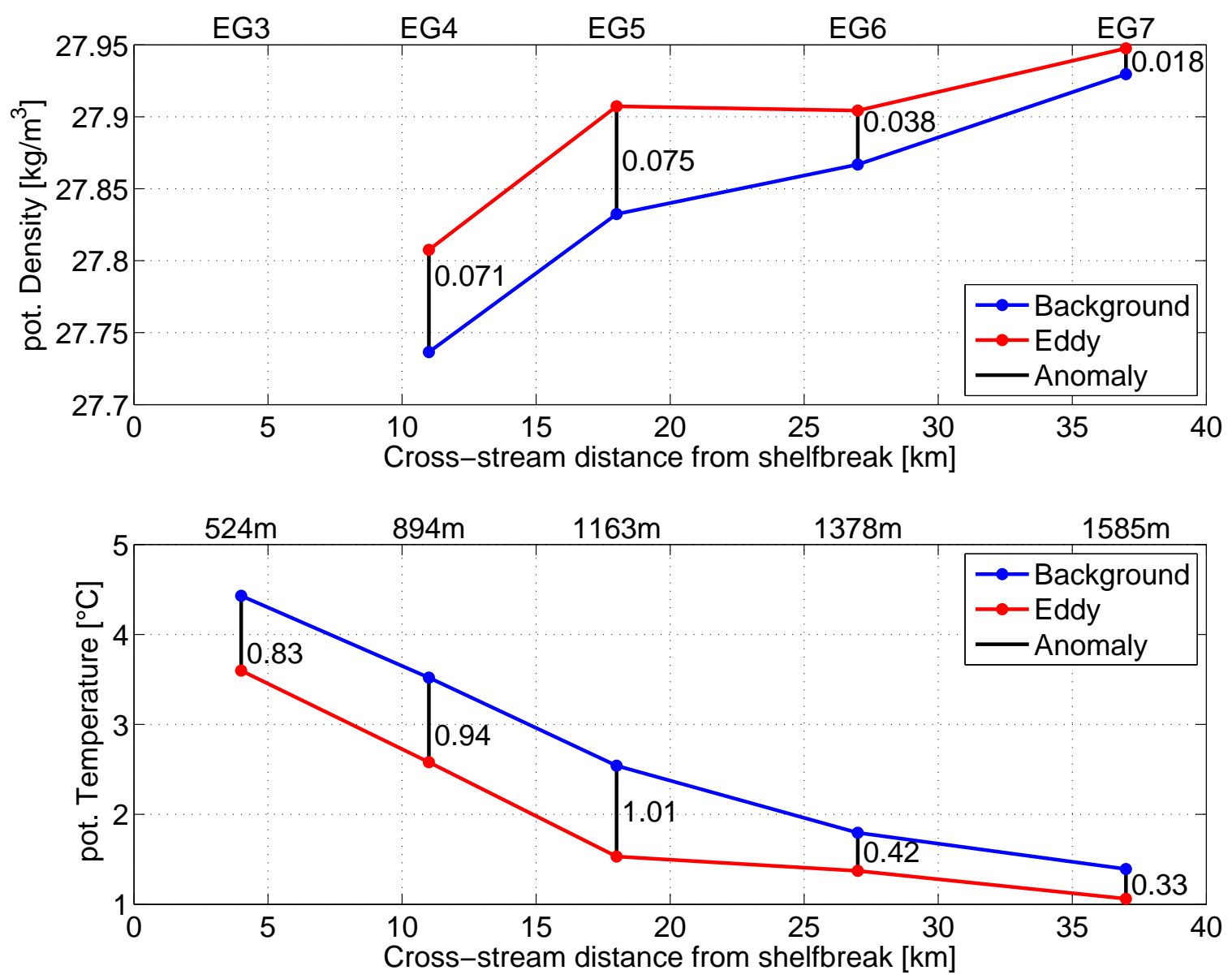

Figure 4-19: Cross-stream variation of eddies. The value shown at the location of EG3 is the average of all eddies passing onshore, near, and offshore of EG3, and likewise for the other moorings. Top panel shows the bottom potential density and bottom panel shows the bottom potential temperature. The values in the background periods (more than 18 hours away from any cyclone) are shown in blue along with the values within the core of the cyclones in red. Note that the salinity sensor on the bottom of EG3 failed and hence there is no density data. 


\subsubsection{Pressure Field of the Composite Cyclone}

The density field inside of DSOW cyclones is of interest both to determine what their transport of overflow water (and other water masses) is as well as to infer what their surface signature is. Unfortunately, none of the profilers on the moorings worked under the high velocity conditions inside of the cyclones. Therefore, we only have full water column hydrographic measurements on the outside of DSOW cyclones (Figure 4-17). However, we do have ADCP measurements of the velocity field inside of the cyclones, as well as the bottom density from the microcats, and outside of the cyclones, we have density profiles. In order to obtain smooth fields, we apply fits to our data for all three of these quantities. The pressure field links all three and allows us to calculate the full density field inside of DSOW cyclones.

During quiescent periods, the profilers measured the whole water column. Since those quiescent periods were rare, the hydrography in the bottom $200 \mathrm{~m}$ was only measured in a very small number of cases and this does not allow us to find the statistically relevant mean density at those depths. The bottom density, however, is well constrained from the microcat there. It can be seen that the mean stratification in the middle water column $(250-650 \mathrm{~m})$ is nearly constant with a buoyancy frequency of $2.3^{*} 10^{-3} 1 / \mathrm{s}$ (Figure $4-20$ ). However, the stratification in the bottom boundary layer must decrease to match the observed bottom density. Above $250 \mathrm{~m}$ depth, the structure is more complicated and we have captured a hint of the shallow cold fresh layer with reduced densities (e.g. Sutherland and Pickart, 2008). Since the top layer is inconsequential for the overflow water transport, we have not attempted to resolve it and are simply extrapolating the same stratification as below. This leads us to the two piecewise linear fits (above and below $650 \mathrm{~m}$ ) that are shown in Figure 4-20.

We have shown that the qualitative structure of DSOW cyclones is made up of 


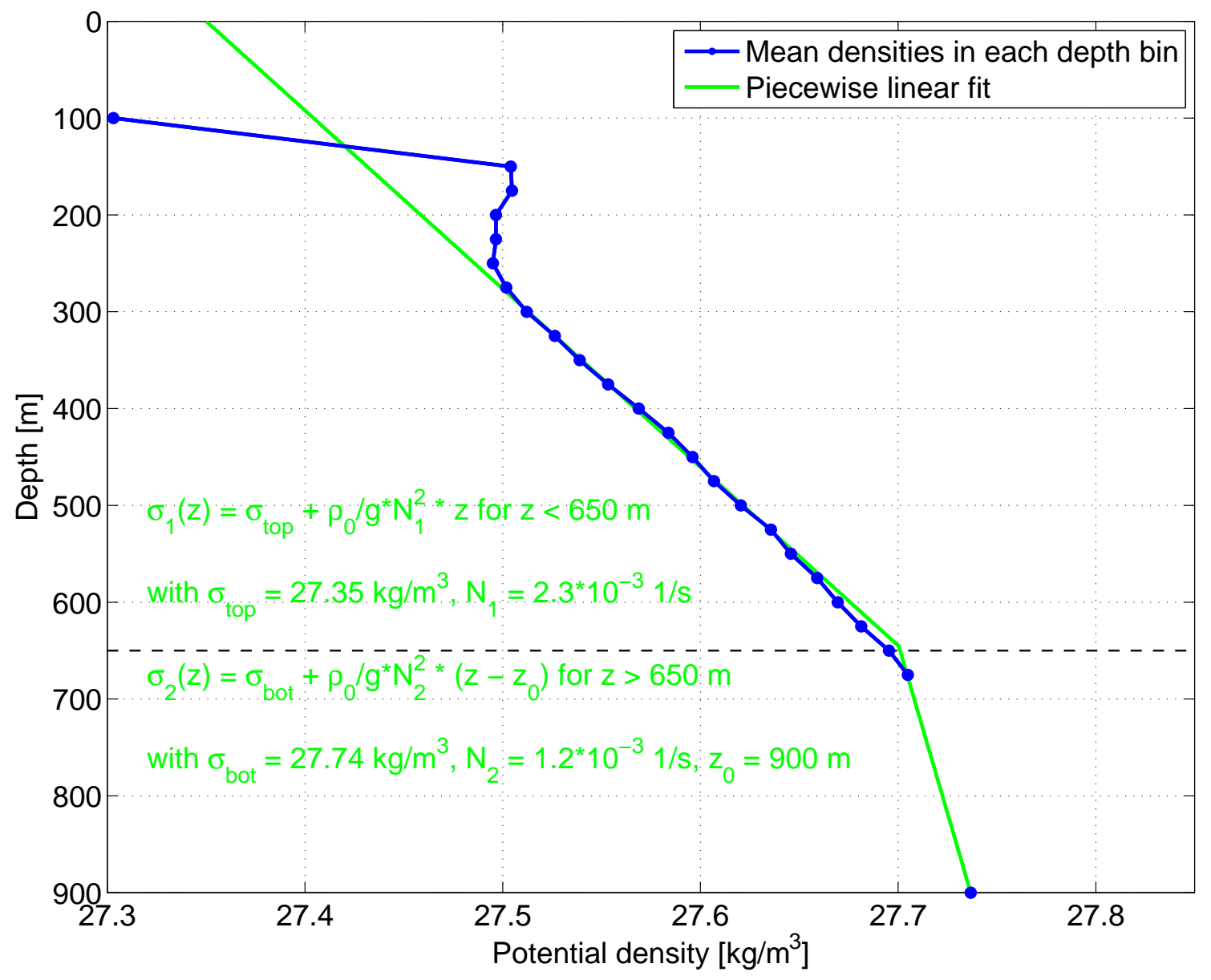

Figure 4-20: Background potential density at EG4 as a function of depth during times more than 18 hours away from DSOW cyclones. The blue dots are $25 \mathrm{~m}$ vertical bins of all available data. The bottom density is from the bottom microcat. The green line is a piecewise linear fit. Note that for the determination of the dense component of the density field in Figure 4-21, the exact structure of the shallower density field (above $\approx 250 \mathrm{~m}$ ) is not relevant. Therefore, the fit in that region is not actually intended to match the data. 
a dense water anomaly near the bottom with an overlying cyclonic velocity field. In particular, the azimuthal velocity near the bottom is very weak and much smaller than the translational velocity. Therefore, the velocity field cannot "trap" fluid by the kinematics discussed by Flierl (1981). A very similar situation to our DSOW cyclones was described in the laboratory experiments of Whitehead et al. (1990). They analyze the scenario in a simplified two layer framework consisting of an upper layer and a lower layer representing the isolated lens of dense water. This lens has the tendency to slump in the outward radial direction. A pressure gradient needs to balance the gravitational acceleration of the lens for it to keep its shape. This pressure gradient is supplied through thermal wind by an azimuthal flow around the lens. In the case of small angular frequency of the circulation around the lens compared to the Coriolis frequency (which is applicable to our DSOW cyclones as well), Whitehead et al. (1990) find that the lower layer pressure can be balanced by anticyclonic flow in the lower layer or by cyclonic flow in the upper layer above the lens. The first case was discussed and its propagation speed was derived by Nof (1983). Whitehead et al. (1990) show that the second case of cyclonic flow in the upper layer also propagates at the same speed as derived by Nof (1983). An integral constraint derived in Whitehead et al. (1990) links the presence of the lens near the bottom and the cyclonic flow above. In order to fulfill the integral constraint, these two features can only be a finite horizontal distance apart and are therefore not free to propagate independently of each other. We conjecture that this is also applicable to the DSOW cyclones described here. It is an explanation for why the cyclonic velocity field and the dense water anomaly co-propagate even though the azimuthal velocity is too weak to "trap" the fluid.

We now use the pressure field as an intermediary to compute the full density field inside of DSOW cyclones. In the following procedure we simplify the radial momentum equation in the frame of reference moving with the cyclone by neglecting friction, 
(a) Azimuthal velocity $[\mathrm{m} / \mathrm{s}]$

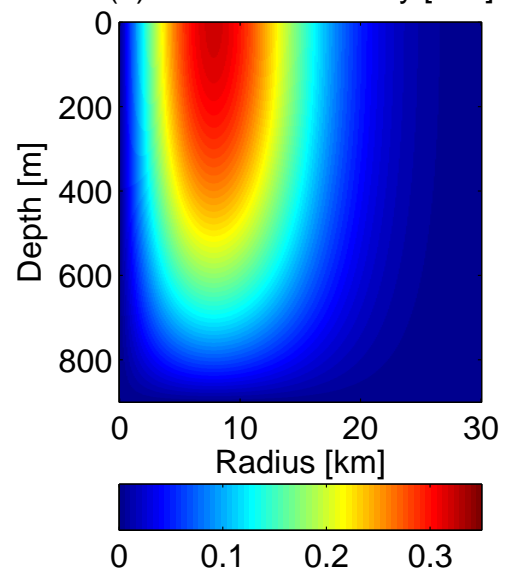

(d) Bottom dens anomaly $\left[\mathrm{kg} / \mathrm{m}^{3}\right]$ (b) Dynamic pressure [Pa]

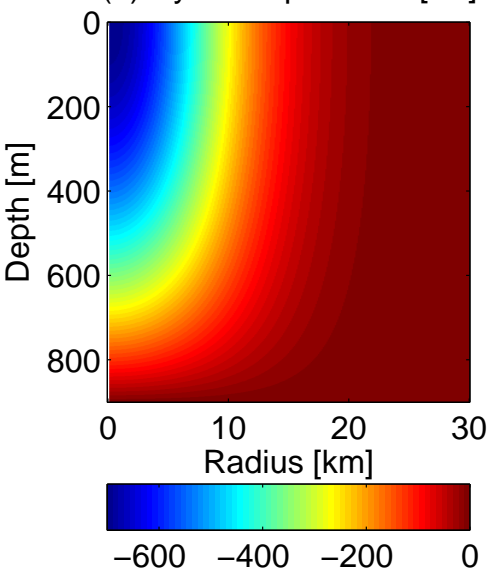

(c) Density anomaly $\left[\mathrm{kg} / \mathrm{m}^{3}\right]$

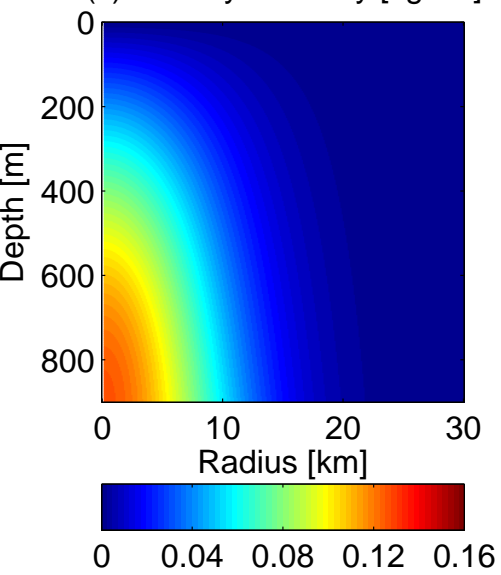

(f) Dens from microcat $\left[\mathrm{kg} / \mathrm{m}^{3}\right]$
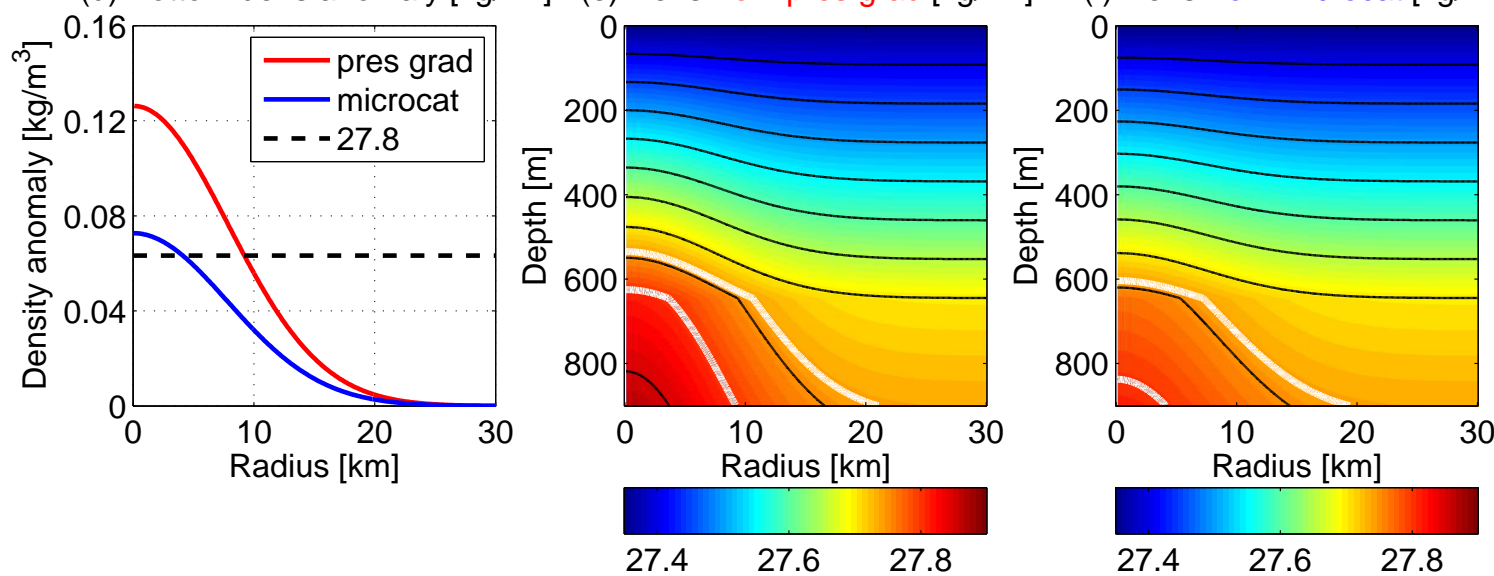

Figure 4-21: Velocity, pressure, and density fields inside smooth fitted DSOW cyclones in the radius-depth plane. (a) Azimuthal velocity, (b) Dynamic pressure from the horizontal integral of the velocity field, (c) Density anomaly from the vertical derivative of the pressure field, (d) Bottom density anomaly from the pressure gradient calculation shown in (c) and from the fit to the bottom microcat data (Figure 4-12); the density anomaly corresponding to a total density of 27.8 is also shown, (e,f) Estimates of the total density which is the sum of the background profile in Figure 4-20 and the density anomaly in (c); the 27.8 and 27.74 isopycnals are contoured in white, (e) is an upper estimate using the anomaly field in (c), (f) is a lower estimate using the anomaly field in (c) divided by 1.7 which is the ratio of the two amplitudes in (d). 
time-dependence, and any non-linear terms not associated with the cyclostrophic balance. This specifically also neglects any asymmetries between the onshore and offshore sides of the eddy introduced by the along-stream translation of the coordinate system used here. To leading order, the following analysis holds, but we note that the neglected terms may result in an $O(1)$ correction to the quantitative result below. The dynamical pressure can be determined from the simplified radial momentum equation (3.1). The integral of the geostrophic and the cyclostrophic terms is the pressure anomaly due to the flow:

$$
p^{\prime}(r)=\rho_{0} \int_{-\infty}^{r}\left(f v\left(r^{\prime}\right)+\frac{v^{2}\left(r^{\prime}\right)}{r^{\prime}}\right) d r^{\prime}
$$

with the boundary condition that the pressure anomaly vanishes far outside of the cyclone: $p^{\prime}(r \rightarrow-\infty)=0$. Hence we need to know the azimuthal velocity as a function of radius and depth, which is obtained from the fits in Figures 4-9 and 4-14 and shown in Figure 4-21a. We then perform the integration in Equation (4.5) at each depth to obtain the dynamic pressure field which is shown in Figure 4-21b. A maximum dynamic pressure anomaly of $-700 \mathrm{~Pa}$ is achieved at the surface in the center of the cyclone. This corresponds to a sea surface height depression of about $7 \mathrm{~cm}$.

The dynamic pressure has to be hydrostatically balanced. This allows us to use the hydrostatic equation to obtain the density anomaly:

$$
\rho^{\prime}(z)=-\frac{1}{g} \frac{\partial p^{\prime}}{\partial z}
$$

This density anomaly is shown in Figure 4-21c. Its structure at the bottom is shown in Figure 4-21d compared to that measured by the microcat. The two curves have 
precisely the same structure: a Gaussian with a radius of $7.8 \mathrm{~km}$. The only difference is that the amplitude of the density anomaly computed from the dynamic pressure is roughly 1.7 times as large as that measured by the microcat. We note that both of these estimation methods are uncertain. The uncertainty of the bottom density anomaly observed from the microcat is $\approx 18 \%$ (compare to the standard error in Figure 4-12). The amplitude of the density anomaly associated with the velocity field is proportional to the azimuthal velocity whose uncertainty is $\approx 23 \%$ (Figure 49). Additionally, we recall that Equation (4.5) neglects several effects leading to a likely $O(1)$ error. The microcat may also be located in a bottom boundary layer in which there is enhanced mixing leading to a weaker $\frac{\partial \rho}{\partial r}$ than in the fluid outside of the bottom boundary layer. In light of these aspects, we conclude that the bottom density estimates in Figure 4-21d do not contradict each other and the true value representative of DSOW cyclones likely lies somewhere between the two. As such, we take the two bottom density amplitudes as upper and lower bounds and present the respective full density fields.

If we add the density anomaly field obtained from the pressure gradient calculation to the full density profile outside of the cyclones (compare Figure 4-20), we obtain the full density field shown in Figure 4-21e. If we divide the density anomaly field (Figure 4-21c) by 1.7 (the ratio between the two anomalies in Figure 4-21d) and add that to the density profile outside of the cyclones, we obtain the full density field in Figure 4-21f. Note the good qualitative and quantitative agreement between the pressure inferred density field and the measurements on the outside of the cyclones (more than $\approx 7-10 \mathrm{~km}$ from the center as shown in Figure 4-17). Both the degree of isopycnal displacement and the densities of the isopycnals most strongly displaced agree well. These two realizations (Figures 4-21e/f) represent upper and lower bounds for the amount of dense water contained within DSOW cyclones. From these two 
estimates we conclude that the 27.8 isopyncal reaches $60-270 \mathrm{~m}$ above the bottom and is confined inside of a radius of $4-9 \mathrm{~km}$ around the cyclone center. The total volume of water denser than 27.8 in a typical DSOW cyclone at the $900 \mathrm{~m}$ isobath is thus estimated as $2-36 \mathrm{~km}^{3}$.

It should be noted that our composite cyclone is at a water depth where the densest ambient water present is typically 27.74 which is more than $0.06 \mathrm{~kg} / \mathrm{m}^{3}$ lighter than the classical DSOW definition of 27.8. Therefore, it might be more appropriate to consider the overflow plume as the water of the density classes that are otherwise absent at this depth. The 27.74 isopycnal is inside of a radius of about $20 \mathrm{~km}$, rises about 300-360 $\mathrm{m}$ above the bottom (Figure 4-21e/f), and contains 130-190 km³. This definition of the plume height depends less on the maximum density in the water column. This is why its relative difference between the lower and upper bounds is much less than in the case of the height of the 27.8 isopycnal. Transport is the volume fluxed past a cross-sectional area divided by the time elapsed. If we divide the volume of overflow water inside of the plume of a typical DSOW cyclone by the period with which the cyclones pass by the mooring array (2 days), we obtain the transport of plume water due to the cyclones. Using the classical definition of overflow water of 27.8, we obtain a transport of $0.01-0.22 \mathrm{~Sv}$. If we take the broader definition for the plume of the 27.74 isopycnal, we obtain a transport of $0.7-1.1 \mathrm{~Sv}$. These values are rather small due to the fact that the cyclones are so high up on the slope and hence do not contain much DSOW. This value would be larger for cyclones that reside farther down the slope.

We conclude that DSOW cyclones typically have a plume thickness of about $300 \mathrm{~m}$ and a depression of the sea surface height of about $4-7 \mathrm{~cm}$. This compares well with the DSOW cyclones in the numerical model study with realistic bathymetry of Käse et al. (2003). In their Figure 9, they show a scatter plot of SSH anomaly due to the 
simulated eddies and the maximum plume thickness. Their median SSH depression and plume thickness fall around $6 \mathrm{~cm}$ and $250 \mathrm{~m}$, respectively.

We also note that the DSOW cyclones, as constructed here, do not have a density anomaly near the surface. This is due to the fact that the azimuthal velocity maximum is so shallow. As noted earlier, this is different from the DSOW cyclone sampled $250 \mathrm{~km}$ farther downstream (Figure 3-12) which has a significant depression of isopyncals in the upper layer. However, it has very little isopycnal deflection at the depth of its maximum azimuthal velocity. Our eddies at $900 \mathrm{~m}$ depth look like the lower half of the eddy pictured in Figure 3-12.

\subsection{Sea-surface Temperature Signature of DSOW Cy- clones}

The sea surface temperature along the East Greenland slope is dominated by the contrast between cold $\left(\approx 0-4^{\circ} \mathrm{C}\right)$ East Greenland Current water on the shelf and warm $\left(\approx 8-12^{\circ} \mathrm{C}\right)$ Irminger Current water in the basin. This water mass front is associated with a surface intensified current tracking the shelfbreak. The $6^{\circ} \mathrm{C} \mathrm{SST}$ isotherm is a good proxy for the frontal location. It can be seen that the front meanders quite substantially (Figure 4-22). Its mean location roughly tracks the $500 \mathrm{~m}$ isobath (slightly deeper than the shelfbreak). One standard deviation of the horizontal frontal offset is about $10 \mathrm{~km}$. The frontal location to within \pm 1 standard deviation is clearly bracketed by the mooring array. The median location of the passage of DSOW cyclones past the mooring array is a few kilometers offshore of the mean location of the $6^{\circ} \mathrm{C}$ isotherm.

The co-location of the SST front and the passage of DSOW cyclones means that 


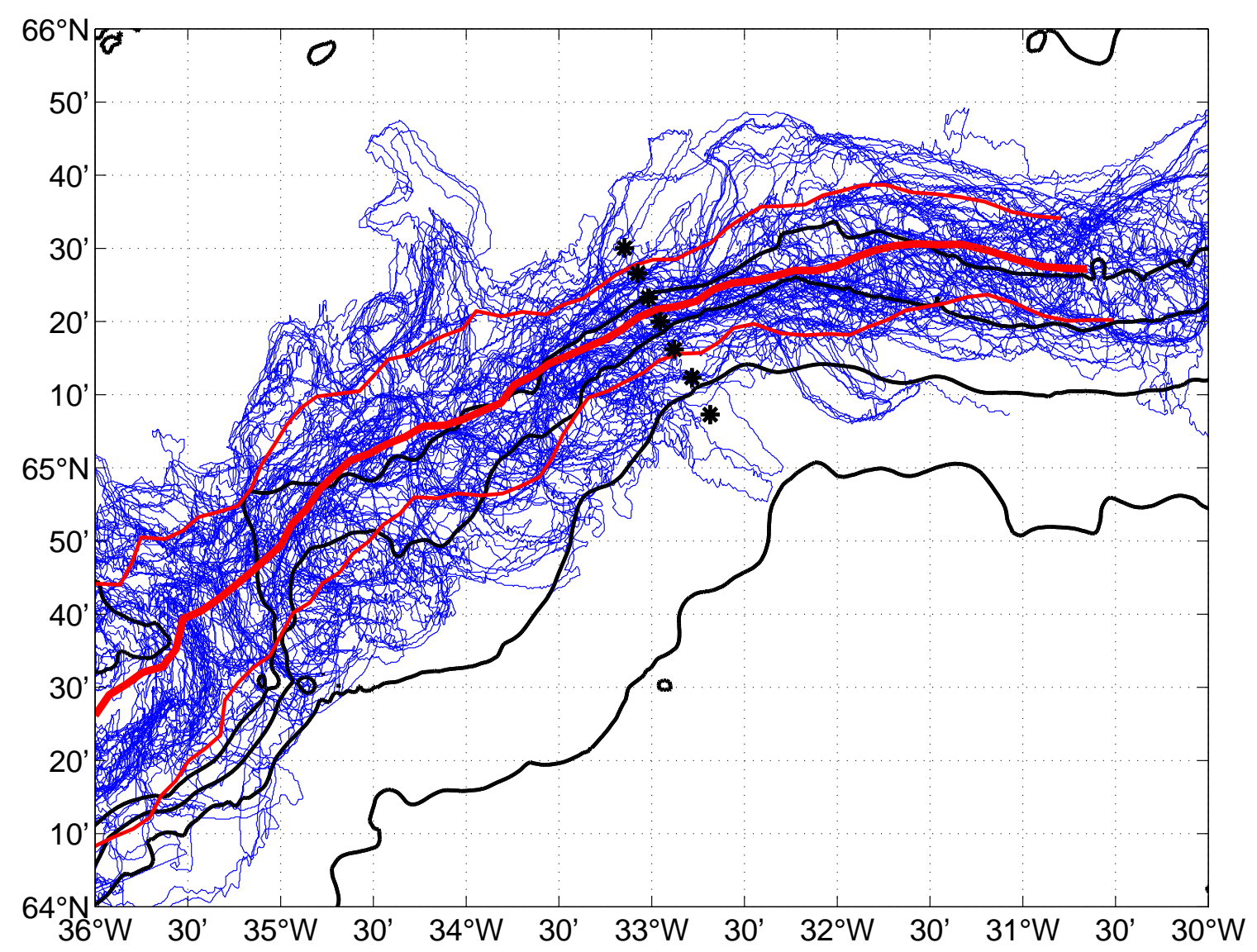

Figure 4-22: Locations of the $6^{\circ} \mathrm{C}$ isotherm in 63 SST images between September 2007 and October 2008 . The $6^{\circ} \mathrm{C}$ isotherm is roughly co-located with the front from cold EGC water to warm IC water. The thick red line shows the mean location of the isotherm and the thin red lines denote the mean \pm 1 standard deviation. The black lines are the $500 \mathrm{~m}, 1000 \mathrm{~m}, 1500 \mathrm{~m}$, and $2000 \mathrm{~m}$ isobaths. The black stars are the mooring array. 
the surface velocity field of the cyclones is generally in close vicinity of the SST front and will likely impact the front. This premise is precisely what was used by Bruce (1995) to track cyclones. The SST disturbances so identified were found to progress equatorward at $0.27 \pm 0.11 \mathrm{~m} / \mathrm{s}$ (standard deviation). This was subsequently interpreted as the typical propagation velocity of DSOW cyclones along the East Greenland slope. As shown in Subsection 4.5.1, our in-situ measurements suggest a typical translational velocity with respect to the bottom of $0.72 \mathrm{~m} / \mathrm{s}$. We now offer an explanation for this large discrepancy.

One simple hypothesis would be that there is a significant interannual variability in DSOW cyclone properties and that during 2007-08 they translated faster than during the time period analyzed by Bruce (1995). In order to address this hypothesis, we repeated the methodology of Bruce (1995) for all MODIS Aqua and Terra Level 2 SST images between September 2007 and October 2008 that were at least partially cloud-free (for a data description see Subsection 3.3.3). Over this year-long period 58 SST disturbances could be identified in more than one SST image, and their tracks are shown in Figure 4-23. Of those 58 eddies, 40 were trackable in the sense that they were identified in SST images more than 6 hours apart. Their propagation speed was $0.37 \pm 0.17 \mathrm{~m} / \mathrm{s}$ (standard deviation). This is slightly faster than the mean of Bruce (1995), but the two estimates actually agree within their error ranges. Hence the hypothesis of interannual variability can be rejected.

The distribution of cross-stream locations of DSOW cyclones inferred from the SST disturbances, however, agrees well with the distribution obtained from our mooring array, although the satellite-derived distribution is slightly narrower (Figure 4-24). This can be explained by the fact that the SST detection depends upon the presence of the SST front. Eddies far onshore or offshore of the SST front might not imprint a distinguishable disturbance onto the SST field (compare the discussion in Subsec- 


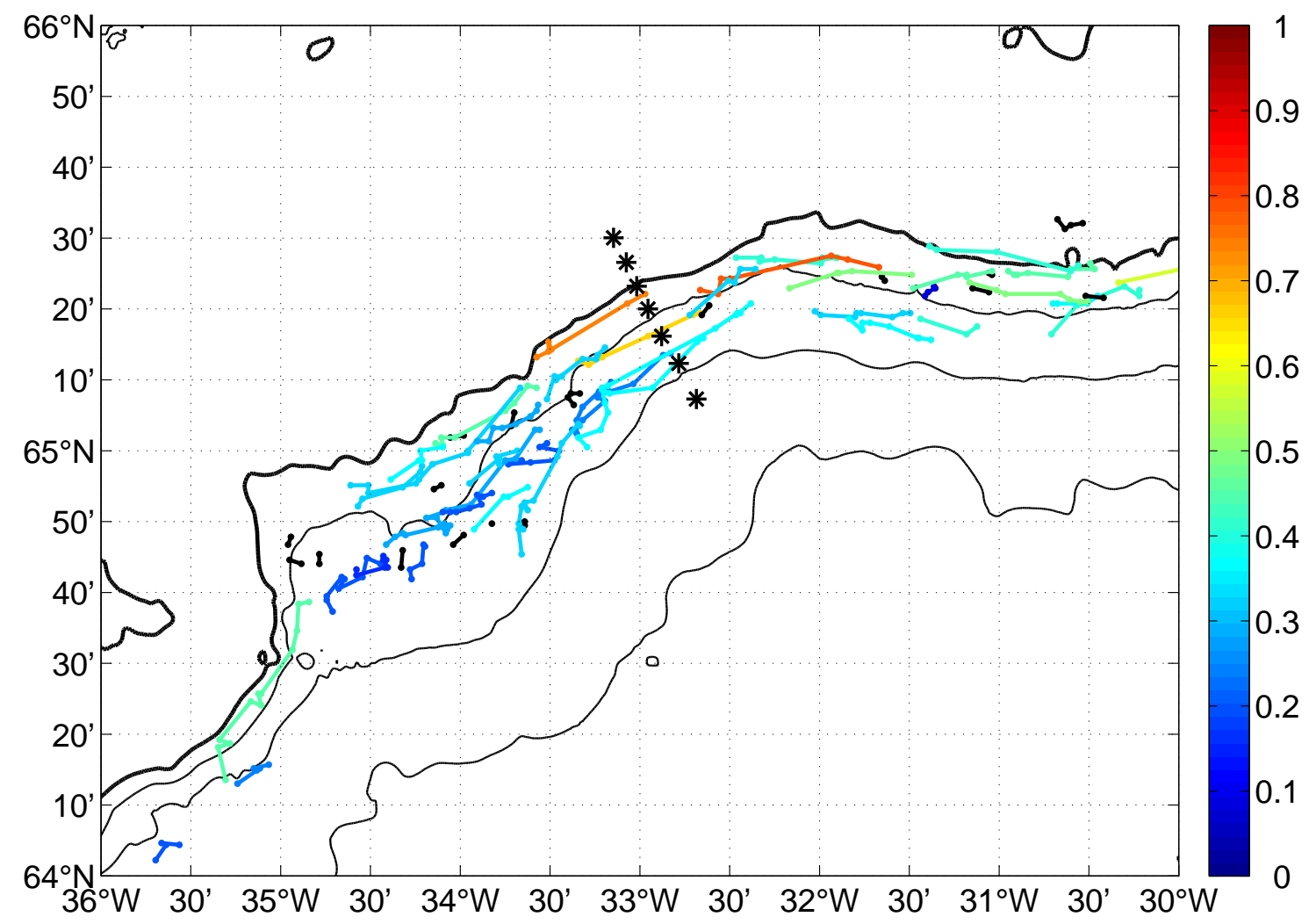

Figure 4-23: Fifty-eight different disturbances to the SST front could be identified in more than one SST image. Each dot corresponds to one identification in an SST image. The SST disturbances for which a speed could be determined are shown in the color corresponding to that determined speed (colorbar ranges from $0 \mathrm{~m} / \mathrm{s}$ to $1 \mathrm{~m} / \mathrm{s}$ ). Non-trackable disturbances are shown in black. The mooring array and the $500 \mathrm{~m}$, $1000 \mathrm{~m}, 1500 \mathrm{~m}$, and $2000 \mathrm{~m}$ isobaths are also shown. 


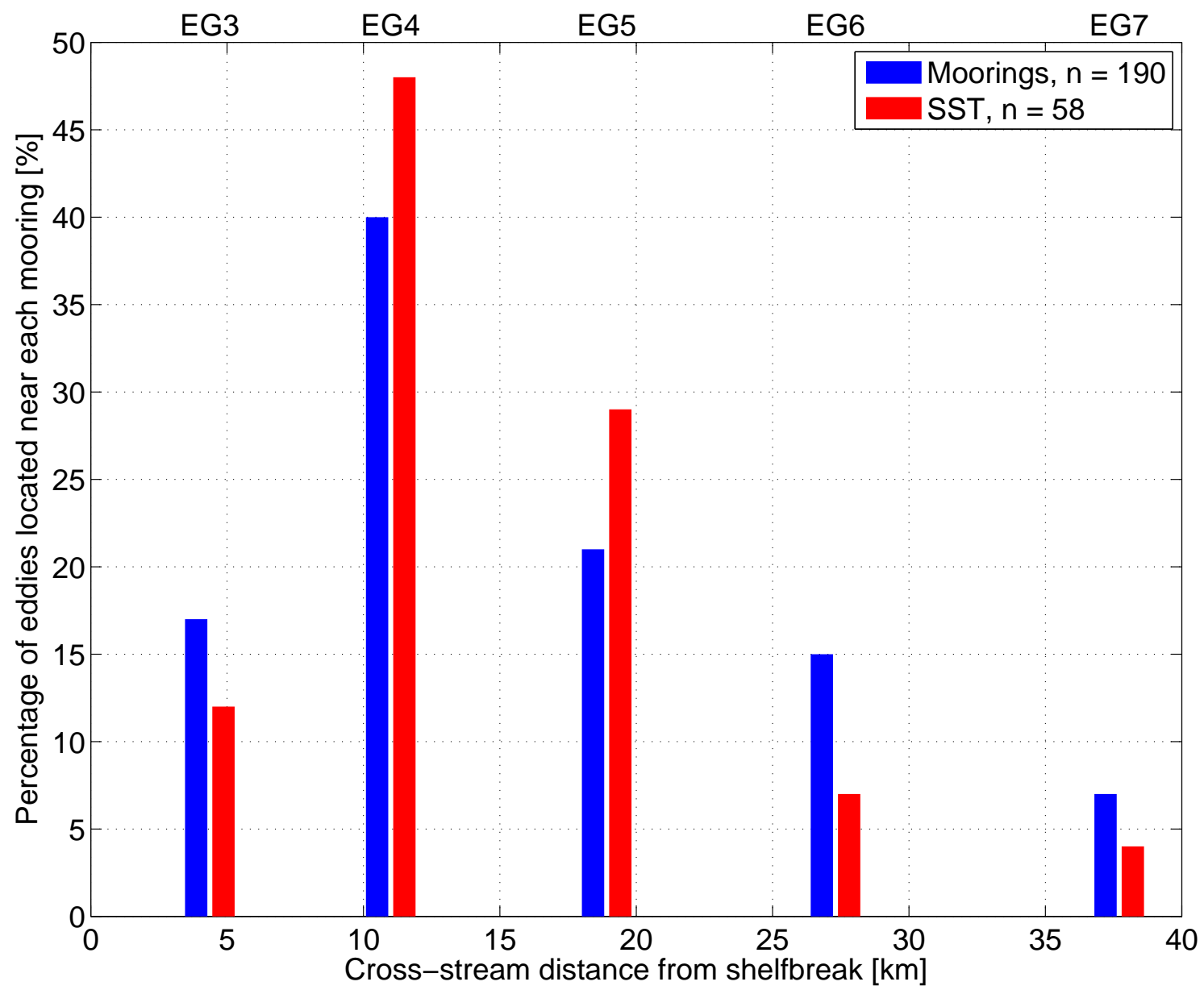

Figure 4-24: Distribution of the cross-stream locations of the 190 eddies identified from the moorings in the 13 record months and of the 58 eddies identified from SST disturbances in the same time. 
tion 3.9.1). This effect, however, does not seem to be very important given that the two distributions are as similar as they are.

A second hypothesis to explain the difference between the DSOW cyclone in-situ translational velocity and the propagation speed of the SST disturbances is that the SST disturbances are not propagating along with the DSOW cyclones. In particular, the SST disturbances could be generated by some process (e.g. subsurface DSOW cyclones or baroclinic instability of the EGC/IC front) and then propagate along the East Greenland slope with the mean surface flow. In this scenario the subsurface DSOW cyclones may initially cause a spiral or hook-like feature on the SST front that cannot keep pace with the swiftly propagating eddy. However, we note that this would not be consistent with the conclusion from Section 4.5 that the DSOW cyclones contain trapped fluid inside their approximate solid body rotation core.

\subsection{Structure of the Background East Greenland Bound- ary Current System}

When the DSOW cyclones were not present at the array the flow velocities were much weaker, and consequently the CTD profilers on the moorings were able to complete a significant number of full water column profiles. As such, vertical sections of hydrography and absolute geostrophic velocity across the mooring array of this background flow state can be constructed (Figures 4-25 and 4-26). All of the major components of the boundary current system are apparent. The Deep Western Boundary Current at this latitude is still in the process of descending to its typical mid-latitude depths and can here be seen to transport DSOW denser than 27.8 near the bottom offshore of the $1000 \mathrm{~m}$ isobath. The thickness of this layer increases up to $300 \mathrm{~m}$ at EG7, 


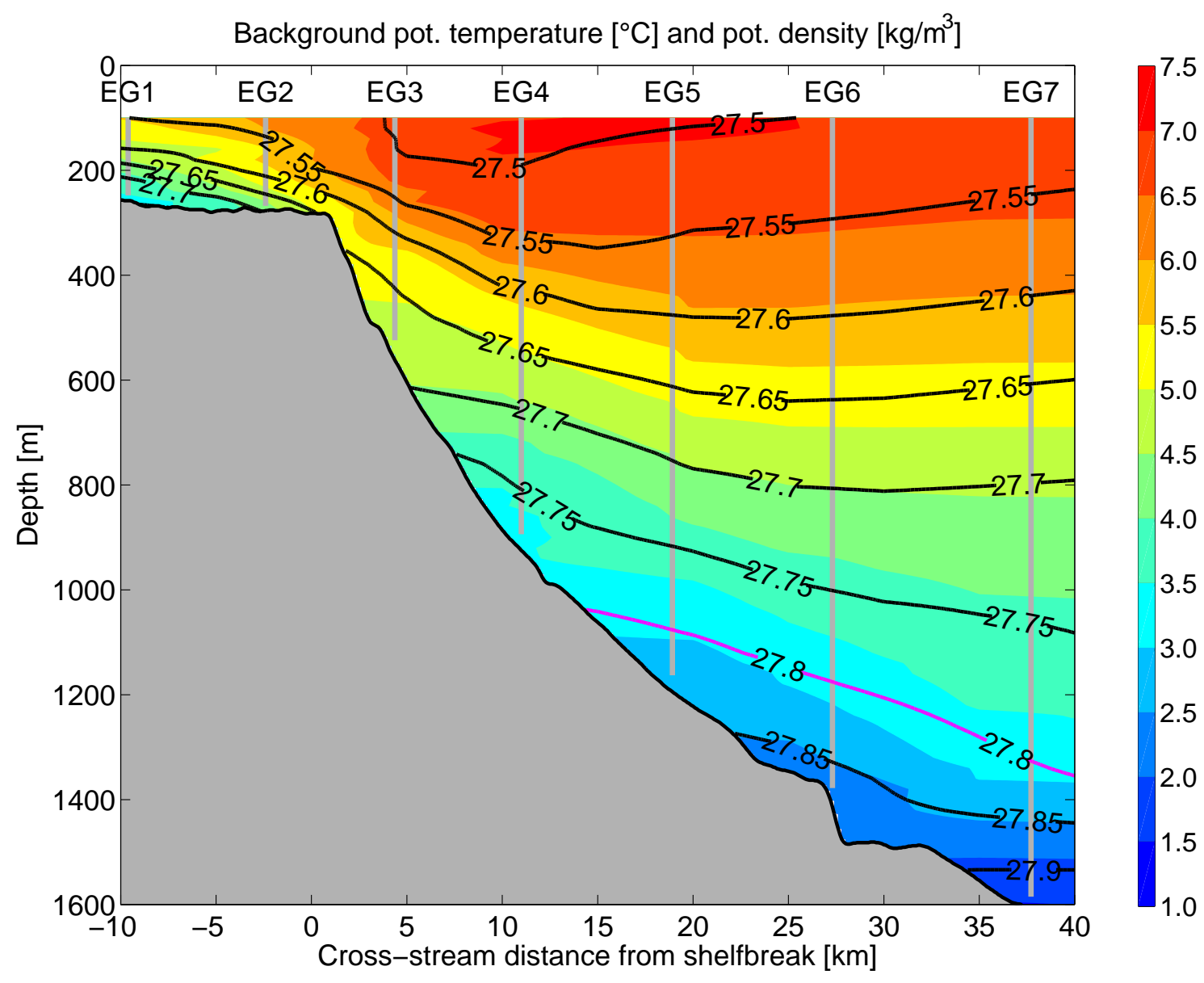

Figure 4-25: Potential temperature and potential density structure of the background flow (more than 18 hours away from cyclones) on the East Greenland slope. The mooring locations are shown in gray. The 27.8 isopycnal delimiting overflow water is shown in magenta.

and there is a bottom intensified flow of up to $0.2 \mathrm{~m} / \mathrm{s}$ at depth. If we integrate the flow over the water denser than 27.8 covered by our moorings, we obtain an overflow water transport of $0.9 \mathrm{~Sv}$.

Near-bottom mooring array measurements $\approx 85 \mathrm{~km}$ upstream and $\approx 85 \mathrm{~km}$ downstream of our location imply an overflow water transport of $5.2 \mathrm{~Sv}$ in this region (Dickson and Brown, 1994). Our estimate is about 15\% of this value. Aside from possible interannual variability, there are two contributing factors that help explain 


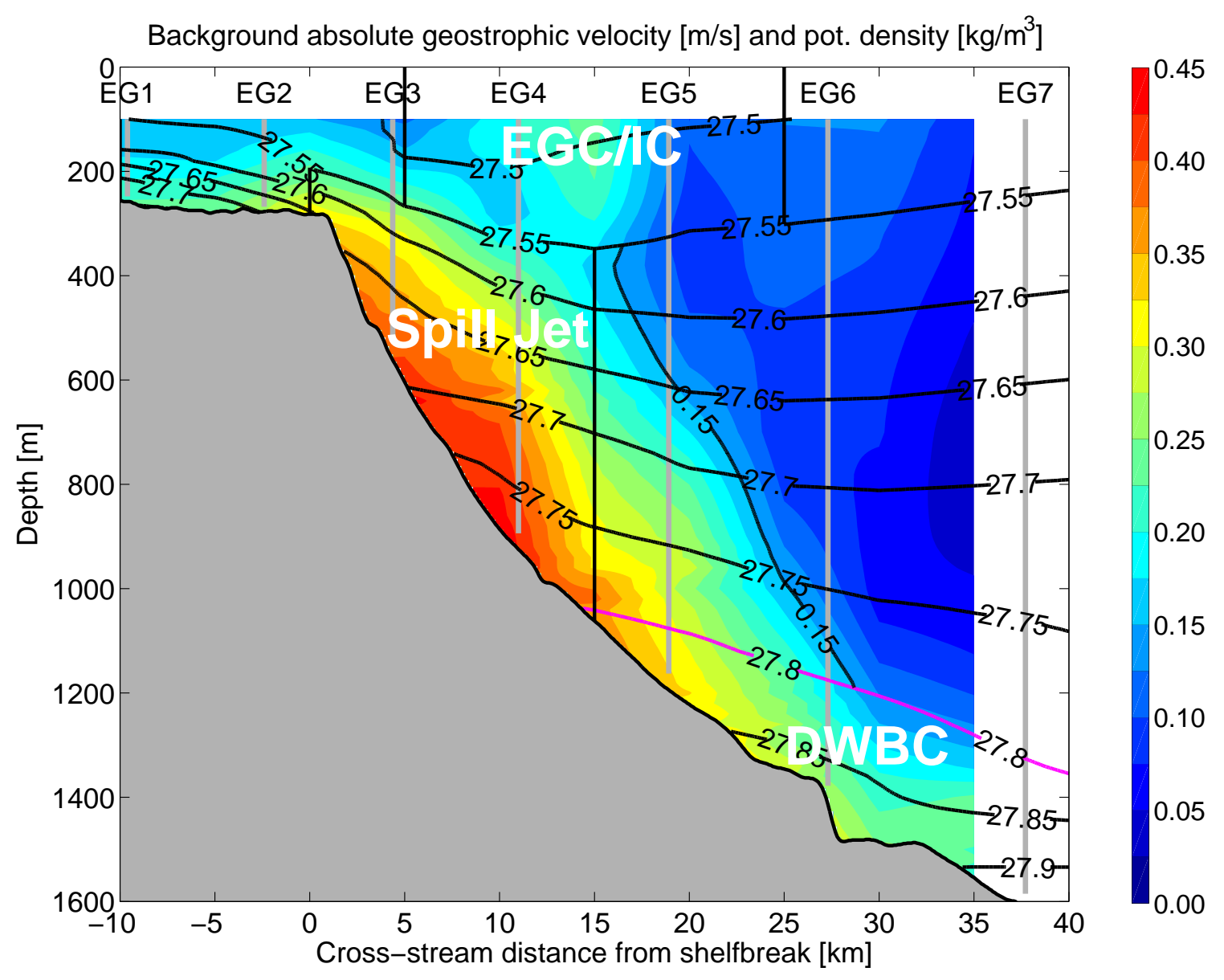

Figure 4-26: Absolute geostrophic alongstream velocity and potential density structure of the background flow. Lines delimiting the different currents are shown. Spill Jet definition 1 is $27.55>\sigma>27.8 \mathrm{~kg} / \mathrm{m}^{3}$ and $0<y<15 \mathrm{~km}$. Spill Jet definition 2 is $27.55>\sigma>27.8$ and $u>0.15 \mathrm{~m} / \mathrm{s}$. East Greenland Current/Irminger Current definition is $\sigma<27.55 \mathrm{~kg} / \mathrm{m}^{3}$ and $5<y<25 \mathrm{~km}$. Deep Western Boundary Current definition is $\sigma>27.8 \mathrm{~kg} / \mathrm{m}^{3}$. 
this large discrepancy. The first is that our mooring array covers only about half of the offshore domain measured by Dickson and Brown (1994). In particular, Dickson and Brown (1994) observed overflow water transport down to the $2600 \mathrm{~m}$ isobath with the core being in $\approx 1700 \mathrm{~m}$ (close to our EG7 depth). This means we have measurements in the region that accounted for about half of the transport of Dickson and Brown (1994). Taking this into account, we conclude that our estimate of the mean background DSOW transport is about 30\% of what Dickson and Brown (1994) observed. The remaining $70 \%$ is presumably due to the fact that Dickson and Brown (1994) did not distinguish between times of cyclone presence and absence. This implies that the background flow only accounts for a fraction of the total overflow water transport, with the majority achieved by the DSOW cyclones. We note that our estimate in Subsection 4.5.4 of the dense water transport in cyclones of $\lesssim 1 \mathrm{~Sv}$ also does not account for this discrepancy, but is also biased by the fact that the estimate is relatively high up on the slope. Overflow water transport in cyclones farther down the slope is disproportionately larger.

The dominant signature of the background flow in our sections is part of the East Greenland Spill Jet. As presented in Brearley et al. (2012), a significant fraction of the dense water passing through Denmark Strait does not sink with the overflow plume, but remains on the East Greenland shelf. Farther downstream some of this water is forced across the shelfbreak and subsequently descends, mixes, and accelerates, leading to a bottom intensified alongstream flow around the $800 \mathrm{~m}$ isobath that resides inshore and shallower that the DWBC. The passing DSOW cyclones (Magaldi et al., 2011) as well as wind events (Harden et al., 2012) appear to drive the spilling. In the four synoptic CTD sections analyzed by Brearley et al. (2012), it is likely that there was some signature of DSOW cyclones in the velocity field. By removing the times influenced by DSOW cyclones, we are able to resolve the Spill Jet in its isolation. 
The absolute geostrophic velocity field (Figure 4-26) agrees with the measured ADCP velocities at EG4 (Figure 4-20) in that the velocity increases with depth, but never exceeds $0.5 \mathrm{~m} / \mathrm{s}$. This suggests that the extreme absolute geostrophic velocities of up to $1.8 \mathrm{~m} / \mathrm{s}$ reported in Brearley et al. (2012) are a combination of the Spill Jet flow and the passage of a strong DSOW cyclone. Note also the close agreement between our background flow velocity field and that of Magaldi et al. (2011) reproduced in Figure 3-7. Again, the velocities in the model are slightly larger than our background velocities on account of including the effect of DSOW cyclones.

The mean section of Figure 4-26 shows that the East Greenland Spill Jet is a permanent feature of the boundary current system south of Denmark Strait. In order to assess the transport of the Spill Jet, we define its cross-sectional area in two different ways, one being a very strict (lower bound) definition and the other being more inclusive (Figure 4-26). In both definitions, the Spill Jet is bounded by the 27.55 and 27.8 isopycnals. Considering only the flow on the upper slope between $0 \mathrm{~km}$ and $15 \mathrm{~km}$ cross-stream distance, we obtain a geostrophic transport of $2.1 \mathrm{~Sv}$. If we also include the flow on the shelf and out to the $0.15 \mathrm{~m} / \mathrm{s}$ velocity isotach, the transport increases to $3.9 \mathrm{~Sv}$. The more restrictive definition yields a transport similar to the total (ageostrophic) transport of $1.8 \mathrm{~Sv}$ reported by Magaldi et al. (2011) from the numerical model of the region. The more encompassing definition is somewhat smaller than the $5.0 \mathrm{~Sv}$ reported by Brearley et al. (2012). It should, however, be noted that that study was based on only four synoptic CTD sections and also likely included some signature of DSOW cyclones. In addition, we expect the geostrophic transports to be an overestimate of the total (ageostrophic) transport.

The Spill Jet is formed from dense water originating on the shelf that spills across the shelfbreak. As such, this water could undergo vortex stretching analogous to the overflow water crossing over the Denmark Strait sill. If this were the case, one might 

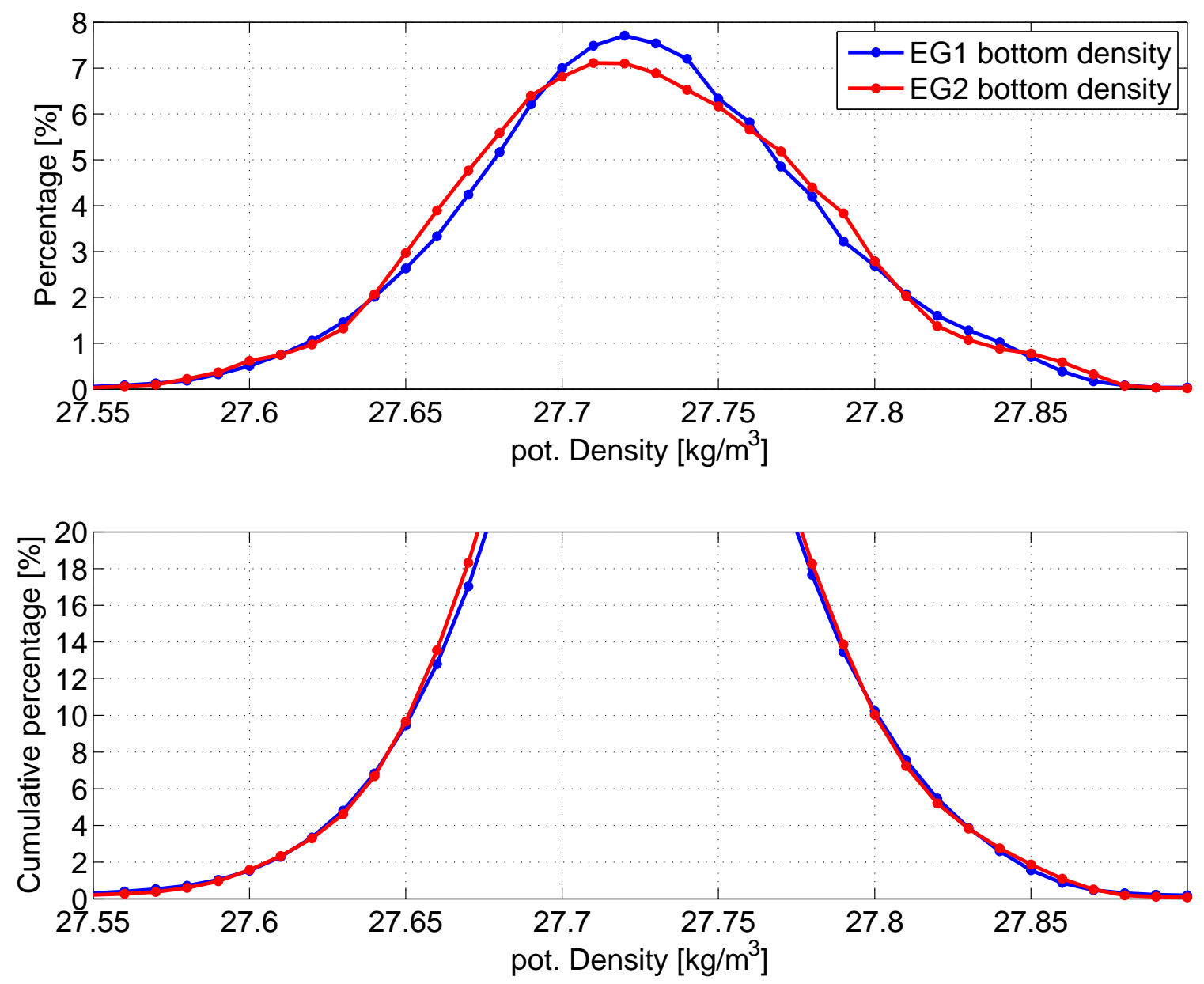

Figure 4-27: Distribution of bottom potential density on the shelf at EG1 (248 m) and EG2 $(268 \mathrm{~m})$. Top panel are the percentages of density measurements of the total 13 months long record that fall into each of the $0.01 \mathrm{~kg} / \mathrm{m}^{3}$ wide bins. Bottom panel is the cumulative percentage counting both from the lightest water towards denser water and from the densest water towards lighter water. The water is denser than $27.8 \mathrm{~kg} / \mathrm{m}^{3}$ for $10 \%$ of the time. 
assume that some of the cyclones we have observed originate from this local spilling process. This is not likely, however, since the bottom densities found on the shelf are only somewhat denser than our mean density in the core of the cyclones $\left(27.81 \mathrm{~kg} / \mathrm{m}^{3}\right)$. Locally, the water on the shelf is denser than that for about $7 \%$ of the time (compare Figure 4-27). Farther upstream on the shelf, bottom densities up to 27.9 have been observed (Brearley et al., 2012). As part of the spilling process, there will in any case be some mixing and entrainment (compare the discussion in Section 3.10) and subsequent mixing and entrainment during the along-isobath flow of the spilled water. As such it is highly unlikely that the water from the shelf retains its high density to the extent that it could account for the high densities observed inside of the cyclones (compare Figure 4-11). Additionally, the initial vortex height at the shelfbreak would be $300 \mathrm{~m}$ or less. Already upon reaching the $600 \mathrm{~m}$ isobath, the vortex height would have doubled leading to Rossby numbers of 1 in the cyclones. This would lead to stronger azimuthal velocities than observed. Hence the cyclones that we observe are only consistent with originating from water overflowing the Denmark Strait sill.

The final component of the boundary current system is the East Greenland Current/Irminger Current, which is surface intensified at a cross-stream distance of about $15 \mathrm{~km}$ (Figure 4-26). Since our hydrographic measurements did not extend to the surface, we are missing the top $100 \mathrm{~m}$ of that current. Irrespective of whether we extrapolate the velocity to be the constant value measured at $100 \mathrm{~m}$ or extend the average shear between $100 \mathrm{~m}$ and $200 \mathrm{~m}$ to the top $100 \mathrm{~m}$, the transport of the EGC/IC is approximately $1.0 \mathrm{~Sv}$.

It should be noted that we have not fully covered either the EGC/IC or the DWBC. The transport estimates for these boundary current components should therefore be taken as lower bounds. This is due to the fact that the design goal of the mooring array was to capture the Spill Jet, a task we have now achieved for the state without 
DSOW cyclones.

\subsection{Discussion}

Using data from a cross-shelfbreak mooring array, we were able to identify 190 DSOW cyclones. On average, an eddy passed by every other day, most of them around the $900 \mathrm{~m}$ isobath. The composite velocity field of a DSOW cyclone shows that they appear to typically propagate at $0.47 \mathrm{~m} / \mathrm{s}$ with respect to the mean flow which is consistent with the propagation of a topographic Rossby wave. Their propagation velocity with respect to the bottom is $0.72 \mathrm{~m} / \mathrm{s}$, and they have a peak azimuthal velocity of $0.22 \mathrm{~m} / \mathrm{s}$ at a radius of $7.8 \mathrm{~km}$. These values are substantially different than the statistics presented by Bruce (1995) or the $25-35 \mathrm{~km}$ distance between consecutive eddies seen in the numerical model of Spall and Price (1998). The findings of these studies are contrasted in Table 4.2. We speculate that the differences may be due to the fact that the SST disturbances tracked by Bruce (1995) propagate with the mean flow rather than with the cyclones underneath.

The mean background flow in the absence of DSOW cyclones reveals that the East Greenland Spill Jet is a strong permanent feature transporting 2.1-3.9 Sv (depending on the definition) of water of intermediate density equatorward. The background speed of the DWBC is $\approx 0.2 \mathrm{~m} / \mathrm{s}$. It transports DSOW $\left(\sigma>27.8 \mathrm{~kg} / \mathrm{m}^{3}\right)$ at depths greater than $1100 \mathrm{~m}$, which is farther downslope than where the majority of the DSOW cyclones reside. This means that, at this location $280 \mathrm{~km}$ downstream of Denmark Strait, the overflow water transport occurs in two modes: in the DSOW cyclones higher up on the continental slope, and in the background flow farther down the slope. The increased turbulent kinetic energy levels associated with the cyclones likely lead to more mixing and entrainment in the pathway of the cyclones. The 
Table 4.2: Summary of DSOW cyclone statistics. SST-derived values from Bruce (1995) are contrasted with the values obtained from a subsurface mooring array in this study.

\begin{tabular}{|c|c|c|c|c|c|}
\hline & & & ruce (1995) & & his study \\
\hline Variable & Name & Mean & Method & Mean & Method \\
\hline$u_{t}+u_{b}$ & $\begin{array}{l}\text { Eddy trans- } \\
\text { lational speed }\end{array}$ & $\begin{array}{l}0.27 \mathrm{~m} / \mathrm{s} \\
\pm 0.11 \mathrm{~m} / \mathrm{s}\end{array}$ & $\begin{array}{l}\mathrm{n}=33, \text { feature } \\
\text { tracking in SST }\end{array}$ & $0.72 \mathrm{~m} / \mathrm{s}$ & $\begin{array}{c}\mathrm{n}=101, \text { composite } \\
\text { eddy velocities }\end{array}$ \\
\hline$R_{0}$ & Eddy radius & $17 \mathrm{~km}$ & $\begin{array}{c}\mathrm{n}=46, \text { spiral } \\
\text { dimensions in SST }\end{array}$ & $7.8 \mathrm{~km}$ & $\begin{array}{c}\mathrm{n}=101, \text { composite } \\
\text { eddy velocities }\end{array}$ \\
\hline$u_{a}$ & $\begin{array}{l}\text { Peak azimuthal } \\
\text { velocity }\end{array}$ & & & $0.22 \mathrm{~m} / \mathrm{s}$ & $\begin{array}{c}\mathrm{n}=101, \text { composite } \\
\text { eddy velocities }\end{array}$ \\
\hline$D$ & $\begin{array}{c}\text { Distance } \\
\text { between eddies }\end{array}$ & $54 \mathrm{~km}$ & $\begin{array}{c}\mathrm{n}=54, \text { features in } \\
\text { same SST image }\end{array}$ & $130 \mathrm{~km}$ & $D=\left(u_{t}+u_{b}\right) * T$ \\
\hline$T$ & $\begin{array}{c}\text { Time } \\
\text { between eddies }\end{array}$ & 2.3 days & $T=D /\left(u_{t}+u_{b}\right)$ & 2.1 days & $\begin{array}{c}\mathrm{n}=190, \text { eddy } \\
\text { center identification }\end{array}$ \\
\hline$\alpha^{\prime}$ & $\begin{array}{c}\text { Eddy } \\
\text { descent rate }\end{array}$ & $2.3 \mathrm{~m} / \mathrm{km}$ & $\begin{array}{c}\mathrm{n}=35, \text { center } \\
\text { locations along slope }\end{array}$ & $2.7 \mathrm{~m} / \mathrm{km}$ & $\alpha^{\prime}=\frac{v_{b}}{u_{t}+u_{b}} \frac{\Delta h}{\Delta y}$ \\
\hline
\end{tabular}

spatial offset between the DSOW transport modes implies that the cyclones have a more limited effect on the mixing and entrainment of the background flow of DSOW than if the two transport modes were occurring at a similar water depth. We note, however, that this may not be the case farther upstream where the vertical separation between the two is likely less.

Coincidental in time with our mooring array, an individual mooring was maintained at the sill of Denmark Strait (see Figure 3-1 for its location). It was in $650 \mathrm{~m}$ of water and overlapped in time with our array for 11 months. The mooring contained a microcat at the bottom measuring temperature and salinity, and an upward-facing ADCP at the bottom measuring velocity throughout the water column. For more details on the mooring and the data, see Jochumsen et al. (2012). The depth-mean flow in the strait was directed equatorward at $0.22 \mathrm{~m} / \mathrm{s}$, but the variability was large. The mean bottom density in the strait during the year-long deployment was $28.00 \mathrm{~kg} / \mathrm{m}^{3}$. This is denser than the mean value $\left(27.94 \mathrm{~kg} / \mathrm{m}^{3}\right)$ at our deepest mooring EG7 and 
again points to the significant levels of entrainment in the first several hundred kilometers of the Deep Western Boundary Current.

The auto-correlation time scales for both the hydrography and the velocity at the sill are short, roughly a day. Cross-correlations indicate that an increase in flow through the strait leads an increase of the bottom density by about a third of a day. This co-variability is due to well-known Denmark Strait boluses (e.g. Macrander et al., 2007). This means that the variability at the strait is mainly due to the intermittent presence of dense water. The period of maximum variability in the strait has been estimated as 5 days (Voet and Quadfasel, 2010) which is longer than that measured farther downstream. In 2007-08, we also find this period to be $\approx 5$ days at the strait.

The vortex stretching hypothesis of Spall and Price (1998) can explain the formation of intense DSOW cyclones along the East Greenland slope in the presence of a steady overflow at the sill. However, there is strong variability at the sill on a similar time scale as the eddy variability observed at our array. One then wonders if the variability at the strait is related to the DSOW cyclones. A lagged correlation between the bottom density in the strait and the bottom density at the mooring array over the 11 months of joint deployment indicates that the bottom densities at the mooring array lag the bottom densities in the strait by about 5 days. The amplitude of this correlation is $\approx 0.2-0.3$ and increases with the water depth and mean density at the mooring array. It is strongest at EG7 and weakest, but still detectable, at EG4. The correlations at EG5-EG7 are all different from zero to $67 \%$ statistical significance assessed from a Monte Carlo simulation with 4000 iterations. The correlations between the velocity at the strait and the bottom densities at the mooring array are slightly weaker, but qualitatively similar and also have a maximum at a lag of 5 days.

A simple estimate of the signal propagation speed $u=L / T$ for the $280 \mathrm{~km}$ between the strait and our mooring array traversed in 5 days leads to $u \approx 0.65 \mathrm{~m} / \mathrm{s}$. This is 
close to the calculated DSOW cyclone translational velocity of $0.72 \mathrm{~m} / \mathrm{s}$ and much faster than the mean flow velocities of about $0.2 \mathrm{~m} / \mathrm{s}$. This implies that the variable part of the overflow water (i.e. the intermittently present densest part) crossing Denmark Strait is transported along the East Greenland slope in DSOW cyclones and not in the more quiescent background flow. It also supports the notion that the variability in Denmark Strait directly leads to the formation of DSOW cyclones.

The period of maximum variability at the mooring array is $\approx 2$ days when we consider the cyclone passing frequency (Section 4.4) and about 2.6 days for the alongstream velocity record at EG4 (Section 3.4). In light of the fact that the period of maximum variability in the strait ( 5 days) is about twice as long as at the mooring array, we suggest the following scenario. Some DSOW cyclones are formed from Denmark Strait boluses carrying the densest overflow water. In some instances the boluses themselves have cyclonic rotation (Våge et al., 2011). These are then intensified downstream via the vortex stretching mechanism. Other DSOW cyclones are formed from the more steady/less energetic and less dense part of the outflow from Denmark Strait and are generated solely by the vortex stretching mechanism (recall that Spall and Price (1998) generate cyclones from a steady outflow). Further work is needed to verify these ideas.

The degree to which DSOW descends seems to depend upon whether it is transported in the cyclones or in the background flow. A counter-intuitive aspect of overflow dynamics (e.g. Price and O'Neil Baringer, 1994) is that overflow water which starts out at a higher density leads to a lighter final water mass product than water that originates at a lower density. We note that this is qualitatively consistent with the hypothesis that energetic boluses of the densest overflow water going through the strait evolve into DSOW cyclones. In this scenario, the flow has a greater density difference with respect to the ambient water, entrains more rapidly and reduces its 
density significantly. As a result, it does not descend as much and leads to the DSOW cyclones that we observe on the continental slope at intermediate depths. Conversely, following periods of weaker flow exporting less dense DSOW out of the strait, the entrainment is weaker. This results in a less energetic flow that can descend to greater depths. As such, its total entrainment is weaker and it may account for the denser background DSOW transport that we observe on the continental slope at greater depths.

An additional aspect that may be responsible for the different depths of the DSOW transported in the cyclones versus in the background flow is $\beta$-drift. As an isolated cyclone self-advects to the east on a planetary $\beta$-plane, it slowly drifts northward (Early et al., 2011). The topographic $\beta$-plane equivalent is a self-advection with the shallower water on the right for the DSOW cyclones, which would imply a slow drift up the slope. This could counter-act the descent due to friction and lead to the DSOW cyclones residing higher up on the slope.

The fact that DSOW cyclones are not observed at the latitude of Cape Farewell may in part be due to the change in topography of the continental slope progressing southward. Between Denmark Strait and $35^{\circ} \mathrm{W}(\approx 100 \mathrm{~km}$ downstream of our mooring array) the bottom slope in the vicinity of the $900 \mathrm{~m}$ isobath is between 0.01 and 0.08. Using Equation (4.2) this leads to topographic Rossby wave speeds in the range of $0.1-0.7 \mathrm{~m} / \mathrm{s}$, which is qualitatively similar to the $0.45 \mathrm{~m} / \mathrm{s}$ inferred at the mooring array location. Near $35^{\circ} \mathrm{W}$, the bottom slope drastically increases (note the change in horizontal distance between the $500 \mathrm{~m}$ and $1500 \mathrm{~m}$ isobaths in Figures 3-1 and 3-2). Equatorward of this, the bottom slope (near the $900 \mathrm{~m}$ isobath) remains between 0.1 and 0.2 all the way to Cape Farewell. Such a large slope would imply topographic Rossby wave speeds around 1-2 m/s, which are likely unsustainable for a finite amplitude non-linear eddy. This may contribute to the spin down of the DSOW 
cyclones, although a more thorough investigation is needed to elucidate this.

\subsection{Acknowledgments}

We are grateful for helpful discussions about the content of this chapter with Tom Haine, Ken Brink, Paola Rizzoli, James Girton, Jonathan Lilly, Gunnar Voet, Jeff Carpenter, Kjetil Våge, Karl Helfrich, and Joe Pedlosky. We thank Héðinn Valdimarsson and Detlef Quadfasel for sharing the mooring data in Denmark Strait. Creation of the MODIS satellite data sets is credited to the NASA Ocean Biology Processing Group (OBPG), the NASA Jet Propulsion Laboratory (JPL), and the University of Miami Rosenstiel School of Marine and Atmospheric Science (RSMAS). 


\section{Chapter 5}

\section{Summary and Discussion}

We now summarize the main results of the work in this thesis and discuss some of the implications and questions following from the work.

\subsection{Summary of Major Findings of the Thesis}

The Western Arctic shelfbreak current is the main conduit transporting Pacific Water away from the Chukchi Sea. As such, its evolution and dynamics impact to lowest order the fate of PW in the Arctic Ocean. The current has distinct seasonal configurations, and here we have undertaken the first thorough investigation of the summer time state of the current. At different times during the summer months, the current transports one of two different types of summer PW: Alaskan Coastal Water (ACW) and Chukchi Summer Water (CSW). The structure and dynamics of the current are different between the two. In the former case the current is surface intensified with a mean speed of $0.28 \mathrm{~m} / \mathrm{s}$. In this state the current is baroclinically and barotropically unstable and sheds surface intensified eddies containing summer water. In the latter case the current is bottom intensified with a mean speed of $0.22 \mathrm{~m} / \mathrm{s}$. In this 
configuration the current is baroclinically unstable and sheds mid-depth intensified warm core eddies. Both currents are projected to spin down over a distance of a few hundred kilometers which implies that summer PW will not be transported into the Canadian Arctic Archipelago via this pathway.

In the second part of the thesis we have provided the first quantitative description of Denmark Strait Overflow Water cyclones using in-situ mooring data. The observations reveal that a DSOW cyclone progresses along the East Greenland slope every other day. On average, the DSOW cyclones reside at a water depth of $900 \mathrm{~m}$ some $300 \mathrm{~km}$ downstream of Denmark Strait, although their position ranges from $500 \mathrm{~m}$ to $1600 \mathrm{~m}$ depth. The cyclones self-advect at a speed of $0.47 \mathrm{~m} / \mathrm{s}$ and are also carried by the mean flow of $0.25 \mathrm{~m} / \mathrm{s}$ leading to a total propagation speed of $0.72 \mathrm{~m} / \mathrm{s}$ along the East Greenland slope. They reach their peak azimuthal velocity of $0.22 \mathrm{~m} / \mathrm{s}$ at a radius of $7.8 \mathrm{~km}$. DSOW cyclone statistics lack any seasonality, indicating their formation to be independent of atmospheric forcing. It is suggested that some DSOW cyclones may be formed from Denmark Strait boluses. In the absence of DSOW cyclones, the East Greenland Spill Jet is shown to be a year-round feature that transports $2-4 \mathrm{~Sv}$ in a bottom intensified flow along the upper continental slope.

\subsection{Questions Raised by the Work in the Thesis}

One of the major conclusions from the study of the dynamics of the summertime Western Arctic shelfbreak current is it that neither of the two configurations of the current is stable enough to transport summer PW all way to the first entrance of the CAA. Instead, the current sheds eddies with summer PW properties into the basin. This hypothesis depends on the assumption that the stability characteristics do not change along the Alaskan and Canadian Beaufort slopes. Conversely, we calculated 
that the shelfbreak current should be able to transport winter PW into the CAA. In order to test the hypothesis, a mooring was recently deployed at the southern end of Amundsen Strait. The mooring should be able to reveal if the shelfbreak current is still intact at this first entrance into the CAA. It will be interesting to see what PW properties the mooring measures and whether the velocity structure implies the presence of the shelfbreak current transporting winter PW as predicted.

The inability of the shelfbreak current to transport the summer PW to the CAA points to a larger importance of the Beaufort Gyre and the Transpolar Drift as a pathway for PW to enter Fram Strait and the CAA. Note that the Beaufort GyreTranspolar Drift route is a significantly longer distance travelled at a slower speed implying a much longer transit time. This also means that the heat stored in the summer PW will be more readily transported offshore with a greater potential for melting sea-ice. As the inflow of PW through Bering Strait continues to warm (Woodgate et al., 2010), this implies that the dynamics of the Western Arctic shelfbreak current will play an even greater role in the reduction of the sea-ice cover in the Canada Basin. Currently, the last remaining area covered by multi-year sea-ice in the Arctic Ocean is north of the CAA. We speculate that this may be due to the fact that the summer PW is not directly transported to this location.

While the results of this thesis have quantified the structure and the statistics of Denmark Strait Overflow Water cyclones on the East Greenland slope, the formation processes and the fate of DSOW cyclones still remain unclear. In particular, it needs to be established whether the boluses observed at the Denmark Strait sill in fact evolve into DSOW cyclones. This would imply that the densest overflow water is subject to the strongest entrainment and ends up relatively high on the East Greenland slope. The lateral separation between the majority of the DSOW cyclones and the bulk of the DSOW transport within the background flow of the DWBC at our mooring array 
location implies that the impact of the cyclones on the entrainment at that location is weak. However, as pointed out, this may not be the case farther upstream and it needs to be addressed what the best parameterization of this for use in general circulation models would be. For example, one might presume that all the overflow water might end up in DSOW cyclones if the overflow waters were to increase in density or the ambient Irminger Sea water were to become lighter.

The ubiquity of both DSOW cyclones and the East Greenland Spill Jet at $65^{\circ} \mathrm{N}$ raises the question of what their fate is. Using a CTD section at $60^{\circ} \mathrm{N}$, Brearley et al. (2012) argued that the Spill Jet may have undergone a transition in which double diffusion plays an important role to form the lower part of the East Greenland Current farther downstream along the East Greenland slope. The variability in mooring observations near Cape Farewell, the southern tip of Greenland, shows no indication of the presence of DSOW cyclones (Bacon and Saunders, 2010; Daniault et al., 2011a; Våge and Pickart, pers. comm. 2012). In particular, the variability is weak on the 2 day time-scale that we see at our mooring array. This implies that the flow structure of the DSOW cyclones must either have disintegrated along that distance or that the cyclones have propagated into the Irminger Sea basin. It needs to be determined whether some of the water transported in the DSOW cyclones gets entrained into the DWBC or is mixed into the Irminger Sea intermediate waters possibly impacting the open ocean deep convection there. The evolution of the East Greenland boundary current system clearly needs to be better quantified.

The high-resolution mooring array data used in this thesis clearly resolved some mesoscale dynamics that had previously not been identified as clearly in oceanic measurements. Due to the record length, our signal to noise ratio is large leading to robust results. This has provided observational support to various theoretical conclusions from geophysical fluid dynamics. It remains to be shown whether other 
oceanic boundary currents also exhibit similar structures of the energy conversions due to baroclinic and barotropic instability. In addition, one wonders how many oceanic cyclones have a similarly clear structure agreeing with the Gaussian eddy shape. The alongstream structure of the translational velocity of the cyclones with respect to the mean flow is an observation that was previously not possible and may lead to further theoretical investigations. 


\section{Appendix A}

\section{Data Processing of the East Greenland Mooring Array}

\section{A.1 Description of Planned Array}

The plan was to measure hydrographic and velocity properties across the East Greenland shelf and slope for one year starting in September 2007. A mooring array was devised that was made up of seven moorings and five different instruments. The mooring locations are detailed in Table A.1 and a side view of the planned measurements is shown in Figure A-1.

The different instruments are:

- Coastal Moored Profiler was programmed to crawl along the mooring wire and profile between roughly $100 \mathrm{~m}$ and the bottom depth twice a day (00UTC and 06UTC). It contained pressure, temperature, and conductivity sensors.

- McLane Moored Profiler was programmed to crawl along the mooring wire and profile between roughly $100 \mathrm{~m}$ and the bottom depth twice a day (00UTC and 
Table A.1: Location, cross-stream distance, and bottom depth of the seven moorings along the East Greenland slope. The deployment period was September 4th, 2007 to October 4th, 2008.

\begin{tabular}{|l|l|l|l|l|}
\hline Mooring name & Latitude & Longitude & Distance from shelfbreak & Bottom depth \\
\hline \hline EG1 & $65^{\circ} 30.0^{\prime} \mathrm{N}$ & $33^{\circ} 8.8^{\prime} \mathrm{W}$ & $-10.1 \mathrm{~km}$ & $248 \mathrm{~m}$ \\
\hline EG2 & $65^{\circ} 26.6^{\prime} \mathrm{N}$ & $33^{\circ} 4.5^{\prime} \mathrm{W}$ & $-2.9 \mathrm{~km}$ & $268 \mathrm{~m}$ \\
\hline EG3 & $65^{\circ} 23.2^{\prime} \mathrm{N}$ & $33^{\circ} 1.0^{\prime} \mathrm{W}$ & $3.9 \mathrm{~km}$ & $524 \mathrm{~m}$ \\
\hline EG4 & $65^{\circ} 20.0^{\prime} \mathrm{N}$ & $32^{\circ} 57.3^{\prime} \mathrm{W}$ & $10.5 \mathrm{~km}$ & $894 \mathrm{~m}$ \\
\hline EG5 & $65^{\circ} 16.2^{\prime} \mathrm{N}$ & $32^{\circ} 52.7^{\prime} \mathrm{W}$ & $18.4 \mathrm{~km}$ & $1163 \mathrm{~m}$ \\
\hline EG6 & $65^{\circ} 12.3^{\prime} \mathrm{N}$ & $32^{\circ} 47.0^{\prime} \mathrm{W}$ & $26.9 \mathrm{~km}$ & $1378 \mathrm{~m}$ \\
\hline EG7 & $65^{\circ} 7.3^{\prime} \mathrm{N}$ & $32^{\circ} 41.1^{\prime} \mathrm{W}$ & $37.3 \mathrm{~km}$ & $1585 \mathrm{~m}$ \\
\hline
\end{tabular}

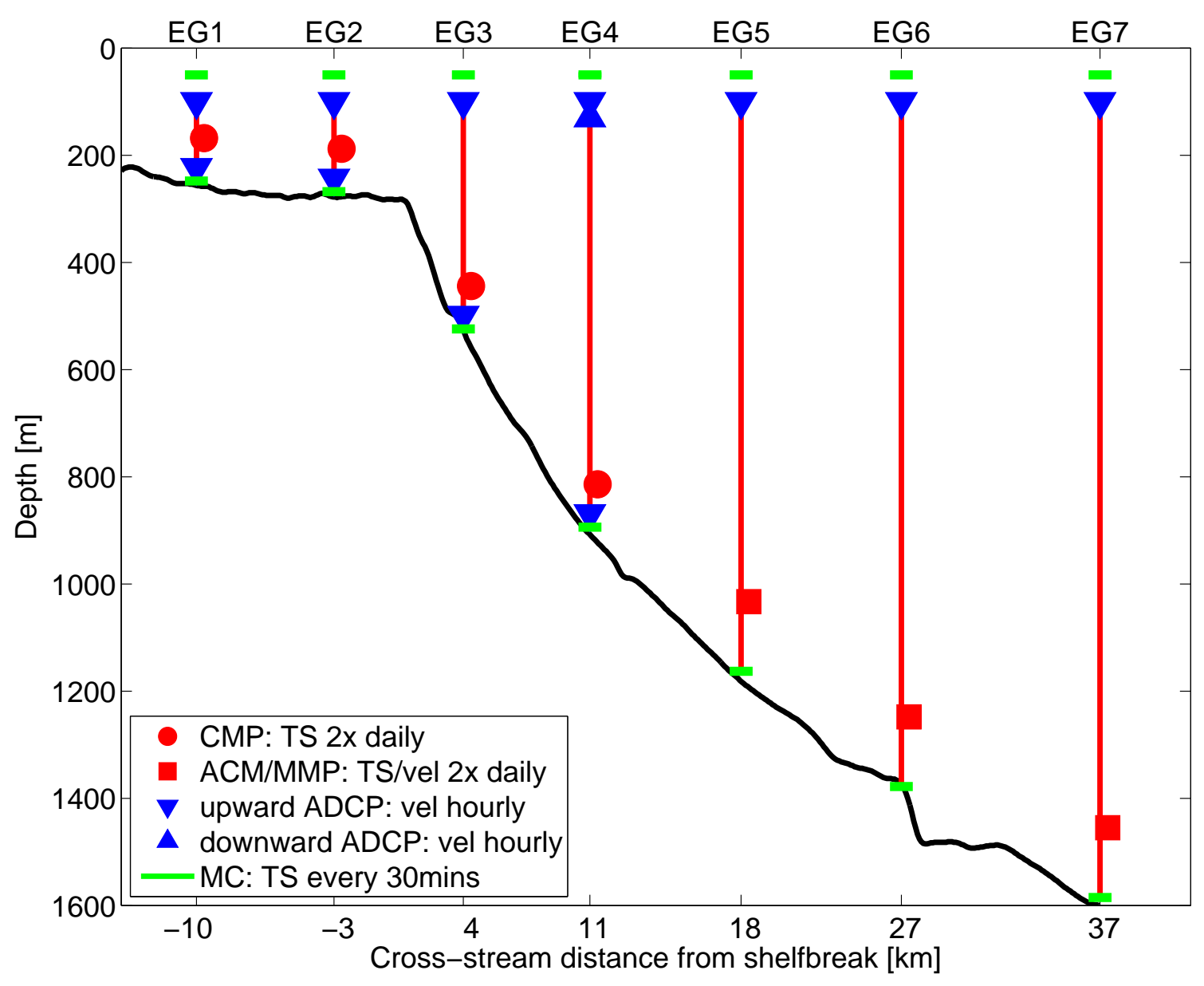

Figure A-1: Sideview of mooring array with different instruments marked in the legend. 
06UTC). It contained pressure, temperature, and conductivity sensors as well as an Acoustic Current Meter designed to measure velocity in the immediate vicinity of the instrument.

- Upward looking Workhorse RDI ADCP was mounted on a steel sphere at roughly $100 \mathrm{~m}$ depth as well as at the bottom of moorings EG1 and EG2. It was programmed to measure the velocity above the instrument hourly in $8 \mathrm{~m}$ bins.

- Upward looking Longranger RDI ADCP was mounted on bottom of moorings EG3 and EG4 and downward looking Longranger RDI ADCP was mounted on the steel sphere at roughly $100 \mathrm{~m}$ depth on mooring EG4. It was programmed to measure the velocity above/below the instrument hourly in $20 \mathrm{~m}$ bins.

- Microcat mounted on an aluminum tube on a $43 \mathrm{~m}$ long mooring wire connected to steel sphere and microcat mounted on the bottom of mooring. It was programmed to measure pressure (except for the bottom microcats on EG6 and EG7), temperature, and conductivity every 30 minutes.

\section{A.2 Mooring Blowdown}

The currents along the East Greenland slope were stronger than anticipated. Therefore, the buoyancy on the top floats of the moorings was insufficient to keep them upright under strong velocity conditions. The result is that the moorings were subject to vertical motion. Under those conditions, the top part of the mooring wire would still be vertical, but the bottom part would be at a significant (at times exceeding $30^{\circ}$ ) angle with respect to the vertical. This resulted in the issues detailed below. 
The pressure sensors on the top microcats and the tilt sensors on the bottom ADCPs went out of range leading to data loss. The moored profiler could only crawl up and down the mooring wire when the angle of the wire with respect to the vertical was small to moderate. Otherwise they would just stop at the depth at which they were located.

The top microcats were attached to an aluminum tube. This tube got crushed during mild to severe blowdowns and therefore lost its buoyancy. This occurred between a few days and about six months into the deployment for the different moorings. When the tube got crushed, the position of the microcat changed from $43 \mathrm{~m}$ above the top steel sphere to $43 \mathrm{~m}$ below. However, when reaching those depths, the pressure sensors wrapped around and indicated that the actual depth was shallower. Since we determined this to be incorrect based on the above physical process, we applied the additional information that the falling depth was $2 * 43 \mathrm{~m}$ as determined from the mooring diagram.

When the pressure sensors on the top microcats of EG3, EG5, EG6, and EG7 went beyond a particular depth, they just flatlined. This results in data loss at those times. The depths where this happened was $155 \mathrm{~m}$ (EG3), $519 \mathrm{~m}$ (EG5), $524 \mathrm{~m}$ (EG6), and $525 \mathrm{~m}$ (EG7). The salinity sensor malfunctioned on EG5 when its depth exceeded $375 \mathrm{~m}$.

These blowdown related issues lead to biased data loss during high velocity conditions. That is to say that measurement statistics during weak flow conditions are good while they are bad during strong flows. As a result, the record length statistics (such as mean and standard deviation) computed from the available measurements (mainly including weak flow conditions) likely differ significantly from the true statistics (including all flow conditions) of the respective quantity in the water column.

We have measurements of the vertical amount by which the moorings got blown 
down. This is related to the pressure exerted by the flow onto the mooring wire and the top float. Therefore, a mathematical relation exists between the blowdown depth and the column integrated flow speed. We attempted to find that relation, but it was concluded that in the present case this relation is non-unique making it impossible to constrain the relation from the available data to infer the water velocity on the East Greenland slope. The qualitative information (larger blowdown depth results from larger flow speed) still holds true though.

\section{A.3 ADCP Compass Correction}

The top upward looking ADCP was mounted onto the top sphere providing buoyancy. However, this sphere was made of steel. The steel of the sphere is magnetic (due to both permanent and induced magnetism). The magnetic field of the steel sphere superimposes onto the Earth's magnetic field that the compass in the ADCP is supposed to measure. Therefore, the magnetic field information recorded by the ADCP compass is contaminated. In our case, this contamination is so great that, for all practical purposes, the ADCP velocities are useless unless an appropriate compass correction is applied. This section deals with the theory behind and the details of this correction.

The order of magnitude of this effect was that for the full $360^{\circ}$ that each of the compasses should have recorded for at least a very short time during the deployment year, some ADCP compasses only ever measured directions within a $100^{\circ}$ range. This means that the other $260^{\circ}$ of possible directions received zero counts.

An applicable compass correction should have been measured before deployment of the ADCPs. Therefore, we need to back them out. For this we make use of ocean current velocities made from ADCPs on the bottom (EG1-3), the ADCP below the 
top sphere (EG4), and the ACMs (EG5-7). There is a region of overlap where those instruments measured essentially the same water motion as the top ADCPs. We will therefore attempt to find a compass correction that when it is applied to the top ADCPs brings the current measurement from the top ADCPs in agreement with the current measurements from the instruments below. This, however, makes the big assumption that the current measurements from the lower instruments are correct and that in particular they are not not affected by compass deviation issues themselves. We have not (and cannot!) verified that those lower measurements are correct.

\section{A.3.1 Theory of Magnetic Compass Deviation}

The theory of magnetic compass deviation due to the presence of hard (permanent magnetism) and soft (induced magnetism) steel is developed in detail in a manual that the NGIA has issued (National Geospatial-Intelligence Agency, 2004). It provides the theory for correction mechanisms and also gives step by step instructions for how to apply compass corrections to ships' compasses.

While we refer to the manual for details, the essence of the theory described in the manual is that the combined effects of different configurations of steel in the vicinity of a compass lead to a compass deviation. A compass deviation is a difference between the true magnetic north and the direction in which the compass needle points. This compass deviation is a function of the direction with respect to true magnetic north. The main point is that this function has a special functional form with only five independent parameters:

$$
\gamma(\beta)-\beta=A+B \sin (\beta)+C \cos (\beta)+D \sin (2 \beta)+E \cos (2 \beta)
$$

where $\beta$ is the true magnetic north heading and $\gamma$ the direction in which the compass 


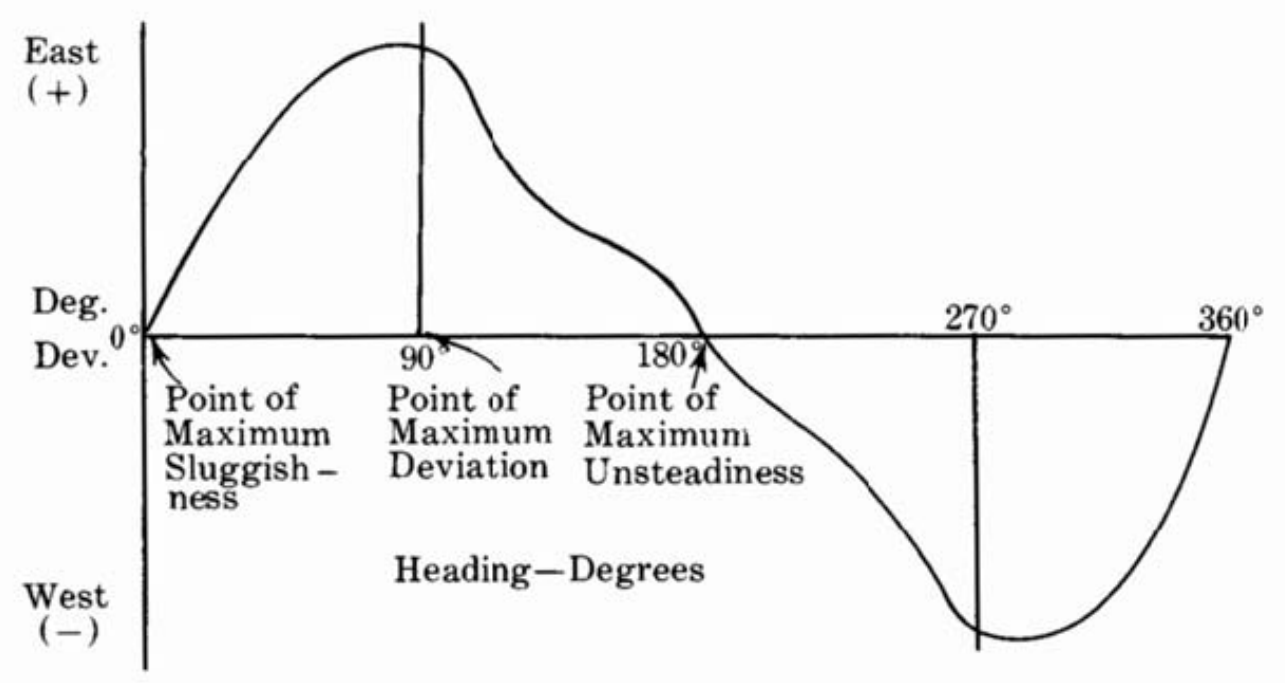

Figure A-2: Schematic of compass deviation curve. Figure from National GeospatialIntelligence Agency (2004).

\begin{tabular}{|c|c|c|c|c|c|}
\hline Coefficient & Type deviation curve & $\begin{array}{l}\text { Compass } \\
\text { headings of } \\
\text { maximum } \\
\text { deviation }\end{array}$ & Causes of such errors & Corrections for such errors & $\begin{array}{c}\text { Magnetic or compass } \\
\text { headings on which to apply } \\
\text { correctors }\end{array}$ \\
\hline$A$ & Constant. & Same on all. & 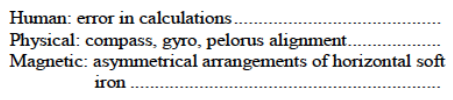 & $\begin{array}{l}\text { Check methods and calculations } \\
\text { Check alignments } \\
\text { Rare arrangement of soft iron rods }\end{array}$ & Any. \\
\hline$B$ & Semicircular $\sin \varnothing$ & $\begin{array}{l}090^{\circ} \\
270^{\circ}\end{array}$ & $\begin{array}{l}\text { Fore-and-aft component of permanent magnetic field.... } \\
\text { Induced magnetism in asymmetrical vertical iron } \\
\text { forward or aft of compass }\end{array}$ & $\begin{array}{l}\text { Fore-and-aft } B \text { magnets. } \\
\text { Flinders bar (forward or aft) }\end{array}$ & $090^{\circ}$ or $270^{\circ}$. \\
\hline C & Semicircular $\cos \varnothing$ & $\begin{array}{l}000^{\circ} \\
180^{\circ}\end{array}$ & $\begin{array}{l}\text { Athwartship component of permanent magnetic field.... } \\
\text { Induced magnetism in asymmetrical vertical iron port or } \\
\text { starboard of compass.... }\end{array}$ & $\begin{array}{l}\text { Athwartship } C \text { magnets } \\
\text { Flinders bar (port or starboard) }\end{array}$ & $000^{\circ}$ or $180^{\circ}$. \\
\hline$D$ & Quadrantal $\sin 2 \varnothing$. & $\begin{array}{l}045^{\circ} \\
135^{\circ} \\
225^{\circ} \\
315^{\circ}\end{array}$ & $\begin{array}{l}\text { Induced magnetism in all symmetrical arrangements of } \\
\text { horizontal soft iron. }\end{array}$ & $\begin{array}{l}\text { Spheres on appropriate axis. } \\
\text { (athwartship for }+D \text { ) } \\
\text { (fore and aft for }-D \text { ) } \\
\qquad \text { See sketch } a\end{array}$ & $045^{\circ}, 135^{\circ}, 225^{\circ}$, or $315^{\circ}$ \\
\hline E & Quadrantal $\cos 2 \varnothing$. & $\begin{array}{l}000^{\circ} \\
090^{\circ} \\
180^{\circ} \\
270^{\circ}\end{array}$ & $\begin{array}{l}\text { Induced magnetism in all asymmetrical arrangements } \\
\text { of horizontal soft iron. }\end{array}$ & $\begin{array}{l}\text { Spheres on appropriate axis. } \\
\text { (port forward, starboard aft for }+E \text { ) } \\
\text { (starboard forward, port aft for }-E \text { ) } \\
\text { See sketch } b\end{array}$ & $000^{\circ}, 090^{\circ}, 180^{\circ}$, or $270^{\circ}$ \\
\hline Heeling & $\begin{array}{l}\text { Oscillations with roll } \\
\text { or pitch. } \\
\text { Deviations with } \\
\text { constant list. }\end{array}$ & $\begin{array}{ll}0000^{\circ} & \\
1809 & \text { roll } \\
0909 & \\
270^{\circ} & \text { pitch }\end{array}$ & $\begin{array}{l}\text { Change in the horizontal component of the induced or } \\
\text { permanent magnetic fields at the compass due to } \\
\text { rolling or pitching of the ship }\end{array}$ & $\begin{array}{l}\text { Heeling magnet (must be re-adjusted } \\
\text { for latitude changes) }\end{array}$ & $\begin{array}{l}090^{\circ} \text { or } 270^{\circ} \text { with dip } \\
\text { needle. } \\
000^{\circ} \text { or } 180^{\circ} \text { while rolling. }\end{array}$ \\
\hline
\end{tabular}

Deviation $=A+B \sin \varnothing+C \cos \varnothing+D \sin 2 \varnothing+E \cos 2 \varnothing \quad(\varnothing=$ compass heading $)$

Figure A-3: Table of components of the compass deviation as shown in Equation (A.1). Figure from National Geospatial-Intelligence Agency (2004). 
needle points as defined in Figure A-4 below. All that follows is an attempt to determine the five constants $(A, B, C, D$, and $E$ ) for each of the moorings and apply it as a compass correction.

There is nothing about the correction mechanisms developed in the NGIA manual that is special to ships. It treats the ships as a sum of symmetric and antisymmetric arrangements of hard and soft steel in the vicinity of the compass. The steel sphere in the vicinity of the ADCP is nothing else. Therefore we consider the same theory to be applicable.

Just as in a ship, there is a forward direction to an ADCP though due to the symmetry of the ADCP, it may be less obvious. But it suffices to note that there is such a direction that is defined for an instrument and remains self-consistent as such throughout the life of the instrument. We will call this the forward direction and all the angles that we are concerned with are with respect to the forward direction.

For the following discussion, we define a few angles below that are also shown in the sketch in Figure A-4.

Defined directions:

- $a$ : Forward direction of ADCP

- $b$ : Current direction, direction in which the water is moving

- $c$ : True magnetic north. The direction into which a correctly compensated compass will point.

- $d$ : Direction in which the compass of the ADCP points as a result of the magnetic steel in the vicinity that has not been compensated for.

- $e$ : True geographical north (lines of constant longitude)

Defined angles: 


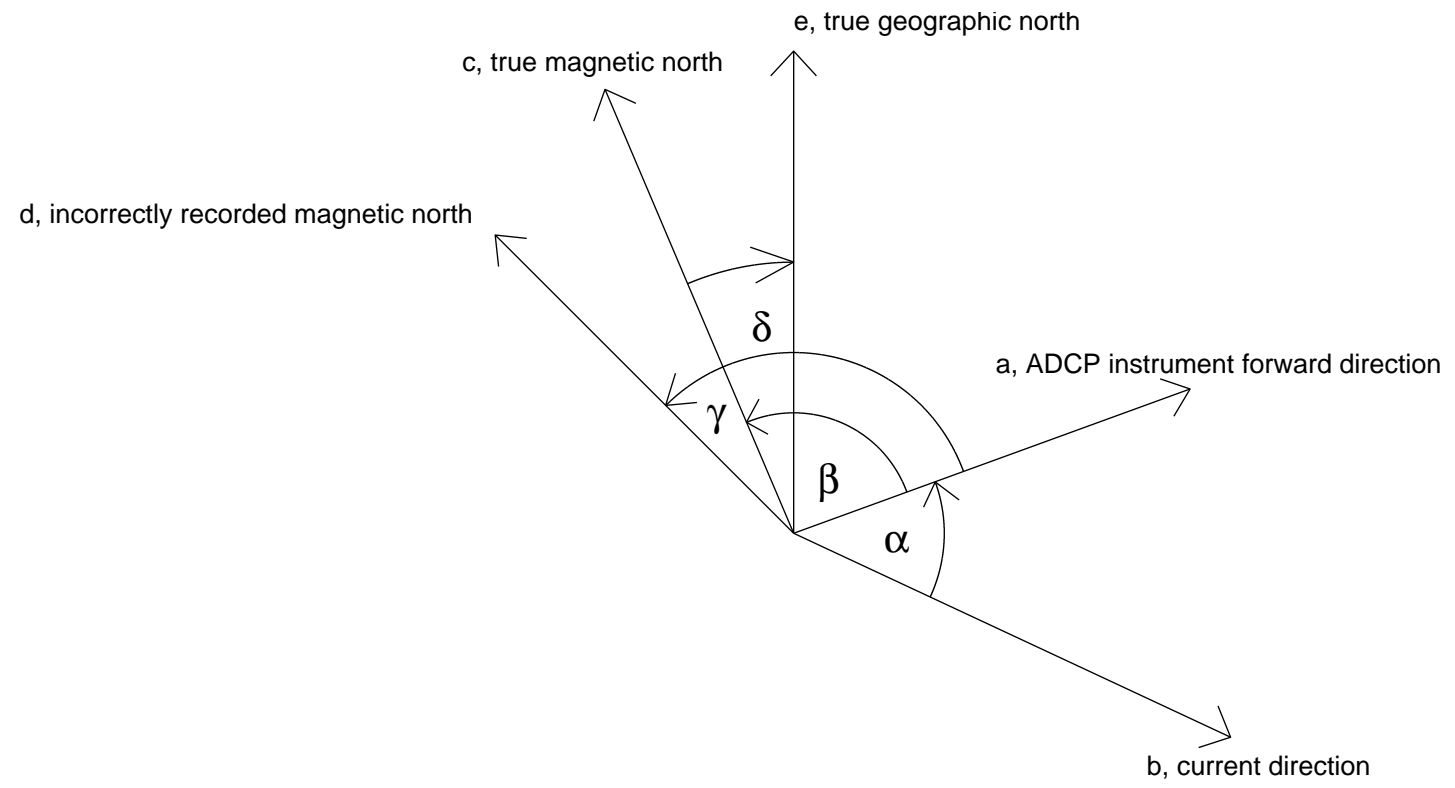

Figure A-4: Definition sketch of the directions and angles mentioned in the text. Note that we are using the mathematical convention of 0 in the eastward direction and an increase in the counter-clockwise direction.

- $\alpha$ : Angle between $b$ and $a$, current direction in instrument coordinates

- $\beta$ : Angle between $a$ and $c$, true magnetic north in instrument coordinates

- $\gamma$ : Angle between $a$ and $d$, recorded uncompensated ADCP compass heading. Note that this does not yet account for the magnetic declination $\delta$ which is only applied during processing on shore after the recovery.

- $\delta$ : Angle between $c$ and $e$, magnetic declination. It can be retrieved from http://ngdc.noaa.gov/geomag/magfield.shtml for any location and time on the globe. It is $-23^{\circ} 43^{\prime}$ on Sep 1, 2007 and $-23^{\circ} 23^{\prime}$ on Sep 1, 2008 at the mooring location.

List measured quantities:

- $\delta$ : Magnetic declination from NGDC chart 
- $\gamma$ : Recorded uncorrected compass heading of upper ADCP

- $D_{b o t}=\alpha+\beta+\delta$ : Output of lower ADCP/ACM after onshore processing that was not affected (as assumed!) by compass deviation issues: recorded correct current direction in correct geographical earth coordinates. It should be noted that the ADCP internally records the current direction in magnetic coordinates $(\alpha+\beta)$ and the addition of the magnetic declination $(\delta)$ occurs only onshore during processing, but is nonetheless the variable saved in the available dataset.

- $D_{\text {top }}=\alpha+\gamma+\delta$ : Output of upper ADCP after onshore processing that was affected by compass deviation issues: recorded current direction in incorrect geographical earth coordinates

What we need to construct the compass deviation curve (true magnetic heading vs. difference between incorrectly reported magnetic heading and true magnetic heading):

- Forward direction of ADCP in correct magnetic earth coordinates: $\beta=(\underline{\alpha+\beta+\delta})-$ $(\alpha+\delta)=(\underline{\alpha+\beta+\delta})-(\underline{\alpha+\gamma+\delta})+\underline{\gamma}=\underline{D_{b o t}}-\underline{D_{t o p}}+\underline{\gamma}$ where underlined quantities are measured quantities.

- Magnetic deviation of compass due to presence of steel in the vicinity: $\beta-\gamma=$ $\underline{(\alpha+\beta+\delta})-(\underline{\alpha+\gamma+\delta})=\underline{D_{b o t}}-\underline{D_{t o p}}$

Now we are able to construct the uncompensated compass deviation curve $\beta$ vs. $\beta-\gamma$. This can also be plotted as $\beta$ vs. $\gamma$ and then inverted as $\gamma$ vs. $\beta$. However, since the compass deviations that we are dealing with in the present case are of large amplitude, the inversion is not unique and $\beta(\gamma)$ becomes multivalued. The next subsection gives details on how we deal with that.

The inversion will give a function to compute the corrected/true magnetic heading of the instrument as a function of the uncorrected magnetic heading, i.e. $\beta(\gamma)$. This 
function will, however, in general not be defined for all measured uncorrected magnetic headings $\gamma$.

The correction is then applied to obtain the corrected upper current direction:

- Corrected upper current direction: $D_{\text {top }}^{\text {corr }}=\alpha+\beta(\gamma)+\delta=(\underline{\alpha+\gamma+\delta})+\beta(\underline{\gamma})-$ $\underline{\gamma}=\underline{D_{t o p}}+\beta(\underline{\gamma})-\underline{\gamma}$ where we take advantage of the previously determined function $\beta(\gamma)$ where it is defined and return $N a N$ otherwise.

\section{A.3.2 Implementation of Method}

Figure A-5 shows an example for mooring EG4 of both the analytic curve fitting to $\beta-\gamma$ and the inversion to obtain $\beta(\gamma)$. Figure A-6 shows a comparison between the top direction histograms before and after the correction with the bottom direction histogram. There are two non-trivial aspects in the process.

The first issue is how to go from the given data to a smooth compass deviation curve. Measurements from the top ADCP and bottom ADCP/ACM are considered to be overlapping when their nominal measurement depth is within $20 \mathrm{~m}$ of each other and their temporal separation is less than half an hour. This overlapping data set allows for scatter plots of direction as well as for a pointwise plotting of the uncompensated compass deviation curve. A smooth analytic function needs to be determined from this curve with scatter. For this we employ Matlab's curve fitting toolbox by forcing a fit to Equation (A.1).

The other issue is how to invert the $\gamma(\beta)$ function. The mapping from $\beta$ to $\gamma$ is unique and defined for all $\beta$ and hence a function. However, there are some $\gamma$ that map to more than one $\beta$ and some $\gamma$ that map to no $\beta$. This means that the mapping $\gamma$ to $\beta$ is not a function, but has to be defined for only a subset of the domain. This is due to the fact that the amplitude of the compass deviation is as 


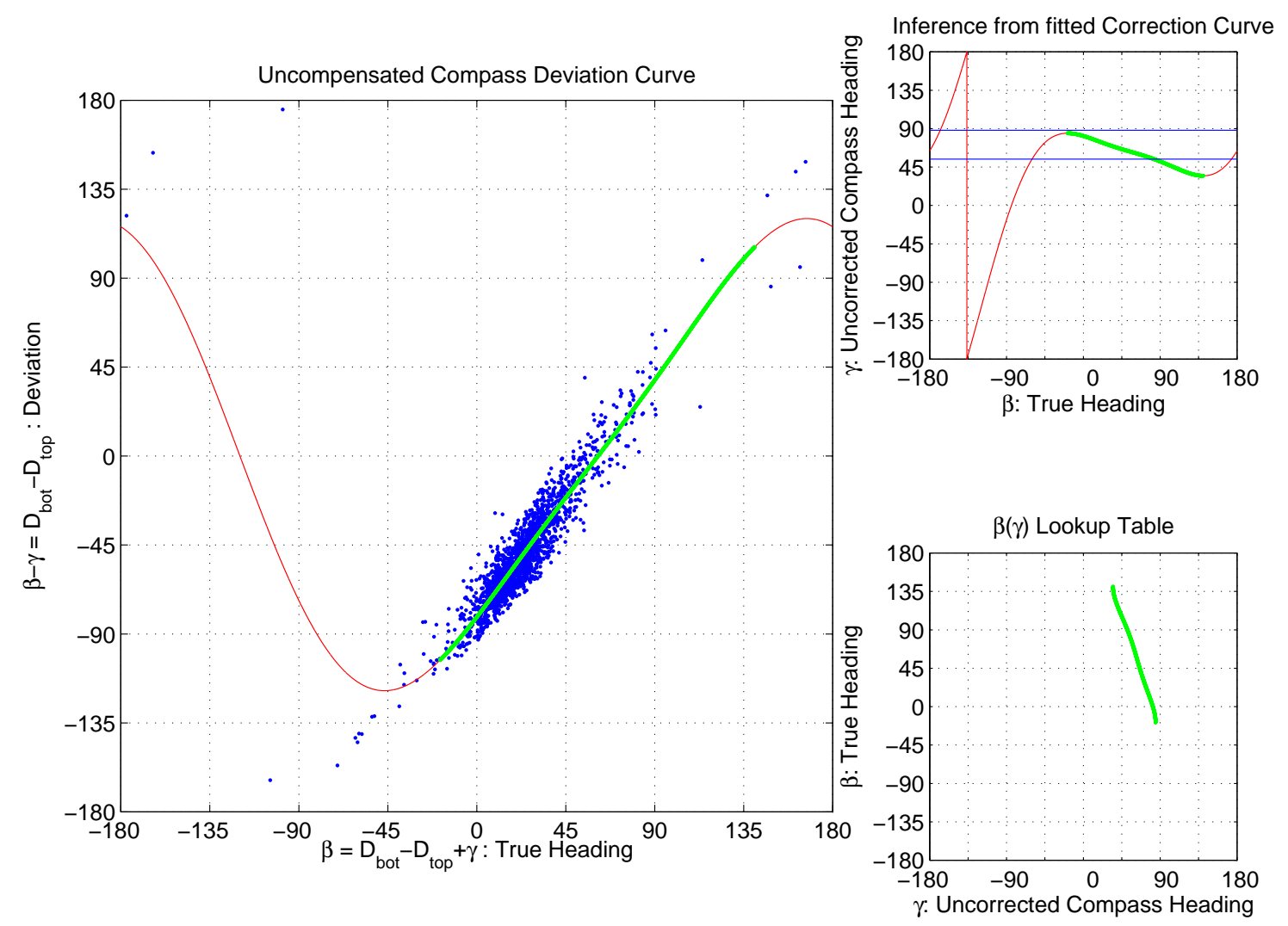

Figure A-5: Analysis plots for compass correction of top ADCP on mooring EG4. Left panel plots $\beta-\gamma$ as a function of $\beta$. Top right panel plots the fitted $\gamma$ as a function of $\beta$. Bottom right panel plots the inverted $\beta$ as a function of $\gamma$. Blue dots are data points from when the top and bottom ADCP measurements were within $20 \mathrm{~m}$ vertical and half an hour in time. Red line is the fitted functional form to the data scatter in $\beta-\gamma$ as a function of $\beta$. Green thick line is the range over which the fitted function can be inverted to yield a lookup table of $\beta(\gamma)$. 

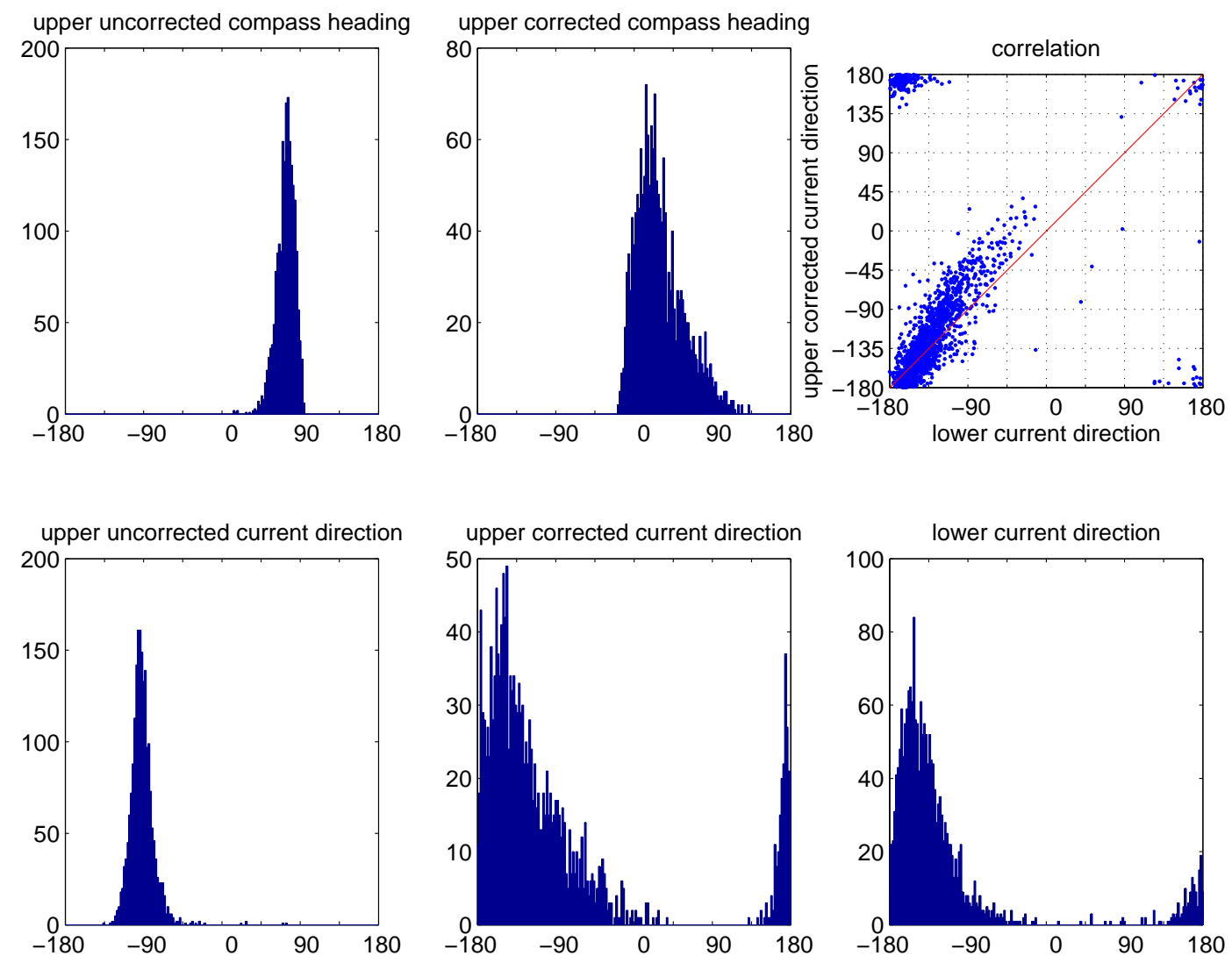

Figure A-6: Plots with results of the compass correction of top ADCP on mooring EG4 to judge the success of the compass correction. Top left and center panel show histograms of the compass heading before and after the correction. Note how the range of headings covered was increased by the correction and how the distribution was actually flipped, i.e. the longer tail is on the left before the correction and on the right after the correction. Top right panel shows a scatter plot of the upper corrected current direction versus the lower current direction. If the data were to fall on the red line, the correction would have been perfect. Note that the due to the periodicity of directions $\left(-180^{\circ}=180^{\circ}\right)$, the data scatter in the four corners of the plot actually all abut each other. Bottom row of panels are histograms of the current directions. Note that a perfect compass correction would render the middle and right panels to be identical. They clearly are not, but nonetheless, they are much more similar to each other than to the left panel. 
large as $100^{\circ}$ for some moorings. This means that there is even a reversal of direction, i.e. for the incorrectly recorded magnetic direction increasing, the correct magnetic heading is actually decreasing. The amplitude in the EG2 case is small enough that the inversion is directly possible. This is the case that supposedly happens most of the time in the situations envisioned in the discussion of National Geospatial-Intelligence Agency (2004).

For the cases of EG1 and EG3-7, different branches of the $\gamma(\beta)$ curve have to be subselected for the inversion. They are qualitatively different with respect to how $\gamma$ varies with a variation of $\beta$, i.e. w.r.t. to the sign of $\frac{\partial \gamma}{\partial \beta}$. Comparing the results, it becomes clear that $\frac{\partial \gamma}{\partial \beta}<0$ is the region to choose while $\frac{\partial \gamma}{\partial \beta}>0$ produces no useful results. This means that for all those moorings, the sense of change is reversed.

The range of $\beta$ where $\frac{\partial \beta}{\partial \gamma}<0$ is very narrow (less than $100^{\circ}$ for some moorings). However, the range of $\gamma$ that $\beta$ is mapped to in this region is significantly wider. This is referred to as the region where the compass needle is "sluggish" by National Geospatial-Intelligence Agency (2004); compare also Figure A-2. So even though the incorrectly recorded compass headings are only confined to a very narrow range, we are able to recover a wider range of actual true instrument orientations. The physical interpretation is that the moorings where embedded in a mostly unidirectional flow (actually a narrow band variation around that major direction) and the ADCPs representing the biggest asymmetric drag part on the otherwise symmetric spheres were always located in the wake of the spheres. This is just how any asymmetric blunt object will orient itself in a flow.

Nonetheless, the employed method fails to determine the correct magnetic instrument heading for some incorrectly recorded magnetic instrument headings. For those headings, a correction of the velocity is not possible. This leads to a biased (as a function of instrument heading and therefore most likely current direction) exclusion 
Table A.2: Percentage of time when the employed correction method failed to determine the correct magnetic instrument heading. Percentages are shown both for the times when the top ACDP and bottom ADCP/ACM overlapped their measurements in space and time and for the full records of the top ADCP.

\begin{tabular}{|l|r|r|}
\hline Mooring & Overlapping time $\%$ & Full time $\%$ \\
\hline EG1 & $30.2 \%$ & $30.6 \%$ \\
\hline EG2 & $0 \%$ & $0 \%$ \\
\hline EG3 & $8.4 \%$ & $15.1 \%$ \\
\hline EG4 & $12.4 \%$ & $15.6 \%$ \\
\hline EG5 & $0 \%$ & $0 \%$ \\
\hline EG6 & $2.3 \%$ & $6.1 \%$ \\
\hline EG7 & $4.9 \%$ & $3.5 \%$ \\
\hline
\end{tabular}

of data. While this is unfortunate, the method uses a physically justified procedure to determine the correct current direction for the majority of the top ADCP data. The amount of times when the correction method failed is shown in Table A.2 both as a percentage of the full data record of the top ADCP and as a percentage of time when there was an overlapping coverage between the top ADCP and bottom ADCP/ACM.

The top ADCP velocities on mooring EG1 had been corrected for in a more ad-hoc way by Ben Harden before (Harden et al., 2012). Since EG1 is not at the focus of our current study and our method has a large failure rate for that mooring, we just reverted to using the correction from Ben Harden for mooring EG1 and our method for moorings EG2-7.

\section{A.4 Detiding}

The raw time series at each depth for the ADCP and ACM records contain horizontal tidal motions that are likely stronger on the outer shelf than on the slope. The suite of Matlab programs T_TIDE (Pawlowicz et al., 2002) perform a tidal fit to the data 

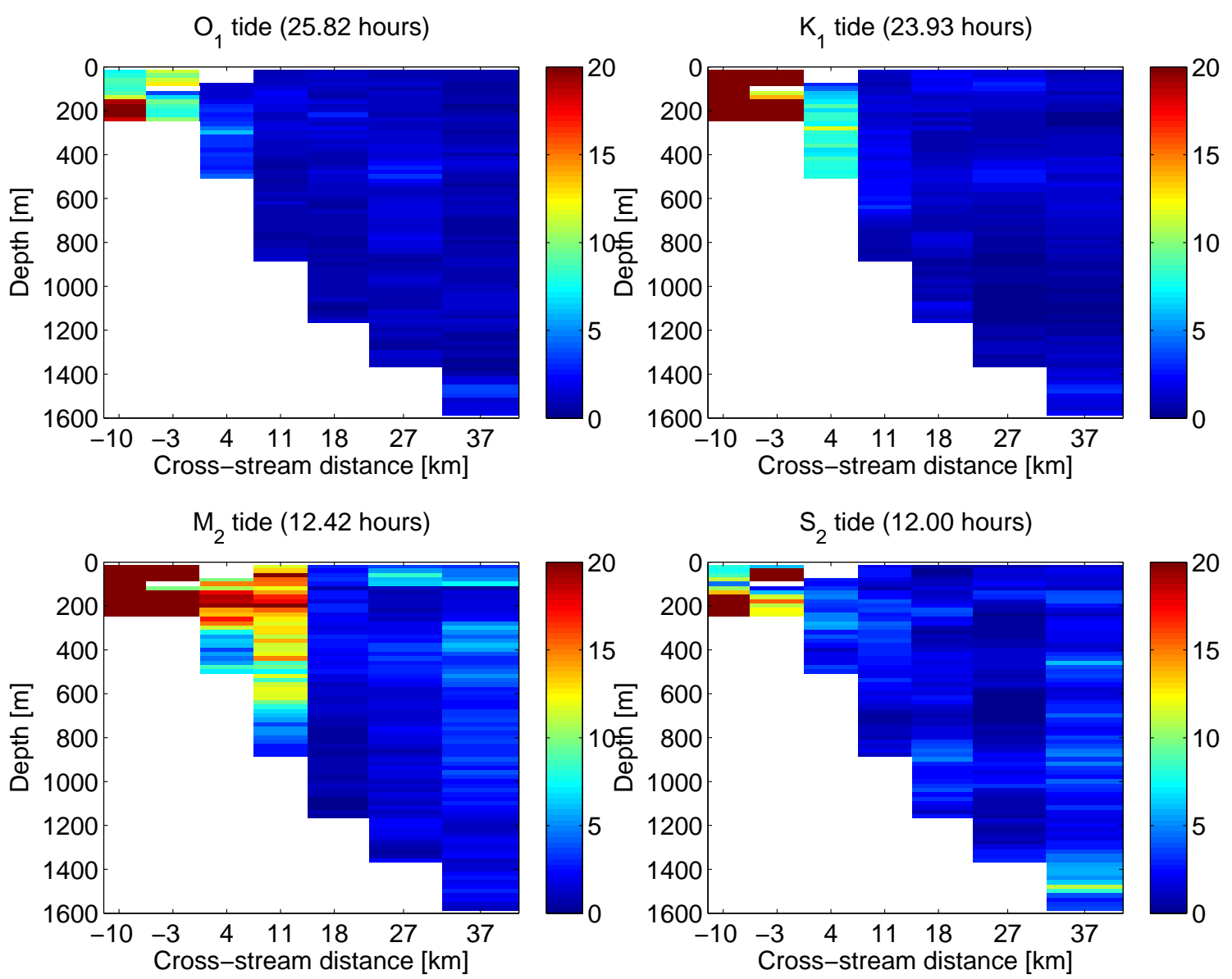

Figure A-7: Signal to noise ratio of four major constituents as a function of crossstream distance and depth.

and allow to identify the major tidal components for removal from the record. In order to identify the diurnal and semi-diurnal tides, the hourly sampling frequency of the ADCPs is ideal while the 6-/18-hourly ACM sampling frequency is theoretically only marginally able to resolve those tides.

The investigation for choosing the parameters, methods and ranges for detiding are presented below. It is found that there are four major constituents that can be fitted beyond doubt to the records of moorings EG1 and EG2 with signal to noise ratios (SNR) in excess of 20. As shown in Figure A-7 they also show up in a non- 
trivial manner for the ADCP records of EG3 and EG4 on the upper slope, while the deep water ADCPs and ACMs on EG5 to EG7 do not depict a significant signal strength. The four major identified tidal components are: lunar $\mathrm{O}_{1}$ (25.82 hours), principal lunisolar $\mathrm{K}_{1}$ (23.93 hours), lunar semi-diurnal $\mathrm{M}_{2}$ (12.42 hours), and solar $\mathrm{S}_{2}$ (12.00 hours).

The program also lists the different tidal constituents sorted by SNR, and it is found that at least two of these four constituents are always among the four most dominant constituents with the rest variously taken up by constituents with roughly yearly periods. These yearly constituents aliases of a possible seasonal cycle and are limited by the fact that their periods are similar to the total record length. Therefore, they are unphysical and we neglect those constituents and only focus on the ones that have a clear and relevant physical interpretation.

The program then proceeds to predict the timeseries of the four major constituents for each mooring and depth level and subtracts this from the full record to obtain a detided timeseries. The predicted tides have an RMS velocity of up to $0.08 \mathrm{~m} / \mathrm{s}$ on the shelf (EG1 and EG2), but due to the enormous variability on other time scales, even those strong tidal velocities only contribute $25 \%$ or less of the total variability (compare Figure A-8). This is a good consistency check on the meaningfulness of the detided timeseries. In particular, the detided timeseries contains about $75 \%$ of the original variability and is therefore not just the minute remainder of a strong, dominant tidal signal.

We compare the tidal fits at different depth levels and for neighboring moorings. T_TIDE, when it is applied, is oblivious to those nearby data points. However, the signals rise above the noise in many locations and they should therefore be well correlated both in the vertical and in the horizontal. This is confirmed and gives additional confidence in the method. In fact both the amplitude and the phase 


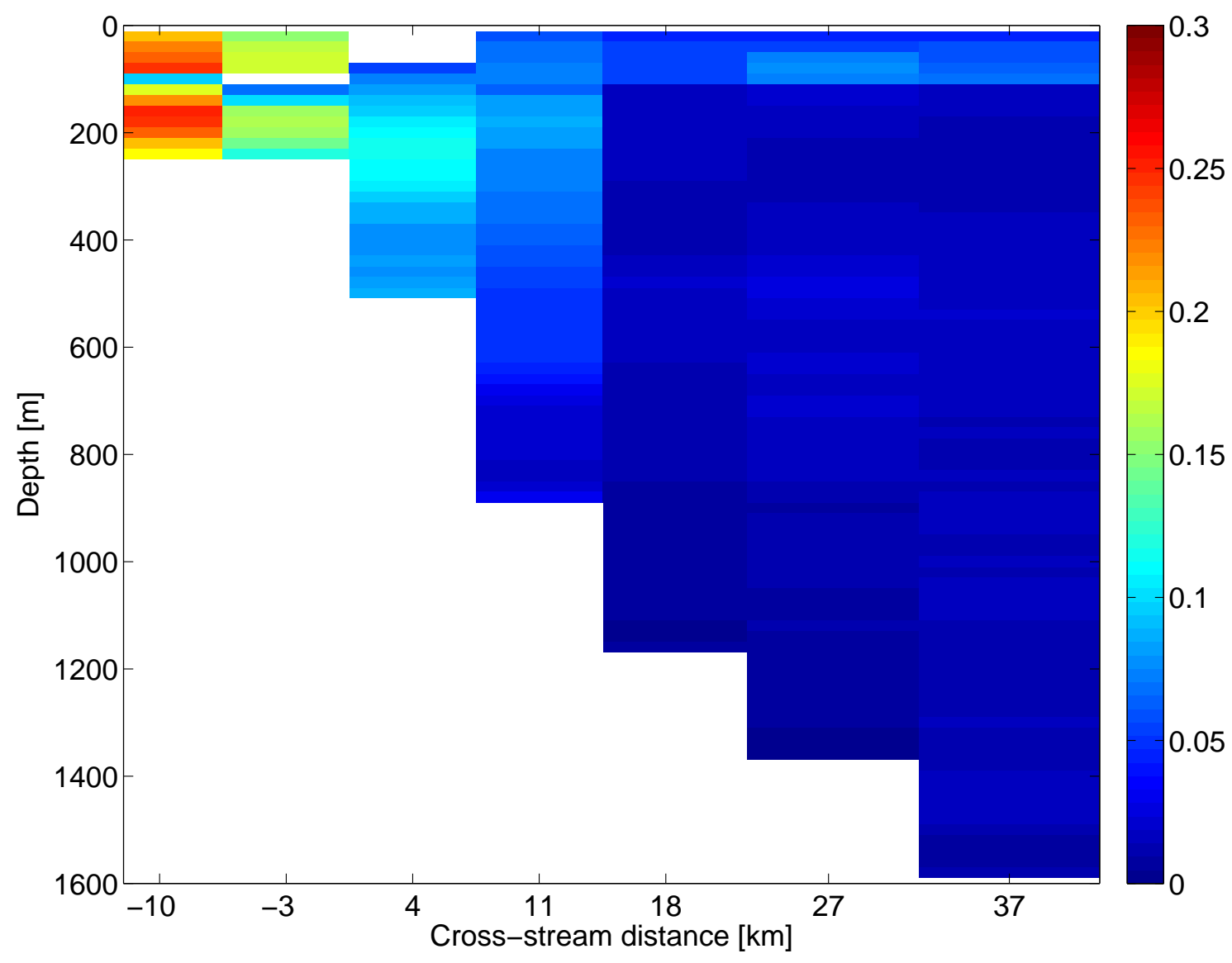

Figure A-8: Ratio of the RMS velocities of the predicted tide $\left(\mathrm{O}_{1}+\mathrm{K}_{1}+\mathrm{M}_{2}+\mathrm{S}_{2}\right)$ to the RMS velocities of the total raw signal. 
especially of the $\mathrm{M}_{2}$ tide vary smoothly in the vertical.

Based on the above analysis, it was chosen to only detide moorings EG1-3. Also the top ADCP record on EG3 was too short (9 days) for a tidal analysis.

\section{A.5 Determination of Alongstream Direction}

This section deals with how we determined one self-consistent alongstream direction. An alternative would be to define a "local" (and/or even time-varying) alongstream direction for each mooring. However, this would imply convergence or divergence along the line of moorings for what would be defined as purely alongstream flow. For this reason, we do not consider this.

There are three different analysis steps that were done to determine an appropriate alongstream direction. As a final outcome, an alongstream direction of $-160^{\circ} \mathrm{T}$, i.e. west-south-westwards was chosen.

The first step was a Mercator projection map as shown in Figure A-9. This map is used to extract the direction of the isobaths as they are represented in the GEBCO 30 second data base which in the absence of multi-beam shipboard data is the best we have available. The along-bathymetry lines seem to be close to $-150^{\circ} \mathrm{T}$.

The second step was a histogram of all directions measured as shown in Figure A-10. This counts up all the individual measurements of current directions that were ever taken. As such it counts each ADCP measurement with the same weight as each ACM measurement. The bias due to this, however, is not a lowest order signal as for each $20 \mathrm{~m}$ vertical bin and 24 hours there are a roughly equal number of ADCP (1 depth bin times 24 time points $=24)$ measurements and ACM (10 depth bins times 2 time points $=20$ ) measurements. The well-peaked histogram is again suggestive of a direction near $-160^{\circ} \mathrm{T}$. A principal axis determination weighting the observed flow 


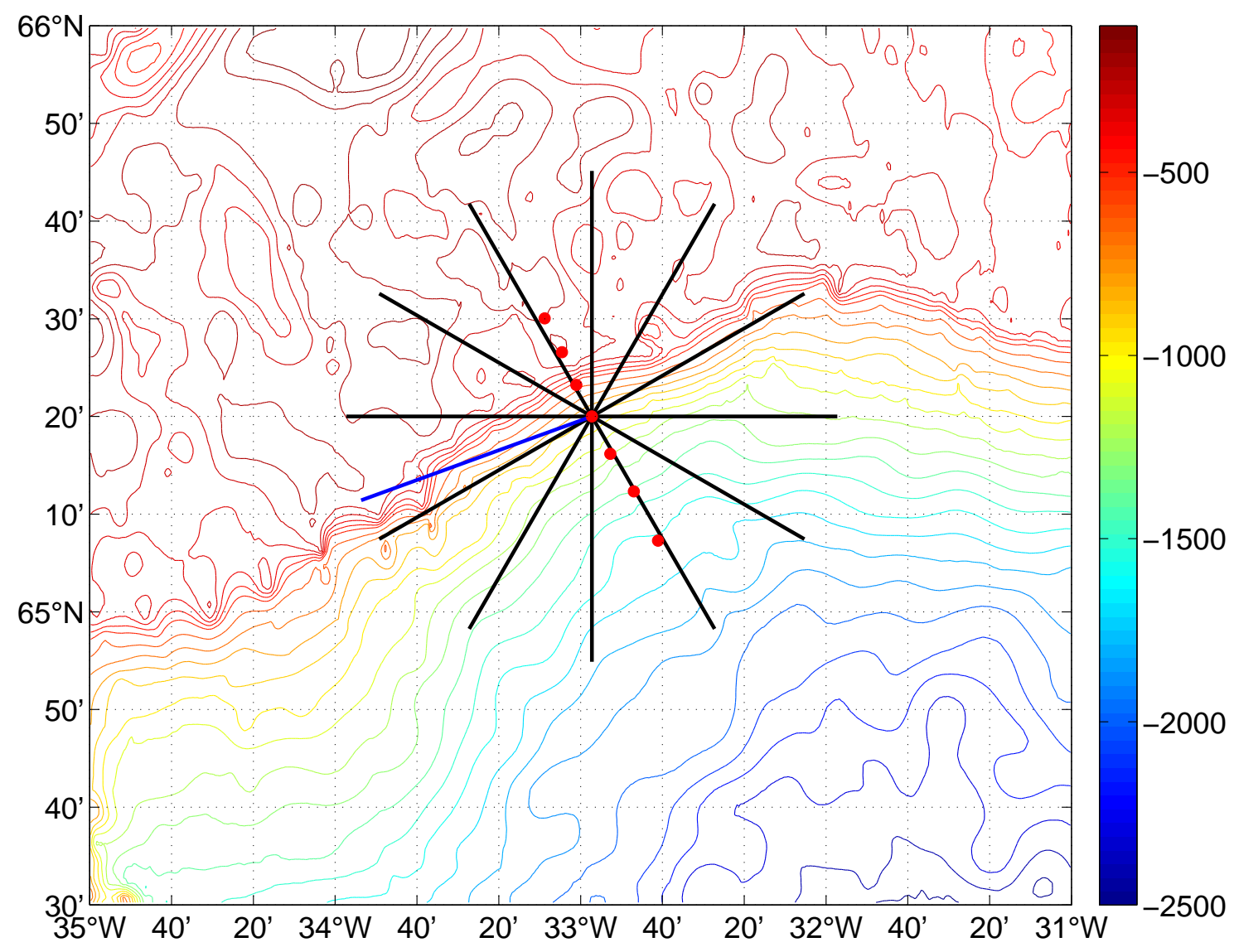

Figure A-9: Mercator map of study region with $30^{\circ}$ angles indicated. Finally determined $-160^{\circ}$ along-stream direction is shown by blue line. Elevation data from GEBCO 30 second grid. 


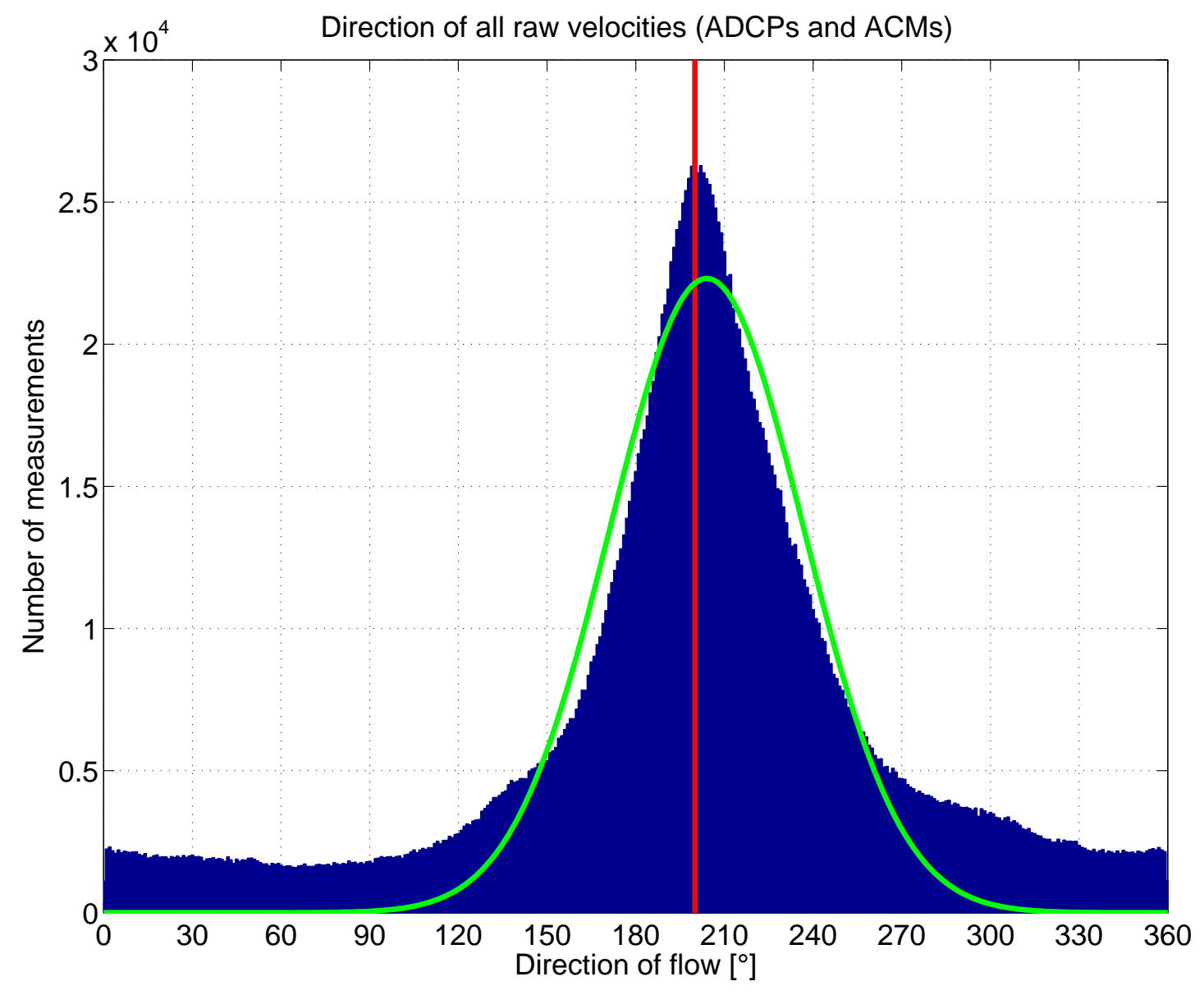

Figure A-10: Histogram of all measured directions from ADCPs and ACMs not corrected for different temporal and spatial resolution of those instruments. Red line indicates $-160^{\circ}=200^{\circ}$ and green line is a Gaussian fit centered on $204^{\circ}$.

directions by their associated speeds is similarly peaked in the vicinity of $-160^{\circ} \mathrm{T}$.

The third step was an investigation of rose histograms for all current directions. In order to get around the possible data distribution bias mentioned in the above step, rose histograms were investigated for all individual instruments on the moorings. Also, all measurements from $200 \mathrm{~m}$ bins were summarized and compared. Though there are some variations throughout the mooring array, none are as such inconsistent with the picture gained from the first two steps. In particular, it should be noted 
that the flows on the upper slope (400 m to $1000 \mathrm{~m}$ depth, moorings EG3 to EG5) have a much reduced level of variability compared to the rest. This, not surprisingly, is indicative of a stronger topographic control of the flow at those locations.

\section{A.6 Description of Structure Array Containing Moor- ing Array Data}

The following describes the final data set that is ready for distribution. It is consolidated into a handy format of one Matlab structure variable. This is not gridded, smoothed, or interpolated in any way, but it nonetheless provides quick access to the available data.

This structure variable is called var and it contains six rows and seven colums: $\operatorname{var}($ in, $\mathrm{mm})=\operatorname{var}(1: 6,1: 7)$. The columns refer to the seven moorings $\mathrm{mm}=1: 7$ and the rows refer to the different instruments in $=1: 6$ :

- in = 1: CMP resp. MMP $/ \mathrm{ACM}$

- in = 2: Upward looking ADCP on steel sphere (only EG2-7). At EG1, Ben Harden's corrected grid is fully assigned to the bottom ADCP

- in = 3: Upward looking ADCP on bottom (only EG1-4)

- in = 4: Downward looking ADCP below steel sphere (only EG4)

- in $=5:$ Top microcat

- in $=6:$ Bottom microcat

The following variables are stored in the structure array: 
- String with mooring name, e.g. EG1

$\operatorname{var}(\mathrm{in}, \mathrm{mm}) \cdot \operatorname{moor}=[]$;

- String describing the instrument type, any one of: CMP, MMP/ACM, ADCP, $\mathrm{MC}$

$\operatorname{var}($ in, $\mathrm{mm})$. instrument $=[]$;

- String describing the instrument (e.g. Upward looking ADCP on EG4) $\operatorname{var}($ in, mm) .description $=[]$;

- Comments relevant to how the respective variables differ from the standard case. Also notes which variables are evaluated at instrument time and depth vectors rather than at the time and depth matrices

$\operatorname{var}($ in, mm $) \cdot$ comment $=[]$;

- Latitude and longitude of mooring [decimal degrees]

$\operatorname{var}(\mathrm{in}, \mathrm{mm}) \cdot \mathrm{lat}=[]$;

$\operatorname{var}(\mathrm{in}, \mathrm{mm}) \cdot \operatorname{lon}=[]$;

- Cross sectional distance of mooring $[\mathrm{km}]$ and bottom depth $[\mathrm{m}]$

$\operatorname{var}($ in, mm) .dist $=[]$;

$\operatorname{var}(\mathrm{in}, \mathrm{mm}) \cdot$ bot_depth $=[]$;

- Nominal instrument depth [m]

$\operatorname{var}(\mathrm{in}, \mathrm{mm})$.inst_depth_nominal $=[]$;

- Vertical velocity of instrument $[\mathrm{m} / \mathrm{s}]$, upwards positive, for $\mathrm{MC}$ estimated as $-\mathrm{dp} / \mathrm{dt}$

$\operatorname{var}(\mathrm{in}, \mathrm{mm})$. inst_w $=[]$; 
- Instrument time [Matlab date format] and depth [m] for variables like heading and tem on ADCP

$\operatorname{var}(\mathrm{in}, \mathrm{mm})$. inst_time $=[]$;

$\operatorname{var}($ in, mm).inst_depth $=[]$;

- Time [Matlab date format] and depth [m] for variables estimated at more than one depth: matrix format. Depth may have been computed from pressure using sw_dpth. Time increases from the left to the right. Depth increases from top to bottom.

$\operatorname{var}(\mathrm{in}, \mathrm{mm}) \cdot$ time $=[]$;

$\operatorname{var}(\mathrm{in}, \mathrm{mm}) \cdot$ depth $=[]$;

- Temperature $\left[{ }^{\circ} \mathrm{C}\right]$ and salinity []

$\operatorname{var}(\mathrm{in}, \mathrm{mm}) \cdot$ tem $=[]$;

$\operatorname{var}(\mathrm{in}, \mathrm{mm}) \cdot \mathrm{sal}=[]$;

- pot. temperature $\left[{ }^{\circ} \mathrm{C}\right]$ and pot. density $\left[\mathrm{kg} / \mathrm{m}^{3}\right]$ computed using sw_ptmp and sw_pden. pot. density is given as sw_pden - 1000

$\operatorname{var}(\mathrm{in}, \mathrm{mm}) \cdot$ the $=[]$;

$\operatorname{var}(\mathrm{in}, \mathrm{mm}) \cdot \mathrm{sig}=[]$;

- Unrotated detided (for EG1-3) velocities $[\mathrm{m} / \mathrm{s}]$

$\operatorname{var}(\mathrm{in}, \mathrm{mm}) \cdot \mathrm{u}=[]$;

$\operatorname{var}(\mathrm{in}, \mathrm{mm}) \cdot \mathrm{v}=[]$;

$\operatorname{var}(\mathrm{in}, \mathrm{mm}) \cdot \operatorname{spd}=[]$;

$\operatorname{var}(\mathrm{in}, \mathrm{mm}) \cdot \operatorname{dir}=[]$; in degrees mathematical convention

- Rotated (in streamwise coordinates) detided (for EG1-3) velocities $[\mathrm{m} / \mathrm{s}]$ $\operatorname{var}(\mathrm{in}, \mathrm{mm}) \cdot \mathrm{ur}=[]$; 
$\operatorname{var}(\mathrm{in}, \mathrm{mm}) \cdot \operatorname{vr}=[]$;

$\operatorname{var}(\mathrm{in}, \mathrm{mm})$.streamwise_angle $=[]$;

$\operatorname{var}($ in, mm) .ur_vr_formula $=[]$;

- For EG1-3 we also save the tidal velocities and the velocities containing the original tidal signal $[\mathrm{m} / \mathrm{s}]$

$\operatorname{var}(i \mathrm{n}, \mathrm{mm}) \cdot$ u_with_tide $=[]$;

$\operatorname{var}(\mathrm{in}, \mathrm{mm}) \cdot \mathrm{v} \_$with_tide $=[]$;

$\operatorname{var}(\mathrm{in}, \mathrm{mm}) \cdot$ u_tide $=[]$;

$\operatorname{var}(\mathrm{in}, \mathrm{mm}) \cdot \mathrm{v}_{\text {_tide }}=[]$;

- Vertical velocity from ADCP $[\mathrm{m} / \mathrm{s}]$, upwards positive $\operatorname{var}(\mathrm{in}, \mathrm{mm}) \cdot \mathrm{w}=[]$;

- Error velocity from ADCP $[\mathrm{m} / \mathrm{s}]$, for $\mathrm{ACM}$ it is set to 1 if flagged and to 0 if passed scancount and inclination criteria

$\operatorname{var}(\mathrm{in}, \mathrm{mm})$.errvel $=[]$;

- Instrument orientation w.r.t. magnetic north $\left[^{\circ}\right]$

$\operatorname{var}($ in, $\mathrm{mm}) \cdot$ heading $=[]$;

$\operatorname{var}($ in, mm) $\cdot$ pitch $=[]$;

$\operatorname{var}(\mathrm{in}, \mathrm{mm}) \cdot \operatorname{roll}=[]$;

$\operatorname{var}($ in, $\mathrm{mm})$.inclination $=[]$;

- Scancount for ACM averaging

$\operatorname{var}($ in, $\mathrm{mm}) \cdot$ scancount $=[]$;

- Fall time [Matlab date format] of Microcat, i.e. time when aluminum tube got crushed/lost its buoyancy and the microcat fell from above to below the steel 
sphere

$\operatorname{var}(\mathrm{in}, \mathrm{mm}) \cdot$ fall_time $=[]$;

The size of the saved structure variable is $206 \mathrm{MB}$.

\section{A.7 Discussion of Sources of Errors}

To this point, we have attempted to determine the most likely values for different quantities of physical interest. However, there are of course both random and systematic errors affecting each of these quantities. In particular due to the presence of the systematic errors, the error ranges respectively the limits of confidence of the final quantities are ill-defined. Therefore, rather than trying to quote the final values plus/minus a (possibly large but unlikely) error estimate, we list (in no particular order) the sources of random and systematic errors and estimate their scale if available. We group this by the different variables.

As a further general remark, one should remember that all the corrections as described earlier in this document may either lead to a near-correct final value or to an additional introduction of systematic errors.

In addition, it has been demonstrated that the distributions of the dependent variables are all strongly affected by non-random data drop-out. That is to say that while each individual measurement that was achieved may actually be of good quality, the sum of those achieved measurements may still be a very poor representation of the statistics of that variable in space or time.

The four independent variables of space and time are:

- $x$ : along-stream distance/location in alongstream direction

- GPS accuracy: $\approx 10 \mathrm{~m}$ 
- Horizontal advection of mooring during vertical falling of anchor: $\approx 50 \mathrm{~m}$

- Quality of bathymetric data. Note that we only have the global interpolated data sets of ETOPO 1 minute and GEBCO 30 second available. In addition, there has been one echosounder transect along the Spill Jet line, but no multibeam data has been aquired in the region: $\approx 2 \mathrm{~km}$

- Horizontal excursion of mooring instruments during blowdown: up to $500 \mathrm{~m}$

- $y$ : cross-stream distance/location in cross-stream direction

- Points raised above for $x$ also hold.

- It was attempted to position the moorings on a straight line and for analysis they were projected to actually be on a straight line: $\approx 1 \mathrm{~km}$

- $z:$ depth

- Depth has been computed from pressure, so the pressure accuracy determines the depth accuracy.

- Pressure to depth conversion using sw_dpth: $\approx 20 \mathrm{~m}$

- Clock drift of pressure sensors: $\approx 20 \mathrm{~min}$

- Pressure sensor outside of its rated depth resulted in a (corrected) wrapping of the pressure readings on the order of $300 \mathrm{~m}$.

- Blowdowns moved pressure sensor below its detection limit at around $520 \mathrm{~m}$ at which state we either kept the value around $520 \mathrm{~m}$ for velocity measurements or discontinued to report values for temperature and salinity. 
- Bottom microcats on EG6 and EG7 are missing pressure sensors, so their depth is inferred from MMPs and mooring diagram: $\approx 15 \mathrm{~m}$

- Location of sphere with respect to dangling microcats: possibly up to $50 \mathrm{~m}$

- Inaccurate knowledge of water depth at mooring locations: $\approx 200 \mathrm{~m}$

- $t$ : time

- Clock drifts: $\approx 20 \mathrm{~min}$

- Offsets: largest detected offset was 11 hours

- Finite averaging time for measurements is different from the nominal time point at which the quantity is reported: $\approx 10 \mathrm{~min}$

- Quoting measured profiles at the nominal time rather than at the time of the actual measurement during the profile: 30-60 min for deep profiles

The dependent hydrography and velocity variables are:

- $T$ : temperature

- Regular instrument noise and drift issues: $\approx 0.002{ }^{\circ} \mathrm{C}$ for the microcats and larger for the other instruments

- Note that temperature is the only quantity in this list that did not encounter any error sources specific to this mooring array

- $S$ : salinity

- Instrument drift: detected drift was 0.1 salinity units in half a year; other drift events possibly went unnoticed

- Stability of conductivity ratio measurement and partially strongly increased noise level 
- Calibration to microcats or CTDs and the associated distance in space and/or time between the instrument to be calibrated and the instrument with which it is calibrated: example of EG3 moored profiler where it was 0.07 salinity units

- Vertical distance between calibration instruments: $\approx 10 \mathrm{~m}$

- Partially subjective choices when the constant calibration corrections are applied

- Salinity computation requires information about conductivity, temperature, and pressure. Beyond, the error sources in conductivity, temperature is well known, while pressure has the problems listed above: at $5{ }^{\circ} \mathrm{C}$ and $1000 \mathrm{~m}$ depth and for a constant conductivity ratio, an error in pressure of $100 \mathrm{~m}$ introduces a salinity error of 0.05 salinity units

- $\theta_{0}, \sigma_{0}$ : potential temperature and potential density

- Calculated from temperature, salinity, and pressure: standard error propagation of the above listed errors

- ur, vr: horizontal along-stream and cross-stream velocity components/speed and direction of velocity

- Heading inaccuracies associated with magnetic compass deviation and vertical component of magnetic field: velocity direction errors of up to $180^{\circ}$

- Instrument inclination of ACMs: up to $20 \%$ underestimation of actual horizontal velocities

- Tidal fit only applied to three moorings and four tidal frequencies 
- Inaccuracy of along-stream direction determination: $\approx 10^{\circ}$ of direction or the difference between $0 \mathrm{~m} / \mathrm{s}$ and $0.17 \mathrm{~m} / \mathrm{s}$ cross-stream flow for a speed of $1 \mathrm{~m} / \mathrm{s}$ directed in the the alongstream direction 


\section{Bibliography}

Aagaard, K., 1989: A Synthesis of the Arctic Ocean Circulation. Rapports et ProcèsVerbaux des Réunions, 11.

Aagaard, K., L. Coachman, and E. Carmack, 1981: On the Halocline of the Arctic Ocean. Deep Sea Research Part I: Oceanographic Research, 28, 529-545.

Aksenov, Y., V. Ivanov, A. Nurser, S. Bacon, I. Polyakov, A. Coward, A. NaveiraGarabato, and A. Beszczynska-Möller, 2011: The Arctic Cicumpolar Boudary Current. Journal of Geophysical Research, 116 (C9), C09 017.

Allen, J. and P. Newberger, 1996: Downwelling Circulation on the Oregon Continental Shelf. Part I: Response to Idealized Forcing. Journal of Physical Oceanography, 26 (10), 2011-2035.

Bacon, S. and P. Saunders, 2010: The Deep Western Boundary Current at Cape Farewell: Results from a Moored Current Meter Array. Journal of Physical Oceanography, 40 (4), 815-829.

Brearley, J., R. Pickart, H. Valdimarsson, S. Jonsson, R. Schmitt, and T. Haine, 2012: The East Greenland Boundary Current System South of Denmark Strait. Deep-Sea Research Part I, 63 (1), 1-19. 
Brink, K., F. Bahr, and R. Shearman, 2007: Alongshore Currents and Mesoscale Variability near the Shelf Edge off Northwestern Australia. Journal of Geophysical Research, 112 (C5), C05 013, doi:10.1029/2006JC003725.

Brink, K. and S. Lentz, 2010: Buoyancy Arrest and Bottom Ekman Transport. Part I: Steady Flow. Journal of Physical Oceanography, 40, 621-635.

Brown, O. and P. Minnett, 1999: MODIS Infrared Sea Surface Temperature Algorithm: Algorithm Theoretical Basis Document, Version 2.0. Tech. rep., University of Miami, available at http://modis.gsfc.nasa.gov/data/atbd/atbd_ $\bmod 25 \cdot \mathrm{pdf}$.

Bruce, J., 1995: Eddies Southwest of the Denmark Strait. Deep Sea Research Part I: Oceanographic Research Papers, 42 (1), 13-17.

Bryan, K. and M. Cox, 1967: A Numerical Investigation of Oceanic General Circulation. Tellus, 19, 54-80.

Carpenter, J. and M. Timmermans, 2012: Deep Mesoscale Eddies in the Canada Basin, Arctic Ocean. Geophysical Research Letters, 39 (20), L20 602.

Cavalieri, D. and S. Martin, 1994: The Contribution of Alaskan, Siberian, and Canadian Coastal Polynyas to the Cold Halocline Layer of the Arctic Ocean. Journal of Geophysical Research, 99 (C9), 18343.

Chao, S. and P. Shaw, 1996: Initialization, Asymmetry, and Spindown of Arctic Eddies. Journal of Physical Oceanography, 26 (10), 2076-2092.

Chao, S. and P. Shaw, 1998: Eddy Maintenance and Attrition in a Vertically Sheared Current under Arctic Ice. Journal of Physical Oceanography, 28 (12), 2427-2443. 
Chao, S. and P. Shaw, 1999: Close Interactions between two Pairs of Heton-like Vortices under Sea Ice. Journal of Geophysical Research, 104, 23.

Chapman, D., 2003: Separation of an Advectively Trapped Buoyancy Current at a Bathymetric Bend. Journal of Physical Oceanography, 33 (5), 1108-1121.

Checkley, D. and J. Barth, 2009: Patterns and Processes in the California Current System. Progress in Oceanography, 83 (1), 49-64.

Climate-Radar Data Inventories, 2010: Barrow Post Rogers Airport Weather Station. Tech. rep., NOAA National Climatic Data Center.

Curry, R. and C. Mauritzen, 2005: Dilution of the Northern North Atlantic Ocean in Recent Decades. Science, 308 (5729), 1772-1774.

Danabasoglu, G., W. Large, and B. Briegleb, 2010: Climate Impacts of Parameterized Nordic Sea Overflows. Journal of Geophysical Research, 115 (C11), C11 005.

Daniault, N., P. Lherminier, and H. Mercier, 2011a: Circulation and Transport at the Southeast Tip of Greenland. Journal of Physical Oceanography, 41, 437-457, doi:10.1175/2010JPO4428.1.

Daniault, N., H. Mercier, and P. Lherminier, 2011b: The 1992-2009 Transport Variability of the East Greenland-Irminger Current at $60^{\circ}$ N. Geophysical Research Letters, 38 (7), L07 601.

D’Asaro, E., 1988a: Generation of Submesoscale Vortices: A New Mechanism. Journal of Geophysical Research, 93 (C6), 6685-6693.

D'Asaro, E., 1988b: Observations of Small Eddies in the Beaufort Sea. Journal of Geophysical Research, 93 (C6), 6669-6684. 
D'Asaro, E., C. Lee, L. Rainville, R. Harcourt, and L. Thomas, 2011: Enhanced Turbulence and Energy Dissipation at Ocean Fronts. Science, 332 (6027), 318.

Dickson, R. and J. Brown, 1994: The Production of North Atlantic Deep Water: Sources, Rates, and Pathways. Journal of Geophysical Research, 99 (C6), 12 31912341.

Dickson, R., J. Meincke, S. Malmberg, and A. Lee, 1988: The "Great Salinity Anomaly" in the Northern North Atlantic 1968-1982. Progress in Oceanography, $20(2), 103-151$.

Durand, M., L. Fu, D. Lettenmaier, D. Alsdorf, E. Rodriguez, and D. EstebanFernandez, 2010: The Surface Water and Ocean Topography Mission: Observing Terrestrial Surface Water and Oceanic Submesoscale Eddies. Proceedings of the IEEE, 98 (5), 766-779.

Early, J., R. Samelson, and D. Chelton, 2011: The Evolution and Propagation of Quasigeostrophic Ocean Eddies. Journal of Physical Oceanography, 41 (8), 15351555.

Environmental Working Group, 1998: Joint U.S.-Russian Atlas of the Arctic Ocean for the Summer Period. CD-ROM, National Snow and Ice Data Center, Boulder, Colorado, USA.

Federiuk, J. and J. Allen, 1995: Upwelling Circulation on the Oregon Continental Shelf. II: Simulations and Comparisons with Observations. Journal of Physical Oceanography, 25 (8), 1867-1889.

Fer, I., G. Voet, K. Seim, B. Rudels, and K. Latarius, 2010: Intense Mixing of the Faroe Bank Channel Overflow. Geophysical Research Letters, 37 (2). 
Flierl, G., 1981: Particle Motions in Large-Amplitude Wave Fields. Geophysical 83 Astrophysical Fluid Dynamics, 18 (1-2), 39-74.

Fratantoni, P. and R. Pickart, 2003: Variability of the Shelf Break Jet in the Middle Atlantic Bight: Internally or Externally Forced. Journal of Geophysical Research, 108, 3166, doi:10.1029/2002JC001326.

Gawarkiewicz, G., F. Bahr, R. Beardsley, and K. Brink, 2001: Interaction of a Slope Eddy with the Shelfbreak Front in the Middle Atlantic Bight. Journal of Physical Oceanography, 31 (9), 2783-2796.

Gill, A. and A. Clarke, 1974: Wind-induced Upwelling, Coastal Currents and Sealevel Changes. Deep-Sea Research, 21 (5), 325-345.

Girton, J. and T. Sanford, 2003: Descent and Modification of the Overflow Plume in the Denmark Strait. Journal of Physical Oceanography, 33 (7), 1351-1364.

Girton, J., T. Sanford, and R. Käse, 2001: Synoptic Sections of the Denmark Strait Overflow. Geophysical Research Letters, 28 (8), 1619-1622.

Grebmeier, J. and R. Harvey, 2005: The Western Arctic Shelf-Basin Interactions (SBI) Project: An Overview. Deep-Sea Research Part II, 52 (24-26), 3109-3115, doi:10.1016/j.dsr2.2005.10.004.

Griffiths, R. and P. Linden, 1981: The Stability of Buoyancy-driven Coastal Currents. Dynamics of Atmospheres and Oceans, 5 (4), 281-306.

Haine, T. and J. Marshall, 1998: Gravitational, Symmetric, and Baroclinic Instability of the Ocean Mixed Layer. Journal of Physical Oceanography, 28 (4), 634-658.

Haine, T. W., 2010: High-Frequency Fluctuations in Denmark Strait Transport. Geophysical Research Letters, 37 (14), L14601. 
Hall, M., 1994: Synthesizing the Gulf Stream Thermal Structure from XBT Data. Journal of Physical Oceanography, 24, 2278-2287, doi:10.1175/1520-0485(1994) $024<2278:$ STGSTS $>2.0 . \mathrm{CO} ; 2$.

Hansen, B. and S. Østerhus, 2000: North Atlantic-Nordic Seas Exchanges. Progress in Oceanography, 45 (2), 109-208.

Harden, B., I. Renfrew, and G. Petersen, 2011: A Climatology of Wintertime Barrier Winds off Southeast Greenland. Journal of Climate, 24, 4701-4717.

Harden, B. E., R. S. Pickart, and I. A. Renfrew, 2012: Observational Evidence for the Formation of the East Greenland Spill Jet. Journal of Physical Oceanography, submitted.

Hoyer, J. and D. Quadfasel, 2001: Detection of Deep Overflows with Satellite Altimetry. Geophysical Research Letters, 28 (8), 1611-1614.

Huang, R. and R. Schmitt, 1993: The Goldsbrough-Stommel Circulation of the World Oceans. Journal of Physical Oceanography, 23 (6), 1277-1284.

Hunkins, K., 1974: Subsurface Eddies in the Arctic Ocean. Deep-Sea Research Part I, 21 (12), 1017-1033.

Huthnance, J., 1978: On Coastal Trapped Waves: Analysis and Numerical Calculation by Inverse Iteration. Journal of Physical Oceanography, 8 (1), 74-92.

Jakobsson, M., R. Macnab, L. Mayer, R. Anderson, M. Edwards, J. Hatzky, H. Schenke, and P. Johnson, 2008: An Improved Bathymetric Portrayal of the Arctic Ocean: Implications for Ocean Modeling and Geological, Geophysical and Oceanographic Analyses. Geophysical Research Letters, 35 (4), L07 602, doi: 10.1029/2008GL033520. 
Jochumsen, K., D. Quadfasel, H. Valdimarsson, and S. Jonsson, 2012: Variability of the Denmark Strait Overflow: Moored Time Series from 1996-2011. Journal of Geophysical Research, accepted.

Jones, E., J. Swift, L. Anderson, M. Lipizer, G. Civitarese, K. Falkner, G. Kattner, and F. McLaughlin, 2003: Tracing Pacific Water in the North Atlantic Ocean. Journal of Geophysical Research, 108 (C4), 3116.

Jungclaus, J., J. Hauser, and R. Käse, 2001: Cyclogenesis in the Denmark Strait Overflow Plume. Journal of Physical Oceanography, 31 (11), 3214-3229.

Kalnay, E., et al., 1996: The NCEP/NCAR 40-year Reanalysis Project. Bulletin of the American Meteorological Society, 77 (3), 437-471.

Karcher, M., F. Kauker, R. Gerdes, E. Hunke, and J. Zhang, 2007: On the Dynamics of Atlantic Water Circulation in the Arctic Ocean. Journal of Geophysical Research, 112 (C4), C04S02.

Käse, R., J. Girton, and T. Sanford, 2003: Structure and Variability of the Denmark Strait Overflow: Model and Observations. Journal of Geophysical Research, 108 (C6), 3181.

Käse, R. and A. Oschlies, 2000: Flow through Denmark Strait. Journal of Geophysical Research, 105 (28), 527-28.

Kattsov, V., V. Ryabinin, J. Overland, M. Serreze, M. Visbeck, J. Walsh, W. Meier, and X. Zhang, 2010: Arctic Sea-ice Change: a Grand Challenge of Climate Science. Journal of Glaciology, 56 (200), 1115-1121.

Köhl, A., R. Käse, D. Stammer, and N. Serra, 2007: Causes of Changes in the Denmark Strait Overflow. Journal of Physical Oceanography, 37 (6), 1678-1696. 
Krauss, W., 1996: A Note on Overflow Eddies. Deep Sea Research Part I: Oceanographic Research Papers, 43 (10), 1661-1667.

Lauderdale, J., S. Bacon, A. Garabato, and N. Holliday, 2008: Intensified Turbulent Mixing in the Boundary Current System of Southern Greenland. Geophysical Research Letters, 35 (4), L04611.

Lazier, J., 1988: Temperature and Salinity Changes in the Deep Labrador Sea, 19621986. Deep Sea Research Part A. Oceanographic Research Papers, 35 (8), 12471253.

Lazier, J., R. Hendry, A. Clarke, I. Yashayaev, and P. Rhines, 2002: Convection and Restratification in the Labrador Sea, 1990-2000. Deep-Sea Research Part I, 49 (10), 1819-1835, doi:10.1016/S0967-0637(02)00064-X.

Lozier, M., M. Reed, and G. Gawarkiewicz, 2002: Instability of a Shelfbreak Front. Journal of Physical Oceanography, 32 (3), 924-944.

MacCready, P., 1994: Frictional Decay of Abyssal Boundary Currents. Journal of Marine Research, 52 (2), 197-217, doi:10.1357/0022240943077073.

Macrander, A., R. Käse, U. Send, H. Valdimarsson, and S. Jónsson, 2007: Spatial and Temporal Structure of the Denmark Strait Overflow Revealed by Acoustic Observations. Ocean Dynamics, 57 (2), 75-89.

Magaldi, M., T. Haine, and R. Pickart, 2011: On the Nature and Variability of the East Greenland Spill Jet: A Case Study in Summer 2003. Journal of Physical Oceanography, 41 (12), 2307-2327.

Manley, T. O. and K. Hunkins, 1985: Mesoscale Eddies of the Arctic Ocean. Journal of Geophysical Research, 90 (C3). 
Marshall, J. and R. Plumb, 2007: Atmosphere, Ocean and Climate Dynamics: An Introductory Text. Academic Press.

Mauritzen, C., 1996: Production of Dense Overflow Waters Feeding the North Atlantic across the Greenland-Scotland Ridge. Part 1: Evidence for a Revised Circulation Scheme. Deep Sea Research Part I: Oceanographic Research Papers, 43 (6), 769-806.

Melling, H., et al., 2008: Fresh-Water Fluxes via Pacific and Arctic Outflows Across the Canadian Polar Shelf. in Arctic-Subarctic Ocean Fluxes: Defining the Role of the Northern Seas in Climate.

Morrison, A., J. Billings, K. Doherty, and J. Toole, 2000: The McLane Moored Profiler: A Platform for Physical, Biological, and Chemical Oceanographic Measurements. Proceedings of the Oceanology International 2000 Conference, 7-10.

Mountain, D. G., 1974: Bering Sea Water on the North Alaskan Shelf. Ph.D. thesis, University of Washington.

Muench, R., J. Gunn, T. Whitledge, P. Schlosser, and W. Smethie Jr, 2000: An Arctic Ocean Cold Core Eddy. Journal of Geophysical Research, 105 (C10), 23 997-24, doi:10.1029/2000JC000212.

Muench, R., J. Schumacher, and S. Salo, 1988: Winter Currents and Hydrographic Conditions on the Northern Central Bering Sea Shelf. Journal of Geophysical Research, 93 (C1), 516-526.

Naderi, F., M. Freilich, and D. Long, 1991: Spaceborne Radar Measurement of Wind Velocity Over the Ocean-An Overview of the NSCAT Scatterometer System. Proceedings of the IEEE, 79 (6), 850-866. 
National Geospatial-Intelligence Agency, 2004: Handbook of Magnetic Compass Adjustment. Tech. rep., National Geospatial-Intelligence Agency, Bethesda, MD.

Newton, J. and B. Sotirin, 1997: Boundary Undercurrent and Water Mass Changes in the Lincoln Sea. Journal of Geophysical Research, 102 (C2), 3393-3403.

Nguyen, A., D. Menemenlis, and R. Kwok, 2011: Arctic Ice-ocean Simulation with Optimized Model Parameters: Approach and Assessment. Journal of Geophysical Research, 116 (C04025), doi:10.1029/2010JC006573.

Nikolopoulos, A., K. Borenäs, R. Hietala, and P. Lundberg, 2003: Hydraulic Estimates of Denmark Strait Overflow. Journal of Geophysical Research, 108, 3095.

Nikolopoulos, A., R. Pickart, P. Fratantoni, K. Shimada, D. Torres, and E. Jones, 2009: The Western Arctic Boundary Current at $152^{\circ} \mathrm{W}$ : Structure, Variability, and Transport. Deep Sea Research Part II: Topical Studies in Oceanography, 56 (17), 1164 - 1181, doi:10.1016/j.dsr2.2008.10.014.

Nof, D., 1983: The Translation of Isolated Cold Eddies on a Sloping Bottom. Deep Sea Research Part A. Oceanographic Research Papers, 30 (2), 171-182.

Orvik, K., Ø. Skagseth, and M. Mork, 2001: Atlantic Inflow to the Nordic Seas: Current Structure and Volume Fluxes from Moored Current Meters, VM-ADCP and SeaSoar-CTD Observations, 1995-1999. Deep Sea Research Part I: Oceanographic Research Papers, 48 (4), 937-957.

Ou, H. and A. Gordon, 1986: Spin-Down of Baroclinic Eddies Under Sea Ice. Journal of Geophysical Research, 91, 7623-7630.

Overland, J. and A. Roach, 1987: Northward flow in the Bering and Chukchi Seas. Journal of Geophysical Research, 92 (C7), 7097-7105. 
Panteleev, G., D. Nechaev, A. Proshutinsky, R. Woodgate, and J. Zhang, 2010: Reconstruction and Analysis of the Chukchi Sea Circulation in 1990-1991. Journal of Geophysical Research, 115 (C8), C08023.

Paquette, R. and R. Bourke, 1981: Ocean Circulation and Fronts as Related to Ice Melt-back in the Chukchi Sea. Journal of Geophysical Research, 86 (C5), 42154230.

Pawlowicz, R., B. Beardsley, and S. Lentz, 2002: Classical Tidal Harmonic Analysis including Error Estimates in MATLAB using T_TIDE. Computers and Geosciences, 28 (8), 929-937, doi:10.1016/S0098-3004(02)00013-4.

Pedlosky, J., 1987: Geophysical fluid dynamics. Second edition ed., Springer.

Pedlosky, J., 2003: Waves in the Ocean and Atmosphere: Introduction to Wave Dynamics. Springer.

Pickart, R., G. Moore, D. Torres, P. Fratantoni, R. Goldsmith, and J. Yang, 2009: Upwelling on the Continental Slope of the Alaskan Beaufort Sea: Storms, Ice, and Oceanographic Response. Journal of Geophysical Research, 114, doi:10.1029/ 2008JC005009.

Pickart, R., M. Spall, G. Moore, T. Weingartner, R. Woodgate, K. Aagaard, and K. Shimada, 2011: Upwelling in the Alaskan Beaufort Sea: Atmospheric Forcing and Local versus Non-local Response. Progress in Oceanography, 88, 78-100, doi: doi:10.1016/j.pocean.2010.11.005.

Pickart, R. and G. Stossmeister, 2008: Outflow of Pacific Water from the Chukchi Sea to the Arctic Ocean. Chinese Journal of Polar Oceanography, 19 (002), 135-148. 
Pickart, R., F. Straneo, and G. Moore, 2003: Is Labrador Sea Water Formed in the Irminger Basin? Deep-Sea Research Part I, 50 (1), 23-52, doi:10.1016/ S0967-0637(02)00134-6.

Pickart, R., D. Torres, and P. Fratantoni, 2005a: The East Greenland Spill Jet. Journal of Physical Oceanography, 35 (6), 1037-1053, doi:10.1175/JPO2734.1.

Pickart, R., T. Weingartner, L. Pratt, S. Zimmermann, and D. Torres, 2005b: Flow of Winter-transformed Pacific Water into the Western Arctic. Deep-Sea Research Part II, 52 (24-26), 3175-3198, doi:10.1016/j.dsr2.2005.10.009.

Pickart, R., et al., 2010: Evolution and Dynamics of the Flow through Herald Canyon in the Western Chukchi Sea. Deep-Sea Research Part II, 57 (1-2), 5-26, doi:10. 1016/j.dsr2.2009.08.002.

Pohlmann, H., F. Sienz, and M. Latif, 2006: Influence of the Multidecadal Atlantic Meridional Overturning Circulation Variability on European Climate. Journal of Climate, 19 (23), 6062-6067.

Price, J. and M. O'Neil Baringer, 1994: Outflows and Deep Water Production by Marginal Seas. Progress in Oceanography, 33 (3), 161-200.

Proshutinsky, A. and M. Johnson, 1997: Two Circulation Regimes of the Wind-driven Arctic Ocean. Journal of Geophysical Research, 102 (C6), 12 493-12.

Rudels, B., E. Fahrbach, J. Meincke, G. Budéus, and P. Eriksson, 2002: The East Greenland Current and its Contribution to the Denmark Strait Overflow. ICES Journal of Marine Science: Journal du Conseil, 59 (6), 1133.

Rudels, B., E. Jones, L. Anderson, and G. Kattner, 1994: On the Intermediate Depth Waters of the Arctic Ocean. Geophysical Monograph Series, 85, 33-46. 
Sambrotto, R., J. Goering, and C. McRoy, 1984: Large Yearly Production of Phytoplankton in the Western Bering Strait. Science, 225 (4667), 1147.

Schauer, U. and A. Beszczynska-Möller, 2009: Problems with Estimation and Interpretation of Oceanic Heat Transport-Conceptual Remarks for the Case of Fram Strait in the Arctic Ocean. Ocean Science, 5, 487-494.

Schauer, U., R. Muench, B. Rudels, and L. Timokhov, 1997: Impact of Eastern Arctic Shelf Waters on the Nansen Basin Intermediate Layers. Journal of Geophysical Research, 102, 3371-3382.

Schulze, L., R. Pickart, G. Moore, M. Charette, K. Arrigo, G. van Dijken, and S. Danielson, 2012: Long-term Trends of Upwelling and Impacts on Primary Productivity in the Beaufort Sea. Deep-Sea Research, submitted.

Schulze, L. M. and R. S. Pickart, 2012: Seasonal Variation of Upwelling in the Alaskan Beaufort Sea: Impact of Sea Ice Cover. Journal of Geophysical Research, 117 (C6), C06 022 .

Shimada, K., E. Carmack, K. Hatakeyama, and T. Takizawa, 2001: Varieties of Shallow Temperature Maximum Waters in the Western Canadian Basin of the Arctic Ocean. Geophysical Research Letters, 28 (18).

Shimada, K., M. Itoh, S. Nishino, F. McLaughlin, E. Carmack, and A. Proshutinsky, 2005: Halocline Structure in the Canada Basin of the Arctic Ocean. Geophysical Research Letters, 32, L03 605, doi:10.1029/2004GL021358.

Smith, P., 1976: Baroclinic Instability in the Denmark Strait Overflow. Journal of Physical Oceanography, 6 (3), 355-371. 
Solomon, S., D. Qin, M. Manning, Z. Chen, M. Marquis, K. Averyt, M. Tignor, and H. Miller, 2007: Contribution of Working Group I to the Fourth Assessment Report of the Intergovernmental Panel on Climate Change. Cambridge University Press.

Spall, M., 2004: Boundary Currents and Watermass Transformation in Marginal Seas. Journal of Physical Oceanography, 34 (5), 1197-1213.

Spall, M. and J. Pedlosky, 2008: Lateral Coupling in Baroclinically Unstable Flows. Journal of Physical Oceanography, 38 (6), 1267-1277, doi:10.1175/2007JPO3906.1.

Spall, M. and J. Price, 1998: Mesoscale Variability in Denmark Strait: The PV Outflow Hypothesis. Journal of Physical Oceanography, 28 (8), 1598-1623.

Spall, M. A., R. S. Pickart, P. Fratantoni, and A. Plueddemann, 2008: Western Arctic Shelfbreak Eddies: Formation and Transport. Journal of Physical Oceanography, 38 (8), 1644-1668, doi:10.1175/2007JPO3829.1.

Steele, M., J. Morison, W. Ermold, I. Rigor, M. Ortmeyer, and K. Shimada, 2004: Circulation of Summer Pacific Halocline Water in the Arctic Ocean. Journal of Geophysical Research, 109 (C2), C02 027, doi:10.1029/2003JC002009.

Steele, M., J. Zhang, and W. Ermold, 2010: Mechanisms of Summertime Upper Arctic Ocean Warming and the Effect on Sea Ice Melt. Journal of Geophysical Research, 115 (C11), C11 004.

Sutherland, D. and C. Cenedese, 2009: Laboratory Experiments on the Interaction of a Buoyant Coastal Current with a Canyon: Application to the East Greenland Current. Journal of Physical Oceanography, 39 (5), 1258-1271.

Sutherland, D. and R. Pickart, 2008: The East Greenland Coastal Current: Structure, 
Variability, and Forcing. Progress in Oceanography, 78 (1), 58-77, doi:10.1016/j. pocean.2007.09.006.

Swaters, G. and G. Flierl, 1991: Dynamics of Ventilated Coherent Cold Eddies on a Sloping Bottom. Journal of Fluid Mechanics, 223, 565-587.

Swift, J., 2003: NBP03-04a Service Group Bottle Data Documentation. Tech. rep., Scripps Institution of Oceanography.

Timmermans, M., J. Toole, A. Proshutinsky, R. Krishfield, and A. Plueddemann, 2008: Eddies in the Canada Basin, Arctic Ocean, Observed from Ice-tethered Profilers. Journal of Physical Oceanography, 38, 133-145.

Våge, K., R. Pickart, M. Spall, H. Valdimarsson, S. Jónsson, D. Torres, S. Østerhus, and T. Eldevik, 2011: Significant Role of the North Icelandic Jet in the Formation of Denmark Strait Overflow Water. Nature Geoscience, 4 (10), 723-727.

van Heijst, G., 2010: Dynamics of Vortices in Rotating and Stratified Fluids. Lecture Notes in Physics, 805 (Chapter 1), 1-34, doi:10.1007/978-3-642-11587-5_1.

Voet, G. and D. Quadfasel, 2010: Entrainment in the Denmark Strait Overflow Plume by Meso-scale Eddies. Ocean Science, 6, 301-310.

von Appen, W. and R. Pickart, 2012: Two Configurations of the Western Arctic Shelfbreak Current in Summer. Journal of Physical Oceanography, 42 (3), 329351, doi:10.1175/JPO-D-11-026.1.

Watanabe, E., 2011: Beaufort Shelfbreak Eddies and Shelf-basin Exchange of Pacific Summer Water in the Western Arctic Ocean Detected by Satellite and Modeling Analyses. Journal of Geophysical Research, 116 (C08034), doi:10.1029/ 2010JC006259. 
Watanabe, E. and H. Hasumi, 2009: Pacific Water Transport in the Western Arctic Ocean Simulated by an Eddy-Resolving Coupled Sea Ice-Ocean Model. Journal of Physical Oceanography, 39 (9), 2194-2211, doi:10.1175/2009JPO4010.1.

Weingartner, T., D. Cavalieri, K. Aagaard, and Y. Sasaki, 1998: Circulation, Dense Water Formation, and Outflow on the Northeast Chukchi Shelf. Journal of Geophysical Research, 103 (C4), 7647-7661.

Weingartner, T., S. Danielson, and T. Royer, 2005: Freshwater Variability and Predictability in the Alaska Coastal Current. Deep Sea Research Part II: Topical Studies in Oceanography, 52 (1-2), 169-191.

Whitehead, J., M. Stern, G. Flierl, and B. Klinger, 1990: Experimental Observations of Baroclinic Eddies on a Sloping Bottom. Journal of Geophysical Research, 95 (C6), 9585-9610.

Winsor, P. and D. Chapman, 2004: Pathways of Pacific Water across the Chukchi Sea: A Numerical Model Study. Journal of Geophysical Research, 109 (C3), C03 002.

Woodgate, R. and K. Aagaard, 2005: Revising the Bering Strait Freshwater Flux into the Arctic Ocean. Geophysical Research Letters, 32 (2), doi:10.1029/ 2004GL021747.

Woodgate, R., K. Aagaard, R. Muench, J. Gunn, G. Bjork, B. Rudels, A. Roach, and U. Schauer, 2001: The Arctic Ocean Boundary Current along the Eurasian Slope and the Adjacent Lomonosov Ridge: Water Mass Properties, Transports and Transformations from Moored Instruments. Deep-Sea Research Part I, 48, 17571792 .

Woodgate, R., K. Aagaard, J. Swift, W. Smethie, and K. Falkner, 2007: Atlantic 
Water Circulation over the Mendeleev Ridge and Chukchi Borderland from Thermohaline Intrusions and Water Mass Properties. Journal of Geophysical Research, 112.

Woodgate, R., K. Aagaard, and T. Weingartner, 2005a: A Year in the Physical Oceanography of the Chukchi Sea: Moored Measurements from Autumn 19901991. Deep-Sea Research Part II, 52 (24-26), 3116-3149, doi:10.1016/j.dsr2.2005. 10.016 .

Woodgate, R., K. Aagaard, and T. Weingartner, 2005b: Monthly Temperature, Salinity, and Transport Variability of the Bering Strait Through Flow. Geophysical Research Letters, 32, doi:10.1029/2004GL021880.

Woodgate, R., T. Weingartner, and R. Lindsay, 2010: The 2007 Bering Strait Oceanic Heat Flux and Anomalous Arctic Sea-ice Retreat. Geophysical Research Letters, 37 (1), L01 602, doi:10.1029/2009GL041621.

Worthington, L., 1969: An Attempt to Measure the Volume Transport of Norwegian Sea Overflow Water through the Denmark Strait. Deep-Sea Research, Supplement to Volume 16, 421-432. 